\title{
A quantitative analysis of an average cultured neuron
}

\author{
Dissertation \\ for the award of the degree \\ "Doctor rerum naturalium" \\ of the Georg-August-Universität Göttingen \\ within the doctoral programme IMPRS for Neurosciences \\ of the Georg-August University School of Science (GAUSS)
}

\author{
submitted by \\ Sebastian Jähne \\ from Berlin, Germany \\ Göttingen, March 2019
}




\section{Examination Board}

\section{Thesis Committee}

Prof. Dr. Silvio O. Rizzoli

Department of Neuro- and Sensory Physiology

University Medical Centre, Göttingen, Germany

Prof. Dr. Nils Brose

Department of Molecular Neurobiology

Max Planck Institute for Experimental Medicine, Göttingen, Germany

Prof. Dr. Manfred Lindau

Professor of Applied \& Engineering Physics

Cornell University, Ithaca NY, USA

\section{Extended Examination Board}

Dr. Camin Dean

Group of Trans-synaptic Signalling

European Neuroscience Institute, Göttingen, Germany

Prof. Dr. Ralf Heinrich

Department of Cellular Neurobiology

Schwann-Schleiden-Forschungszentrum, Göttingen, Germany

Prof. Dr. Manuela Schmidt

Research Group on Somatosensory Signaling and Systems Biology

Faculty of Biology and Psychology, University of Göttingen

And Max Planck Institute of Experimental Medicine, Göttingen, Germany

Date of oral examination: 20.05.2019 


\section{Affidavit}

I hereby declare that I prepared this dissertation independently, and with no other sources and aids than quoted.

Sebastian Jähne 
Dedication

Meinen Eltern. 
Table of Contents

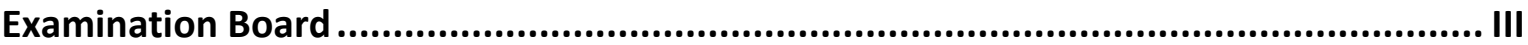

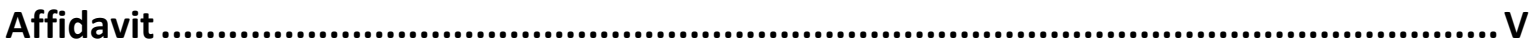

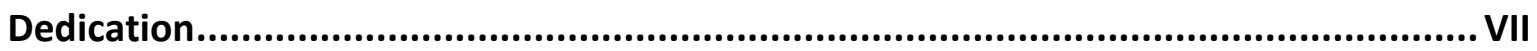

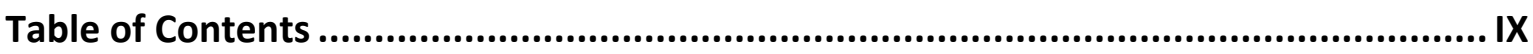

Acknowledgements .................................................................................................... XII

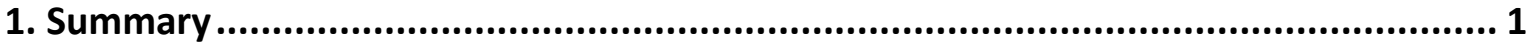

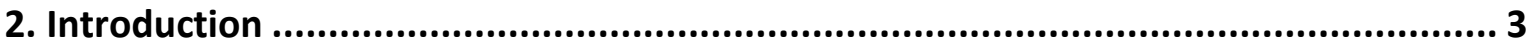

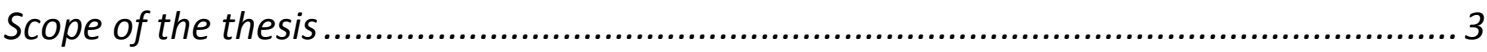

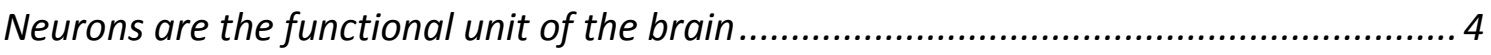

Neurons are functionally compartmentalized ........................................................ 5

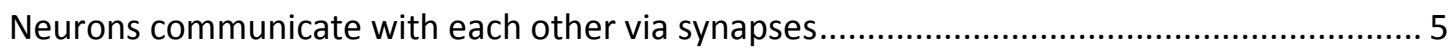

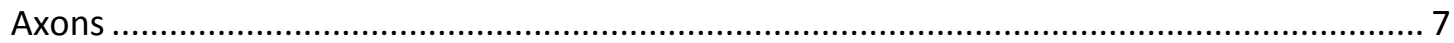

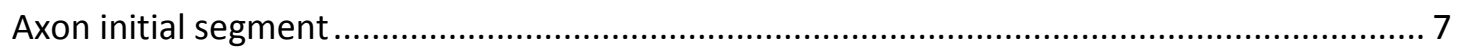

Dendrites, dendritic spines and the postsynaptic compartment.......................................... 8

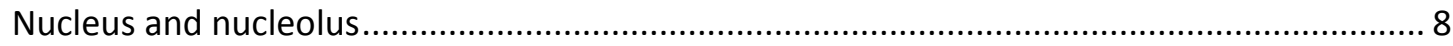

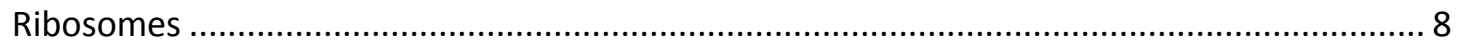

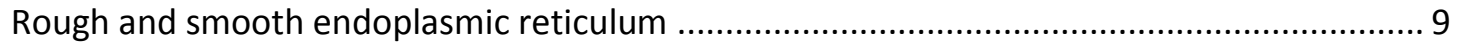

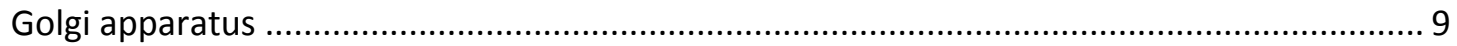

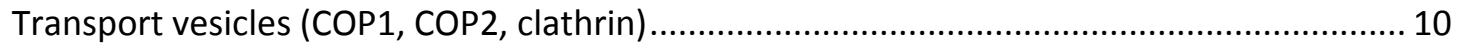

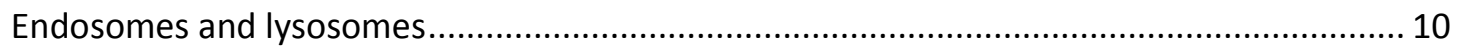

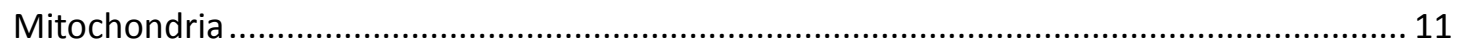

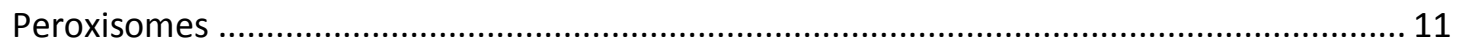

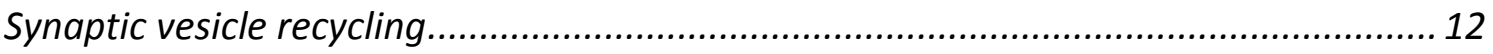

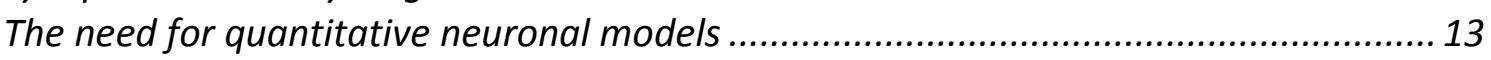

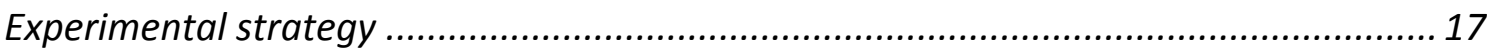

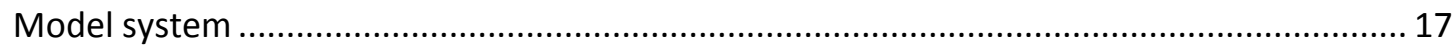

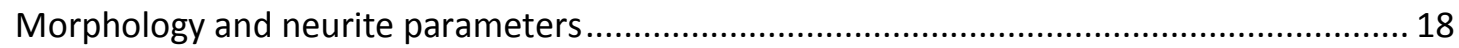

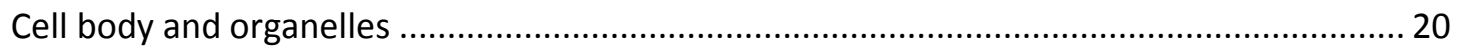

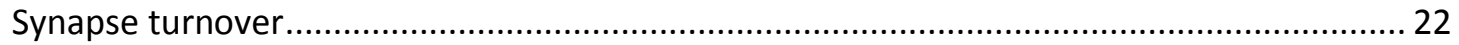

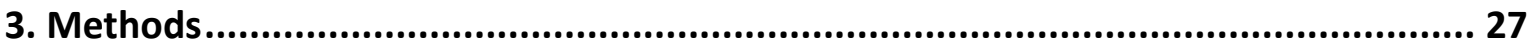

Primary hippocampal cultures, preparation and maintenance .................................... 27

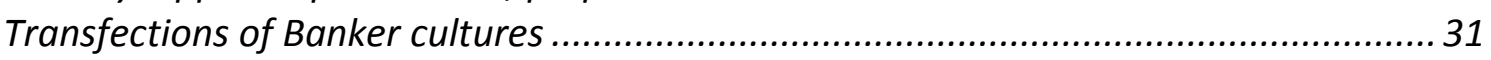

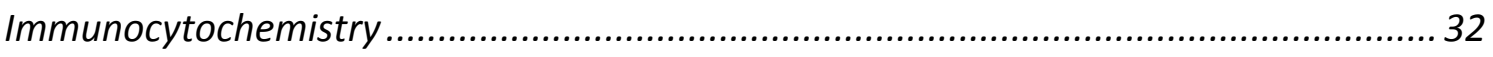

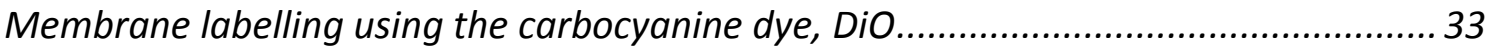

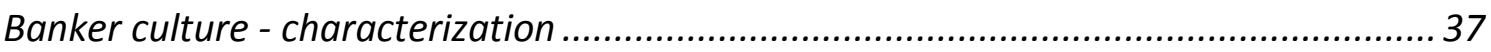

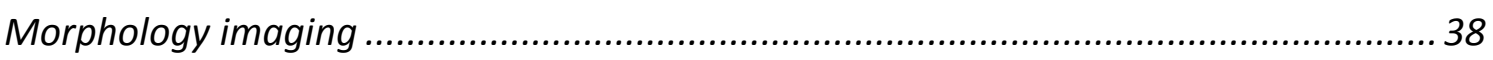

Analysis of widefield images to determine neuronal morphology parameters .............. 39

Confocal imaging of neuronal cell bodies and organelles............................................ 39

Extracting and analysing object parameters for different organelles imaged by confocal

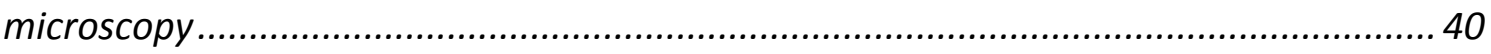

Stochastic optical reconstruction microscopy imaging of organelles ........................... 41 
Analysis of 3D-dSTORM data - extracting volume parameters ..................................... 44

Focused lon Beam Scanning electron microscopy..................................................... 44

Determining volumes of mitochondria, nuclei, and neuronal cell bodies from FIB-SEM

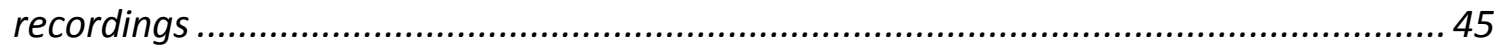

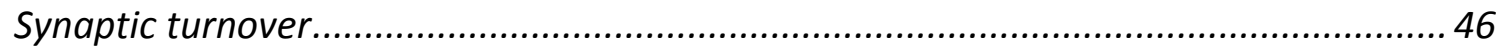

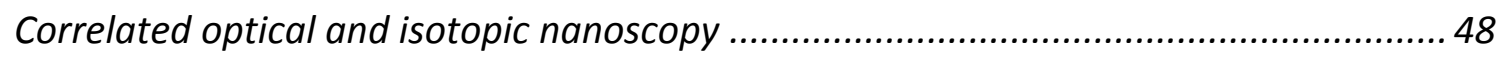

Analysis and correlation of synaptic turnover and presynaptic activity ......................... 48

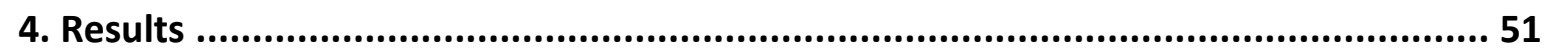

Banker culture are mainly consisting of glutamatergic and GABAergic neurons ........... 51

Banker culture neurons have a wide ranging axonal tree and a smaller dendritic tree .57

The number of pre-and postsynapses in cultured hippocampal neurons is correlated.. 63

Organelles have varying sizes and distributions depending on their location in different

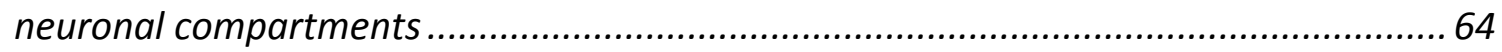

Neuronal organelles occupy most of the cell body volume .......................................... 129

FIB-SEM measurements enabled the reconstruction of entire neuronal cell bodies, of

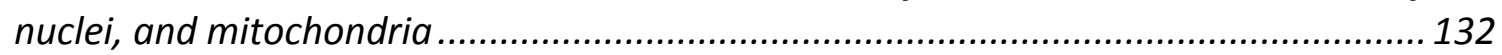

3D-dSTORM can improve volumetric measurements and can serve as a replacement for

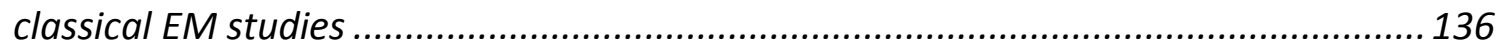

Presynaptic protein turnover is correlated to synaptic activity................................... 141

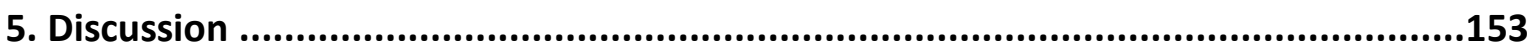

Banker cultures serve as a good model system for the quantitative molecular assessment of neurons, as they are mostly consisting of a monolayer of pyramidal

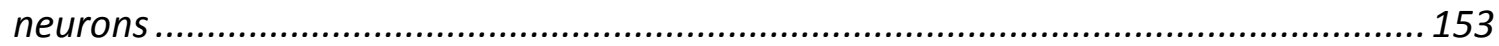

The size and distribution of neuronal organelles and compartments varies depending on

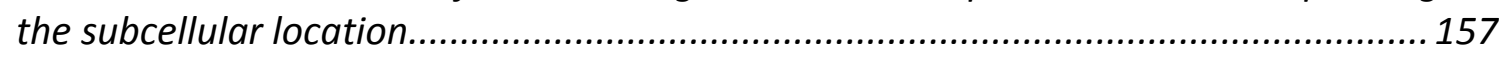

Organelles and compartments occupy most of the cell body volume.......................... 158

Presynaptic protein turnover is correlated to synaptic activity................................... 160

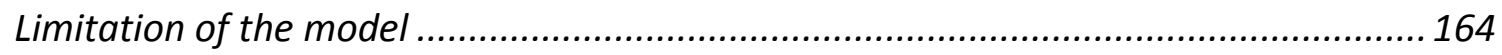

The functional characterization of neurons is a first step towards a quantitative

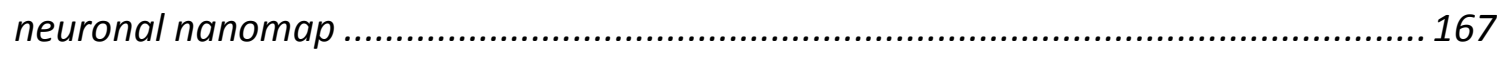

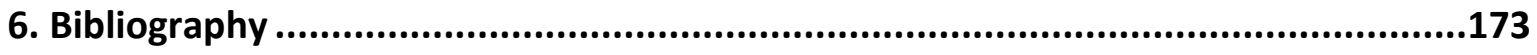

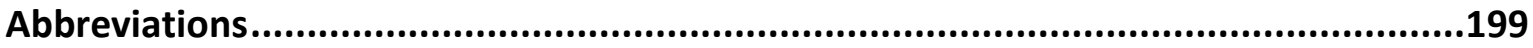

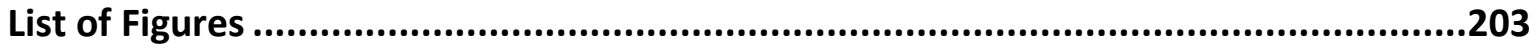

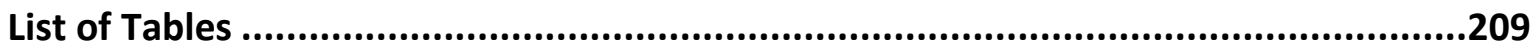

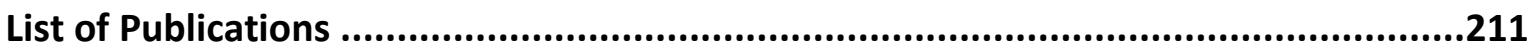

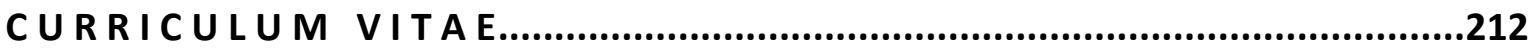




\section{Acknowledgements}

I would like to thank Silvio Rizzoli for his supervision throughout my PhD. I am grateful that he gave me the opportunity to work in this lab, on this particular project, which has and is still challenging, but as such a motivation for me to develop myself scientifically. His support, scientifically and personally was unmatched. I also want to thank him for his help with the MATLAB scripts.

Furthermore, I would like to thank my thesis committee members Nils Brose and Manfred Lindau for the helpful and constructive discussions during and outside of my thesis committee meetings.

I would like to thank all of my lab members and collaborators who allowed me to carryout this project and who helped me to bring this project a step further.

In this regard, I would like to thank Martin Lehmann for his help with the STORM experiments. I greatly thank Hanna Wildhagen for the many discussions on how to best analyse super-resolution microscopy data and for her help with developing an adequate volumetric analysis. Wiebke Möbius, Marie-Theres Weil, Torben Ruhwedel, and Christos Nardis were a big help with the FIB-SEM measurements. Thank you for your help with the sample preparation, for measuring and manually reconstructing the samples for me.

I also want to thank Sinem Saka for introducing me to nanoSIMS, a wonderful technique, which I am happy to be able to have access to for my experiments. Similarly, I would like to thank Angela Vogts for her help with the nanoSIMS measurements at the IOW in Warnemünde. I learned a lot about the technique during these visits. Thank you for the extra amount of time you put in to realize our measurements.

I would like to thank Yu Zhao and Alejandro Restrepo for choosing to do a lab rotation under my supervision. I could not have hoped for better students.

Tina and Nicole, I would like to thank for their help with the neuronal preparations.

I would like to thank everyone in the lab for creating a stimulating and nice environment that at times felt like home. Especially, I would like to thank Martin for endless discussions on our projects. Also for having me at his place once per week for food and 
games. I really enjoyed these times. I am glad to have shared my office with Sven, who has endured all my questions and moments of panic in a motivating and calming way. I would also like to thank him for his help with and input to the synapse turnover project.

I would like to thank Kathi, who I have probably been sharing time with most in the past years since we sit next to each other, Eugenio for being the most knowledgeable person I know apart from being a good friend who I can count on.

I would like to thank my friends in Göttingen that I was fortunate to get to know during the last 6 years. Carlos and Paola, you are the best roommates I can imagine. Georg and Michael, Thommi und Bea who have made my time in Göttingen that little bit better.

I am indebted to Stephan, Anneke, and Andrea my three best friends, who have been with me throughout the journey, who have not let me down even if I haven't been much around in the last years. I am happy and grateful to know you and I will always try my best to be there for you.

I would like to thank my parents, who have always supported me and my decisions. They have always been there when I needed them, but have always left me the freedom to develop and push myself. I am glad you pushed me to go to Ireland and to finance me during that time.

Jenni, I would like to thank for being with me through these years that were definitely not easy a lot of the times. I am who I am also because of you. Thank you!

I would like to thank Sinem! You are a wonderful person and I am tremendously glad to know you. Thank you for being with me at the last steps of this journey. Thank you for making every day better. 


\section{Summary}

Neurons are the functional unit of the brain. They have been extensively studied, from a molecular perspective up to brain wide levels. Nonetheless, we are still missing a quantitative description of the neuronal components. I present here a comprehensive description of cultured hippocampal neurons and their compartments and organelles. I used a combination of fluorescence microscopy, super-resolution microscopy, and electron microscopy to determine the distributions, volumes, and compartment specific differences of 32 organelle markers. I found that organelles occupy almost $90 \%$ of the neuronal cell body, which implicated diffusional constraints. Comparing organelle sizes across axons, dendrites, and cell bodies, I could show that most organelles are significantly different when located in different compartments. Finally, I was able to show that the number of pre- and postsynapses per cultured neuron is tightly correlated despite a strong disparity between the axonal and dendritic volumes. The dataset provided here is the basis for a quantitative molecular nanomap of a cultured hippocampal neuron, which in addition to the organelle composition will contain the molecular composition.

Furthermore, I used correlated optical and isotopic imaging to study the protein turnover at synapses. I found that the presynaptic protein turnover is correlated to synaptic activity at the single synapse level. This is interesting as it shows for the first time a direct coupling of synaptic activity to protein turnover. Chronically inhibiting synaptic activity produced a homeostatic scaling effect with increased protein turnover. 


\section{Introduction}

Scope of the thesis

Neurons are the main functional unit of the brain. In an effort to elucidate brain function, neurons have been extensively studied, from a whole brain perspective right down to individual functional pathways within neurons. For example, recent efforts have been undertaken to study the connectome, i.e. the connectivity of all neurons, of entire brains (Hildebrand et al., 2017; Oh et al., 2014; Zheng et al., 2018), functional brain circuits have been reconstructed and linked to behaviour (Haesemeyer et al., 2018; Takemura et al., 2013). Even the transcriptome and proteome of brains and brain regions have been elucidated (Hawrylycz et al., 2012; Kang et al., 2011; Lein et al., 2007). The transcriptome can now even be studied on a single cell level in situ (Wang et al., 2018). Big efforts are being made to bring together this information into in silico brain models like envisioned by the Blue Brain Project (http://bluebrain.epfl.ch) and the Human Brain Project (http://www.humanbrainproject.eu). We now also know many details about individual functional pathways within neurons, for example about synaptic vesicle (SV) exo- and endocytosis (Jahn and Fasshauer, 2012; Rizzoli, 2014; Saheki and De Camilli, 2012).

Although we know much on the morphologies of different neuron types, their composition, and their wiring, surprisingly little is known about the quantitative composition of these cells. If we want to fully understand basic neuronal functions, like the synaptic vesicle cycle, the regulation of protein turnover, synaptic activity, synaptic plasticity, and ultimately the entire brain it will be necessary to know the components/molecules and their amounts within a cell, as well as the functional make-up of these cells, i.e. the organelle composition, their volumes and their distributions.

I am here setting out to go the first steps towards such a quantitative neuronal model, by combining super-resolution microscopy, electron microscopy, and large-scale fluorescence imaging of a standardized, hippocampal neuron culture. I aim to determine the cellular morphology, including the numbers and volumes of neurites, the cell body volumes, and the composition, sizes and distributions of various organelles. These measurements can be combined with quantitative mass spectrometry and comparative imaging to develop a standardized quantitative model of a hippocampal neuron. 
Neurons are the functional unit of the brain

Already in the $19^{\text {th }}$ century Golgi and Ramon y Cajal used histological stainings to describe the structure of the brain, describing various cell types, including neurons, astrocytes, microglia, and oligodendrocytes. Ramon Y Cajal showed that neurons had a soma and processes coming off of this soma. Based on their morphology he classified several different types of neurons, such as Purkinje cells and pyramidal cells (Cajal, 1894).

Also, he and others described the neuronal connections as being very tight. In fact so tight that it was debated for some time whether the cells were a continuum (retinal theory) or individual entities separated by a plasma membrane (neuron theory). It was much later confirmed that neurons were in fact separated by membranes with clefts of down to $200 \AA$ (Palay, 1956).

Even though, there are many different neuron types with various different functions, neurons share a common set of features, which makes them special. First of all, they have the aforementioned processes, which can be called neurites. They may span up to a meter in distance and cover a few $\mathrm{mm}^{3}$, forming thousands of connections with other neurons (Fletcher and Theriot, 2004; Kandel, 2013a; Li et al., 2010). The neurites can be classified as axons or dendrites, which brings me to the second special feature of neurons: they are polarized. This means that they have a dendritic tree that can receive input from other neurons and an axon that generates output. This polarity is the basis for a directional flow of information between neurons (Dotti et al., 1988).

Thirdly, neurons share the common feature of being electrically and chemically excitable. The neuronal membrane is generally a non-permeable lipid bilayer, which through a number of different ion channels and ion pumps has an ion gradient across the bilayer. This gradient leads to the resting membrane potential. Through a stimulation, voltage gated ion channels can be opened, leading to a change in this resting potential. A strong depolarization of the neuron can result in an action potential, which will cause the generation of an output signal to the connected neurons (Kandel, 2013b).

This brings me to the fourth common feature of neurons: synapses. Neurons possess a number of highly specialized contact points called synapses, where a presynaptic signal 
can be chemically or electrically transmitted to the postsynaptic cell (Gray, 1959; Palay, 1956).

\section{Neurons are functionally compartmentalized}

The ability of neurons to communicate with one another is directly connected to their structure. Its morphology and its ultrastructure are required for its functionality. Thus, knowing or understanding the morphology and ultrastructure will help us to understand some of its functions better.

Neurons are made up of and contain several compartments that are responsible for segregating neuronal functions from one another. Some of these compartments are common with other cell types, such as the organelles of the secretory pathway like the endoplasmic reticulum and the Golgi apparatus. Other compartments are neurons specific like the axon, dendrites, and the synaptic connections between them. Each compartment within a cell has specialized functions, a specific composition and morphology. Each is important for maintaining proper cellular function. I will provide here an overview over the most common organelles and how they can be differentiated from one another.

\section{Neurons communicate with each other via synapses}

Probably the most special feature of neurons is the synapse. It is the connection between neurons, a highly specialized area where the presynaptic cell contacts the postsynaptic cell. There are two main types of synapses, chemical and electrical synapses, the former one being the prevalent type found in the brain. Electrical synapses have a connection via channels, so called gap junctions, which connect the cytoplasm of both cells (Bennett and Zukin, 2004). Via this junction, the electrical signal of one cell can be passed onto the next cell, which allows a synchronization of the electrical signals of the connected neurons (Hormuzdi et al., 2004). While this connection is very direct, its modulations are limited.

That neurons also communicate via chemical substances has already been described almost 100 years ago (Loewi, 1926). These chemical substances are usually small 
compounds such as the amino acids glutamate and $\gamma$-aminobutyric acid (GABA), acetylcholine, amines such as epinephrine and serotonin, small peptides, and gases such as nitric oxide (Kandel, 2013a). Neurotransmitters can have various effects on the postsynaptic neuron, ranging from excitatory and inhibitory signals to modulatory effects. I will focus here mostly on the major excitatory neurotransmitter, glutamate (Santos et al., 2009). Glutamate is an amino acid that can act on ionotropic (AMPA, NMDA, and kainate receptors), as well as metabotropic receptors (mGluRs) on the postsynaptic compartment, where it causes an excitatory postsynaptic potential (EPSP) (Baude et al., 1993; Mayer, 2005; Niswender and Conn, 2010).

Glutamate is stored in synaptic vesicles (SV) located in the presynaptic bouton. Upon the arrival of a stimulus (action potential), voltage-gated calcium channels are opened, which causes SVs to fuse with the presynaptic plasma membrane and to release their glutamate content into the synaptic cleft. The synaptic cleft is a small space at the synapse between the pre- and postsynaptic neurons. The separation of pre- and postsynaptic membranes is often very small, down to $20 \mathrm{~nm}$ (Gray, 1959; Palay, 1956). The transmitter diffuses within the synaptic cleft and can bind the before mentioned ionotropic and metabotropic glutamate receptors. The signals that the postsynaptic neurons receive are integrated and can result in the generation of another action potential in the postsynaptic neuron (Spruston, 2008). For the synaptic integration, the connectivity of the cells plays a vital role. And also the way the connection is formed. Synapses are plastic structures that can be stronger/weaker and this strength can be potentiated or depressed (Herring and Nicoll, 2016). Furthermore, the strength of the connection has a scaling mechanism to maintain a balance (O'Brien et al., 1998; Schanzenbächer et al., 2016; Turrigiano et al., 1998).

Good markers to study presynaptic terminals are synaptophysin, which is a transmembrane protein enriched in synaptic vesicles (Takamori et al., 2006; Wilhelm et al., 2014) and the scaffold protein bassoon, which is specific for the active zone, where SVs are released (Gundelfinger et al., 2016). To specifically look at glutamatergic synapses, it is also possible to use the vesicular glutamate transporter as a marker (Takamori, 2006). 


\section{Axons}

The axon, there is one per neuron, is the main output compartment of the neuron. It often spans several millimetres, and can reach up to one metre in length. It may branch several times. Along the axon, there are specializations, called presynaptic boutons, which are the terminals that connect to the postsynaptic cell. Axons contain a special set of channels, such as voltage gated sodium channels. These channels, together with the semi-permeable plasma membrane create a resting membrane potential. If the neuron is excited, this potential can be depolarized, which may cause an action potential to travel down the axon, which is resulting in the release of neurotransmitters from presynaptic terminals (see above) (Kandel, 2013b). As such the axon is one of the very important structures of a neuron. Since it spans such a long distance, it also presents a challenge for molecular transport out and inside of synapses. The main general transport tracks in axons are microtubules. The motor proteins carrying cargo anterogradely are kinesins, such as KIF1A and KIF1Bß, which have been described to transport SV precursors to synapses (Vale, 2003). KIFC2 and dynein are retrograde motors, which transport cargo out of the axon (Hirokawa et al., 2010). A good axonal marker is the neurofilament protein SMI-310 (Pathak et al., 2013).

\section{Axon initial segment}

The axon initial segment (AIS) is another specialization of neurons. It is located at the axon hillock and contains a special set of cytoskeletal proteins, cell adhesion molecules, extracellular matrix proteins, and a high density of voltage-gated sodium channels (Kole et al., 2008; Leterrier et al., 2015). The AIS has been described as the place where the cytoplasm of the axon is separated from the rest of the neuron. It also likely the place where the incoming information is integrated into new signals, action potentials. Typical cell adhesion molecules (CAM) include NrCAM (glia related CAM) and neurofascin-186. Ankyring and bIV spectrin are axon initial segment specific cytoskeletal proteins. Brevican, a proteoglycan was also shown to localize to the AIS (Grubb and Burrone, 2010; Hedstrom et al., 2007; Kole et al., 2008; Leterrier et al., 2015). 
Dendrites, dendritic spines and the postsynaptic compartment

Dendrites form many processes from the cell body. Their cytoplasm is, in contrast to the axon continuous with the cell body. They contain the postsynapses and are generally understood as the compartment receiving and integrating incoming signals (Spruston, 2008). As such they are highly specialized structures that have been studied in great detail (Cheng et al., 2006; Sheng and Hoogenraad, 2007). A good general marker for identifying dendrites is the microtubule associated protein 2 (MAP-2) (Kaech and Banker, 2006). Actin filaments form a dense network within dendrites (Markham and Fifková, 1986). The postsynaptic compartment can have various morphologies, and can be classified accordingly as stubby, filopodia, thin and mushroom-like (Cheng et al., 2014). Neurotransmitter receptors are mostly clustered in the postsynapse and are part of a highly specialized structure, the postsynaptic density. Typical markers of the postsynaptic compartment are PSD-95 and Homer1 (Brakeman et al., 1997; Cho et al., 1992; Hunt et al., 1996).

\section{Nucleus and nucleolus}

The nucleus contains the DNA of the cell. Since neurons are post-mitotic, its main function is in providing the correct information for protein expression and modulation. It can be easily visualized using DAPI or Hoechst, which bind to DNA. Nuclei are surrounded by an envelope, which contains nuclear pores that are made up of protein complexes (Kosinski et al., 2016; Loschberger et al., 2014; Löschberger et al., 2012). LaminB is part of the nuclear envelope and is as such a good nuclear marker. Nucleoli form subcompartments within the nucleus and are the main place for the biogenesis of ribosomes. Fibrillarin is enriched in nucleoli (Swedlow and Lamond, 2001).

\section{Ribosomes}

Ribosomes are the main sites of mRNA translation into proteins (Alberts, 2008). They are multi-protein complexes produced in nucleoli, containing proteins such as S3, S6, and L7 that can be used as markers. The majority of ribosomes is connected to the endoplasmic reticulum. While they were shown to be mostly located in the cell body, they can be 
located in dendrites and axons, which might indicate local protein synthesis in these compartments (Cajigas et al., 2012; Hanus and Schuman, 2013).

\section{Rough and smooth endoplasmic reticulum}

The endoplasmic reticulum forms many tubules and sheets, and is mainly involved in protein and lipid production (Shemesh et al., 2014). It is often closely linked to the nuclear envelope, but can also extend into dendrites and axons (Krijnse-Locker et al., 1995; Shemesh et al., 2014; Spacek and Harris, 2018). The lumen of the endoplasmic reticulum can store calcium. This calcium can be released by the opening of calcium channels via second messengers, like the opening of $I P_{3}$-gated calcium channels by the second messenger IP (Verkhratsky, 2002). The ER itself can be classified as rough ER, containing ribosomes along its tubules and smooth ER, not being lined by ribosomes. The rough ER is the main location where protein synthesis takes place and where proteins are post-translationally modified (Palade, 1975). Ribophorin 1 and 2, components of the oligosaccharyl transferase were shown to be markers of the rough ER (Kreibich et al., 1978; Rolls et al., 2002). The smooth ER is mainly implicated in lipid synthesis. A good general ER marker is the protein disulphide isomerase (PDI), which is involved in the correct formation of disulphide bonds within newly synthesized proteins (Wilkinson and Gilbert, 2004). Calnexin, calreticulin, and CPT1c are additional proteins associated to the ER (Sierra et al., 2008; Williams, 2006).

\section{Golgi apparatus}

The Golgi apparatus is another organelle of the secretory pathway (Bonifacino and Glick, 2004; Farquhar and Palade, 1998). It is a further part of the protein production and modification pathway. It is build-up of cisternae, which are ordered in phases. Proteins that enter the Golgi apparatus after coming from the ER enter the cis phase, move through the medial up to the trans phase and leave the organelle via the trans Golgi network. They may undergo post-translational modifications such as O-linked glycosylation, phosphorylations, and sulfations. Ultimately they are sorted for transport to their target organelle (Farquhar and Palade, 1998; Ladinsky et al., 1999). Each Golgi 
phase is characterized by specific, enriched proteins. For example, GM130 is a cis Golgi marker, TGN38 and TGN46 are trans Golgi network markers, and Golgi58K is a general Golgi marker (Munro, 1998; Revelo et al., 2014). In neurons the Golgi apparatus has been found in the cell body, in dendrites, and in axons (Pierce et al., 2001).

Transport vesicles (COP1, COP2, clathrin)

Neurons possess a high number of transport vesicles. It is postulated that these have different functions and a different molecular composition. They take part in targeting molecules to their correct position. There are for example vesicles that traffic from the ER to the Golgi apparatus. They are coated by the coat protein COP2. COP1 vesicles traffic proteins from the Golgi to the ER. Most other vesicles are coated by clathrin (Bonifacino and Glick, 2004). Specific effector molecules, such as Rab proteins regulate the targeting of these vesicles to the correct compartment (Bonanomi et al., 2006; Novick and Zerial, 1997; Zerial and McBride, 2001).

\section{Endosomes and lysosomes}

Endosomes are very heterogeneous organelles. They are membrane based structures without a very distinct morphology and molecular make up. They are implicated to play a role in protein sorting. Rab proteins specifically localize to the different endosomes and can be used as markers (Zerial and McBride, 2001). For example, rab11 is localized to recycling endosomes. Rab5 is a marker for early endosomes, rab7 for late endosomes. Though, there are these distinctions, the molecular composition of endosomes is not quite clear and is probably less distinct than that of other organelles (Miaczynska and Zerial, 2002). Lysosomes are connected to the endocytic pathway. They have a low $\mathrm{pH}$ and are implicated in the degradation of proteins. LAMP-1 is a typical lysosomal marker (Luzio et al., 2007). 


\section{Mitochondria}

Mitochondria are the main energy production site in cells. They produce ATP and are made up of an inner and an outer membrane. The inner membrane forms cristae and is the site of ATP production. Mitochondria are highly dynamic structures and can move along microtubules. They have their own DNA. Their subcellular location is usually linked to places with high energy demands. Synapses, which require a lot of ATP, contain a lot of mitochondria (Palay, 1956). The enzyme cytochrome C oxidase (inner membrane) and TOMM20 (outer membrane) are good mitochondrial markers (Betzig et al., 2006; Claude, 1946b, 1946a; van de Linde et al., 2008).

\section{Peroxisomes}

Peroxisomes are important organelles involved in lipid metabolism and in the removal of substances and reactive oxygen species. They have a special set of enzymes that can carry-out oxidative reactions. A major enzyme involved in this process is catalase, which uses hydrogen peroxide to oxidise toxic substances such as alcohol and formaldehyde. Catalase has been used as a marker for peroxisomes (Baudhuin et al., 1965). PMP70, is a peroxisomal membrane protein (Kamijo et al., 1992). 


\section{Synaptic vesicle recycling}

One of the most studied functional pathways within neurons is synaptic vesicle recycling. It is at the heart of synaptic function and has been studied in high detail and was reviewed several times (Rizzoli, 2014; Südhof, 2004). Thus, I will only give a small overview here. As mentioned in the previous section, chemical synapses rely on the release of neurotransmitter from the presynaptic neuron. This happens at specialized structures in the axon, synaptic boutons. They have been first described in the 50 s during the advancement of electron microscopy (Gray, 1959; Palay, 1956). Presynaptic boutons have a size of about $0.37 \mu \mathrm{m}^{3}$ (Wilhelm et al., 2014) and they contain SVs (Palay, 1956). The number of SVs depends strongly on the neuron type and organism (Denker et al., 2011a). SVs have a diameter of about $40-45 \mathrm{~nm}$ (Takamori et al., 2006). SVs have a very specific set of proteins and lipids that helps them to carry-out their release function (Takamori et al., 2006). SVs store neurotransmitter molecules, in the case of glutamatergic neurons (which is the main neuron type studied here) glutamate. The concentration of glutamate is ranging between $60 \mathrm{mM}$ and $150 \mathrm{mM}$ (Burger et al., 1989). The SVs fuse with the PM upon stimulation, a process called exocytosis. The first visual evidence of exocytosis was provided with the advancement of electron microscopy, especially of rapid freezing technologies (Heuser and Reese, 1973; Heuser et al., 1979). By now, this process and the machinery involved has been very thoroughly dissected. For example, there are voltage gated calcium channels that open upon the arrival of an action potential. The calcium influx has an influence on synaptotagmin, which is the major calcium sensor on SVs (Brose et al., 1992; Matthew et al., 1981; Sinha et al., 2011; Südhof and Rizo, 1996). Probably through a conformational change it triggers the fusion of already primed SVs. SNARE proteins, in the case of SVs two copies of SNAP-25, synaptobrevin, and syntaxin1a are known to be involved in forming tight bundles between the SV and the plasma membrane, which eventually through tightening of the bundle allows the fusion of both membranes (Jahn and Fasshauer, 2012; Jahn and Scheller, 2006; Jahn et al., 2003). The triple A ATPase NSF is required to release the SNARE bundle after fusion (Söllner et al., 1993).

After its fusion, SVs are recycled through a process termed endocytosis (Saheki and De Camilli, 2012). Again here, we know many details about the machinery involved. In short, 
SVs are thought (amongst other scenarios) to be recycled from the plasma membrane by clathrin mediated endocytosis. Clathrin forms triskelia and was shown to form around endocytosing vesicles (Heuser and Reese, 1973). In order to target it to the plasma membrane in the first place it requires adaptor proteins, such as AP-2, AP-180, and stonin 2. These adaptors interact with SV proteins and clathrin molecules, which subsequently form a coat made of triskelia consisting of clathrin light and heavy chains. Finally, to aid the bending of the membrane BAR-domain proteins are required (Daumke et al., 2014; Saheki and De Camilli, 2012; Südhof, 2004). The almost reformed SV is pinched-off the plasma membrane by dynamin. The clathrin coat is later disassembled with the help of chaperones, such as Hsc70. Subsequently, the precursor SVs are refilled with neurotransmitters. For example, after its release, glutamate is taken up again into the synapse by glutamate transporters. The reloading of glutamate into SVs is achieved via vesicular glutamate transporters, which require a proton gradient, generated by the vATPase located in the SV membrane (Ahnert-Hilger et al., 2004).

While there are many more details known about synaptic vesicle recycling, there are still several points of controversy. It is for example debated, whether SVs fully collapse into the plasma membrane during fusion or if they only open transiently ("kiss-and-run" exocytosis) (Ceccarelli et al., 1973; Rizzoli and Jahn, 2007). Also the retrieval of SVs has been largely debated (Jähne et al., 2015; Jockusch et al., 2005). Next to the clathrin mediated endocytosis explained above, a bulk retrieval and ultrafast endocytosis have been described (Cheung et al., 2010; Clayton et al., 2007, 2010; Watanabe et al., 2013b, 2013a). Similarly, it has been very difficult to elucidate the biogenesis and ageing of SVs (Rizzoli, 2014).

\section{The need for quantitative neuronal models}

As illustrated above, neurons are compartmentalized, each of these compartments and organelles indicating a function. Some of these functions, such as synaptic vesicle recycling at the synapse are highly specialized and neuron specific. There have been recent attempts to unveil the neuronal composition for example with proteomic approaches (Oguri et al., 2002; Yu et al., 2004). However, these attempts are mostly of a relative/qualitative nature as they compare the levels, but not absolute molecular 
numbers with each other. In other attempts, sub-cellular compartments have been assessed, as for example the active zone (Morciano et al., 2009) and the postsynaptic density (Sheng and Hoogenraad, 2007). Quantitative information on almost all the other compartments and organelles is lacking, though. Recently, two major studies have set out to describe the molecular composition of subcellular compartments, namely on synaptic vesicles and on the presynaptic bouton (Takamori et al., 2006; Wilhelm et al., 2014), showing the following:

Takamori et al. published in 2006 the first comprehensive and quantitative study on synaptic vesicles, determining their average physical parameters such as size, mass, and density. They determined the protein and major lipid content (Takamori et al., 2006). Due to the quantitative nature of their measurements, they were able to make some observations previously not possible to show. First, they showed that a quarter of the entire membrane is lined by proteins. This might limit lipid diffusion and accessibility (Ritchie et al., 2005). As they determined the amounts of each protein present they were able to look at the abundance of these proteins in functional pathways. As an example, the vesicular SNAREs that are required for exocytosis are present in high copy numbers. This is presumably a safety factor, assuring the releasability of SVs even in extreme situations. That there is this safety factor was also shown before, while studying the Drosophila NSF mutant comatose. In the mutant, vesicle exocytosis was retained for 2 to 3 minutes after temperature induced inactivation of NSF (Littleton et al., 1998). Conversely, Takamori et al. showed that the number of vesicular ATPases per SV is limited with on average only two copies being present. Thus, the vesicle reloading might not always be possible (Ahnert-Hilger et al., 2004).

Wilhelm et al. took this concept one step further and provided a quantitative view on presynaptic boutons by determining the ultrastructure, the proteins copy numbers and protein positions within boutons (Wilhelm et al., 2014). This allowed them to show the dense packing of proteins in synapses. This might present a constraint for the diffusion of molecules. It also might limit the availability of compounds present at low copies. Knowing the protein copy numbers, they were able to study specific pathways, such as exo- and endocytosis and look at bottlenecks (this would not be possible to achieve with relative amounts). They found that the components involved in exocytosis were highly 
abundant, again ensuring SV fusion upon the arrival of stimuli. Conversely, the components of the endocytic pathway were partially limiting. Wilhelm et al. modelled that the clathrin molecules only support the endocytosis of $7 \%$ of all SVs at a time. $11 \%$ of all SVs would be able to be pinched off by the available dynamin molecules. This might be sufficient, as endocytosis may happen at a much slower pace (it is not directly connected to the fast arrival of stimuli). Remarkably, they also found that proteins that are part of the same functional process have similar/correlated copy numbers. This suggests a tight control of the biogenesis of synaptic molecules. It is not clear, where this control is taking place, as it has been difficult to study the biogenesis (Rizzoli, 2014).

These two studies are landmark studies indicating the importance of a quantitative assessment of cellular compartments. It is clear that if we really want to understand neuronal functions and tie together the information provided by studies on individual functional pathways, we will need to quantitatively assess the whole neuron. Most of the functional pathways are tightly interconnected, such as the secretory pathway including ER, Golgi apparatus, and various sorting vesicles with synaptic vesicle recycling. Thus, it does not make sense to study them in isolation. I am setting out to study the compartments and organelles of cultures hippocampal neurons in order to assess their volumes, their distributions, and their subcellular differentiation. With this information I aim to provide a basis for functional studies. In the future, it is our goal to combine this dataset with quantitative protein data to create a neuronal nanomap. 


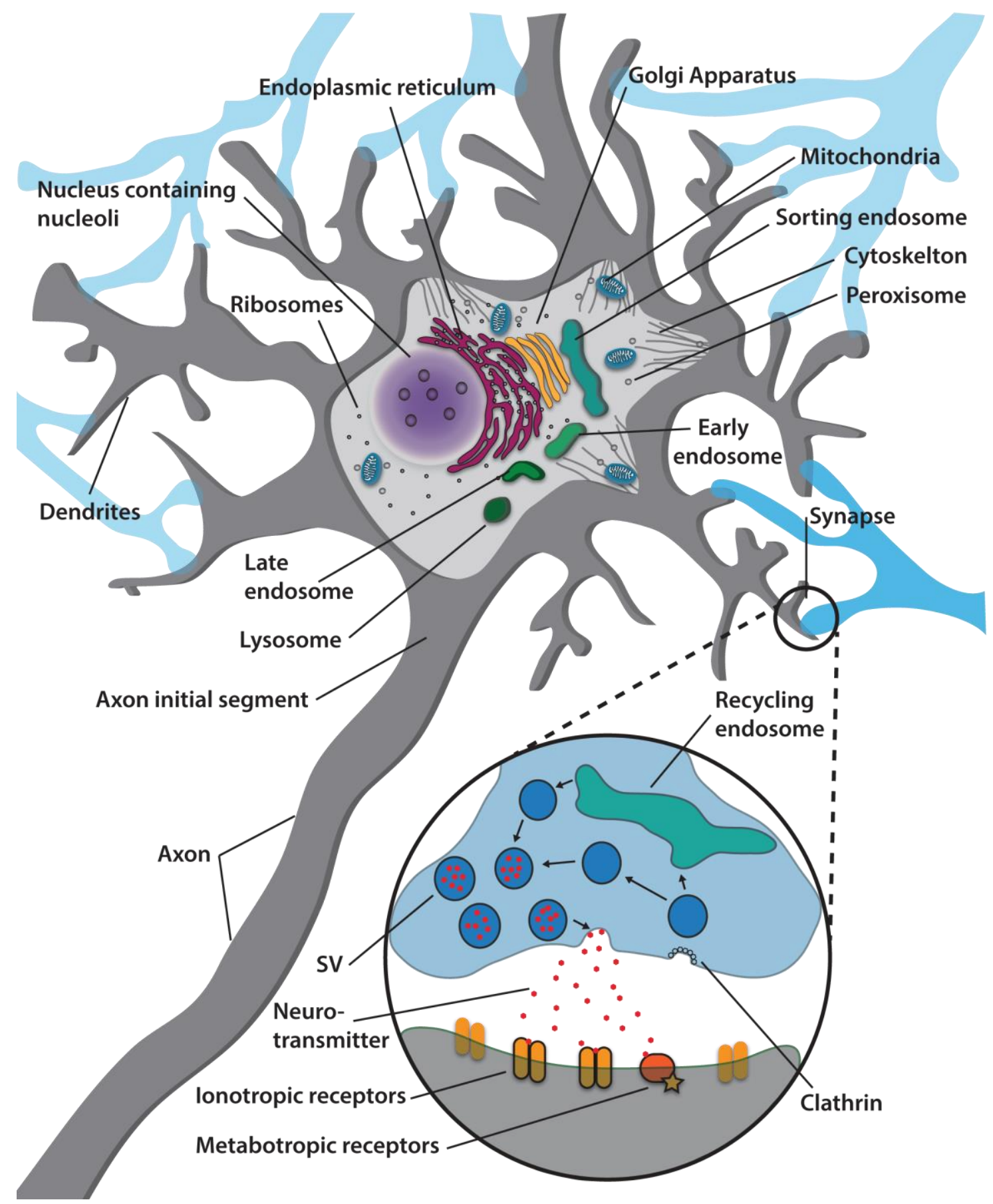

Figure 1: Morphology and functional organization of neurons and synapses. Schematic of a neuron and its organelles, including a close-up of a synapse depicting neurotransmission. SVs containing neurotransmitter exocytose upon stimulation. Neurotransmitter is released and binds ionotropic and metabotropic receptors on the postsynapse. SVs are reformed via clathrin mediated endocytosis. They are recycled directly or via endosomes. Aim of this work is to create a model of an average cultured neuron that combines measurements of the elements depicted in the schematic, e.g. the morphology, the functional organisation, i.e. the organelles and compartments, their volumes and their distribution, as well as on the protein composition. 


\section{Experimental strategy}

In order to obtain this quantitative neuronal model, I will use a strategy based on the presynaptic model described by Wilhelm and colleagues (Wilhelm et al., 2014). Since neurons have a higher level of complexity and are much bigger than a presynaptic bouton, the techniques will have to be adapted or changed accordingly. On the following pages, I will describe the strategy I used towards this model. Some of the choices will be further detailed in the discussion.

\section{Model system}

First, I will need a suitable neuronal model system that fulfils the following criteria: it has to be representative, allow biochemical analysis, and be easily accessible by various imaging techniques. I will determine the volumetric parameters of the neurons and their functional compartmentalization. In the future, I want to combine my results with a quantitative assessment of the neuronal proteome.

Thus, the model system should contain neurons of a specific type that can be isolated for biochemical analysis and fluorescence imaging. To date, the only way to obtain good and reliable quantitative measurements on proteins is to perform quantitative Western blotting or quantitative mass spectrometry (Schwanhäusser et al., 2011; Takamori et al., 2006; Towbin et al., 1992). Both methods require a large amount of sample, and thus can only be performed on a bulk of material. This material should consist mostly of neurons of a specific type to yield reliable data. Using brain tissue, which is undoubtedly the most relevant neuronal preparation, this is difficult to achieve, since there are many different types of neurons, glia, microglia, oligodendrocytes, vessels, and connective tissue present. Neurons cannot be isolated easily without changing their properties massively.

Another, very commonly used, way to study neurons is to use dissociated neuronal cultures. Many studies carried-out on neurons have been done on dispersed hippocampal cultures. These cultures are very well characterized (Kaech and Banker, 2006). Since the neurons can be plated on coverslips in a monolayer, they are easy to image. Conventionally, the neurons are cultured together with glia, which the neurons need as a support for their growth and maintenance (Lester et al., 1989). This again is not ideal for 
the biochemical analysis. Instead of using this co-culture system, I decided to use a layered culture, where the glia are plated in the well of a culture plate and the neurons are grown on coverslips that are placed on top of the well, separated by paraffin dots as spacers. This type of culture is termed sandwich culture or Banker culture (I will refer to it as Banker culture) and it has been thoroughly characterized (Brewer and Cotman, 1989; Kaech and Banker, 2006). It consists almost exclusively of hippocampal neurons bearing minimal contamination of other cell types, which makes it ideal for bulk biochemical analysis, while retaining all the imaging benefits of other culture systems. For this study, I was using Banker cultures of at least DIV21 to ensure a proper development of synapses between the cells (Dotti et al., 1988; Fletcher and Banker, 1989; Friedman et al., 2000).

The neurons of the Banker culture can be scraped off and the proteins can be quantified by mass spectrometry (Schwanhäusser et al., 2011; Wilhelm et al., 2014). The neurons per coverslip can be counted and the protein amounts can be calculated per neuron.

\section{Morphology and neurite parameters}

In order to be able to determine the concentration of these proteins rather than their absolute numbers, it is necessary to know the volumes of the neurons in the Banker culture system. But what does 'volumes' mean here? It means, on the one hand, the overall volume a cell occupies, or in other words the space that its plasma membrane ensheaths. On the other hand, it refers to the volumes taken up by the compartments and organelles within the cell.

A good way to determine the volume of cells and their compartments is to use microscopy. Neurons are polarized, having a complex morphology with a cell body and many neurites that can span several millimetres, in culture. Thus, it makes sense to not only look at the cell body, but also at the neurites. Both pose fundamentally different challenges for microscopy studies. While the neurites are mostly thin, they span a wide area, necessitating a large-scale imaging approach that can capture them in their entirety, while the cell body is a large volume that requires axial sectioning.

In order to describe the neurites and their volumes of the neurons in our model system, I decided to use a fluorescence microscopy approach. 
Cultured neurons can span several millimetres with their neurites and the neurites of many cells overlap, run in parallel, or cross. This makes it hard to identify the neuron that the neurites belong to. In vivo, this has been tackled using transfections with random expression of fluorescent proteins with different spectra, a method called brainbow, or by simply injecting a dye into one particular cell of interest (Honig and Hume, 1986; Livet et al., 2007; Lukas et al., 1998; Mishchenko, 2010; Pu and Berson, 1992; Smith, 2007). In order to define the neurites belonging to one neuron, I used a sparse transfection method with a membrane-bound EGFP. The plasmid was using a promoter that works in neurons, a mix between CMV and chicken beta actin. The EGFP was coupled to a palmitoylation domain that will target it to the neuronal plasma membrane (Liu et al., 1993; Matsuda and Cepko, 2007). In this way, the membrane of the neurons can be imaged in a fluorescent microscope. Mature neurons are not easy to transfect (Washbourne and McAllister, 2002). I used a magnetofection approach to transfect them, as it has been described that it can be tailored to be sparse and that it works in mature cells. The plasmid is coupled to magnetic beads, which are transferred into the culture, which is then placed on top of a magnetic plate. The beads are pulled down towards the cells and enter some cells (Buerli et al., 2007).

To image the transfected neurons is another challenge, since the field of view of a typical microscope is too small to capture the entire neuronal tree. My strategy to overcome this is to use a microscope with a programmable, motorized stage. In this way, a bigger area can be selected, where several images in defined regions are taken and then are stitched together. The next challenge is to then extract information on the neurites, like their numbers, lengths, widths, and branching angles from the obtained images. Typically, the neurites are traced. There are many strategies on how to do this, including many recently developed algorithms that do this automatically (Zhou et al., 2015, 2016). While these algorithms are getting better and allow a large-scale analysis, they still do not have the precision that can be achieved by manual tracing (Donohue and Ascoli, 2011). Thus, I decided to use a semi-automatic approach, the commonly used open source plugin NeuronJ, which runs in ImageJ (Meijering et al., 2004; Schneider et al., 2012). From the resulting tracing data, I will obtain the number of neurites, their length, the branching, 
and their volume. I combined this with a synaptic immunostaining to determine the number of synapses per neuron.

\section{Cell body and organelles}

To determine the cell body volume as well as the organelle and compartment distribution and volumes, I will use a combination of electron microscopy (EM) and confocal fluorescence microscopy. EM has unsurpassed resolution, down to the sub-nanometre range, and is very convenient for structural work, as the samples can be prepared to have a strong membrane contrast using heavy metals such as osmium tetroxide (Deerinck et al., 2010). As such, it is useful for investigating membrane-based organelles and compartments, in fact only with EM most of these organelles were initially described (Palay and Palade, 1955).

While EM has a very good resolution and the potential to reveal organelles, it is usually limited to relatively small imaging volumes, since the sections have to be thin and the imaging area is limited. Recently, techniques have been developed to overcome this limitation, namely serial block-face scanning electron microscopy and focused ion beam scanning electron microscopy (FIB-SEM) (Denk and Horstmann, 2004; Knott et al., 2008, 2011). I will use FIB-SEM microscopy to study the neuronal cell body and its organelles. FIB-SEM relies on a combination of scanning electron microscopy (SEM) and focused ion beam milling of the sample. The sample is placed into the machine as a whole. While the SEM takes images of the surface of the sample, the ion beam mills away the top layer, thus allowing a serial sectioning-like imaging of the sample. Consecutive rounds of milling and imaging are performed, allowing imaging of large samples, even up to entire Drosophila brains, as recently demonstrated by Xu and colleagues (Xu et al., 2017). Thus, it is ideal for my purpose of imaging several neuronal cell bodies and their organelles.

However, one challenge with FIB-SEM is the large amount of data created and the processing thereof. To date, there has been no algorithm developed that can segment the neuronal membrane and the neuronal organelles automatically. Most laboratories working with EM data still rely on manual segmentations. There is some effort being taken to speed up the segmentation of large datasets, including the involvement of many 
people the use of machine learning or recently the attempt to use neural networks (Jones and Spiers, 2018; Plaza et al., 2014).

I decided to manually segment the plasma membrane, the nucleus, and the nucleoli and combine this with an automatized, filter-based segmentation of mitochondria. I compared this with a fully manual segmentation. Since the SEM does not provide a great contrast, it will be difficult to define other organelles in an automated fashion. Furthermore, EM is not good for providing specific molecular identities of the organelles and compartments of interest. For example, the different types of endosomes (early, late, or recycling) will be very difficult to differentiate with EM. This might be circumvented by using immuno-EM (Phan et al., 2017). This is, however, a very challenging technique and the data processing for many different immuno-EM samples would simply be too timeintensive (limited to one label at a time). It can also not be combined with FIB-SEM.

To obtain information on the other organelles, I will combine the FIB-SEM measurements with fluorescence confocal microscopy. Confocal imaging of the cell bodies is much faster, multiple specific molecular labels can be combined, and data processing can be automatized much more reliably. I will label the plasma membrane with an organic carbocyanine dye, DiO, which has been extensively used for tracing and which can be combined with immunostainings (Godement et al., 1987; Honig and Hume, 1986; Lukas et al., 1998; Matsubayashi et al., 2008). It binds mostly to the plasma membrane and can be adjusted in concentration to be sparse enough to distinguish single cells. Most compartments and organelles contain a specific set of proteins. If they are specific to a certain organelle, they can be used as markers. I will use these markers as targets for immunostainings to label the organelles of interest. As a reference point and to define the position of the axon initial segment (AIS), I will combine the DiO and organelle label with an immunostaining against ankyring (Hedstrom et al., 2007; Leterrier et al., 2015; Papandréou and Leterrier, 2018). These three labels can be imaged together. I will acquire z-stacks through neuronal cell bodies with all the different organelles labelled.

From these images I will determine the volume of the cell body and specific information for each organelle. This will include the numbers of each organelle and their distribution in the cell body, the proximal dendrites, and the proximal axon. The volume for each organelle, the dimensions, and the distances to each other will be calculated. 
Confocal microscopy is diffraction-limited. It cannot be used to resolve two objects closer than approximately $200 \mathrm{~nm}$. Thus, when looking at small organelles, such as synaptic vesicles (diameter of around $40 \mathrm{~nm}$ ), the resolution of the microscope is not precise enough to resolve the structures accurately. Apart from EM, there have been two major techniques developed that can overcome the diffraction barrier, stimulated emission depletion (STED) microscopy and stochastic optical reconstruction microscopy (STORM) (Hell and Wichmann, 1994; Klar et al., 2000; Rust et al., 2006; Willig et al., 2006).

I will use STORM, which is based on the separation of fluorophores in time. If a fluorophore is spatially separated, its centre position can be determined with a much higher precision by fitting a Gaussian distribution function. In order to achieve spatially separated fluorophores, one can separate them in time by getting them to blink. This necessitates appropriate fluorophores, lasers that can get the fluorophores to enter a dark state, and a buffer that promotes the transition into the bright state (Heilemann et al., 2008). Using STORM, the resolution limit has been pushed down to less than $10 \mathrm{~nm}$ (Xu et al., 2012). It can also be combined with a circular lens to obtain 3-dimensional information (Huang et al., 2008a, 2008b). I will use dSTORM to obtain a better volume and size estimation for organelles that are known to be smaller.

\section{Synapse turnover}

One question, as mentioned before, we want to elucidate with our model is how the protein turnover is regulated, with a specific focus on its connection to the SV cycle. Unfortunately, the model, as proposed so far, does not contain any dynamic information, which makes the study of protein turnover at different neuronal activities difficult. In the last part of the project, I am going to look at the regulation of synaptic protein turnover by synaptic activity, using a combination of optical and isotopic imaging. Protein turnover is difficult to study with fluorescent microscopy. It has been done using the incorporation of unnatural amino acids (UAAs) and their fluorescent labelling via copper-catalysed azide/alkyne cycloaddition (CLICK chemistry) (Dieterich et al., 2010; tom Dieck et al., 2015). The incorporation of UAAs requires the change of the cell's medium and the replacement of the normal AA with the UAA. This can negatively affect the cells' physiology. 
I have decided to use a complementary technique to visualize newly-produced proteins, secondary ion mass spectrometry (SIMS), more specifically nanoscale SIMS (nanoSIMS). SIMS relies on a primary ion beam that hits the sample and creates secondary ions from the molecules in the sample. This process fragments the molecules. The resulting ions are then analysed in a mass spectrometer. The most commonly used SIMS is time-of-flight SIMS (TOF-SIMS). While it provides information on small peptides and other biomolecules, its resolution is in the micrometre-range. This, as argued before, is not sufficient to study compartments or organelles. However, there is another SIMS technique, termed nanoSIMS that has a much improved spatial resolution, down to approximately $50 \mathrm{~nm}$. This comes at the cost of a higher molecular fragmentation, yielding mostly elemental secondary ions. To specifically label newly-produced proteins, we added an essential amino acid, leucine, containing the rare stable isotope ${ }^{15} \mathrm{~N}$ (usually present at $0.03 \%$ of ${ }^{14} \mathrm{~N}$ ), to the culture medium. ${ }^{15} \mathrm{~N}$-leucine is incorporated just as well as normal leucine. The ${ }^{15} \mathrm{~N}$ label can be localized with the nanoSIMS (Jiang et al., 2014; Peteranderl and Lechene, 2004; Steinhauser and Lechene, 2013). NanoSIMS can also be used to quantify other ions species, like the sulphur, the phosphorous and the metal contents of the cells (Wirtz et al., 2015). It has seven parallel detectors that are arranged after a magnetic sector to count the number of ions selected for. NanoSIMS is useful in showing the overall structure of cells, but it is not very useful in identifying specific substructures or specific molecules, due to the degree of fragmentation. In order to study the protein turnover at synapses, I will therefore combine nanoSIMS with fluorescence microscopy, a method termed correlated optic and isotopic nanoscopy (COIN, see figure 2) (Hassouna et al., 2016; Richter et al., 2017a; Saka et al., 2014; Truckenbrodt et al., 2018). The pre- and postsynapse can be fluorescently labelled using a simple immunocytochemistry approach. I am planning to correlate the pre- and postsynaptic turnover to the activity of these synapses. The activity can be quantified by labelling recycling (exo- and endocytosed vesicles) vesicles with primary labelled antibodies against the lumenal domain of the SV protein synaptotagmin. Whenever a SV exocytoses, the luminal synaptotagmin domain is exposed to the extracellular space, and can be bound by the antibody. The fluorescence of the antibody can then be quantified and represents the amount of vesicles that exocytosed, which is a measure for how active the synapse was (Kraszewski et al., 1995; Truckenbrodt et al., 2018; Wilhelm et al., 2010). 


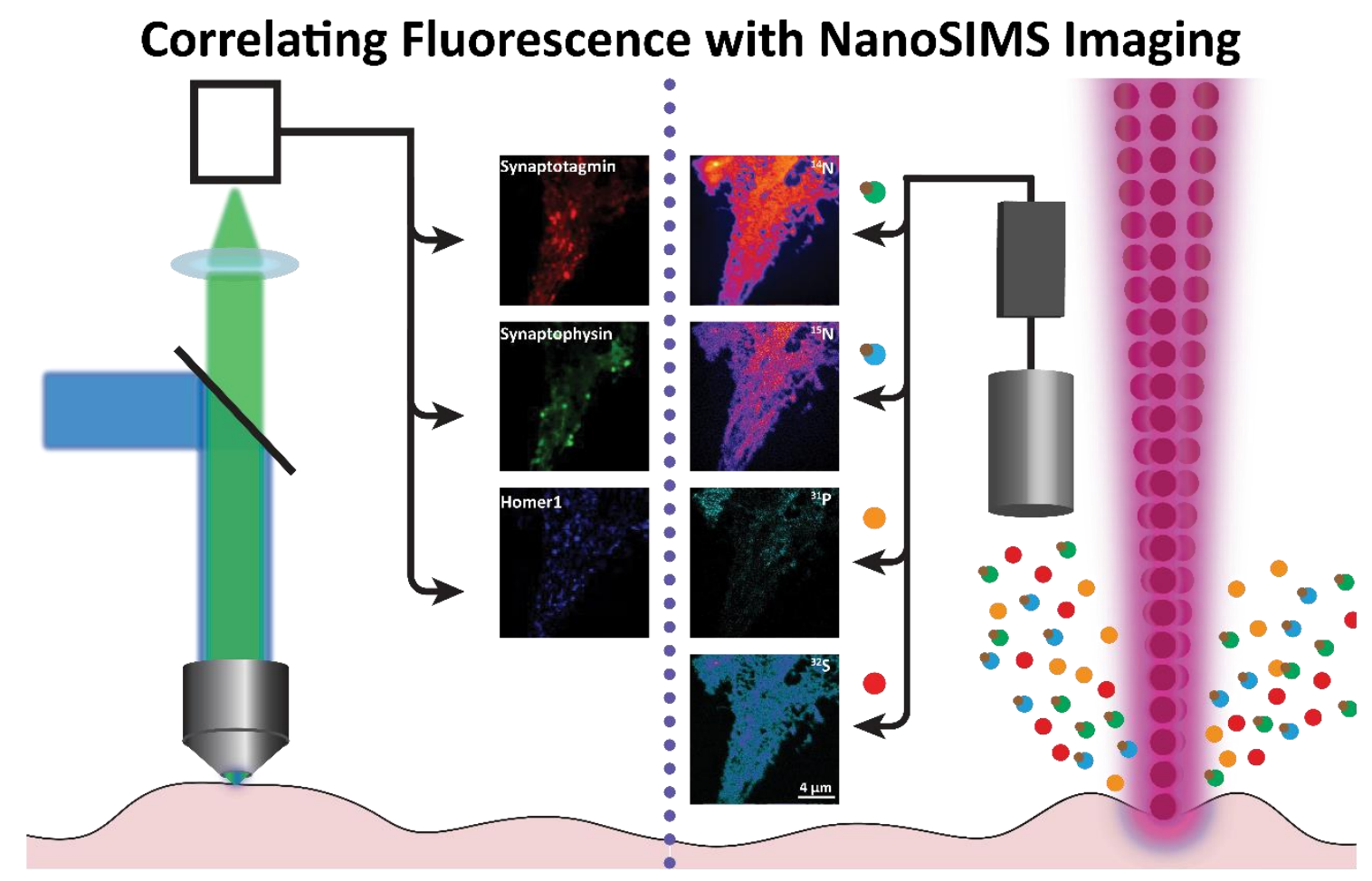

Figure 2: Correlated optic and isotopic nanoscopy. NanoSIMS and fluorescence microscopy can be correlated, providing information both on the elemental and molecular composition of a sample (Saka et al., 2014). A biological sample can be prepared to be both usable in fluorescence microscopy and nanoSIMS. Cells are conventionally fixed and, for example, immunostained for markers of interest (in this case, the synaptic proteins synaptotagmin, synaptophysin, and homer1). They are then embedded in an LR white resin from which $200 \mathrm{~nm}$-thick sections are prepared. These sections are placed on silicon wafers and can then be imaged with a fluorescence microscope (left side), followed by nanoSIMS measurements of the same regions (right side). This sequence is important, since nanoSIMS is a destructive technique. The fluorescence signal containing specific molecular information can then be correlated to the isotope information from the nanosIMS. This can, for example, be used to study protein turnover in subcellular compartments. 


\section{Methods}

Primary hippocampal cultures, preparation and maintenance

As explained in the introduction, we decided to use a sandwich-type primary hippocampal culture (which I will refer to as Banker culture), based on a protocol devised by Gary Banker (Kaech and Banker, 2006). The preparation was made up of two parts, the astroglial preparation and the neuronal preparation. I will briefly explain each of them. The astroglial cells were prepared from cortices of PO Wistar rats two weeks before starting the Banker culture. I cut seven cortices into pieces of approximately $1 \times 1 \mathrm{~mm}$ and washed them three times with HBSS containing 10 mM HEPES (for a list of buffers used for the cell culture, see Table 1). Small tissue pieces, which may be toxic to the cells, were removed from the solution. After the washing step, the buffer was aspirated and the tissue pieces were transferred to a dissociation buffer (12 mL HBSS, $1.5 \mathrm{~mL} 2.5 \%$ trypsin, $1.5 \mathrm{~mL} 1 \%$ DNase). The dissociation mix was rotated for $15 \mathrm{~min}$ at $37^{\circ} \mathrm{C}$. After the incubation, the dissociation buffer was aspirated and the cells were repeatedly washed with glial medium. Using a $10 \mathrm{~mL}$ pipette, I resuspended the tissue pieces in glial medium. The suspension was then filtered to remove remaining tissue. The cells were pelleted using a centrifugation step at $800 \mathrm{rpm}$ for $10 \mathrm{~min}$. The supernatant was removed and the pelleted cells were resuspended in $20 \mathrm{~mL}$ glial medium. The suspension was distributed to four $75 \mathrm{~mL}$ culture flasks, which were filled up to a final volume of $20 \mathrm{~mL}$. After a couple of hours, the medium was changed to remove dead cells and debris. Glia cells were kept at $37^{\circ} \mathrm{C}$ at $5 \% \mathrm{CO}_{2}$, fed every third day with fresh glial medium, and shaken once per week on a rotatory shaker in the presence of $10 \mathrm{mM}$ HEPES to remove microglia.

The astroglial cells were transferred from their culture flasks onto 12-well plates, five days before seeding the neurons. First, the cells were detached from the flasks by adding $3 \mathrm{~mL}$ of a trypsin/EDTA mix (Invitrogen, Cat\# 25300-054). After successful detachment, the enzyme mix was deactivated using glial medium. The loosened cells were pelleted at $800 \mathrm{rpm}$ for $10 \mathrm{~min}$. After resuspension in glial medium, the astroglia were seeded at a density of 10,000 cells per well. One day in advance of preparing the neurons, the glial medium was replaced with N2 medium.

We used hippocampi from E18 Wistar rats for the preparation of hippocampal neuron cultures. In short, hippocampi were dissected-out and transferred to dissociation buffer 
(4.5 $\mathrm{mL} \mathrm{HBSS}, 0.5 \mathrm{~mL} 2.5 \%$ trypsin), in which they were incubated for $15 \mathrm{~min}$ at $37^{\circ} \mathrm{C}$. After the dissociation, hippocampi were washed three times with $5 \mathrm{~mL}$ HBSS. The tissue was then resuspended using a Pasteur pipette. Cells were counted in a Neubauer chamber and seeded at a density of 30,000 neurons $(60,000$ neurons for transfections) per $18 \mathrm{~mm}$ coverslip (Marienfelder). During the attachment phase they were kept in neuronal plating medium.

Astroglial monolayer culture

P1 rat cortex

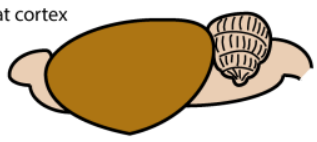

Tissue was dissociated with trypsin and

a cell suspension was prepared.

Glia were grown in glial medium for

10 days ( $85 \%$ confluence).

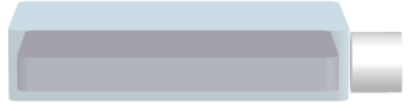

They were plated onto 12 well plates and fed with glial-medium every 3-4 days. Before starting the sandwich culture, the

glial medium was replaced with N2 medium.

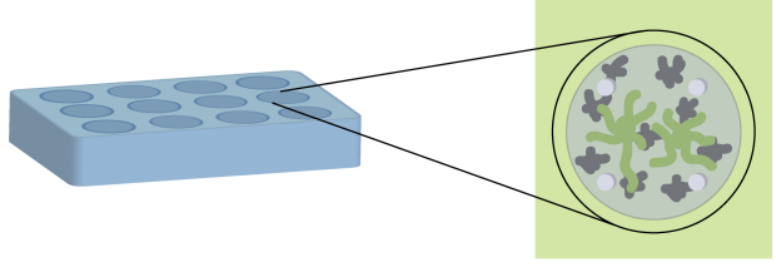

Banker Culture

Glass coverslips were treated with nitric acid for $18 \mathrm{~h}$, cleaned with EtOH, and sterilised at $225^{\circ} \mathrm{C}$. Paraffin dots were applied to the coverslips. Coverslips were coated with poly-L-lysine and pre-treated with neuronal plating medium.

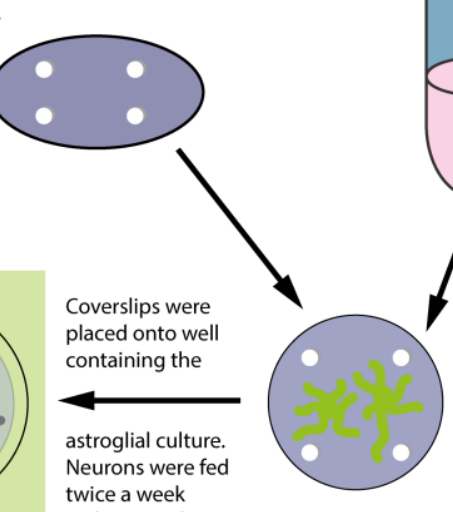

Primary hippocampal neurons

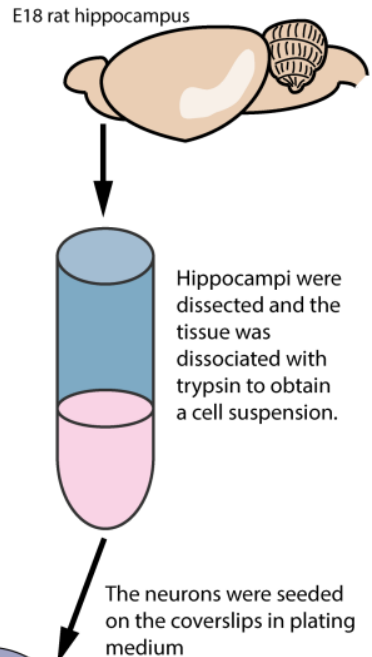

Figure 3: Neuronal Sandwich Culture. Primary culture of hippocampal neurons. Glia and neurons are spatially separated allowing the exchange of neurotrophic factors while keeping the neuronal culture free of glia. Astroglia are prepared from PO rat cortices. The tissue is dissociated with trypsin, and the glial cells grown in glial medium for 10 days, before being seeded onto 12 well plates. In parallel coverslips are treated with concentrated nitric acid, then autoclaved, coated with poly-L-lysine, and finally preincubated with neuronal plating medium for two days. Paraffin dots are applied to the top of the glass as a spacer. Hippocampi are dissected from E18 rats, dissociated, and seeded onto the treated coverslips. After initial attachment, coverslips are flipped top-down onto the wells that contain the astroglia. Cultures are kept in $\mathrm{N} 2$ medium at $37^{\circ} \mathrm{C}$ and $5 \%$ $\mathrm{CO}_{2}$. The cells were used after DIV21 (Kaech and Banker, 2006). 
To reduce contaminations and to improve cell attachment, coverslips were treated in the following way: First, they were placed in concentrated nitric acid overnight, followed by washing steps with $\mathrm{ddH}_{2} \mathrm{O}$ to neutralize the $\mathrm{pH}$. The coverslips were then autoclaved and small wax-dots were applied to their top. These wax dots create a spacer between neurons and glial cells. For mass spectrometry analysis, the wax dots, which cause artefacts in the mass spectrometry, were replaced with silicon rings. The coverslips were then coated with $1 \mathrm{mg} / \mathrm{mL}$ poly-L-lysine in borate buffer (100 mM boric acid solved in sterile water and adjusted to $\mathrm{pH} 8.5$ with $100 \mathrm{mM}$ borate base $\left(\mathrm{Na}_{2} \mathrm{~B}_{4} \mathrm{O}_{7} * 10 \mathrm{H}_{2} \mathrm{O}\right)$ ) overnight at $37^{\circ} \mathrm{C}$. Poly-L-lysine will create a charged layer on the glass surface that improves the neuronal attachment. After the incubation, the excess poly-L-lysine was removed and the coverslips were washed four times with autoclaved $d d \mathrm{H}_{2} \mathrm{O}$. Finally, coverslips were dried and pre-incubated with $1 \mathrm{~mL}$ plating medium. Four hours after plating the neurons, the coverslips were transferred, top down, to the wells containing the astroglia. The culture was maintained at $37^{\circ} \mathrm{C}$ in the presence of $5 \% \mathrm{CO}_{2} .5$-fluoro- $2^{\prime}-$ deoxyuridine (FUDR), an inhibitor of cell proliferation was added to minimise glial growth. Cultures were fed with $500 \mu \mathrm{l}$ of fresh N2 medium every three days.

For the turnover experiments and as a comparison to the Banker culture, I used a conventional co-culture of primary hippocampal neurons (modified from Banker and Cowan, 1977; Beaudoin et al., 2012). The culture was prepared from hippocampi of P0 Wistar rats. Hippocampi were washed with HBSS to remove tissue debris and placed into a dissociation mix (10 mL DMEM, $2 \mathrm{mg}$ cysteine, $100 \mathrm{mM} \mathrm{CaCl}_{2}, 50 \mathrm{mM}$ EDTA, and $25 \mathrm{U}$ sterile papain, bubbled with carbogen for $10 \mathrm{~min}$ and filtered) for $1 \mathrm{~h}$ at $37^{\circ} \mathrm{C}$. Afterwards, the tissue was transferred to inactivation buffer (10 mL DMEM containing fetal calf serum (FCS), $25 \mathrm{mg}$ trypsin inhibitor and $20 \mathrm{mg}$ albumin) for $15 \mathrm{~min}$ at $37^{\circ} \mathrm{C}$. Hippocampi were washed with $5 \mathrm{~mL}$ Neurobasal A (see Table 1), followed by a resuspension, which removed the tissue from the cells.

The dissociated cells were then counted in a Neubauer chamber and 70,000-80,000 cells were seeded onto each well, containing round, $18 \mathrm{~mm}$ coverslips (Marienfelder) that were pre-treated as described for the Banker culture, and neuronal plating medium (Table 1). After two hours the medium was changed to Neurobasal A (1.5 mL per well), 
which was again partially exchanged after two days in culture. Cultures were kept at $37^{\circ} \mathrm{C}$, $5 \% \mathrm{CO}_{2}$, and were used after 21 days in culture.

Table 1: Media and solutions used for the preparation of primary hippocampal neurons.

\begin{tabular}{|c|c|c|}
\hline \multirow[t]{2}{*}{$\begin{array}{l}\text { Neurobasal } \\
\text { medium }\end{array}$} & \multicolumn{2}{|c|}{$\begin{array}{l}500 \mathrm{~mL} \text { Neurobasal A medium containing } 10 \mathrm{~mL} \text { B27 supplement, } \\
5 \mathrm{~mL} \text { Glutamax I-stock and } 1000 \mu \mathrm{l} \text { penicillin }(10,000 \mathrm{U}) / \text { streptomycin } \\
(10 \mathrm{mg}) \mathrm{mix}\end{array}$} \\
\hline & $\begin{array}{l}\text { Neurobasal A } \\
\text { B27 supplement } \\
\text { Glutamax I-stock } \\
\text { Penicillin/Streptomycin mix }\end{array}$ & $\begin{array}{l}\text { Invitrogen, Cat\# 10888-022 } \\
\text { Life Technologies, Cat\# 17504-044 } \\
\text { Lonza, Cat\# } 882027 \\
\text { Biozym, Cat\# } 882082\end{array}$ \\
\hline \multirow[t]{2}{*}{$\begin{array}{l}\text { Neuronal Plating } \\
\text { Medium }\end{array}$} & \multicolumn{2}{|c|}{$\begin{array}{l}\text { MEM plus } 3.3 \mathrm{mM} \text { glucose, } 2 \mathrm{mM} \text { glutamine and } 10 \% \text { vol/vol horse } \\
\text { serum }\end{array}$} \\
\hline & $\begin{array}{l}\text { MEM with Earle's salts } \\
\text { D-glucose } \\
\text { L-glutamine } \\
\text { Horse serum }\end{array}$ & $\begin{array}{l}\text { Life Technologies, Cat\# 51200-046 } \\
\text { Sigma, Cat\# G8769 } \\
\text { Lonza, Cat\# } 882027 \\
\text { Biochrom, Cat\# S9135 }\end{array}$ \\
\hline \multirow[t]{2}{*}{ CMF-HBSS } & \multicolumn{2}{|c|}{$\begin{array}{l}\text { Calcium-, magnesium-, and bicarbonate-free Hank's balanced salt } \\
\text { solution buffered with } 10 \text { mM HEPES, } \mathrm{pH} \mathrm{7,3}\end{array}$} \\
\hline & $\begin{array}{l}\text { 1x HBSS } \\
1 \mathrm{M} \text { HEPES buffer, } \mathrm{pH} 7.3\end{array}$ & $\begin{array}{l}\text { Invitrogen, Cat\# 14175-095 } \\
\text { Invitrogen, Cat\# 15630-056 }\end{array}$ \\
\hline \multirow[t]{2}{*}{ Glial Medium } & \multicolumn{2}{|c|}{$\begin{array}{l}\text { MEM (Minimal essential medium) }+0.6 \% \mathrm{wt} / \mathrm{vol} \text { glucose, } 100 \mathrm{U} / \mathrm{mL} \\
\text { penicillin, } 100 \mathrm{\mu g} / \mathrm{mL} \text { streptomycin and } 10 \% \mathrm{vol} / \mathrm{vol} \text { horse serum }\end{array}$} \\
\hline & $\begin{array}{l}\text { MEM with with Earle's salts } \\
\text { D-Glucose }\end{array}$ & $\begin{array}{l}\text { Life Technologies, Cat\# 51200-046 } \\
\text { Sigma, Cat\# G8769 }\end{array}$ \\
\hline
\end{tabular}




\begin{tabular}{|l|l|l|}
\hline & $\begin{array}{l}\text { L-glutamine } \\
\text { Penicillin/Streptomycin mix } \\
\text { Horse Serum }\end{array}$ & $\begin{array}{l}\text { Lonza, Cat\# 882027 } \\
\text { Biozym, Cat\# 882082 } \\
\text { Biochrom, Cat\# S9135 }\end{array}$ \\
$\begin{array}{l}\text { Meuronal } \\
\text { Medium }\end{array}$ & $\begin{array}{l}\text { MEM plus N2 supplement: } \\
99 \text { parts of MEM } \\
1 \text { part of } 100 x \text { N2 } \\
0.6 \% \text { wt/vol glucose }\end{array}$ & $\begin{array}{l}\text { Life Technologies, Cat\# 51200-046 } \\
\text { Invitrogen, Cat\# 17502048 } \\
\text { Sigma, Cat\# G8769 }\end{array}$ \\
\hline N2 contains & $\begin{array}{l}10 \mathrm{mM} \text { sodium pyruvate, } 1 \mathrm{mM} \text { putrescine, } 0.2 \mu \mathrm{M} \text { progesterone, } 0.3 \\
\mu \mathrm{M} \text { selenium dioxide, } 1 \mathrm{mg} / \mathrm{mL} \text { bovine transferrin, } 50 \mu \mathrm{g} / \mathrm{mL} \text { insulin }\end{array}$ \\
\hline
\end{tabular}

\section{Transfections of Banker cultures}

In order to label the neurites of entire neurons, I transfected the Banker culture with a membrane bound GFP construct. The plasmid I used contains an EGFP linked to the palmitoylation domain of GAP43. The palmitoylation domain is targeting the EGFP to the plasma membrane. The plasmid is expressed under a pGAC promoter, which is a mix of a chicken-beta-actin and a CMV promoter (Matsuda and Cepko, 2007). I tested and optimized many different transfection protocols, from calcium-phosphate transfections, over lipofections to magnetofections with the aim to find a method yielding sparse transfections, keeping the cultures viable, and allowing transfections of mature, synapse forming cultures (Washbourne and McAllister, 2002). In the end, magnetofections worked the best for my purposes. The protocol was based on the manufacturers protocol (Buerli et al., 2007).

In short, the coverslips containing the neurons (DIV 12,60K) were turned around and placed into a new plate containing $500 \mu \mathrm{L}$ of their own medium. A magnetofection mix was prepared. The neuromag beads (OZBIOSCIENCES) were vortexed for 10 seconds. For each $18 \mathrm{~mm}$ coverslip, $1.5 \mu \mathrm{L}$ neuromag beads were used and placed into an Eppendorf tube. The plasmid was mixed with optimem medium (Thermo Fischer). For one coverslip $0.6 \mu \mathrm{g}$ of plasmid were mixed with $50 \mu \mathrm{L}$ optimem. This mix was added to the neuromag 
beads and left to incubate for $15 \mathrm{~min}$, ensuring proper binding of the plasmid to the magnetic beads. Afterwards, $50 \mu \mathrm{L}$ magnetofection mix was added to the wells containing the coverslips and the cells were incubated on a magnetic plate for $15 \mathrm{~min}$ at $37^{\circ} \mathrm{C}$. Finally, the coverslips were transferred back into their wells. After three more days, in which the expression of the plasmid occurred in the transfected cells, the neurons were fixed and immunostained as described below.

\section{Immunocytochemistry}

The immunostaining protocol was modified from a common lab protocol that has previously been published (Denker et al., 2011b; Wilhelm et al., 2014). It was used for most of the described experiments. Modifications will be mentioned in the respective sections. In general: neurons were fixed either with $4 \%$ paraformaldehyde (PFA) or glyoxal $\left(7.15 \mathrm{~mL} \mathrm{H} \mathrm{H}_{2} \mathrm{O}, 1.99 \mathrm{~mL} \mathrm{EtOH}, 0.79 \mathrm{~mL} 40 \%\right.$ glyoxal stock, $0.08 \mathrm{~mL}$ acetic acid, adjusted to $\mathrm{pH} 5$ with $\mathrm{NaOH}$ ) depending on the target. Glyoxal is in some cases the better fixative choice (Richter et al., 2017b). Cells were incubated in the fixative for $30 \mathrm{~min}$ on ice and for another 30 min at RT. After the fixation excess aldehydes were quenched with PBS (150 mM NaCl, $20 \mathrm{mM} \mathrm{Na}{ }_{2} \mathrm{HPO}_{4}, \mathrm{pH}$ 7.4) containing $100 \mathrm{mM}$ glycine and $100 \mathrm{mM}$ ammonium chloride $\left(\mathrm{NH}_{4} \mathrm{Cl}\right)$. The cells were then permeabilized using PBS with $0.1 \%$ Triton X-100 (Sigma-Aldrich, 9002-93-1) and a blocking reagent (referred to as permeabilization solution). Permeabilization of the cell membrane ensured good penetration of the antibodies. All antibodies used in the study were tested for optimal blocking conditions, which ensures specific binding of the antibody to its antigen. Tested were $2 \%, 3 \%$, and $5 \%$ bovine serum albumine (BSA, Sigma), as well as $2 \%$ and $3 \%$ tryptone/peptone (T/P, Sigma). The optimal conditions are mentioned in the antibody table (Table 2).

After the permeabilization and blocking, the primary antibody/antibodies were applied. Antibodies were diluted in permeabilization solution as specified by the antibody manufacturer. Where necessary, dilutions were adjusted based on the staining results. Then, the coverslips were again washed three times for $5 \mathrm{~min}$ in permeabilization solution. 
Secondary antibodies specific to the primary antibodies and linked to different dyes (depending on the application, for a full list see Table 4) were diluted in permeabilization solution. Again, the neurons were incubated in the antibody mix for 1 hour at RT. From this point on, care was taken to avoid bleaching of the dyes. To remove unspecifically bound antibodies, the coverslips were washed three times for 5 min in high salt PBS (500 $\left.\mathrm{mM} \mathrm{NaCl}, 2.7 \mathrm{mM} \mathrm{KCl}, 10 \mathrm{mM} \mathrm{Na}_{2} \mathrm{HPO}_{4}, 2 \mathrm{mM} \mathrm{KH}_{2} \mathrm{PO}_{4}, \mathrm{pH} 7.4\right)$ and twice for $5 \mathrm{~min}$ in 1 $\mathrm{mL}$ PBS.

Nuclei were labelled using Hoechst (Thermo Scientific, Cat\#: 33342). $1 \mathrm{~mL}$ of a 1:1000 dilution of a $1 \mathrm{mg} / \mathrm{mL}$ stock solution was used for the 10 min incubation, followed by two 5 min washes in $1 \mathrm{~mL}$ PBS.

Finally, the coverslips were dried and embedded in $7 \mu$ l Mowiol (2.4 g Mowiol 4-88

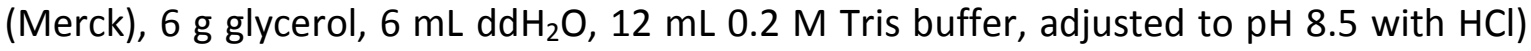
on a microscopy slide (Menzel Superfrost Plus, Thermo Scientific). Embedding was carried out over night at RT. The slides were stored at $4^{\circ} \mathrm{C}$ until imaging.

Membrane labelling using the carbocyanine dye, DiO

For the organelle stainings, the immunostaining protocol was combined with a membrane staining. The cell's membrane was stained with the carbocyanine dye, DiO (3,3'-dioctadecyloxacarbocyanine perchlorate, Molecular Probes, Cat\#: D275), modifying a protocol by Matsubayashi and colleagues (Matsubayashi et al., 2008). DiO was stored in a stock solution of $2 \mathrm{mg} / \mathrm{mL}$ solved in N,N-Dimethylformamide (DMF, Sigma, Cat\#: D8654). This stock was prepared by continuously mixing DiO crystals with DMF at $50^{\circ} \mathrm{C}$ for $20 \mathrm{~min}$. For the membrane staining, the DiO stock was diluted to $0.4 \mu \mathrm{g} / \mathrm{mL}$ in cold PBS. Neurons were incubated with this solution for $20 \mathrm{~min}$ at $37^{\circ} \mathrm{C}$. Unbound dye was washed off three times for 5 min with PBS. Finally, the coverslips were dried and embedded in Mowiol as described in the previous section. The slides were stored at $4^{\circ} \mathrm{C}$ until imaging. 
Table 2: Primary antibodies used to label organelles, compartments, and cytoskeletal elements. The host, supplier, and catalogue numbers are given. Each antibody was tested for optimal conditions. The fixation and blocking methods, as well as the dilution used are provided.

\begin{tabular}{|c|c|c|c|c|c|c|}
\hline Antigen & Antibody & Supplier & Catalogue \# & Fixation & Blocking & Dilution \\
\hline $\begin{array}{c}\text { alpha } \\
\text { internexin }\end{array}$ & $\begin{array}{c}\text { rabbit } \\
\text { polyclonal }\end{array}$ & LSBio & LS-B10413 & $4 \%$ PFA & BSA $5 \%$ & $1: 500$ \\
\hline $\begin{array}{c}\text { alpha- } \\
\text { tubulin }\end{array}$ & $\begin{array}{c}\text { rabbit } \\
\text { polyclonal }\end{array}$ & $\begin{array}{l}\text { Synaptic } \\
\text { Systems }\end{array}$ & 302203 & $4 \%$ PFA & BSA $5 \%$ & $1: 500$ \\
\hline Ankyrin G & $\begin{array}{c}\text { mouse clone } \\
\text { N106/36 }\end{array}$ & Neuromab & $\begin{array}{c}A_{-} \\
10673030\end{array}$ & $4 \%$ PFA & mixed & $1: 500$ \\
\hline Bassoon & $\begin{array}{c}\text { mouse } \\
\text { monoclonal }\end{array}$ & Enzo & $\begin{array}{l}\text { ADI-VAM- } \\
\text { PSO03 }\end{array}$ & $4 \%$ PFA & BSA $3 \%$ & $1: 150$ \\
\hline Bassoon & $\begin{array}{c}\text { rabbit } \\
\text { polyclonal }\end{array}$ & $\begin{array}{l}\text { Synaptic } \\
\text { Systems }\end{array}$ & 141002 & $4 \%$ PFA & BSA $3 \%$ & $1: 500$ \\
\hline Beta actin & $\begin{array}{c}\text { mouse } \\
\text { monoclonal, } \\
\mathrm{AC} 15\end{array}$ & $\begin{array}{l}\text { Sigma- } \\
\text { Aldrich }\end{array}$ & A5441 & $4 \%$ PFA & BSA $5 \%$ & $1: 100$ \\
\hline Beta actin & $\begin{array}{c}\text { rabbit } \\
\text { polyclonal }\end{array}$ & $\begin{array}{c}\text { Novus } \\
\text { Biologicals }\end{array}$ & NB600-503 & $4 \%$ PFA & BSA $5 \%$ & $1: 200$ \\
\hline $\begin{array}{c}\text { tubulin beta- } \\
3 \text { chain }\end{array}$ & $\begin{array}{c}\text { rabbit } \\
\text { polyclonal }\end{array}$ & $\begin{array}{c}\text { Cell } \\
\text { Signalling } \\
\end{array}$ & $5568 S$ & 4\% PFA & BSA $5 \%$ & $1: 200$ \\
\hline brevican & $\begin{array}{c}\text { mouse } \\
\text { polyclonal }\end{array}$ & $\begin{array}{c}\text { Novus } \\
\text { Biologicals }\end{array}$ & NBP2-15616 & $4 \%$ PFA & BSA $5 \%$ & $1: 100$ \\
\hline calnexin & $\begin{array}{c}\text { rabbit } \\
\text { polyclonal }\end{array}$ & Abcam & ab22595 & Glyoxal & BSA $5 \%$ & $1: 100$ \\
\hline calreticulin & $\begin{array}{c}\text { rabbit } \\
\text { monoclonal } \\
\text { D3E6 }\end{array}$ & $\begin{array}{c}\text { Cell } \\
\text { Signalling }\end{array}$ & 12228 & Glyoxal & BSA $5 \%$ & $1: 100$ \\
\hline catalase & $\begin{array}{c}\text { rabbit } \\
\text { polyclonal }\end{array}$ & Abcam & ab15834 & 4\% PFA & BSA $5 \%$ & $1: 100$ \\
\hline clathrin & $\begin{array}{c}\text { rabbit } \\
\text { monoclonal }\end{array}$ & $\begin{array}{c}\text { Cell } \\
\text { Signalling } \\
\end{array}$ & $4796 S$ & glyoxal & BSA $5 \%$ & $1: 200$ \\
\hline COP2 & $\begin{array}{c}\text { rabbit } \\
\text { polyclonal }\end{array}$ & $\begin{array}{l}\text { Thermo } \\
\text { Scientific }\end{array}$ & PA1-069A & $4 \%$ PFA & BSA $3 \%$ & $1: 100$ \\
\hline COP1 & $\begin{array}{c}\text { rabbit } \\
\text { polyclonal }\end{array}$ & $\begin{array}{c}\text { Novus } \\
\text { Biological }\end{array}$ & NBP1-85516 & $4 \%$ PFA & BSA $3 \%$ & $1: 100$ \\
\hline CPT1c & $\begin{array}{c}\text { rabbit } \\
\text { polyclonal }\end{array}$ & $\begin{array}{l}\text { Synaptic } \\
\text { Systems }\end{array}$ & custom & $4 \%$ PFA & BSA $5 \%$ & $1: 500$ \\
\hline $\begin{array}{l}\text { DAPI } 1 \\
\mathrm{mg} / \mathrm{mL}\end{array}$ & nuclear stain & $\begin{array}{c}\text { Life } \\
\text { Technologies }\end{array}$ & D1306 & & Mixed & $1 \mu \mathrm{g} / \mathrm{mL}$ \\
\hline EEA1 & $\begin{array}{c}\text { rabbit } \\
\text { polyclonal }\end{array}$ & $\begin{array}{l}\text { Synaptic } \\
\text { Systems }\end{array}$ & 237002 & $4 \%$ PFA & BSA $5 \%$ & 1:1000 \\
\hline EIF6 & $\begin{array}{l}\text { rabbit } \\
\text { monoclonal } \\
\text { D16E9 }\end{array}$ & $\begin{array}{c}\text { Cell } \\
\text { Signalling }\end{array}$ & $3833 S$ & 4\% PFA & BSA $5 \%$ & $1: 400$ \\
\hline ERp72 & $\begin{array}{c}\text { rabbit } \\
\text { monoclonal } \\
\text { D70D12 }\end{array}$ & $\begin{array}{c}\text { Cell } \\
\text { Signalling }\end{array}$ & 5033 & 4\% PFA & BSA $5 \%$ & $1: 100$ \\
\hline fibrillarin & $\begin{array}{c}\text { rabbit } \\
\text { monoclonal } \\
\text { C13C3 }\end{array}$ & $\begin{array}{c}\text { Cell } \\
\text { Signalling }\end{array}$ & $2639 \mathrm{~S}$ & 4\% PFA & T/P 3\% & $1: 200$ \\
\hline
\end{tabular}




\begin{tabular}{|c|c|c|c|c|c|c|}
\hline GM130 & $\begin{array}{c}\text { rabbit } \\
\text { polyclonal }\end{array}$ & $\begin{array}{l}\text { Sigma- } \\
\text { Aldrich }\end{array}$ & G7295 & 4\% PFA & T/P 3\% & $1: 50$ \\
\hline Golgi 58K & $\begin{array}{c}\text { mouse } \\
\text { monoclonal }\end{array}$ & $\begin{array}{l}\text { Sigma- } \\
\text { Aldrich }\end{array}$ & G2404 & $4 \%$ PFA & BSA 3\% & $1: 200$ \\
\hline Homer1 & $\begin{array}{c}\text { rabbit } \\
\text { polyclonal }\end{array}$ & $\begin{array}{l}\text { Synaptic } \\
\text { Systems }\end{array}$ & 160003 & Glyoxal & BSA $5 \%$ & 1.500 \\
\hline LaminB & $\begin{array}{c}\text { rabbit } \\
\text { monoclonal } \\
\text { EPR9701(B) }\end{array}$ & Abcam & ab151735 & $4 \%$ PFA & T/P 3\% & $1: 100$ \\
\hline LAMP1 & $\begin{array}{c}\text { rabbit } \\
\text { polyclonal }\end{array}$ & Abcam & ab24170 & $4 \%$ PFA & BSA $5 \%$ & $1: 100$ \\
\hline MAP2 & $\begin{array}{l}\text { chicken } \\
\text { polyclonal } \\
(\operatorname{lgY})\end{array}$ & Abcam & ab92434 & 4\% PFA & BSA 5\% & $1: 500$ \\
\hline MAP2 & $\begin{array}{c}\text { rabbit } \\
\text { polyclonal }\end{array}$ & $\begin{array}{l}\text { Synaptic } \\
\text { Systems }\end{array}$ & 188002 & 4\% PFA & BSA $5 \%$ & $1: 1000$ \\
\hline $\begin{array}{c}\text { neuro } \\
\text { filament } \mathrm{M}\end{array}$ & $\begin{array}{c}\text { chicken } \\
\text { polyclonal }\end{array}$ & Abcam & ab134458 & $4 \%$ PFA & BSA $5 \%$ & $1: 2000$ \\
\hline $\begin{array}{c}\text { neuro- } \\
\text { filament } \mathrm{H}\end{array}$ & $\begin{array}{c}\text { rabbit } \\
\text { polyclonal }\end{array}$ & LSBio & LS-C143052 & $4 \%$ PFA & BSA $5 \%$ & $1: 1000$ \\
\hline $\begin{array}{c}\text { neuro- } \\
\text { filament L }\end{array}$ & $\begin{array}{c}\text { rabbit } \\
\text { polyclonal }\end{array}$ & $\begin{array}{l}\text { Synaptic } \\
\text { Systems }\end{array}$ & 171002 & 4\% PFA & BSA $5 \%$ & $1: 500$ \\
\hline PDI & $\begin{array}{c}\text { rabbit } \\
\text { monoclonal } \\
\text { C81H6 }\end{array}$ & $\begin{array}{c}\text { Cell } \\
\text { Signalling }\end{array}$ & 3501 & Glyoxal & BSA 3\% & $1: 50$ \\
\hline peripherin & $\begin{array}{c}\text { chicken } \\
\text { polyclonal }\end{array}$ & $\begin{array}{c}\text { Novus } \\
\text { Biologicals } \\
\end{array}$ & NBP1_05423 & $4 \%$ PFA & BSA $5 \%$ & $1: 2000$ \\
\hline PMP70 & $\begin{array}{c}\text { rabbit } \\
\text { polyclonal }\end{array}$ & Abcam & ab85550 & 4\% PFA & BSA $5 \%$ & $1: 300$ \\
\hline PSD95 & $\begin{array}{c}\text { rabbit } \\
\text { monoclonal } \\
\text { D27E113 }\end{array}$ & $\begin{array}{c}\text { Cell } \\
\text { Signalling }\end{array}$ & 3450 & $4 \%$ PFA & BSA 3\% & $1: 100$ \\
\hline Rab11a & $\begin{array}{c}\text { rabbit } \\
\text { polyclonal }\end{array}$ & $\begin{array}{c}\text { Cell } \\
\text { Signalling } \\
\end{array}$ & $2413 s$ & 4\% PFA & BSA 3\% & $1: 50$ \\
\hline Rab5 & $\begin{array}{c}\text { rabbit } \\
\text { monoclonal } \\
\text { C8B1 }\end{array}$ & $\begin{array}{c}\text { Cell } \\
\text { Signalling }\end{array}$ & $3547 \mathrm{~S}$ & $4 \%$ PFA & BSA 3\% & $1: 200$ \\
\hline Rab7 & $\begin{array}{c}\text { rabbit } \\
\text { monoclonal } \\
\text { D95F2 }\end{array}$ & $\begin{array}{c}\text { Cell } \\
\text { Signalling }\end{array}$ & 9367 & $4 \%$ PFA & BSA 3\% & $1: 100$ \\
\hline ribophorin 1 & $\begin{array}{c}\text { rabbit } \\
\text { polyclonal }\end{array}$ & Abcam & ab137668 & $4 \%$ PFA & BSA $5 \%$ & $1: 500$ \\
\hline $\begin{array}{l}\text { ribosomal } \\
\text { protein S3 }\end{array}$ & $\begin{array}{c}\text { rabbit } \\
\text { monoclonal } \\
\text { D50G7 }\end{array}$ & $\begin{array}{c}\text { Cell } \\
\text { Signalling }\end{array}$ & 9538 & $4 \%$ PFA & BSA $3 \%$ & $1: 50$ \\
\hline $\begin{array}{l}\text { ribosomal } \\
\text { protein S6 }\end{array}$ & $\begin{array}{c}\text { rabbit } \\
\text { monoclonal } \\
5 \mathrm{G} 10\end{array}$ & $\begin{array}{c}\text { Cell } \\
\text { Signalling }\end{array}$ & 2217 & $4 \%$ PFA & BSA 3\% & $1: 100$ \\
\hline SMI 310 & $\begin{array}{c}\text { mouse } \\
\text { monoclonal } \\
{[\mathrm{SMI310}]}\end{array}$ & Abcam & ab 24570 & 4\% PFA & BSA 3\% & $1: 200$ \\
\hline $\begin{array}{c}\text { synapto- } \\
\text { brevin }\end{array}$ & $\begin{array}{c}\text { rabbit } \\
\text { polyclonal }\end{array}$ & $\begin{array}{l}\text { Synaptic } \\
\text { Systems }\end{array}$ & 104202 & 4\% PFA & BSA 3\% & $1: 500$ \\
\hline $\begin{array}{l}\text { synapto- } \\
\text { physin } 1\end{array}$ & $\begin{array}{l}\text { guinea pig } \\
\text { polyclonal }\end{array}$ & $\begin{array}{l}\text { Synaptic } \\
\text { Systems }\end{array}$ & 101004 & 4\% PFA & BSA 3\% & $1: 500$ \\
\hline
\end{tabular}




\begin{tabular}{|c|c|c|c|c|c|c|}
\hline $\begin{array}{l}\text { synapto- } \\
\text { tagmin }\end{array}$ & $\begin{array}{c}\text { mouse } \\
\text { monoclonal }\end{array}$ & $\begin{array}{l}\text { Synaptic } \\
\text { Systems }\end{array}$ & 105221 & 4\% PFA & BSA 3\% & $1: 100$ \\
\hline $\begin{array}{l}\text { synapto- } \\
\text { tagmin } \\
\text { Atto647N }\end{array}$ & $\begin{array}{c}\text { mouse } \\
\text { monoclonal } \\
604.1\end{array}$ & $\begin{array}{l}\text { Synaptic } \\
\text { Systems }\end{array}$ & 105 311AT1 & 4\% PFA & BSA 3\% & $1: 120$ \\
\hline TGN38 & $\begin{array}{c}\text { rabbit } \\
\text { polyclonal }\end{array}$ & $\begin{array}{l}\text { Sigma- } \\
\text { Aldrich }\end{array}$ & T9826 & $4 \%$ PFA & T/P 3\% & $1: 100$ \\
\hline TOMM20 & $\begin{array}{c}\text { rabbit } \\
\text { monoclonal }\end{array}$ & $\begin{array}{c}\text { Cell } \\
\text { Signalling }\end{array}$ & 42406S & $4 \%$ PFA & BSA $5 \%$ & $1: 100$ \\
\hline TOMM20 & $\begin{array}{c}\text { rabbit } \\
\text { monoclonal }\end{array}$ & Abcam & ab186735 & $4 \%$ PFA & BSA $5 \%$ & $1: 250$ \\
\hline TOMM20 & $\begin{array}{c}\text { mouse } \\
\text { monoclonal }\end{array}$ & $\begin{array}{l}\text { Sigma- } \\
\text { Aldrich }\end{array}$ & $\begin{array}{c}\text { WH0009804 } \\
\text { M1 }\end{array}$ & 4\% PFA & BSA $5 \%$ & $1: 200$ \\
\hline $\begin{array}{l}\text { transferrin } \\
\text { receptor }\end{array}$ & $\begin{array}{c}\text { rabbit } \\
\text { polyclonal }\end{array}$ & Abcam & ab84036 & $4 \%$ PFA & BSA $5 \%$ & $1: 100$ \\
\hline vGLUT1 & $\begin{array}{l}\text { Guinea pig } \\
\text { polyclonal }\end{array}$ & $\begin{array}{l}\text { Synaptic } \\
\text { Systems }\end{array}$ & 135304 & 4\% PFA & BSA 3\% & $1: 500$ \\
\hline vGLUT1/2 & $\begin{array}{c}\text { Rabbit } \\
\text { polyclonal }\end{array}$ & $\begin{array}{l}\text { Synaptic } \\
\text { Systems }\end{array}$ & 135503 & $4 \%$ PFA & BSA 3\% & $1: 100$ \\
\hline vimentin & $\begin{array}{l}\text { chicken } \\
\text { polyclonal }\end{array}$ & $\begin{array}{c}\text { Novus } \\
\text { Biologicals }\end{array}$ & NB300-223 & $4 \%$ PFA & BSA $5 \%$ & $1: 5000$ \\
\hline vimentin & $\begin{array}{c}\text { rabbit } \\
\text { polyclonal }\end{array}$ & $\begin{array}{l}\text { Synaptic } \\
\text { Systems }\end{array}$ & 172002 & $4 \%$ PFA & BSA $5 \%$ & $1: 500$ \\
\hline
\end{tabular}

Table 3: Primary antibodies used as markers against different cell types to test the composition of the Banker culture.

\begin{tabular}{|c|c|c|c|c|c|}
\hline Cell Type & Marker & Antibody & Supplier & Catalogue \# & Dilution \\
\hline \multirow{2}{*}{ Astrocytes } & GFAP & mouse monoclonal & $\begin{array}{c}\text { Synaptic } \\
\text { Systems }\end{array}$ & 173011 & $1: 500$ \\
\hline \multirow{2}{*}{ GABAergic neurons } & GAD65 & mouse monoclonal & $\begin{array}{c}\text { Synaptic } \\
\text { Systems }\end{array}$ & 198111 & $1: 500$ \\
\cline { 2 - 6 } & GAD67 & rabbit polyclonal & $\begin{array}{l}\text { Synaptic } \\
\text { Systems }\end{array}$ & 198003 & $1: 500$ \\
\hline Glutamatergic neurons & vGLUT & guinea pig polyclonal & $\begin{array}{l}\text { Synaptic } \\
\text { Systems }\end{array}$ & 135304 & $1: 1000$ \\
\hline Microglia & IBA1 & guinea pig polyclonal & $\begin{array}{c}\text { Synaptic } \\
\text { Systems }\end{array}$ & 234004 & $1: 500$ \\
\hline Neurons & Beta 3 tubulin & rabbit polyclonal & Covance & $435 P$ & $1: 500$ \\
\cline { 2 - 6 } & SMI-310 & mouse monoclonal & Abcam & 24570 & $1: 200$ \\
\hline Oligodendrocytes & OLIG2 & rabbit polyclonal & $\begin{array}{l}\text { Synaptic } \\
\text { Systems }\end{array}$ & 292003 & $1: 500$ \\
\hline
\end{tabular}


Table 4: List of secondary antibodies.

\begin{tabular}{|c|c|c|c|c|c|}
\hline Antibody against & fluorophore & species/form & Supplier & Catalogue \# & Dilution \\
\hline chicken IgY & Star 635P & nanobody & NanoTag & N0702-Ab635P-S & $1: 500$ \\
\hline guinea pig IgG & Alexa 488 & donkey & Dianova & $706-545-148$ & $1: 100$ \\
\hline guinea pig IgG & Atto 647N & donkey & Synaptic Systems & custom & $1: 500$ \\
\hline mouse IgG & Atto 647N & goat & Rockland & $610-156-121$ & $1: 500$ \\
\hline mouse IgG & CF 647 & Fab fragment, goat & Biotium & 20042 & $1: 200$ \\
\hline mouse IgG & Cy3 & donkey & Dianova & $715-165-150$ & $1: 100$ \\
\hline rabbit IgG & Atto 647N & goat & Rockland & $611-156-122$ & $1: 500$ \\
\hline rabbit IgG & CF647 & Fab fragment, goat & Biotium & 20045 & $1: 200$ \\
\hline rabbit IgG & Cy3 & donkey & Dianova & $715-165-152$ & $1: 100$ \\
\hline rat IgG & Alexa 488 & donkey & Dianova & $712-545-153$ & $1: 100$ \\
\hline
\end{tabular}

\section{Banker culture - characterization}

The Banker culture has been thoroughly characterized and described (Banker and Cowan, 1977; Benson et al., 1994; Brewer and Cotman, 1989; Dotti et al., 1988; Fletcher and Banker, 1989; Kaech and Banker, 2006). Nonetheless, cultures can vary between different laboratories, which is why I decided to test our culture for its contents, checking for astroglia, microglia, oligodendrocytes, and the proportion of inhibitory neurons. In order to do so, I carried-out the immunostaining protocol described above using the markers listed in table 3. A general neuronal marker was always combined with a marker against the other cell types. To count the number of cells, nuclei were stained with Hoechst (see above). To image the coverslips, I used an inverted epifluorescent microscope, the Nikon Eclipse Ti-E (see Table 5 for filtersets), equipped with an HBO-100W mercury lamp and an IXON X3897 CCD camera (Andor) (EM gain set to $1 \mathrm{MHz}$ at 14-bit. The gain multiplier was set to 300.). The system was controlled via the Nikon NIS-Elements Advanced Research software. All images were acquired using a 20x objective (Plan Apo, oil immersion, 0.75 NA) resulting in a pixel size of $800 \times 800 \mathrm{~nm}$. The microscope stage was automated and can be precisely controlled via the software, which enables a continuous imaging of large areas by taking consecutive fields of view and stitching them together. For the characterization, $5 \times 5$ imaging areas were stitched together, using a 15\% overlap. This ensured large, representative fields of view of 2 by $2 \mathrm{~mm}$. For each marker, three 
separate cultures were prepared, from each culture, 5 areas were sampled. For the analysis, I used ImageJ, an open source software (Schneider et al., 2012). I used a nucleus counter plugin, which is part of the ImageJ package, to automatically count the number of nuclei. The other cells were manually counted.

\section{Morphology imaging}

The neurons that had been transfected with a membrane-targeted EGFP, were immunostained (as described above) against the axon initial segment marker ankyring and against the synaptic vesicle marker synaptophysin (Hedstrom et al., 2007; Leterrier et al., 2015). Hoechst was used to mark nuclei. To image entire neurons, I used the same inverted epifluorescent microscope mentioned above. For these experiments, all images were acquired using a 60x objective (Plan Apo, oil immersion, $1.4 \mathrm{NA}$ ) resulting in a pixel size of $270 \mathrm{~nm} \times 270 \mathrm{~nm}$. For each transfected neuron, the imaging area was adjusted to capture the entire cell with all its processes. In order to catch all neurites, 4 z-layers at $300 \mathrm{~nm}$ intervals were acquired. The programme used a 15\% overlap in the GFP channel to automatically stitch single images. The imaging area was imaged in the GFP channel to visualise $\mathrm{DiO}$, in the $\mathrm{Cy} 3$ channel to visualise the $\mathrm{Cy} 3$ linked secondary antibody specific to the anti-AIS primary antibody, in the Cy5 channel to visualise synaptophysin, and in the DAPI channel to visualise the Hoechst staining of the nuclei.

Table 5: Filter-sets, inverted fluorescence microscope, Nikon Eclipse Ti-E.

\begin{tabular}{|l|l|l|l|}
\hline Filter & Exciter & Beamsplitter & Emitter \\
\hline DAPI & $350 / 50$ & 400 & $460 / 50$ \\
\hline EGFP & $470 / 40$ & 495 & $525 / 50$ \\
\hline Cy3 & $545 / 25$ & 565 & $605 / 70$ \\
\hline Cy5 & $620 / 60$ & 660 & $700 / 75$ \\
\hline
\end{tabular}


Analysis of widefield images to determine neuronal morphology parameters

The neurites of the neurons in a subset of the recorded images were semi-automatically traced using the ImageJ plugin NeuronJ (Meijering et al., 2004; Schneider et al., 2012). The axon was determined via the AIS staining. All remaining neurites were classified as dendrites. Afterwards, the tracings were analysed using a custom written MATLAB script to determine various parameters such as the branch length, branching angles, degree of branching, and the number of neurites. From the presynaptic staining with synaptophysin, the number of synapses per neuron was calculated.

\section{Confocal imaging of neuronal cell bodies and organelles}

In order to obtain more information about the neuronal cell body and its organelles, I carried out immunostainings against specific organelle markers and against the AIS (as a spatial marker and to define the axon). The immunostaining procedure is described above. In order to visualize the plasma membrane, the neurons were treated with DiO (see above).

Confocal imaging of neuronal cell bodies and organelles was performed using the Leica TCS SP5 system, an inverted confocal microscope, equipped with a HCX Plan Apochromat 100x, 1.4 NA oil immersion objective. The microscope was controlled via the Leica LAS AF imaging software. To image the cell body, a sequential z-stack at $500 \mathrm{~nm}$ intervals was performed. The sampling interval was set to $1000 \mathrm{~Hz}$, at a pixel ratio of 1024 x 1024 and a zoom of 2.5. This gave a pixel size of $61 \times 61 \mathrm{~nm}$. The line average was set to 16 and the pinhole was set to Airy 1 (151.48 nm). DiO was excited using a laser tuned to $488 \mathrm{~nm}$, Cy3 by a laser at $561 \mathrm{~nm}$ and Atto647N by a $633 \mathrm{~nm}$ laser. Emissions were recorded using Photomultiplier tubes (PMT, see Table 7 for information on PMT tuning). 
Table 6: Lasers, confocal microscope, Leica TCS SP5.

\begin{tabular}{|l|l|}
\hline Laser type & Excitation wavelength \\
\hline Argon (100 mW) & $458 \mathrm{~nm}, 476 \mathrm{~nm}, 488 \mathrm{~nm}, 496 \mathrm{~nm}, 514 \mathrm{~nm}$ \\
\hline HeliumNeon (1 mW) & $561 \mathrm{~nm}$ \\
\hline HeliumNeon (2 mW) & $594 \mathrm{~nm}$ \\
\hline HeliumNeon (10 mW) & $633 \mathrm{~nm}$ \\
\hline Tunable two-photon laser & $755 \mathrm{~nm}$ \\
\hline
\end{tabular}

Table 7: Setup used for the different fluorophores, confocal microscope, Leica TCS SP5.

\begin{tabular}{|l|l|l|}
\hline Fluorophore & laser line & PMT tuning \\
\hline DiO & $488 \mathrm{~nm}$ & $506-538 \mathrm{~nm}$ \\
\hline Cy3 & $561 \mathrm{~nm}$ & $569-625 \mathrm{~nm}$ \\
\hline Atto647N & $633 \mathrm{~nm}$ & $647-728 \mathrm{~nm}$ \\
\hline
\end{tabular}

Extracting and analysing object parameters for different organelles imaged by confocal microscopy

I used a custom written MATLAB script to analyse the organelle marker stainings imaged by confocal microscopy. In short, the post processing and analysis worked as following: the DiO channel, employing an erosion, dilation method was used to define the cell body region. The Ankyrin G staining was in conjunction with the DiO signal that had not been considered as cell body region used to define the axon initial segment. The remaining DiO signal was considered to be dendritic regions. Within the cell body region, the nucleus region was determined. In most cases the DiO signal is weaker in the nucleus. This feature was used to classify the nucleus region. Within each of these four regions, cell body, proximal axon, proximal dendrite, and nucleus, the organelle markers of interest were 
analysed. The objects, signals of each organelle, were detected and the following parameters were determined:

The area covered, the major axis, the minor axis, the equivalent circle diameter, the perimeter, the presence in the cell body, the presence in the nucleus, the presence in the axon stack, the presence in axon in slice, the percentage of all pixels in the green area in all slices made by the organelle, the $x$-coordinate centre of mass, the $y$-coordinate centre of mass, the z-coordinate centre of mass, the minimum distance from the cell body edge, the minimum distance from the nucleus edge, the approximate depth in $z$, and the minimum distance to the next object.

In order to show the distribution of for some of these parameters, I prepared histograms. The area, major axis, minor axis, equivalent circle diameter, perimeter, percent of volume, minimum distance from cell body edge, minimum distance from nucleus edge, approximate depth in $\mathrm{Z}$, and minimum distance to the next object of each of the detected organelles was compared between the cell body, the axon, and the dendrite regions. A multiple comparison rank-sum Mann-Whitney $U$ test and a Bonferroni correction was used to determine the statistical significance. Furthermore, the number of objects and the proportion of the organelle objects within the cell bodies were extracted from the images.

\section{Stochastic optical reconstruction microscopy imaging of organelles}

In order to obtain better volume estimations for some organelles, I performed three dimensional direct stochastic optical reconstruction microscopy (3D-dSTORM) imaging. For these experiments, only the organelle marker of interest was immunostained against (as described before). I used secondary Fab-fragments labelled with CF647 dyes against the primary antibodies.

For the imaging, I used a STORM system set up in the department of Molecular Pharmacology and Cell Biology of the Leibniz Forschungsinstitut für Molekulare Pharmakologie, Berlin. It has been described in depth by Lehman and colleagues (Lampe et al., 2012; Lehmann et al., 2015). The dSTORM setup was custom build and is based on an inverted Nikon Eclipse Ti microscope, combined with a custom laser combiner, a TIRF 
illuminator system, and an emission splitter (OptoSplit II, Cairn Optics). The splitter contained an astigmatic lens ( $\mathrm{f} 1 / 41 \mathrm{~m}$, Thorlabs L1516RM-A), which allowed the recording of 3D information. An EMCCD (DU-897E, $512 \times 512$, Andor Instruments) was used to acquire the images. The system was controlled using Micro-Manager, an open source software running on ImageJ (Edelstein et al., 2010, 2014; Schneider et al., 2012). As mentioned above, CF647 labelled secondary Fab-fragments were used, as they have been previously described to have ideal characteristics for dSTORM imaging (Lehmann et al., 2015). The CF647 dye was excited using a laser at $643 \mathrm{~nm}$ (150 mW, Toptica) in widefield mode. The laser was reflected off a quadband dichroic (Di01-R405/488/561/635, AHF Analysetechnik) and collected with a longpass filter (BLP01-635R, AHF Analysetechnik). The final pixel size employing a $100 \times 1.49$ NA objective and a 1.5× optovar lens (Nikon) onto the above mentioned camera was $106 \times 106 \mathrm{~nm}$.

In dSTORM it is important that the signal of the fluorophores is separated in time. This is achieved by using a strong laser that can drive the fluorophore into a dark state. After some time, the fluorophore will return back to a bright state, which will create a blinkinglike effect. In order to tune this and prevent the fluorophores from bleaching, I used an imaging solution containing an oxygen scavenger system $(50 \mathrm{mM}$ Tris/ $\mathrm{HCl}, 10 \mathrm{mM} \mathrm{NaCl}$, $10 \mathrm{mM}$ MEA, $10 \%$ glucose, $2000 \mathrm{U} / \mathrm{mL}$ catalase, $50 \mathrm{U} / \mathrm{mL}$ glucose oxidase). The coverslips were placed onto a glass slide containing a void with this imaging solution.

Before starting the actual recording, the sample was exposed to the laser until single molecule blinking was detected. Image acquisition was then performed at a frame rate of $33 \mathrm{~Hz}$, for 24,000 frames. From the resulting image series, the localizations of the fluorophores were extracted. There are many open source software packages, such as ThunderSTORM, simpleSTORM, and RapidSTORM available that can perform this extraction step (Köthe et al., 2014; Ovesný et al., 2014; Wolter et al., 2012). They have been extensively compared and tested (Sage et al., 2015). I used rapidSTORM 3.2, which is a commonly used, reliable, and quick software (Wolter et al., 2012). It relies on fitting a Gaussian to each fluorophore (Levenberg-Marquardt parameter estimation). The following parameters were chosen within the rapidSTORM software: The point spread model was set to 'interpolated 3D', using a tuning z-stack through a bead as reference. The fitting was performed within a window of $600 \mathrm{~nm}$, with the fluorophores required to 
have a minimum distance of 7 pixels between each other. A threshold of 1000 units was applied to remove background and out-of-focus signals. The option 'two-kernel improvement' was used. The analysis yields a file containing the coordinates ( $x, y$, and $z)$ of the fluorophores, their fluorescence intensity, and the occurrence per frame.

Since the total measurement time required to record 24,000 frames is around 15 minutes, the samples were subjected to a slight drift. In order to correct for this drift, we applied fluorescence beads to the coverslips before the measurement. Dark red fluorosphere beads (48 nm, Cat\# F10720, Life Technologies) were suspended in 0.1 $\mathrm{mg} / \mathrm{ml}$ poly-L-lysine solution and samples were incubated with a thin layer of this bead solution for 5 min at RT followed by 3 washes with PBS. The beads are different from the actual fluorophore signals, in that they are not entering a dark state, i.e. they are not blinking (usually visible in at least 1000 consecutive frames). Furthermore, they are brighter than the actual signal (above 20,000 units). These features can be used to distinguish them from the single molecules detected. I used a custom written Python script to identify the beads and to track their displacement per frame. This displacement was then used to adjust the coordinates of the single-molecules detected. After the drift correction, the localization precision for single molecules was $25 \mathrm{~nm}$ in lateral and $60 \mathrm{~nm}$ in axial dimensions. The images shown in the results section were reconstructed from the coordinates using a $10 \times 10 \mathrm{~nm}$ pixel size and a color code for the axial information.

Table 8: dSTORM imaging buffer.

\begin{tabular}{|l|l|l|l|}
\hline Reagent & Concentration & Catalogue \# & Supplier \\
\hline Tris/HCl & $50 \mathrm{mM}$ & & Sigma-Aldrich \\
\hline $\mathrm{NaCl}$ & $10 \mathrm{mM}$ & & Sigma-Aldrich \\
\hline cysteamine & $10 \mathrm{mM}$ & $30070-10 \mathrm{G}$ & Sigma-Aldrich \\
\hline glucose & $10 \%$ & & Sigma-Aldrich \\
\hline catalase & $2000 \mathrm{U} / \mathrm{mL}$ & C40-500MG & Sigma-Aldrich \\
\hline glucose oxidase & $50 \mathrm{U} / \mathrm{mL}$ & G2133-50KU & Sigma-Aldrich \\
\hline
\end{tabular}




\section{Analysis of 3D-dSTORM data-extracting volume parameters}

From the dSTORM dataset one obtains the coordinates of the fluorophores. Usually the labelling of the organelle membranes is not complete, but spotty. In order to obtain a volumetric parameter, one would need to find a way to connect these spots in a meaningful way. The way, I decided to do this is by using alpha shapes. Alpha shapes work by laying a circle (in 2D) or a sphere (3D) with a defined radius on top of two or three coordinate points, respectively. If within the circle or sphere there is no further coordinate point detected, the coordinates are defined as the outside of the shape (Edelsbrunner and Mücke, 1994; Edelsbrunner et al., 1983; Nicovich et al., 2017; Tang et al., 2016). After some testing, I decided to use a radius of $20 \mathrm{~nm}$ reflecting the resolution of the dSTORM setup. The resulting shell of connected outside coordinates was used to calculate the volume of the organelle.

\section{Focused Ion Beam Scanning electron microscopy}

To add on the volumetric information obtained by fluorescence microscopy, I also used electron microscopy, which has unmatched lateral resolution and provides a good structural view of cells and its organelles. The main aim was to image neuronal organelles in the neuronal cell body. Since the cell body is relatively big, I decided to try a technique called focused ion beam scanning electron microscopy (FIB-SEM), which is described in the introduction. The preparation of the samples as well as the imaging were carried-out together with the group of Wiebke Möbius at the Max-Planck-Institute for Experimental Medicine. There general setup and the sample preparation have been described before (Erwig et al., 2019; Weil et al., 2017, 2018).

Banker cultures were prepared as described above and fixed for 1 hour in $4 \%$ paraformaldehyde and $2.5 \%$ glutaraldehyde in PBS. The samples were then quenched with $100 \mathrm{mM} \mathrm{NH}_{4} \mathrm{Cl}$. Afterwards, several contrast enhancing and embedding steps were performed as described before, modified from a protocol by Deerinck and colleagues (Deerinck et al., 2010; Erwig et al., 2019). The neurons were treated with 2\% osmium tetroxide and $0.25 \%$ potassium ferrocyanide $\left(\mathrm{OsO}_{4}\right.$, Electron Microscopy Sciences) for 3 
hours at $4^{\circ} \mathrm{C}$. This enhances the membrane contrast. Afterwards the samples were washed three times for 15 min with filtered $d_{d d H_{2}} \mathrm{O}$ and incubated in $0.1 \%$ thiocarbohydrazide for 1 hour. The cells were then again treated with $2 \% \mathrm{OsO}_{4}$ for 1 hour at RT followed by washing steps in filtered $\mathrm{ddH}_{2} \mathrm{O}$. Another contrast enhancing step with uranyl acetate, which was applied at a concentration of $2 \%$ overnight at $4^{\circ} \mathrm{C}$ was performed. The samples were washed again and then dehydrated. For this the sample was incubated with increasing amounts of ethanol (30\%, 50\%, 75\%, 90\%, 100\%) followed by three dehydration steps with $100 \%$ acetone. For embedding, the acetone was then successively replaced with Epon resin, first in a 1:1 mix with acetone and then in several incubation steps in its pure form. During the final polymerisation, in which the samples were incubated for $48 \mathrm{~h}$ at $60^{\circ} \mathrm{C}$, the coverslips were tilted, so that only a thin film of Epon covered the neurons. This was important as it assured a better accessibility and identification of the cells in the FIB-SEM.

The resulting blocks were then attached to the SEM stub (Science Services GmbH, Pin $12.7 \times 3.1 \mathrm{~mm}$ ). This was achieved by using an epoxy resin filled with silver (Epoxy Conductive Adhesive, EPO-TEK EE 129-4; EMS), which was polymerized overnight at $60^{\circ} \mathrm{C}$. To ensure good conductivity, the samples were coated with a $10 \mathrm{~nm}$ layer of platinum using a sputter coater (EM ACE600, Leica).

The FIB-SEM recordings were performed in a Crossbeam 540 focused ion beam-scanning electron microscope (Carl Zeiss Microscopy $\mathrm{GmbH}$ ). After finding regions of interest, the samples were exposed with a $15 \mathrm{nA}$ and polished with a $7 \mathrm{nA}$ ion beam. The images were taken at $1.5 \mathrm{kV}$ while continuously milling the sample with a $700 \mathrm{pA}$ ion beam. The z-step size was $50 \mathrm{~nm}$ and the pixel size was $5 \times 5 \mathrm{~nm}$.

Determining volumes of mitochondria, nuclei, and neuronal cell bodies from FIB-SEM recordings

FIB-SEM images were post-processed using custom written MATLAB macros. First, the images were binned $(2 \times 2)$ to reduce the noise and the look up table was inverted. Next, the cell body membrane and the nucleus were traced manually. Within the cytosol area, we used an automated, bandpass filter based segmentation to find mitochondria. An 
automated approach was necessary, as the dataset was too large for manual segmentation. Each recorded neuron comprised at least 200, but up to 500 z-slices. To test whether our analysis would yield results comparable to manual segmentation, we manually segmented the mitochondria of one neuronal cell body. From the segmentations, we extracted the volumes taken up by the nucleus, and the mitochondria. Due to the low contrast of the SEM images, it was not possible to automatically detect any other organelles.

\section{Synaptic turnover}

In order to study synaptic protein turnover and correlate it to the synapse's activity, I combined live cell labelling with metabolic labelling. The experiments were carried out using the co-culture system of primary hippocampal cultures described above.

Newly synthesized proteins were labelled with the essential amino acid leucine containing the rare, stable isotope ${ }^{15} \mathrm{~N} .2 .4 \mathrm{mM}{ }^{15} \mathrm{~N}$-leucine were added to the neurons three days prior to their fixation. This is a threefold excess to the leucine amount present in the medium. Most newly made proteins will incorporate the ${ }^{15} \mathrm{~N}$-leucine, which can be located/measured with secondary ion mass spectrometry (SIMS). I combined this metabolic labelling with an approach to measure synaptic activity (Truckenbrodt et al., 2018; Wilhelm et al., 2010). Recycling synaptic vesicles were labelled with a monoclonal antibody against the lumenal domain of synaptotagmin 1 (clone 604.2, Synaptic Systems, Cat \# 105 311AT1). The antibody was conjugated to an Atto647N dye. It was applied to the cultures at a dilution of $1: 120(1 \mathrm{mg} / \mathrm{mL}$ antibody stock) for one hour, just before the fixation. The neurons were fixed in 4\% PFA. An immunostaining against a presynaptic marker, synaptophysin, and against a postsynaptic marker, homer1 or PSD95, was carried-out following the protocol described above. The pre- and postsynaptic stainings were used to identify synapses.

In order to look at the effects of chronic/long-term modulations of synaptic activity on synaptic protein turnover, the above procedure was also carried-out in the presence of tetrodotoxin (TTX) or bicuculline. Tetrodotoxin is an antagonist of voltage gated sodium channels and causes a block of action potentials. This reduces the activity of the neurons 
in the culture. The only remaining activity should be of a spontaneous nature. Bicuculline on the other hand is a GABA receptor antagonist. It blocks the GABAergic neurotransmission in the culture thereby inhibiting inhibitory neurotransmission. Overall, it raises the activity of the cultures. Both modulators were added to the neurons one hour before the addition of ${ }^{15} \mathrm{~N}$-leucine. TTX was added to the culture medium from a stock solution of $3 \mathrm{mM}$ to a final concentration of $1.5 \mu \mathrm{M}$. Bicuculline was diluted from a 50 $\mathrm{mM}$ stock to a final concentration of $20 \mu \mathrm{M}$ in the culture medium.

To enable correlative fluorescent and nanoscopic imaging, the samples were embedded in medium grade LR white (London Resin Company Ltd, Berkshire, England) (Saka et al., 2014). Before starting the embedding, neurons were post-fixed with $4 \%$ PFA and $0.2 \%$ glutaraldehyde for $30 \mathrm{~min}$. This step ensured that the antibodies will be cross-linked to their targets and are not displaced during the embedding steps. Afterwards, the cells were quenched with $100 \mathrm{mM}$ glycine and $100 \mathrm{mM} \mathrm{NH}_{4} \mathrm{Cl}$ for 15 min at RT. LR white is an aromatic acrylic resin that requires the sample to be partially dehydrated. Thus, the cells were dehydrated in successive displacement steps with increasing percentages of EtOH. The cells were incubated on a shaker (75 rpm) for $10 \mathrm{~min}$ in $30 \% \mathrm{EtOH}$ (in $\mathrm{dd}_{2} \mathrm{O}$ ) and for three times 10 min each in $50 \% \mathrm{EtOH}$ (in $\mathrm{ddH}_{2} \mathrm{O}$ ). The dehydration was kept partial to maintain the fluorescence of the fluorophores. LR white is still able to penetrate the cells, even at a partial dehydration. After the dehydration, the sample was incubated in a 1:1 mix of $50 \% \mathrm{EtOH}$ (in dd $\mathrm{H}_{2} \mathrm{O}$ ): LR white for 1 hour at RT. To avoid the coverslips sticking to the culture plate, they were transferred to a new plate and pure LR white was added for 1 hour. After the incubation, the coverslips were dried and placed on a pre-cooled metal plate. Beem ${ }^{\circledR}$ capsules (BEEM Inc., West Chester, PA, USA) were placed on top of them. $10 \mathrm{~mL}$ of LR white were mixed with one drop of LR white accelerator (London Resin Company Ltd, Berkshire, England) and the mix was pipetted into the bottom of the capsules. After $30 \mathrm{~min}$, the LR white had partially polymerized sealing the capsules to the coverslips. A new LR white plus accelerator mix was prepared and the capsules were filled-up with it. For complete polymerization, the samples were cooked for $90 \mathrm{~min}$ at $60^{\circ} \mathrm{C}$. Polymerized samples were left to cool down before removing the coverslips and the capsules. $200 \mathrm{~nm}$ thick sections were cut from the LR white blocks using a Leica UC6 
ultramicrotome (Leica Microsystems, Wetzlar, Germany). They were placed on round silicon wafers ( $2.5 \mathrm{~cm}$ diameter, SIEGERT WAFER GmbH, Aachen).

\section{Correlated optical and isotopic nanoscopy}

Samples were first imaged using a fluorescence microscope before conducting nanoSIMS measurements. This order is important, since the nanoSIMS measurements are inherently destructive. Cell regions were imaged with the epifluorescence microscope setup described above. The $100 x$ objective combined with the $1.5 x$ optovar lens resulted in a pixel size of $106 \times 106 \mathrm{~nm}$. Images in three channels, capturing the synaptotagmin1, the synaptophysin, and the homer1 signals were recorded. To find the same regions in the nanoSIMS, overview images of the wafers were taken and laser markings were added. The incorporation of ${ }^{15} \mathrm{~N}$-leucine into new proteins was measured using a NanoSIMS 50L instrument (Cameca, France) at the Leibniz-Institute for Baltic Sea Research Warnemünde (IOW). The ${ }^{133} \mathrm{CS}^{+}$primary ion beam was used to erode and ionize atoms of the sample. Prior to the actual measurements, sample areas of $50 \times 50 \mu \mathrm{m}$ were sputtered for $90 \mathrm{~s}$ with $600 \mathrm{pA}$ to erode and clean the surface of the sample and to achieve a steady state of secondary ion formation. From the secondary ions created during the recordings, images of ${ }^{12} \mathrm{C}^{-},{ }^{13} \mathrm{C}^{-12} \mathrm{C}^{14} \mathrm{~N}^{-},{ }^{12} \mathrm{C}^{15} \mathrm{~N}^{-},{ }^{31} \mathrm{P}^{-}$, and ${ }^{32} \mathrm{~S}^{-}$were recorded simultaneously using the 6 adjustable detectors of the nanoSIMS. The mass resolution of the instrument is very good and allows even the separation of ${ }^{12} \mathrm{C}^{15} \mathrm{~N}^{-}$from ions with a very similar mass such as ${ }^{13} \mathrm{C}^{14} \mathrm{~N}$. The primary ion beam current was set to $1 \mathrm{pA}$ during the recording and the dwell time per pixel was $4 \mathrm{~ms}$. The scanning parameters were $512 \times 512$ pixels for areas of $18 \mathrm{x}$ $18 \mu \mathrm{m}$ or $256 \times 256$ for areas of $9 \times 9 \mu \mathrm{m}$, resulting in a pixel size of $35.2 \mathrm{~nm}$. One plane was analysed.

\section{Analysis and correlation of synaptic turnover and presynaptic activity}

In order to correlate the fluorescence images with the nanoSIMS images, I first binned the nanoSIMS images in a $3 \times 3$ fashion. This decreases the noise in the nanoSIMS images and evens out the pixel sizes of both recordings. The images were then turned and slightly warped using Photoshop (Adobe) to correct distortions caused by the ion beam and the vacuum of the nanoSIMS. Synaptic turnover and activity were analysed using a custom- 
written MATLAB (MathWorks, Natick, MA, USA) macro and SigmaPlot (Systat Software Inc., Erkrath, Germany). Regions of interest were manually placed on top of presynaptic (marked by synaptophysin) and postsynaptic (Homer1) regions. Care was taken to only choose intact synapses, i.e. the ones that have an opposing pre- and postsynapse. Within these regions, the secondary ion counts and the normalized fluorescence of all channels were determined. In order to obtain the relative amount of new proteins, the ratio of ${ }^{15} \mathrm{~N}^{12} \mathrm{C}$ to ${ }^{14} \mathrm{~N}^{12} \mathrm{C}$ was taken. In the figures it is expressed as fold over the natural abundance of the ${ }^{15} \mathrm{~N}$ isotope (around $0.3 \%$ ). To test for correlations, I used a linear regression analysis. For comparisons of different conditions, I used an ANOVA with a post hoc Bonferroni procedure. A P-value of $<0.05$ was considered statistically significant. 


\section{Results}

I set out to provide the basis for a quantitative molecular model of neurons, by providing the external and internal volumes of neurons and their organelles/compartments in a defined model system: cultured hippocampal neurons.

I will on the following pages present the results that I gained from the experiments that I described. I will start by characterizing the culture system used for the neuronal model. Then I will go on to the morphological description of the neurons, specifically focusing on the neurites. The cell body and organelle descriptions will follow. Finally, I will present the results from the synaptic turnover experiments.

\section{Banker culture are mainly consisting of glutamatergic and GABAergic neurons}

I decided to work with a sandwich-like hippocampal culture derived from E18 rats. As described in the introduction, this culture system has the advantage of mostly separating neurons from glia cells (Banker and Cowan, 1977; Brewer and Cotman, 1989; Kaech and Banker, 2006). This is ideal for neuron-specific mass spectrometry and imaging analysis. Even though this culture system has been described before, there can be variability between preparations. Thus, I first set out to characterize our culture. I used immunocytochemistry against cell type markers in combination with Hoechst stainings. In a commonly used co-culture system, the amount of astroglial cells is quite high, which would interfere with the mass spectrometry analysis (Huettner and Baughman, 1986). This can also be seen in the co-culture system that we use in the lab (Figure 4A). The astroglia form a dense layer on the surface of the coverslips. The neurons are growing on top and in between the glial cells. There are more astroglia present than neuronal cells. I did not quantify the amounts, as it would be difficult to do this automatically (glia cells simply grow too dense). In our Banker culture the amount of astroglia was, as expected, drastically reduced (Figure 4B). Only some occasional single astroglia or small astroglial islands can be observed. Quite a few of the astroglia look like they are disintegrating, i.e. the GFAP signal was dotty. The culture medium is not tailored for them, so I presume that astrocytes might not develop ideally and start to die after a certain DIV stage. I quantified the amounts of astroglia per total number of cells, given by the number of nuclei labelled 
with Hoechst. On average, $3.33 \pm 0.91 \%$ of the cells in the culture are astroglia. This is below the $10 \%$ of glia that Brewer and Cotman determined for this sandwich culture preparation (Brewer and Cotman, 1989).

In addition to astroglia, neuronal cultures may also contain microglia and oligodendrocytes next to neuronal cells. Thus, in order to rule out a major contribution of these cell types to our biochemical analysis, I performed immunostainings against a microglial marker and an oligodendrocyte marker (Figure 5). The allograft inflammatory factor 1 (iba1), is a commonly used microglial marker (Chen et al., 1997; Imai et al., 1996). Only $0.66 \pm 0.21 \%$ of the cells in culture showed an iba1 positive staining. Olig 2 , an oligodendrocyte marker, was not present at all. 
A
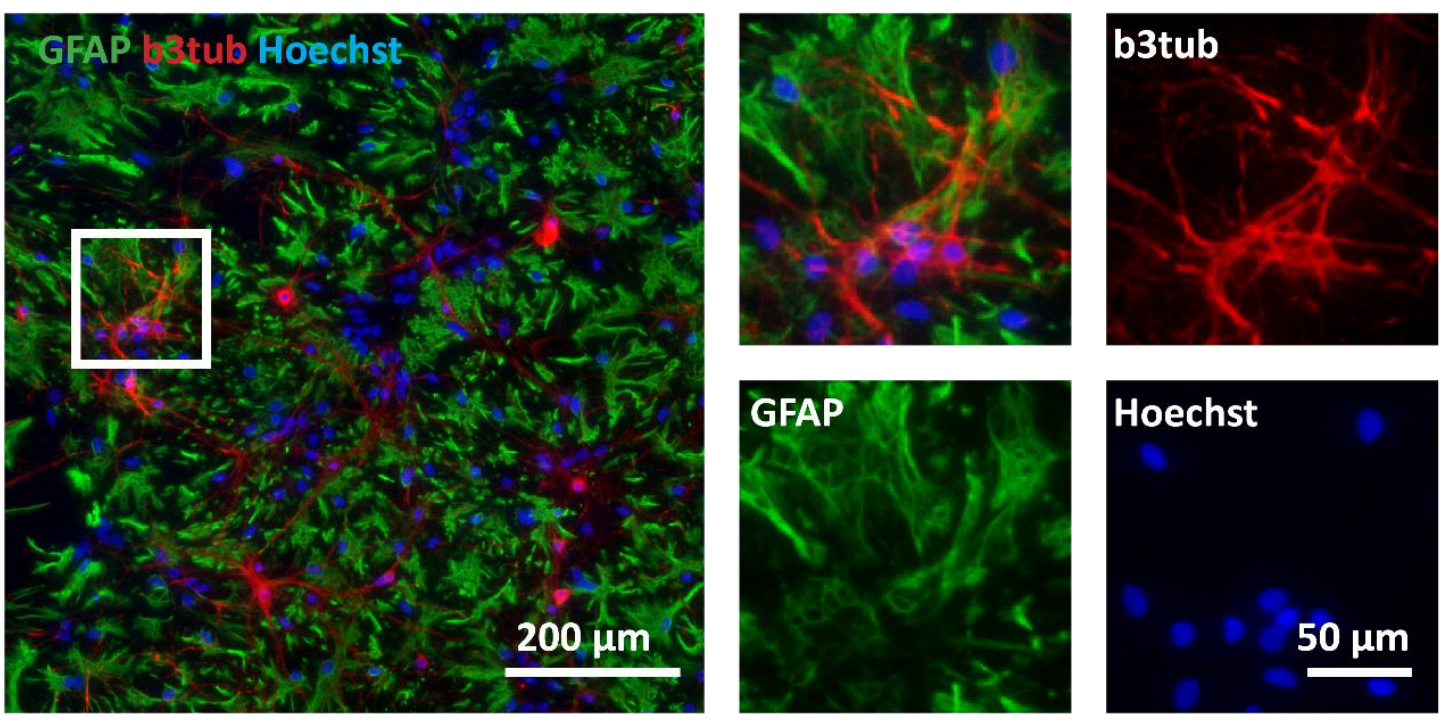

B
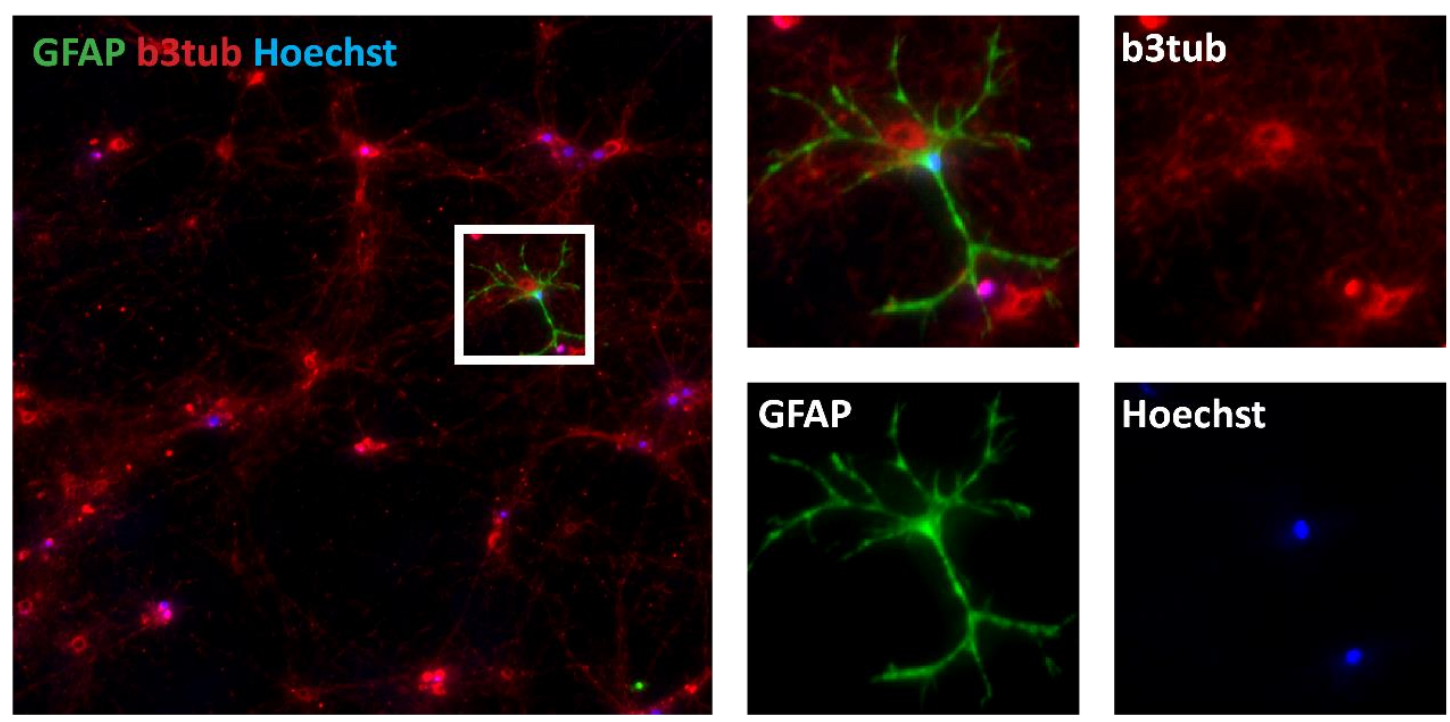

Figure 4: Astroglia contribution to dispersed cultures of rat hippocampal neurons. The Banker culture has a strongly reduced amount of astroglial cells when compared to conventional co-cultures. A A conventional co-culture of hippocampal neurons and astroglia at DIV21. GFAP (Glial fibrillary acidic protein) was immunostained to show astroglial cells (green). Neurons are shown in red, labelled with a beta-3-tubulin staining that is neuron-specific. Nuclei were labelled with Hoechst (blue). Astroglia form a dense layer on the coverslips. B Sandwich culture of E18 rat hippocampal neurons at DIV21. Again, astroglia are shown in green, neurons in red, and nuclei in blue. Only very few astroglia are present in the culture. The white box indicates the region shown in the four panels on the right side. 
A

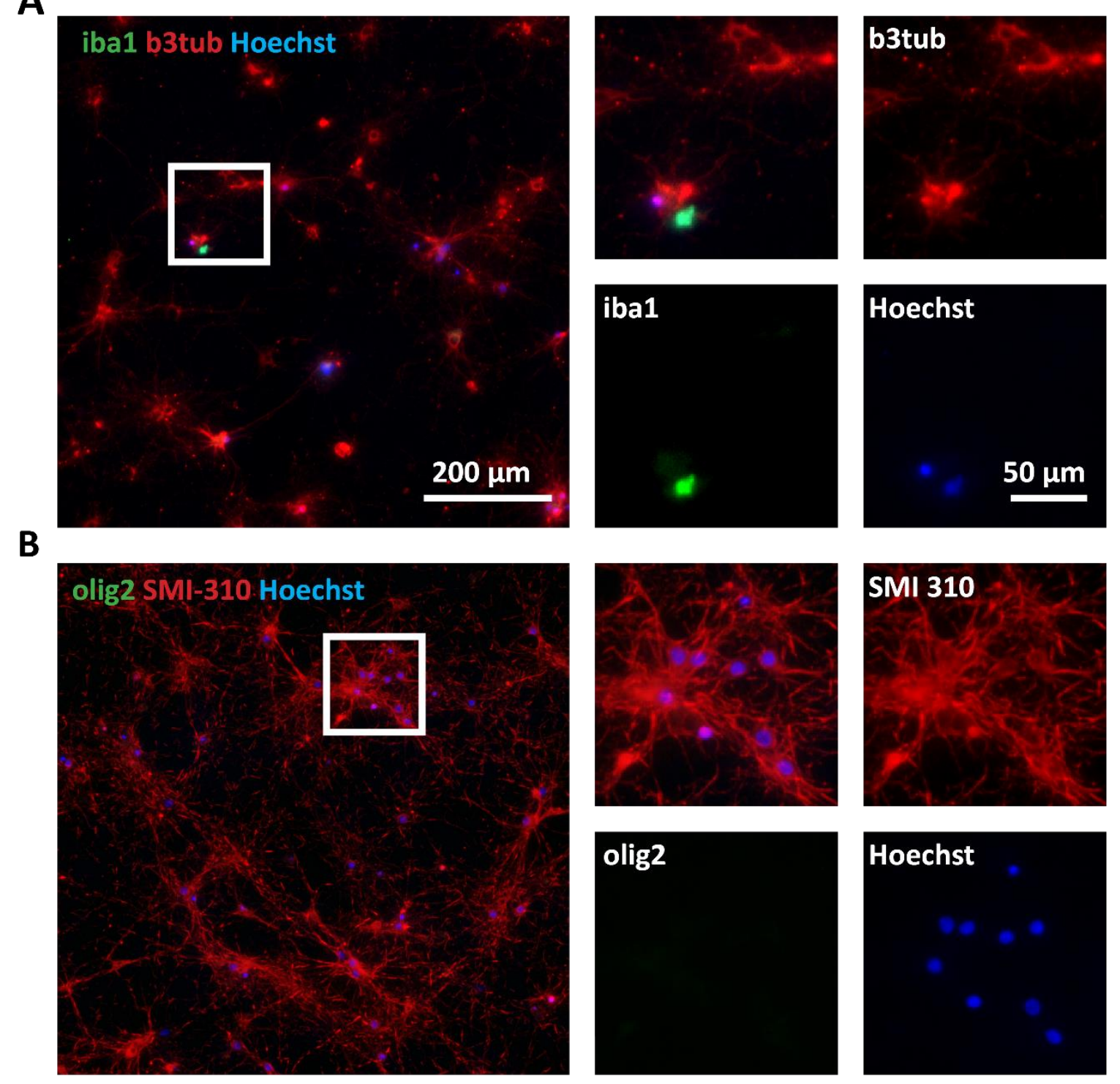

Figure 5: Microglia and oligodendrocyte content in the Banker culture system. Immunostaining of microglia and oligodendrocyte markers in Banker cultures. Only a few microglia can be found in the cultures. No oligodendrocytes can be detected. A Iba1, the allograft inflammatory factor 1, was used as a specific marker for microglia (in green). Neurons were again labelled with beta-3-tubulin (red). Nuclei were stained with Hoechst (blue). Only a few iba1 positive cells were present in the culture. B Olig2 was used to show oligodendrocytes (green). The neurofilament SMI-310 was used as a neuronal marker (red). Nuclei are again stained with Hoechst. No olig2 signal was detected. The white boxes indicate the regions shown in the four panels on the right side 

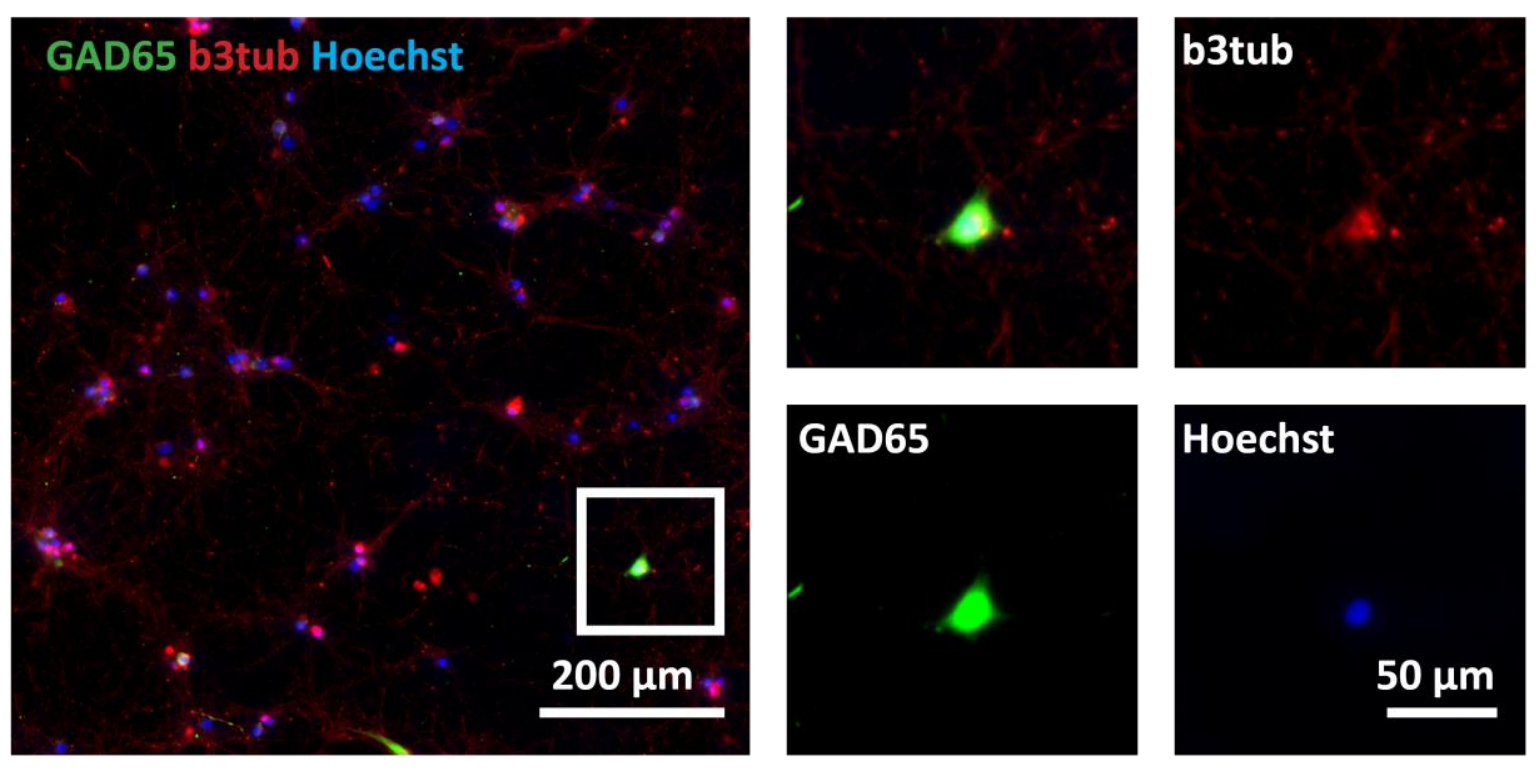

Figure 6: GABAergic cells in Banker cultures. Banker cultures were immunostained against GAD65 (green) and beta-3-tubulin (red). Nuclei are stained with Hoechst (blue). The glutamate decarboxylase GAD65 is a marker for GABAergic cells. A small proportion of the cells in the Banker culture was GABAergic. The white box indicates the regions shown in the four panels on the right side.

Apart from non-neuronal cell types, the Banker culture has several different neuronal cell types. In the pre-natal hippocampus, the most prevalent type of neurons are pyramidal neurons that release glutamate. This prevalence is maintained in cultured hippocampal neurons, which often also keep a pyramidal morphology (Banker and Cowan, 1977; Dotti et al., 1988). Nonetheless, there is a proportion of $10-15 \%$ of interneurons present in the hippocampus, of which the most common type is inhibitory GABAergic interneurons. This is again reflected in the sandwich culture, where Benson et al. found that GABAergic cells make about $6.1 \%$ of all cells at DIV20 (Benson et al., 1994). I tested for the presence of GABAergic cells in our Banker culture by performing immunostainings against GAD65, a glutamate decarboxylase, which is specifically expressed in GABAergic cells (Benson et al., 1994; Hoch and Dingledine, 1986). I found that $8.28 \pm 0.83 \%$ of all cells were positive for GAD65. 
Table 9: Characterization of Banker cultures. The cell density was calculated from the number of nuclei per area. The percentage of glia, oligodendrocytes and GABAergic neurons was calculated from the number of positive cells over the number of nuclei. Per condition, three different cultures were used. For each of the cultures, 10 imaging areas (each $2 \times 2 \mathrm{~mm}^{2}$ ) on two coverslips were analysed. Where possible the values are given as mean plus SEM.

\begin{tabular}{|l|l|}
\hline cell density & $57.86 \pm 3.64$ cells per $\mathrm{mm}^{2}$ \\
\hline glia content (GFAP positive cells) & $3.33 \pm 0.91 \%$ \\
\hline microglia/macrophage content & $0.66 \pm 0.21 \%$ \\
\hline oligodendrocyte content & Traces \\
\hline GABAergic neurons (GAD65 positive cells) & $8.28 \pm 0.83 \%$ \\
\hline estimation of glutamatergic neurons & Approximately $87 \%$ \\
\hline
\end{tabular}


Banker culture neurons have a wide ranging axonal tree and a smaller dendritic tree

After establishing that our Banker culture is suitable for creating the quantitative neuronal model, I started to evaluate the basic morphological parameters of the cells in culture. As mentioned in the introduction, neurons are strongly polarized. Next to the cell body they contain a number of dendrites, which receive input from other neurons and typically one or two axons, which generates an output signal (Inagaki et al., 2001). Axons and dendrites can span several $\mathrm{mm}$ in culture and may be heavily branched (Dotti et al., 1988). Thus, in order to build a comprehensive model, I wanted to determine the number of neurites per neuron, the length per neurite, the branching angles from one neurite to another, and the thickness of the neurites. Neurites of different cells overlap strongly, which makes it very difficult to determine which neurites belong to one cell (Lakadamyali et al., 2012; Smith, 2007). In order to separate the neurites from each other, I decided to use a sparse transfection with a membrane-anchored EGFP. I optimized a magnetofection protocol to only transfect about 10 neurons per coverslip (Buerli et al., 2007). The EGFP localized nicely to the plasma membrane of the neurons and also covered more distal neurites (see Figure 7A). Since Banker cultures do not have direct neuron-glia interactions, they tend to be a little bit more fragile. Thus, I was only able to transfect and maintain cultures up to DIV15. I combined the transfections with an immunostaining against the axon initial segment marker ankyring and the presynaptic marker synaptophysin (see Figure 7A).

Determining the number of dendrites and axons, their length, branching angles and thicknesses, required tracing of the neurites. I used NeuronJ, an ImageJ plugin to semiautomatically trace the neurites (Meijering et al., 2004; Schneider et al., 2012). The ankyring signal served as a marker for the axon: all processes originating from it were considered axonal. In some cases, more than one axon was present. This is not uncommon in cultured neurons (Inagaki et al., 2001). Figure 7B shows an exemplary tracing of one neuron. The dendrites are represented in blue, the axon in red. Dendrites were generally much shorter than the axon. The axons had many branches and were often wrapped around the cell bodies of other neurons (white arrow in Figure 7A). The axonal tree often spanned an area of up to two $\mathrm{mm}^{2}$. 
I used a custom-written MATLAB script to determine the length of the axon and dendrite branches that I traced. While there were some very long neurites, the majority of axon and dendrite branches was relatively short. This is reflected in skewed histograms (see Figure $8 \mathrm{~A}$ ). The average length of the axon branches was $144.44 \pm 8.5 \mu \mathrm{m}$ (mean \pm SEM). The length of the dendrite branches was significantly lower at $83.03 \pm 8.9 \mu \mathrm{m}$ (mean \pm SEM). Also, the number of axon branches was higher than the number of dendrite branches. Here, the range was quite wide, with the numbers of axon branches going from around 20 to 200 (mean number of axon branches plus/minus SEM was $93.4 \pm 33.6$, mean number of dendrite branches plus/minus SEM was $41.4 \pm 14.3)$. The ratio of the number of dendrite branches to one axon branch was 0.44 . Next, I determined the thickness or widths of the axonal and dendritic branches. This was done in an automatic fashion, drawing cross-sections across the traced neurites. Figure $8 \mathrm{~B}$ shows the distribution of the axon and dendrite widths. The mean axon thickness was $1.7643 \pm 9.22 \mathrm{e}^{-3} \mu \mathrm{m}$ (mean \pm SEM) and the mean dendrite thickness $1.7667 \pm 0.022 \mu \mathrm{m}$ (mean \pm SEM). Taking the average length, the average number, and the average thickness of axon and dendrite branches, one can try to estimate the axonal, dendritic and total neurite volume.

I first multiplied the mean number of axon branches per neuron with their mean length:

$$
\begin{aligned}
& \begin{aligned}
\text { Total axonal length } \\
=\text { mean number of axon branches } \\
\times \text { mean length of axon branches }
\end{aligned} \\
& \text { Total axonal length }=93.4 \pm 33.6 \times 144.44 \pm 8.5 \mu \mathrm{m} \\
& =13490.7 \pm 5651.4 \mu \mathrm{m}
\end{aligned}
$$

I performed the same operation for the dendrites:

$$
\begin{aligned}
& \text { Total dendrite length } \\
& \qquad \begin{aligned}
=\text { mean number of dendrite branches } \\
\times \text { mean length of dendrite branches }
\end{aligned} \\
& \begin{aligned}
\text { Total axonal length } & =41.4 \pm 14.3 \times 83.03 \pm 8.9 \mu \mathrm{m} \\
& =3437.4 \pm 1555.8 \mu \mathrm{m}
\end{aligned}
\end{aligned}
$$


I then used the thickness measurements to estimate the volume of axons and dendrites per neuron using a simple cylindrical volume formula, as this is likely to be most accurate (Xu et al., 2013).

Volume of axonal tree $=(\text { width } \div 2)^{2} \times \pi \times$ total axonal length

Volume of axonal tree $=\left(1.76 \pm 9.22 \mathrm{e}^{-3} \mu \mathrm{m} \div 2\right)^{2} \times \pi \times 13490.7 \pm 5651.4 \mu \mathrm{m}$

$$
=32981.4 \pm 14161 \mu \mathrm{m}^{3}
$$

Volume of dendritic tree $=(\text { width } \div 2)^{2} \times \pi \times$ total dendritic length

Volume of dendritic tree $=(1.76 \pm 0.02 \mu \mathrm{m} \div 2)^{2} \times \pi \times 3437.4 \pm 1555.8 \mu \mathrm{m}$

$$
=8426.57 \pm 4023.8 \mu \mathrm{m}^{3}
$$

The sum of the axonal volume and the dendritic volume results in the total volume of neurites per neuron.

Total volume of neurites $=$ volume of axons + volume of dendrites

$=32981.4 \pm 14161 \mu \mathrm{m}^{3}+8426.54 \pm 4023.8 \mu \mathrm{m}^{3}$

$$
=41408 \pm 18185 \mu \mathrm{m}^{3}
$$


A

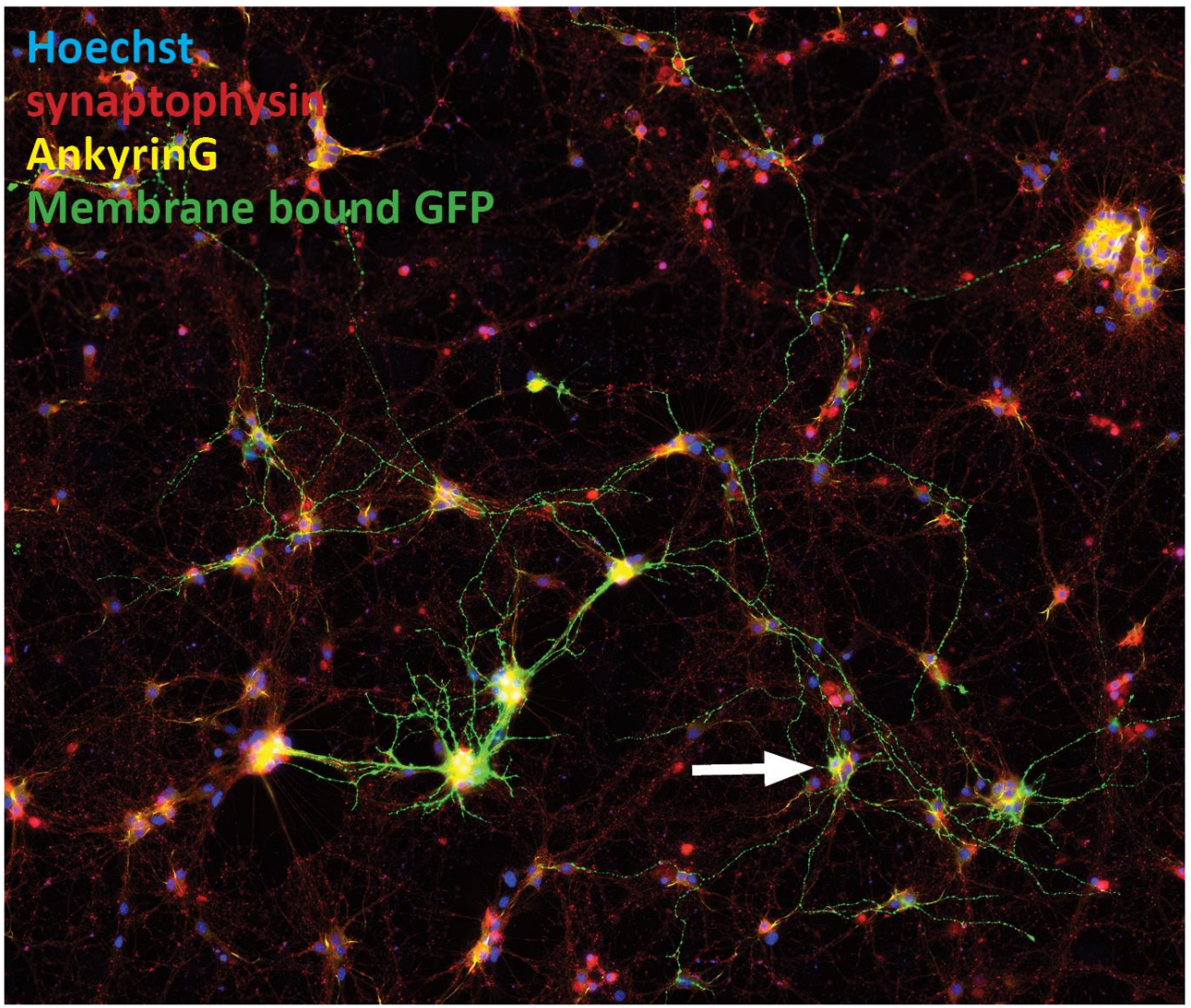

B

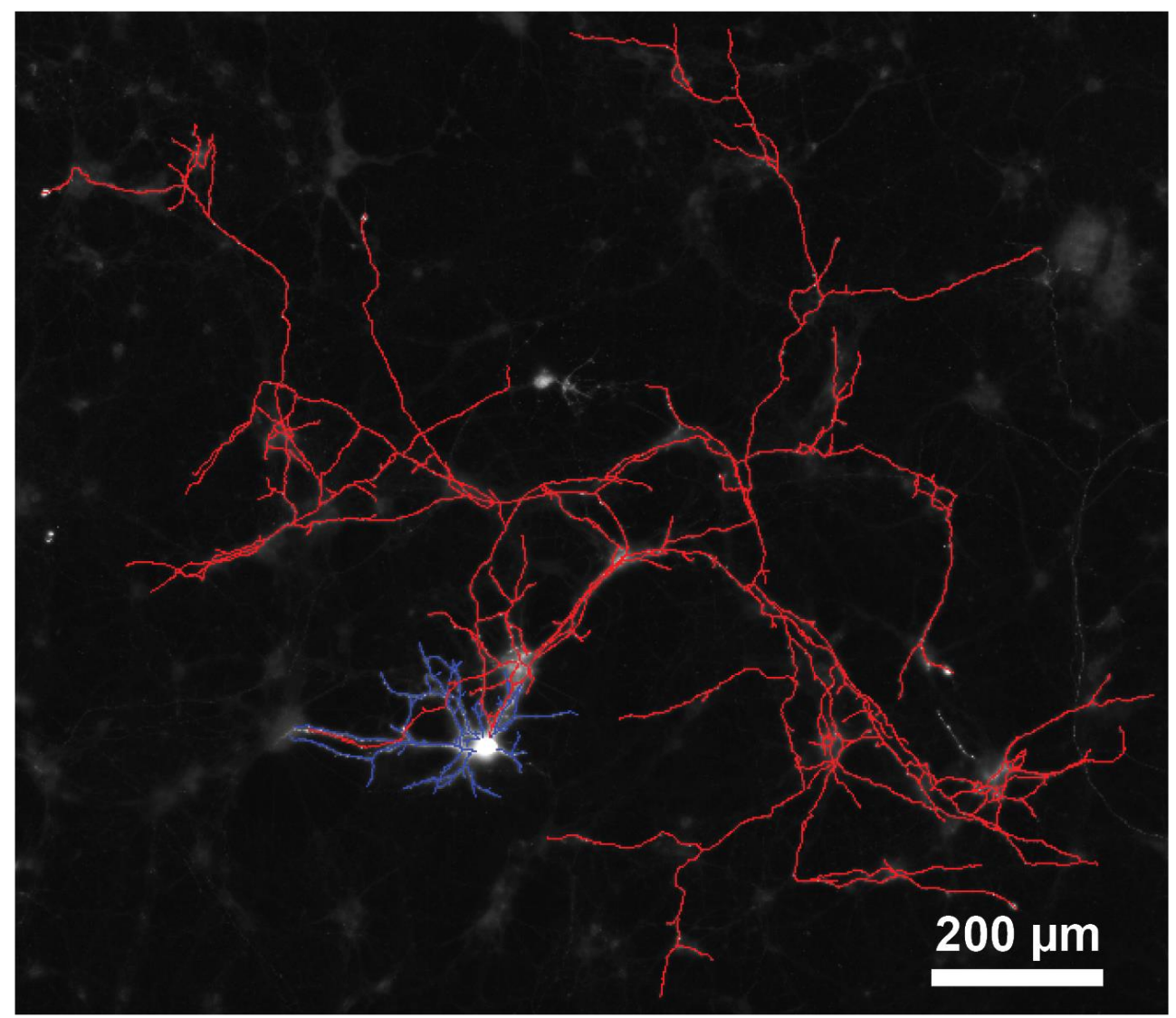


Figure 7: Morphology of cultured hippocampal neurons - transfections with membrane bound EGFP and neurite tracing. A Neurons were sparsely transfected with a membranebound EGFP (green). At DIV15, the cells were fixed and immunostained against the presynaptic marker synaptophysin (red) and the axon initial segment marker ankyring (yellow). Nuclei were stained with Hoechst (blue). The transfection was tailored to only transfect very few cells, allowing the separation and clear identification of neurites belonging to one cell. The membrane bound EGFP distributed evenly along the membrane. Ankyring was used to define the axon. Synaptophysin was used for determining the number of synapses per neuron. B Transfected neurons were semi-automatically traced using the ImageJ plugin NeuronJ (Meijering et al., 2004). Axons (in red) and dendrites (in blue) were distinguished based on the ankyring signal.

From the traced neurites, I also extracted the branching angles, i.e. the angle of a neurite branch to its parent branch. Primary neurites, the ones originating from the cell body were set to $0^{\circ}$ and not included in the analysis. Negative angles (everything above $180^{\circ}$ was treated as negative) were treated as positive. Even though there are some peaks visible, it is not clear whether the neurons have preferred branching angles. There may also be a periodicity, but this is not clear, either (Figure 8C). 
A
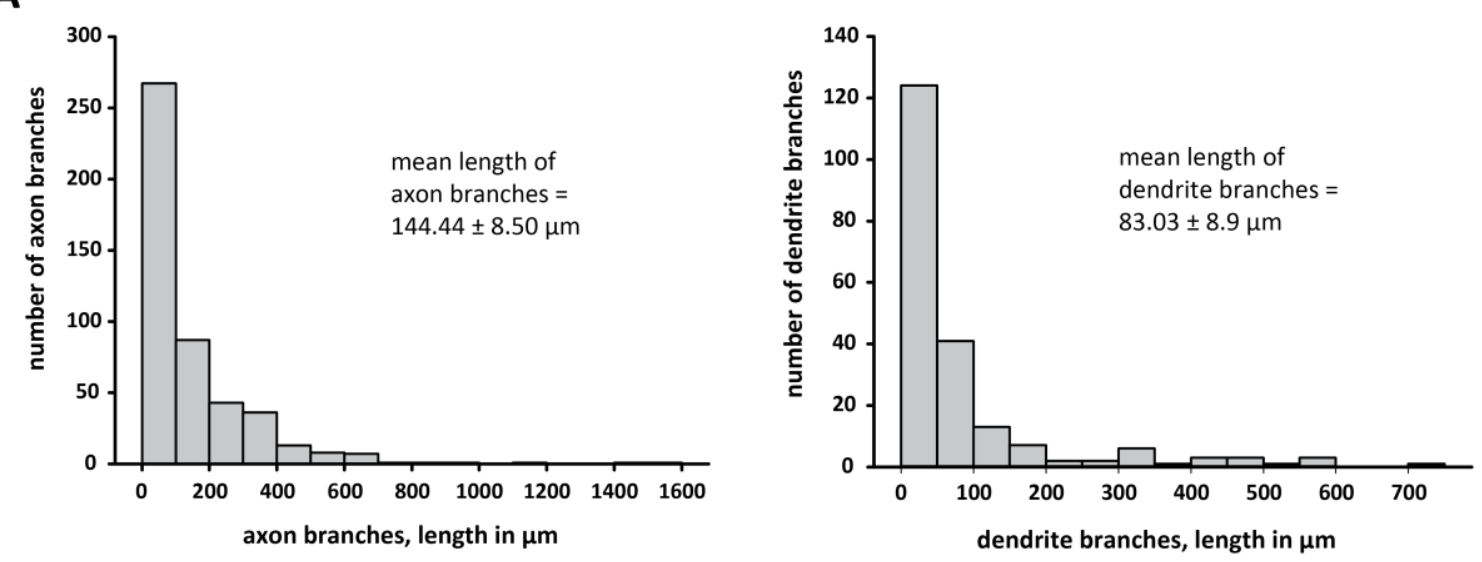

B
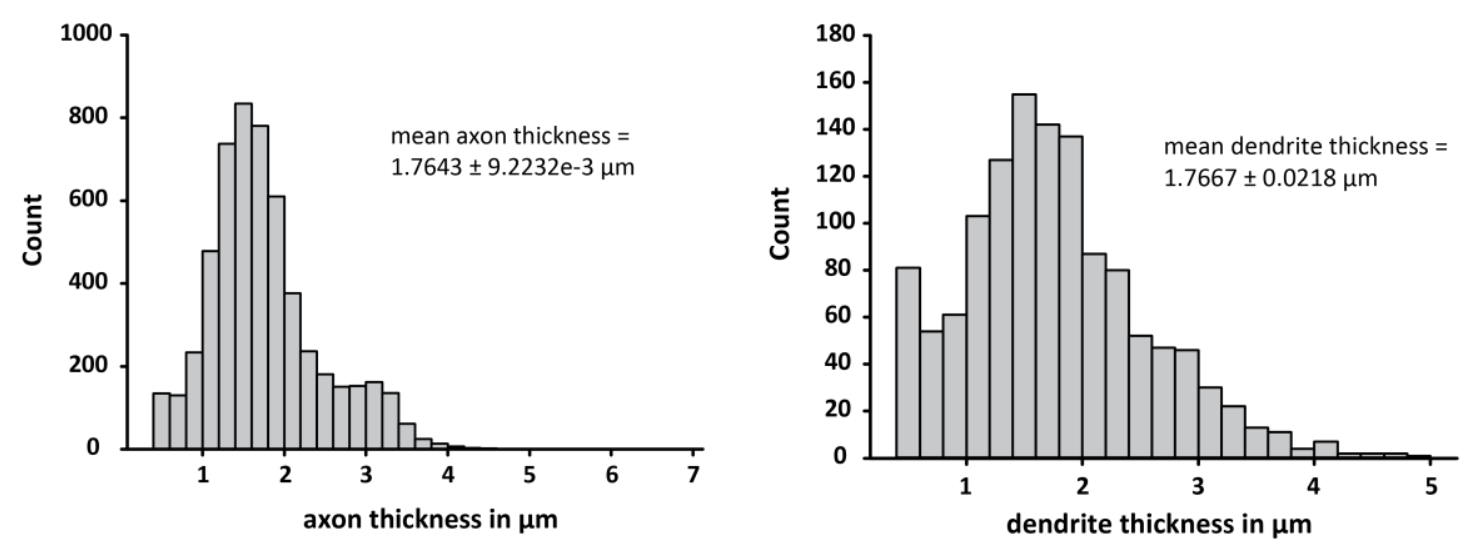

C
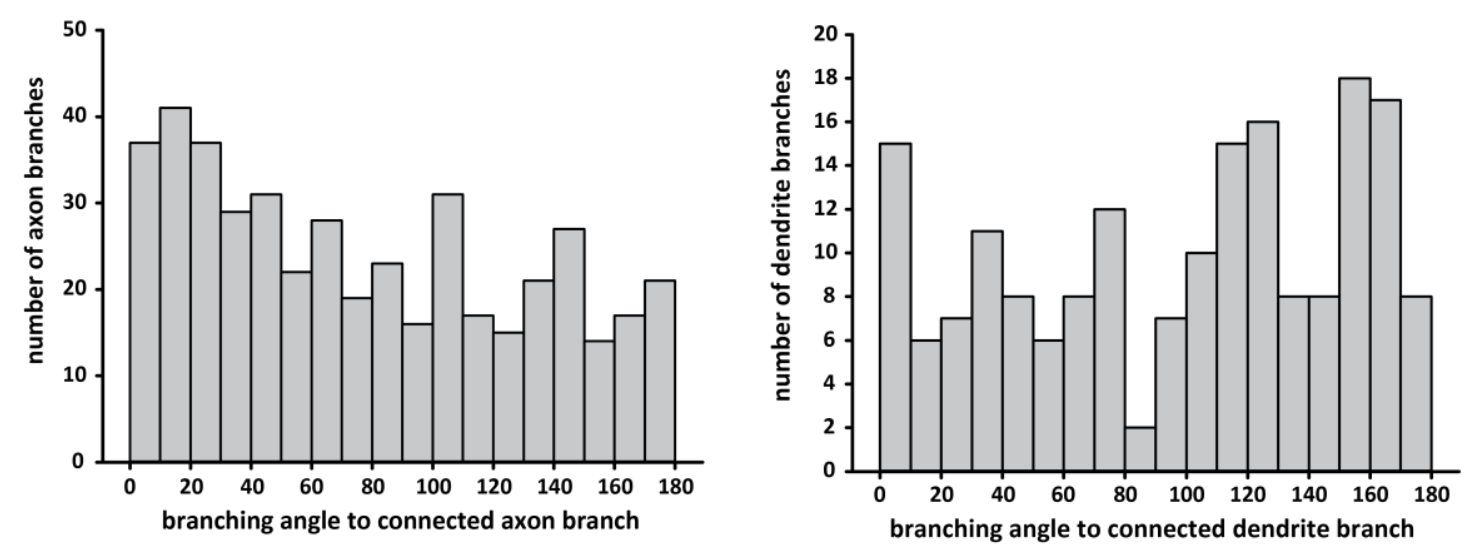

Figure 8: Analysis of neurite lengths, thicknesses, and branching angles. The neurites of the membrane-bound EGFP transfected neurons were traced and subsequently analysed. A Histogram of the length of the axon (left) and dendrite (right) branches. The mean length plus the SEM are given. The distribution is skewed towards shorter neurites. $B$ The thickness of axons (left) and dendrites (right) was determined by automatically crosssectioning the traced branches. The distribution of the thicknesses for axon and dendrite branches is very similar, as is the mean thickness (plus SEM) for each of them. Five neurons were analysed. $C$ Histogram of the branching angles of axon (left) and dendrite 
(right) branches. The angle was defined as the angle to the connected and hierarchically higher branch. The angles were normalized to positive values, i.e. an angle of $-45^{\circ}$ was considered to be the same as $45^{\circ}$. There seems to be no clear tendency for the branching angles.

The number of pre-and postsynapses in cultured hippocampal neurons is correlated I next wanted to determine the number of synapses per neuron in our culture system. In combination with the transfection of the cells with membrane-anchored EGFP, the cells had been immunostained against the presynaptic marker synaptophysin. Using the EGFP signal as a mask, I determined the number of presynaptic areas per neuron (Figure 9A). Using a wider mask on the dendritic areas, I determined the number of postsynapses per neuron (Figure 9B). I analysed 37 cells and found a good correlation between the number of pre- and postsynapses per neuron. On average, a neuron in our culture had $294.25 \pm$ 20.02 presynapses and $299.11 \pm 17.5$ postsynapses (mean \pm SEM). This is close to previous estimates, such as from Cullen et al., who found around 400 synapses per neuron in low density cultures (Cullen et al., 2010).

A

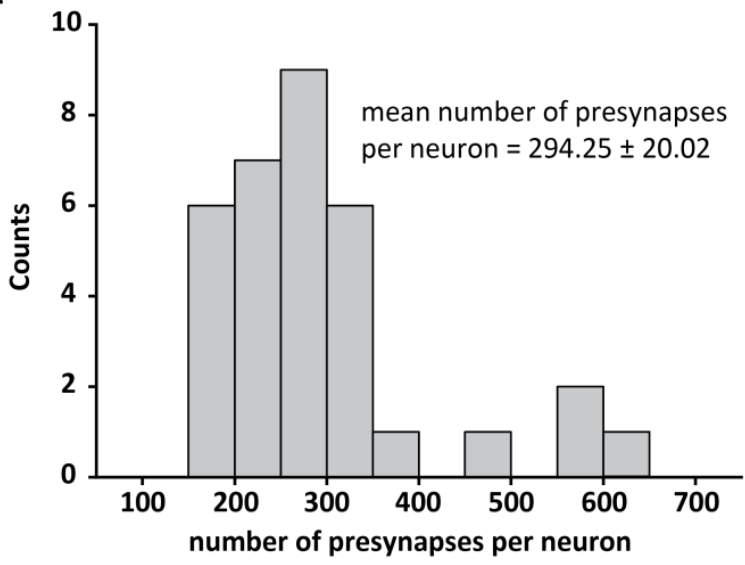

B

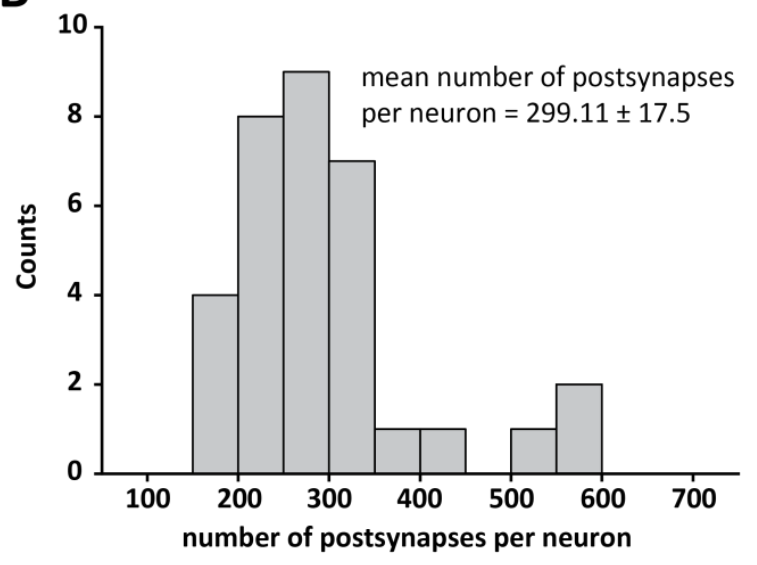

Figure 9: Number of synapses per neuron. The presynaptic marker synaptophysin was used to determine the amount of pre- (A) and postsynapses (B) per neuron. The membrane EGFP signal was used as a mask to define the area of the cell. Then the number of synapse spots was counted within this mask. Both, the number of pre-and postsynapses are close to 300 per neuron. 37 neurons were analysed. Mean values plus SEM are given. 
Organelles have varying sizes and distributions depending on their location in different neuronal compartments

Aside from the outer volume of the neurons in our culture system, there are many internal volumes taken up by organelles, such as the nucleus, the endoplasmic reticulum, the Golgi apparatus, several endosome and vesicle types, peroxisomes, and mitochondria. Thus, in order to understand the neurons in our culture system, it is important to study these organelles, to determine their volumes and their distribution. Since neurons cover a considerable space, I decided to use a confocal fluorescence microscopy approach that would on the one hand allow me to acquire whole neuronal cell bodies and proximal neurites at a high speed while not losing too many details. I imaged 32 different organelle markers that are specific to different organelles, compartments, or cytoskeletal elements within the cell body and proximal neurites. The neuronal plasma membrane was stained with the organic membrane dye DiO and the AIS was marked by an immunostaining against ankyring. The membrane staining allowed me to define the cell body area and the neurite areas, the ankyring signal defined the axon. Within the cell body, the dendritic, and the axonal areas, I used a custom written MATLAB macro to identify the organelle objects. For each object, I determined the area covered, the major axis, the minor axis, the equivalent circle diameter, the perimeter, the presence in the cell body, the presence in the nucleus, the presence in the axon stack, the presence in axon in slice, the percentage of all pixels in the DiO area in all slices made by the organelle, the $x$-coordinate centre of mass, the $y$-coordinate centre of mass, the $z$ coordinate centre of mass, the minimum distance from the cell body edge, the minimum distance from the nucleus edge, the approximate depth in $z$, and the minimum distance to the next object.

These parameters will provide information on the size, the dimensions, and the number of these organelles, as well as their arrangement, i.e. how far they are apart. I can differentiate between the cell body area, the proximal dendrites, and the proximal axon areas. I compared these parameters for each of the organelle markers imaged.

On the following pages, I will present two figures for each of the organelle markers. The first figure will show images of an exemplary neuron, with the membrane, the AIS, and the organelle of interest. The organelle objects detected will be shown for the middle 
plane of the confocal stack and for all the planes (with a color-coded z-dimension). The figure also includes a table with the extracted parameters, their mean value across all the objects that were analysed and the standard deviation, each for the cell body, the axon, and the dendrites. The differences between these parameters were evaluated using a rank-sum test. The second figure will consist of histograms of the area, the major axis, the minor axis, the percentage of total volume taken up by an object, the minimum distances to the cell body, and the minimum distances to the next object. 


\section{beta III tubulin}
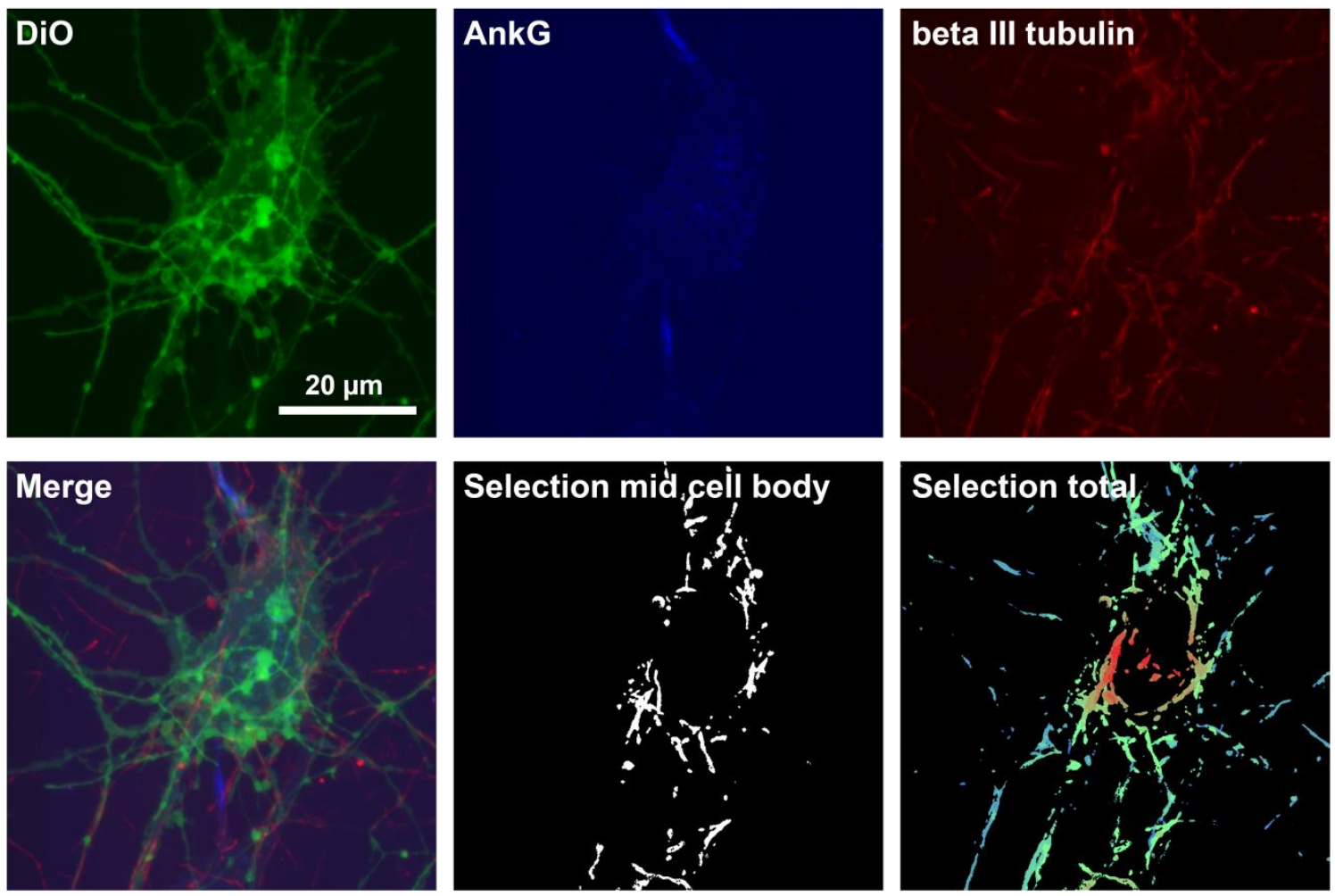

\begin{tabular}{|c|c|c|c|c|c|c|c|c|c|}
\hline properties & $\begin{array}{l}\text { Mean } \\
\text { cell } \\
\text { body }\end{array}$ & $\begin{array}{l}\text { SD cell } \\
\text { body }\end{array}$ & $\begin{array}{l}\text { Mean } \\
\text { axon }\end{array}$ & $\begin{array}{l}\text { SD } \\
\text { axon }\end{array}$ & $\begin{array}{l}\text { Mean } \\
\text { dendrites }\end{array}$ & $\begin{array}{l}\text { SD } \\
\text { dendrites }\end{array}$ & $\begin{array}{l}\text { P value cell } \\
\text { body vs. } \\
\text { axon }\end{array}$ & $\begin{array}{l}\text { P value cell } \\
\text { body vs. } \\
\text { dendrites }\end{array}$ & $\begin{array}{l}\text { P value } \\
\text { axon vs. } \\
\text { dendrites }\end{array}$ \\
\hline Area $\left(\mu \mathrm{m}^{2}\right)$ & 1.361 & 5.389 & 1.064 & 4.022 & 0.354 & 0.971 & & $3.50 \mathrm{E}-273$ & $2.81 E-169$ \\
\hline Major axis $(\mu \mathrm{m})$ & 1.490 & 2.139 & 1.517 & 2.047 & 0.875 & 1.153 & & $3.91 \mathrm{E}-165$ & 1.79E-139 \\
\hline Minor axis $(\mu \mathrm{m})$ & 0.700 & 0.962 & 0.623 & 0.732 & 0.370 & 0.341 & $6.25 \mathrm{E}-09$ & $0.00 \mathrm{E}+00$ & $3.84 \mathrm{E}-178$ \\
\hline $\begin{array}{l}\text { Equivalent circle } \\
\text { diameter }(\mu \mathrm{m})\end{array}$ & 0.873 & 0.985 & 0.813 & 0.833 & 0.492 & 0.457 & & $3.50 \mathrm{E}-273$ & $2.81 \mathrm{E}-169$ \\
\hline Perimeter $(\mu \mathrm{m})$ & 4.740 & 10.019 & 4.679 & 8.056 & 2.546 & 3.465 & & $1.43 E-99$ & $8.23 E-121$ \\
\hline Percent of volume (\%) & 0.018 & 0.086 & 0.011 & 0.039 & 0.004 & 0.012 & $1.22 \mathrm{E}-12$ & $3.36 \mathrm{E}-273$ & $5.04 \mathrm{E}-122$ \\
\hline $\begin{array}{l}\text { Minimum distance from } \\
\text { cell body edge }(\mu \mathrm{m})\end{array}$ & 2.891 & 2.110 & 8.107 & 6.703 & 12.148 & 7.531 & $0.00 \mathrm{E}+00$ & $0.00 \mathrm{E}+00$ & $2.45 \mathrm{E}-199$ \\
\hline $\begin{array}{l}\text { Minimum distance from } \\
\text { nucleus edge }(\mu \mathrm{m})\end{array}$ & 5.454 & 4.667 & 17.002 & 7.922 & 19.429 & 8.540 & $0.00 E+00$ & $0.00 E+00$ & $6.14 \mathrm{E}-56$ \\
\hline $\begin{array}{l}\text { Approximate depth in Z } \\
(\mu \mathrm{m})\end{array}$ & 0.700 & 0.962 & 0.623 & 0.732 & 0.370 & 0.341 & $6.25 \mathrm{E}-09$ & $0.00 \mathrm{E}+00$ & $3.84 \mathrm{E}-178$ \\
\hline $\begin{array}{l}\text { Minimum distance to the } \\
\text { next object }(\mu \mathrm{m})\end{array}$ & 0.783 & 0.367 & 0.688 & 0.350 & 0.673 & 0.456 & $1.19 \mathrm{E}-55$ & $3.85 \mathrm{E}-181$ & \\
\hline
\end{tabular}

Figure 10: Tubulin beta 3 chain, characterization in cell bodies, axons, and dendrites.

Shown in the top panel is the DiO plasma membrane staining in green, the ankyrinG immunostaining in blue, and the beta3tubulin staining in red. All images were acquired by confocal microscopy taking stacks across entire neuronal cell bodies. The images shown are maximum projections of these stacks. The second row shows a merge image of the three markers. The other two images in the second row represent the objects extracted from the organelle staining during the analysis. The middle image shows the objects in the 
middle section of the z-stack, the third image shows all objects color-coded based on the $z$-level. The extracted objects were grouped dependent on their presence in the cell body, the axon, or the dendrite and parameters such as the area, and the percent of total volume for each object were extracted. The table shows the mean values and SDs for these parameters in the different regions. The parameters were compared between the different regions using a multiple comparison ranksum Mann-Whitney $U$ test and a Bonferroni correction. Significant differences are indicated in green. 20 neurons from 2 different cultures were analysed.

\section{beta-3-tubulin}
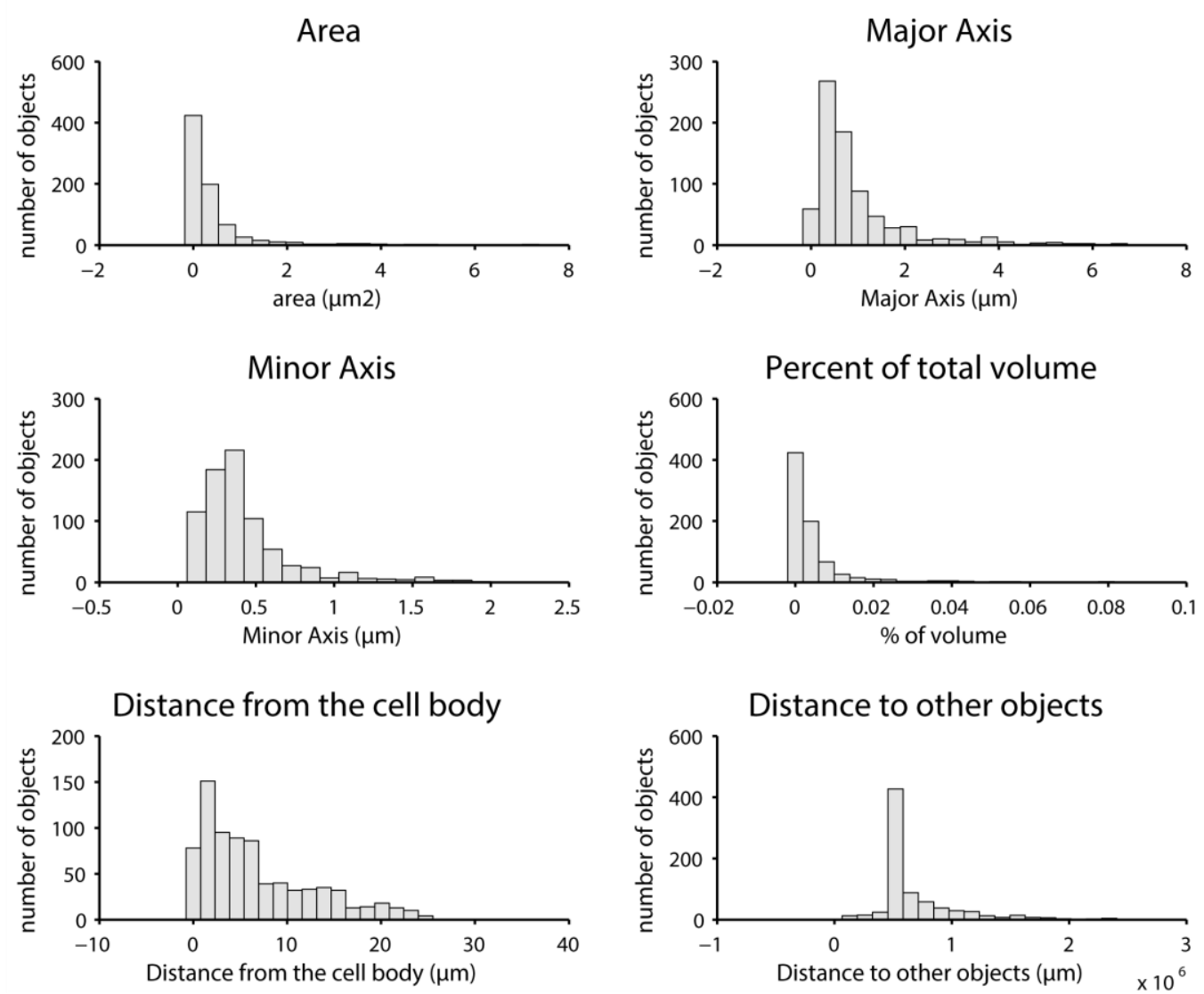

Figure 11: Distribution of tubulin beta 3 chain. From the objects found during the analysis, I extracted several parameters including the area, the axis, the object volume, the distance to the cell body, and the distance to the neighbouring objects. These parameters are given here in the form of histograms. The bin size was chosen according to the data range. 


\section{brevican}
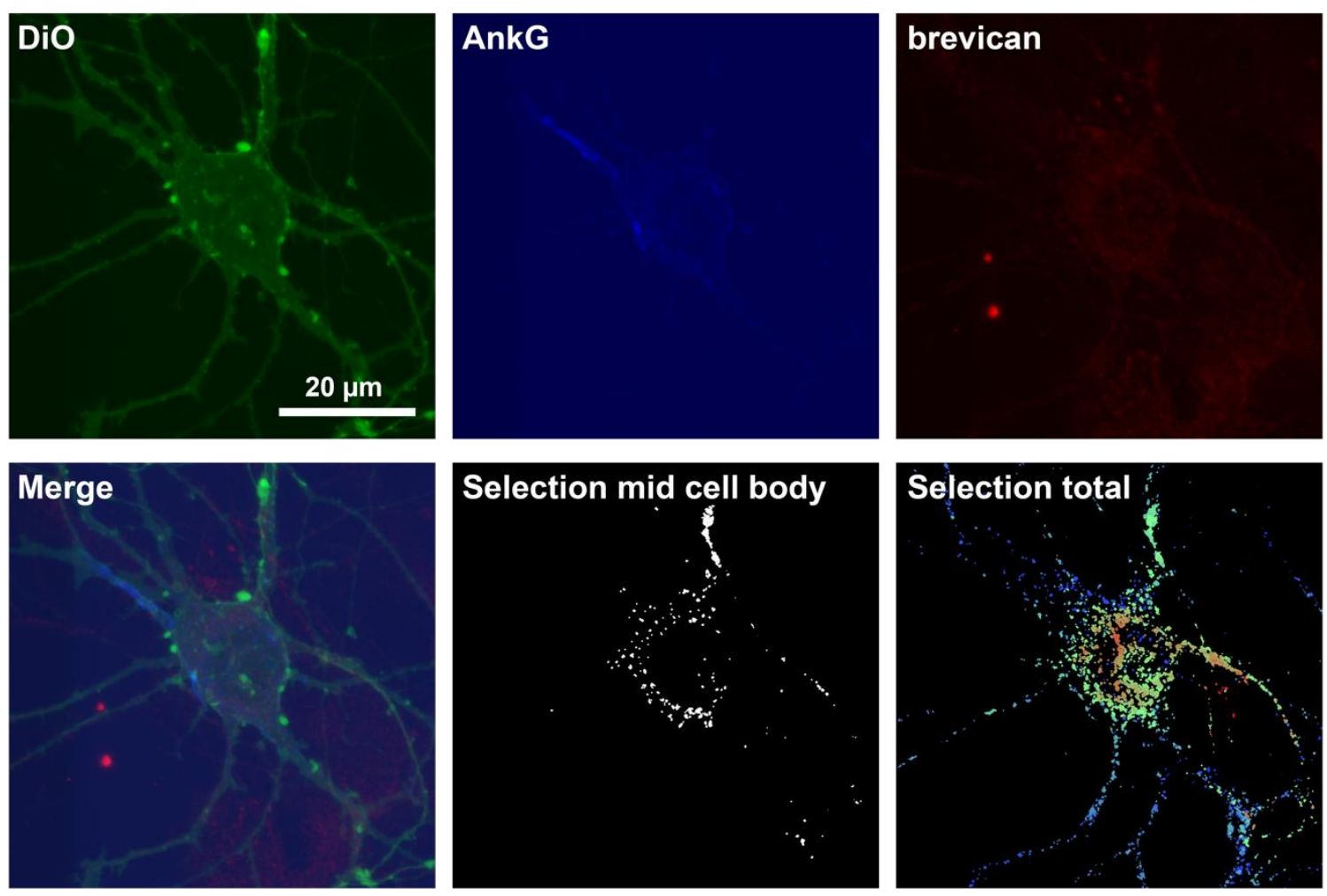

\begin{tabular}{|c|c|c|c|c|c|c|c|c|c|}
\hline properties & $\begin{array}{l}\text { Mean } \\
\text { cell } \\
\text { body }\end{array}$ & $\begin{array}{l}\text { SD cell } \\
\text { body }\end{array}$ & $\begin{array}{l}\text { Mean } \\
\text { axon }\end{array}$ & $\begin{array}{l}\text { SD } \\
\text { axon }\end{array}$ & $\begin{array}{l}\text { Mean } \\
\text { dendrites }\end{array}$ & $\begin{array}{l}\text { SD } \\
\text { dendrites }\end{array}$ & $\begin{array}{l}\text { P value cell } \\
\text { body vs. } \\
\text { axon }\end{array}$ & $\begin{array}{l}\text { P value cell } \\
\text { body vs. } \\
\text { dendrites }\end{array}$ & $\begin{array}{l}\text { P value } \\
\text { axon vs. } \\
\text { dendrites }\end{array}$ \\
\hline Area $\left(\mu \mathrm{m}^{2}\right)$ & 0.893 & 6.743 & 0.723 & 6.289 & 0.153 & 0.489 & $2.21 \mathrm{E}-07$ & $8.26 \mathrm{E}-257$ & $1.43 \mathrm{E}-66$ \\
\hline Major axis $(\mu \mathrm{m})$ & 0.805 & 1.512 & 0.750 & 1.305 & 0.498 & 0.489 & & $5.89 \mathrm{E}-132$ & $1.74 \mathrm{E}-40$ \\
\hline Minor axis $(\mu \mathrm{m})$ & 0.520 & 0.886 & 0.468 & 0.776 & 0.317 & 0.237 & $2.22 \mathrm{E}-10$ & $0.00 \mathrm{E}+00$ & 7.17E-78 \\
\hline $\begin{array}{l}\text { Equivalent circle } \\
\text { diameter }(\mu \mathrm{m})\end{array}$ & 0.573 & 0.899 & 0.527 & 0.802 & 0.361 & 0.254 & & $8.26 \mathrm{E}-257$ & $1.43 \mathrm{E}-66$ \\
\hline Perimeter $(\mu \mathrm{m})$ & 2.959 & 10.072 & 2.834 & 10.947 & 1.398 & 2.079 & & $4.68 \mathrm{E}-146$ & $3.58 \mathrm{E}-42$ \\
\hline Percent of volume (\%) & 0.019 & 0.160 & 0.017 & 0.167 & 0.003 & 0.010 & & $1.01 \mathrm{E}-201$ & $3.13 \mathrm{E}-85$ \\
\hline $\begin{array}{l}\text { Minimum distance from } \\
\text { cell body edge }(\mu \mathrm{m})\end{array}$ & 3.215 & 1.980 & 8.672 & 6.641 & 11.942 & 7.744 & $0.00 \mathrm{E}+00$ & $0.00 \mathrm{E}+00$ & $2.76 \mathrm{E}-78$ \\
\hline $\begin{array}{l}\text { Minimum distance from } \\
\text { nucleus edge }(\mu \mathrm{m})\end{array}$ & 3.337 & 3.090 & 13.818 & 7.070 & 17.987 & 9.161 & $0.00 \mathrm{E}+00$ & $0.00 \mathrm{E}+00$ & $2.55 \mathrm{E}-82$ \\
\hline $\begin{array}{l}\text { Approximate depth in } Z \\
(\mu \mathrm{m})\end{array}$ & 0.520 & 0.886 & 0.468 & 0.776 & 0.317 & 0.237 & $2.22 \mathrm{E}-10$ & $0.00 \mathrm{E}+00$ & 7.17E-78 \\
\hline $\begin{array}{l}\text { Minimum distance to the } \\
\text { next object }(\mu \mathrm{m})\end{array}$ & 0.634 & 0.220 & 0.669 & 0.309 & 0.729 & 0.571 & & & \\
\hline
\end{tabular}

Figure 12: Brevican, characterization in cell bodies, axons, and dendrites. Shown in the top panel is the DiO plasma membrane staining in green, the ankyrinG immunostaining in blue, and the brevican staining in red. All images were acquired by confocal microscopy taking stacks across entire neuronal cell bodies. The images shown are maximum projections of these stacks. The second row shows a merge image of the three markers. The other two images in the second row represent the objects extracted from the 
organelle staining during the analysis. The middle image shows the objects in the middle section of the z-stack, the third image shows all objects color-coded based on the z-level. The extracted objects were grouped dependent on their presence in the cell body, the axon, or the dendrite and parameters such as the area, and the percent of total volume for each object were extracted. The table shows the mean values and SDs for these parameters in the different regions. The parameters were compared between the different regions using a multiple comparison ranksum Mann-Whitney $U$ test and a Bonferroni correction. Significant differences are indicated in green. 20 neurons from 2 different cultures were analysed.

\section{brevican}
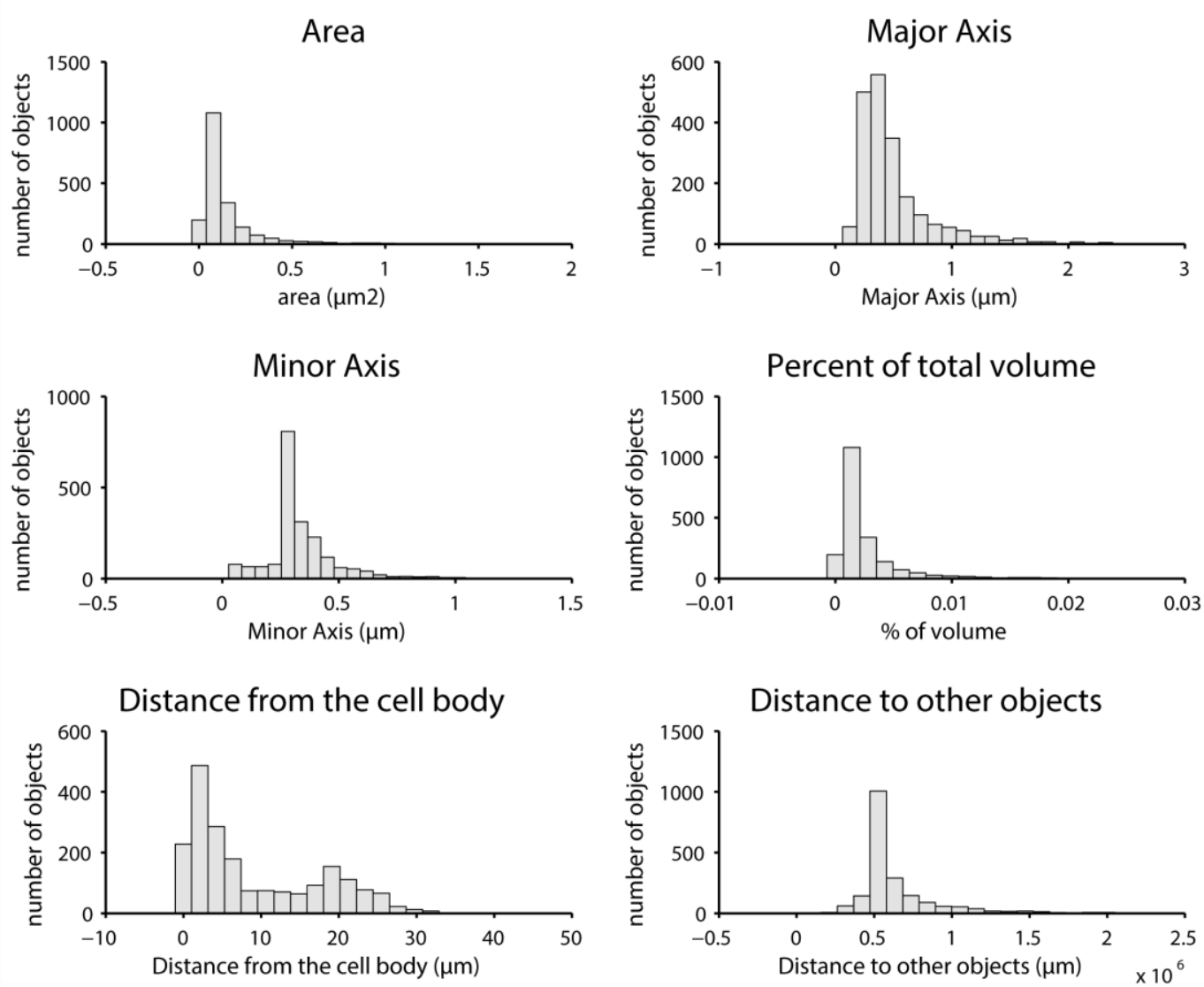

Figure 13: Distribution of brevican. From the objects found during the analysis, I extracted several parameters including the area, the axis, the object volume, the distance to the cell body, and the distance to the neighbouring objects. These parameters are given here in the form of histograms. The bin size was chosen according to the data range. 


\section{calnexin}
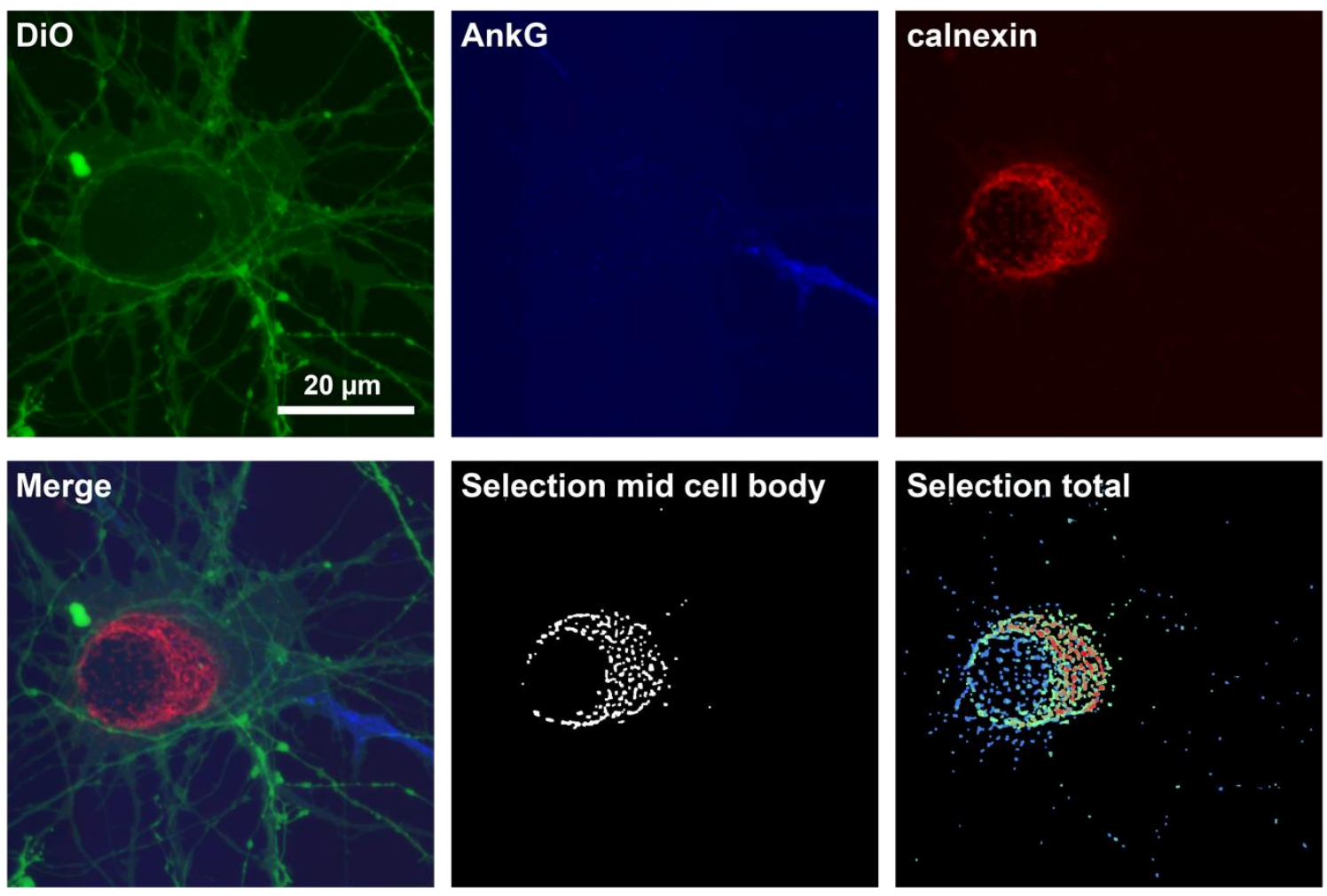

\begin{tabular}{|c|c|c|c|c|c|c|c|c|c|}
\hline properties & $\begin{array}{l}\text { Mean } \\
\text { cell } \\
\text { body }\end{array}$ & $\begin{array}{l}\text { SD cell } \\
\text { body }\end{array}$ & $\begin{array}{l}\text { Mean } \\
\text { axon }\end{array}$ & $\begin{array}{l}\text { SD } \\
\text { axon }\end{array}$ & $\begin{array}{l}\text { Mean } \\
\text { dendrites }\end{array}$ & $\begin{array}{l}\text { SD } \\
\text { dendrites }\end{array}$ & $\begin{array}{l}\text { P value cell } \\
\text { body vs. } \\
\text { axon }\end{array}$ & $\begin{array}{l}\text { P value cell } \\
\text { body vs. } \\
\text { dendrites }\end{array}$ & $\begin{array}{l}\text { P value } \\
\text { axon vs. } \\
\text { dendrites }\end{array}$ \\
\hline Area $\left(\mu \mathrm{m}^{2}\right)$ & 0,374 & 0,576 & 0,214 & 0,232 & 0,165 & 0,154 & $8,75 E-73$ & $0,00 E+00$ & $4,14 \mathrm{E}-19$ \\
\hline Major axis $(\mu \mathrm{m})$ & 0,895 & 0,939 & 0,631 & 0,460 & 0,542 & 0,346 & $3,32 \mathrm{E}-52$ & $1,09 \mathrm{E}-256$ & $5,13 \mathrm{E}-10$ \\
\hline Minor axis $(\mu \mathrm{m})$ & 0,513 & 0,269 & 0,406 & 0,139 & 0,357 & 0,146 & $6,71 E-87$ & $0,00 E+00$ & $4,65 E-23$ \\
\hline $\begin{array}{l}\text { Equivalent circle } \\
\text { diameter }(\mu \mathrm{m})\end{array}$ & 0,615 & 0,314 & 0,477 & 0,212 & 0,416 & 0,191 & $8,75 E-73$ & $0,00 E+00$ & $4,14 \mathrm{E}-19$ \\
\hline Perimeter $(\mu \mathrm{m})$ & 2,335 & 2,459 & 1,648 & 1,116 & 1,440 & 0,842 & $7,71 E-53$ & $4,30 \mathrm{E}-250$ & $8,90 \mathrm{E}-10$ \\
\hline Percent of volume (\%) & 0,006 & 0,010 & 0,003 & 0,004 & 0,002 & 0,002 & 9,87E-91 & $0,00 E+00$ & $4,72 \mathrm{E}-14$ \\
\hline $\begin{array}{l}\text { Minimum distance from } \\
\text { cell body edge }(\mu \mathrm{m})\end{array}$ & 3,780 & 2,341 & 8,784 & 7,084 & 12,188 & 7,420 & $1,26 \mathrm{E}-120$ & $0,00 E+00$ & $3,13 E-58$ \\
\hline $\begin{array}{l}\text { Minimum distance from } \\
\text { nucleus edge }(\mu \mathrm{m})\end{array}$ & 4,414 & 4,187 & 16,599 & 8,684 & 20,692 & 9,024 & $0,00 E+00$ & $0,00 E+00$ & $1,71 \mathrm{E}-48$ \\
\hline $\begin{array}{l}\text { Approximate depth in Z } \\
(\mu \mathrm{m})\end{array}$ & 0,513 & 0,269 & 0,406 & 0,139 & 0,357 & 0,146 & $6,71 E-87$ & $0,00 E+00$ & $4,65 \mathrm{E}-23$ \\
\hline $\begin{array}{l}\text { Minimum distance to the } \\
\text { next object }(\mu \mathrm{m})\end{array}$ & 0,723 & 0,446 & 0,922 & 0,781 & 1,017 & 1,205 & $9,01 E-18$ & & \\
\hline
\end{tabular}

Figure 14: Calnexin, characterization in cell bodies, axons, and dendrites. Shown in the top panel is the DiO plasma membrane staining in green, the ankyrinG immunostaining in blue, and the calnexin staining in red. All images were acquired by confocal microscopy taking stacks across entire neuronal cell bodies. The images shown are maximum projections of these stacks. The second row shows a merge image of the three markers. The other two images in the second row represent the objects extracted from the 
organelle staining during the analysis. The middle image shows the objects in the middle section of the z-stack, the third image shows all objects color-coded based on the z-level. The extracted objects were grouped dependent on their presence in the cell body, the axon, or the dendrite and parameters such as the area, and the percent of total volume for each object were extracted. The table shows the mean values and SDs for these parameters in the different regions. The parameters were compared between the different regions using a multiple comparison ranksum Mann-Whitney $U$ test and a Bonferroni correction. Significant differences are indicated in green. 20 neurons from 2 different cultures were analysed.

\section{calnexin}
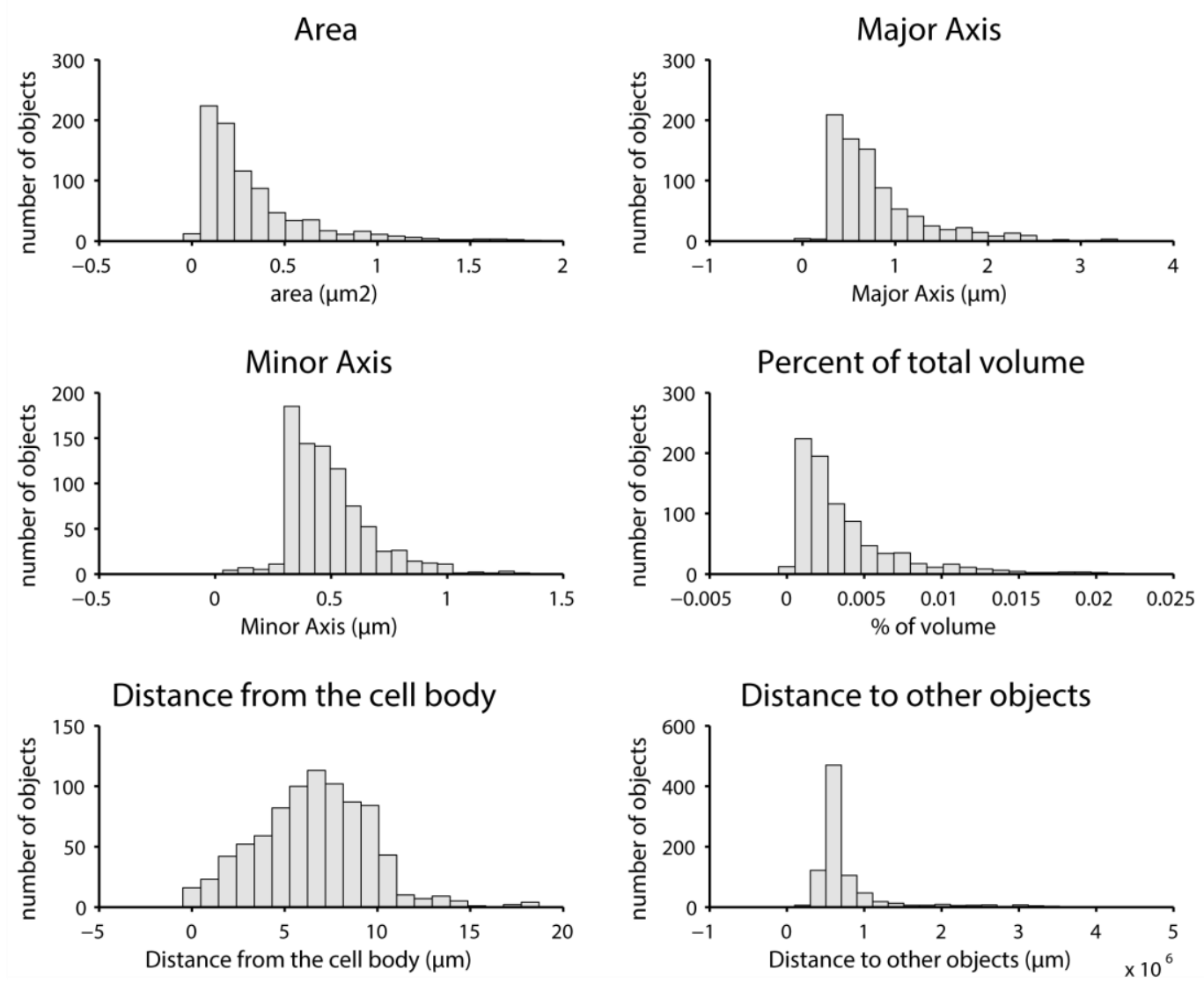

Figure 15: Distribution of calnexin. From the objects found during the analysis, l extracted several parameters including the area, the axis, the object volume, the distance to the cell body, and the distance to the neighbouring objects. These parameters are given here in the form of histograms. The bin size was chosen according to the data range. 


\section{calreticulin}
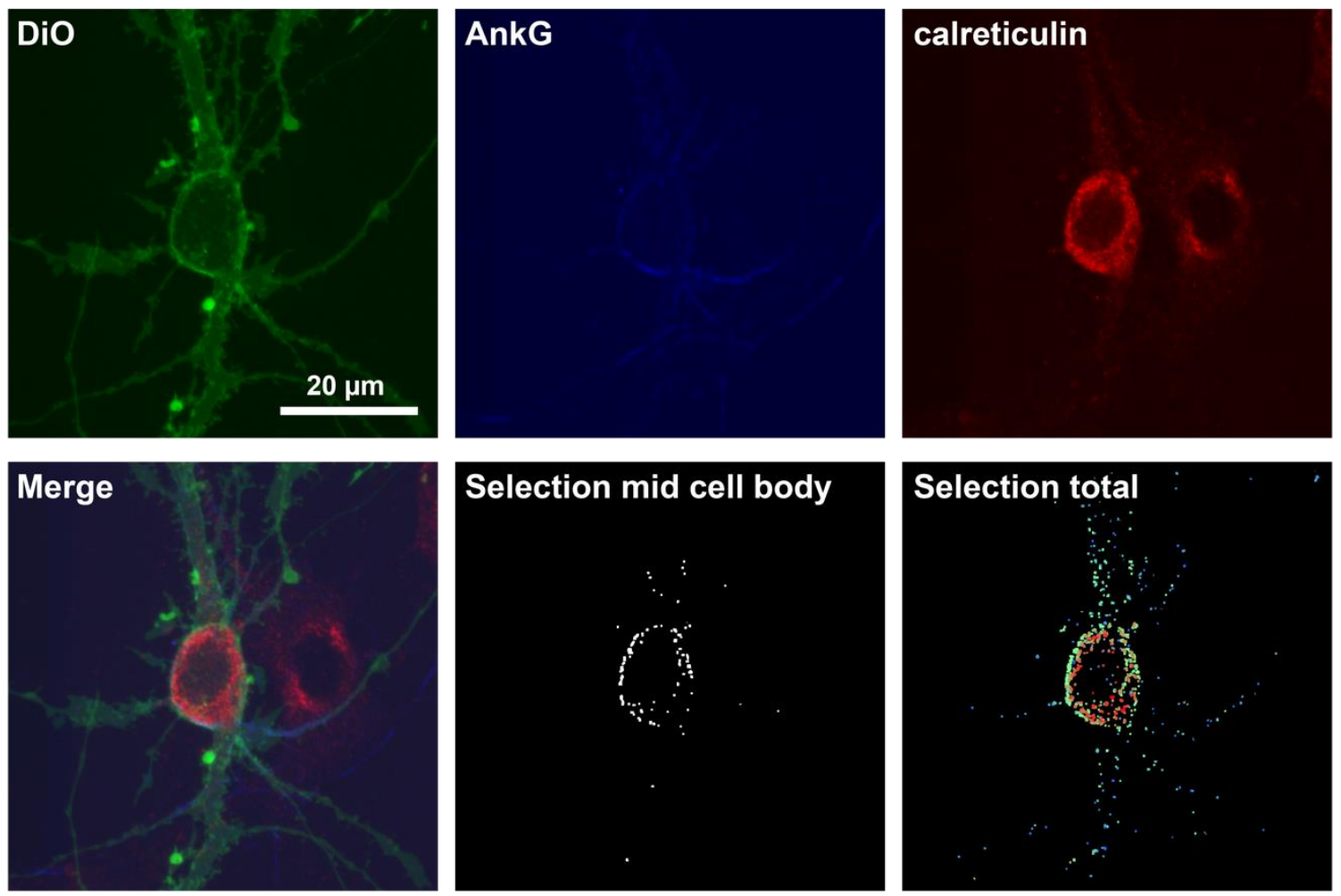

\begin{tabular}{|c|c|c|c|c|c|c|c|c|c|}
\hline properties & $\begin{array}{l}\text { Mean } \\
\text { cell } \\
\text { body }\end{array}$ & $\begin{array}{l}\text { SD cell } \\
\text { body }\end{array}$ & $\begin{array}{l}\text { Mean } \\
\text { axon }\end{array}$ & $\begin{array}{l}\text { SD } \\
\text { axon }\end{array}$ & $\begin{array}{l}\text { Mean } \\
\text { dendrites }\end{array}$ & $\begin{array}{l}\text { SD } \\
\text { dendrites }\end{array}$ & $\begin{array}{l}\text { P value cell } \\
\text { body vs. } \\
\text { axon }\end{array}$ & $\begin{array}{l}\text { P value cell } \\
\text { body vs. } \\
\text { dendrites }\end{array}$ & $\begin{array}{l}\text { P value } \\
\text { axon vs. } \\
\text { dendrites }\end{array}$ \\
\hline Area $\left(\mu \mathrm{m}^{2}\right)$ & 0,181 & 0,140 & 0,118 & 0,066 & 0,107 & 0,079 & $7,74 \mathrm{E}-54$ & $3,18 \mathrm{E}-121$ & $5,46 \mathrm{E}-07$ \\
\hline Major axis $(\mu \mathrm{m})$ & 0,547 & 0,283 & 0,427 & 0,151 & 0,407 & 0,195 & $1,12 \mathrm{E}-36$ & $4,49 \mathrm{E}-78$ & \\
\hline Minor axis $(\mu \mathrm{m})$ & 0,416 & 0,090 & 0,346 & 0,103 & 0,319 & 0,118 & $1,26 E-52$ & $1,00 \mathrm{E}-131$ & \\
\hline $\begin{array}{l}\text { Equivalent circle } \\
\text { diameter }(\mu \mathrm{m})\end{array}$ & 0,459 & 0,140 & 0,370 & 0,115 & 0,345 & 0,131 & $7,74 \mathrm{E}-54$ & $3,18 \mathrm{E}-121$ & \\
\hline Perimeter $(\mu \mathrm{m})$ & 1,447 & 0,705 & 1,145 & 0,381 & 1,092 & 0,487 & $1,32 \mathrm{E}-39$ & $3,91 \mathrm{E}-85$ & \\
\hline Percent of volume (\%) & 0,004 & 0,003 & 0,002 & 0,002 & 0,003 & 0,002 & $1,41 \mathrm{E}-41$ & $2,25 \mathrm{E}-35$ & \\
\hline $\begin{array}{l}\text { Minimum distance from } \\
\text { cell body edge }(\mu \mathrm{m})\end{array}$ & 3,665 & 2,606 & 7,766 & 6,048 & 11,275 & 7,433 & $2,83 \mathrm{E}-69$ & $3,37 \mathrm{E}-226$ & $1,39 E-24$ \\
\hline $\begin{array}{l}\text { Minimum distance from } \\
\text { nucleus edge }(\mu \mathrm{m})\end{array}$ & 4,285 & 4,484 & 14,781 & 6,862 & 18,757 & 8,000 & $6,95 \mathrm{E}-287$ & $0,00 E+00$ & $5,97 \mathrm{E}-26$ \\
\hline $\begin{array}{l}\text { Approximate depth in Z } \\
(\mu \mathrm{m})\end{array}$ & 0,416 & 0,090 & 0,346 & 0,103 & 0,319 & 0,118 & $1,26 \mathrm{E}-52$ & $1,00 \mathrm{E}-131$ & \\
\hline $\begin{array}{l}\text { Minimum distance to the } \\
\text { next object }(\mu \mathrm{m})\end{array}$ & 0,780 & 0,463 & 1,107 & 1,245 & 1,416 & 1,591 & $1,46 \mathrm{E}-05$ & $2,14 \mathrm{E}-30$ & $2,35 \mathrm{E}-05$ \\
\hline
\end{tabular}

Figure 16: Calreticulin, characterization in cell bodies, axons, and dendrites. Shown in the top panel is the DiO plasma membrane staining in green, the ankyring immunostaining in blue, and the calreticulin staining in red. All images were acquired by confocal microscopy taking stacks across entire neuronal cell bodies. The images shown are maximum projections of these stacks. The second row shows a merge image of the three markers. The other two images in the second row represent the objects extracted 
from the organelle staining during the analysis. The middle image shows the objects in the middle section of the z-stack, the third image shows all objects color-coded based on the z-level. The extracted objects were grouped dependent on their presence in the cell body, the axon, or the dendrite and parameters such as the area, and the percent of total volume for each object were extracted. The table shows the mean values and SDs for these parameters in the different regions. The parameters were compared between the different regions using a multiple comparison ranksum Mann-Whitney $U$ test and a Bonferroni correction. Significant differences are indicated in green. 20 neurons from 2 different cultures were analysed.

calreticulin
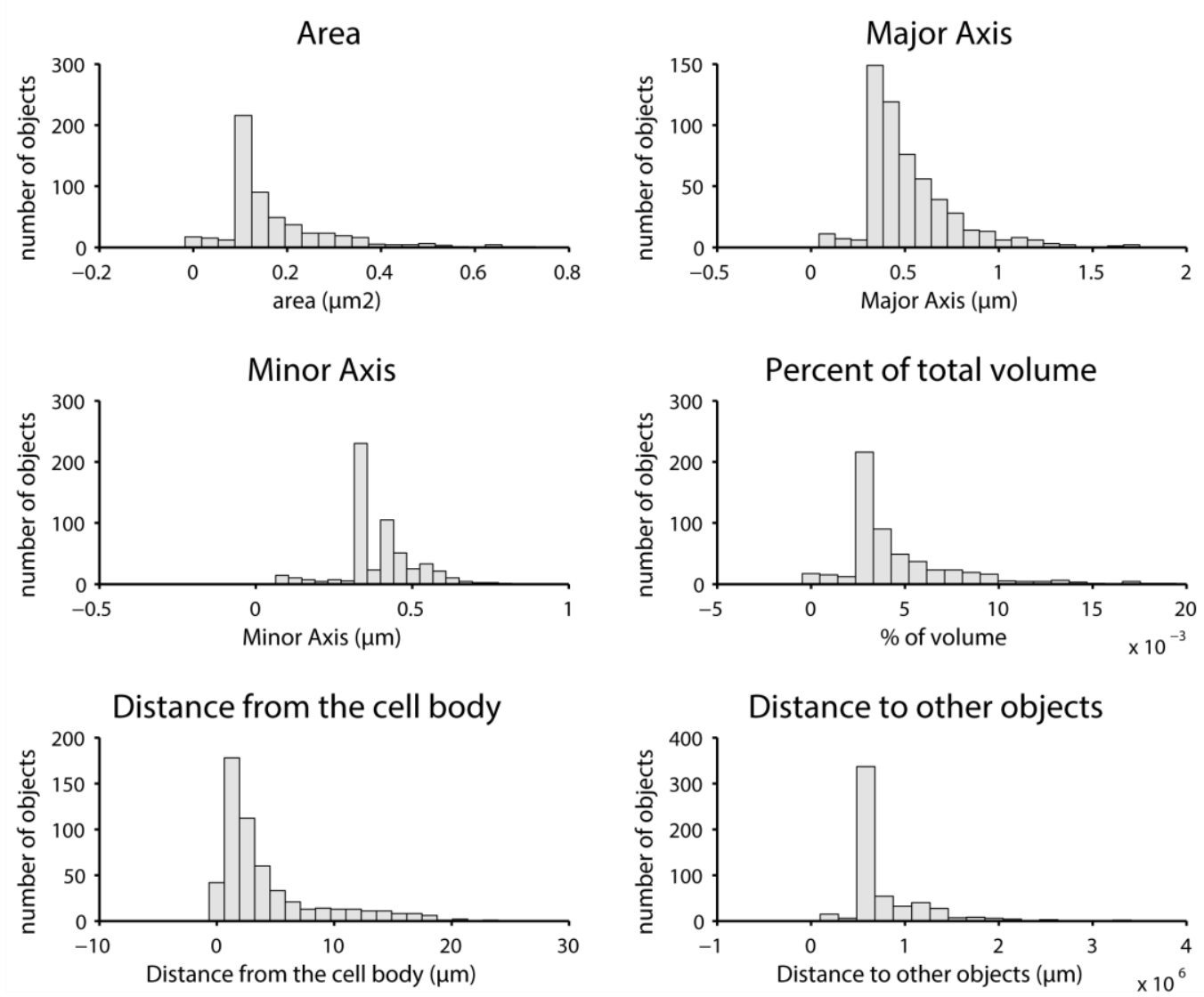

Figure 17: Distribution of calreticulin. From the objects found during the analysis, I extracted several parameters including the area, the axis, the object volume, the distance to the cell body, and the distance to the neighbouring objects. These parameters are given here in the form of histograms. The bin size was chosen according to the data range. 


\section{catalase}
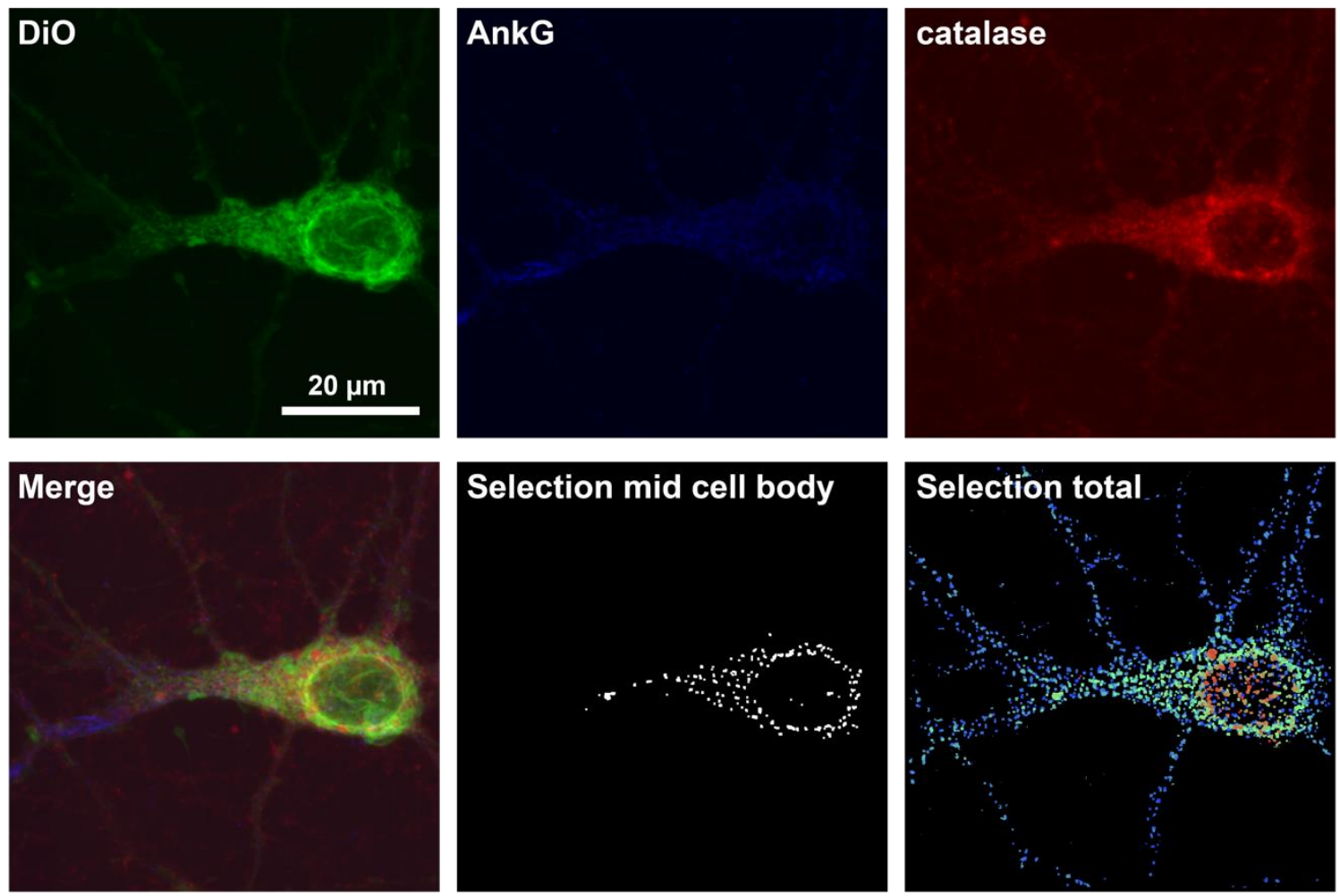

\begin{tabular}{|c|c|c|c|c|c|c|c|c|c|}
\hline properties & $\begin{array}{l}\text { Mean } \\
\text { cell } \\
\text { body }\end{array}$ & $\begin{array}{l}\text { SD cell } \\
\text { body }\end{array}$ & $\begin{array}{l}\text { Mean } \\
\text { axon }\end{array}$ & $\begin{array}{l}\text { SD } \\
\text { axon }\end{array}$ & $\begin{array}{l}\text { Mean } \\
\text { dendrites }\end{array}$ & $\begin{array}{l}\text { SD } \\
\text { dendrites }\end{array}$ & $\begin{array}{l}\text { P value cell } \\
\text { body vs. } \\
\text { axon }\end{array}$ & $\begin{array}{l}\text { P value cell } \\
\text { body vs. } \\
\text { dendrites }\end{array}$ & $\begin{array}{l}\text { P value } \\
\text { axon vs. } \\
\text { dendrites }\end{array}$ \\
\hline Area $\left(\mu \mathrm{m}^{2}\right)$ & 0.185 & 0.118 & 0.160 & 0.136 & 0.115 & 0.096 & $2.01 \mathrm{E}-137$ & $0.00 E+00$ & $2.59 \mathrm{E}-103$ \\
\hline Major axis $(\mu \mathrm{m})$ & 0.556 & 0.230 & 0.522 & 0.261 & 0.441 & 0.221 & & $6.59 \mathrm{E}-193$ & 1.14E-69 \\
\hline Minor axis $(\mu \mathrm{m})$ & 0.421 & 0.088 & 0.368 & 0.144 & 0.307 & 0.137 & 3.17E-196 & $0.00 \mathrm{E}+00$ & $1.18 \mathrm{E}-117$ \\
\hline $\begin{array}{l}\text { Equivalent circle } \\
\text { diameter }(\mu \mathrm{m})\end{array}$ & 0.468 & 0.127 & 0.418 & 0.171 & 0.348 & 0.157 & $2.01 \mathrm{E}-137$ & $0.00 E+00$ & $2.59 \mathrm{E}-103$ \\
\hline Perimeter $(\mu \mathrm{m})$ & 1.469 & 0.582 & 1.384 & 0.674 & 1.157 & 0.559 & & $2.33 \mathrm{E}-226$ & 2.93E-78 \\
\hline Percent of volume (\%) & 0.003 & 0.002 & 0.002 & 0.002 & 0.002 & 0.002 & $1.28 \mathrm{E}-142$ & $4.99 \mathrm{E}-226$ & $6.32 \mathrm{E}-35$ \\
\hline $\begin{array}{l}\text { Minimum distance from } \\
\text { cell body edge }(\mu \mathrm{m})\end{array}$ & 3.604 & 2.220 & 9.299 & 7.457 & 11.509 & 7.484 & $0.00 E+00$ & $0.00 \mathrm{E}+00$ & 2.99E-60 \\
\hline $\begin{array}{l}\text { Minimum distance from } \\
\text { nucleus edge }(\mu \mathrm{m})\end{array}$ & 4.284 & 3.728 & 18.027 & 8.834 & 19.790 & 8.774 & $0.00 \mathrm{E}+00$ & $0.00 \mathrm{E}+00$ & \\
\hline $\begin{array}{l}\text { Approximate depth in Z } \\
(\mu \mathrm{m})\end{array}$ & 0.421 & 0.088 & 0.368 & 0.144 & 0.307 & 0.137 & 3.17E-196 & $0.00 E+00$ & $1.18 \mathrm{E}-117$ \\
\hline $\begin{array}{l}\text { Minimum distance to the } \\
\text { next object }(\mu \mathrm{m})\end{array}$ & 0.628 & 0.233 & 0.645 & 0.367 & 1.027 & 1.150 & & $8.15 E-33$ & 4.67E-53 \\
\hline
\end{tabular}

Figure 18: Catalase, characterization in cell bodies, axons, and dendrites. Shown in the top panel is the DiO plasma membrane staining in green, the ankyring immunostaining in blue, and the catalase staining in red. All images were acquired by confocal microscopy taking stacks across entire neuronal cell bodies. The images shown are maximum projections of these stacks. The second row shows a merge image of the three markers. The other two images in the second row represent the objects extracted from the 
organelle staining during the analysis. The middle image shows the objects in the middle section of the z-stack, the third image shows all objects color-coded based on the z-level. The extracted objects were grouped dependent on their presence in the cell body, the axon, or the dendrite and parameters such as the area, and the percent of total volume for each object were extracted. The table shows the mean values and SDs for these parameters in the different regions. The parameters were compared between the different regions using a multiple comparison ranksum Mann-Whitney $U$ test and a Bonferroni correction. Significant differences are indicated in green. 20 neurons from 2 different cultures were analysed.

catalase
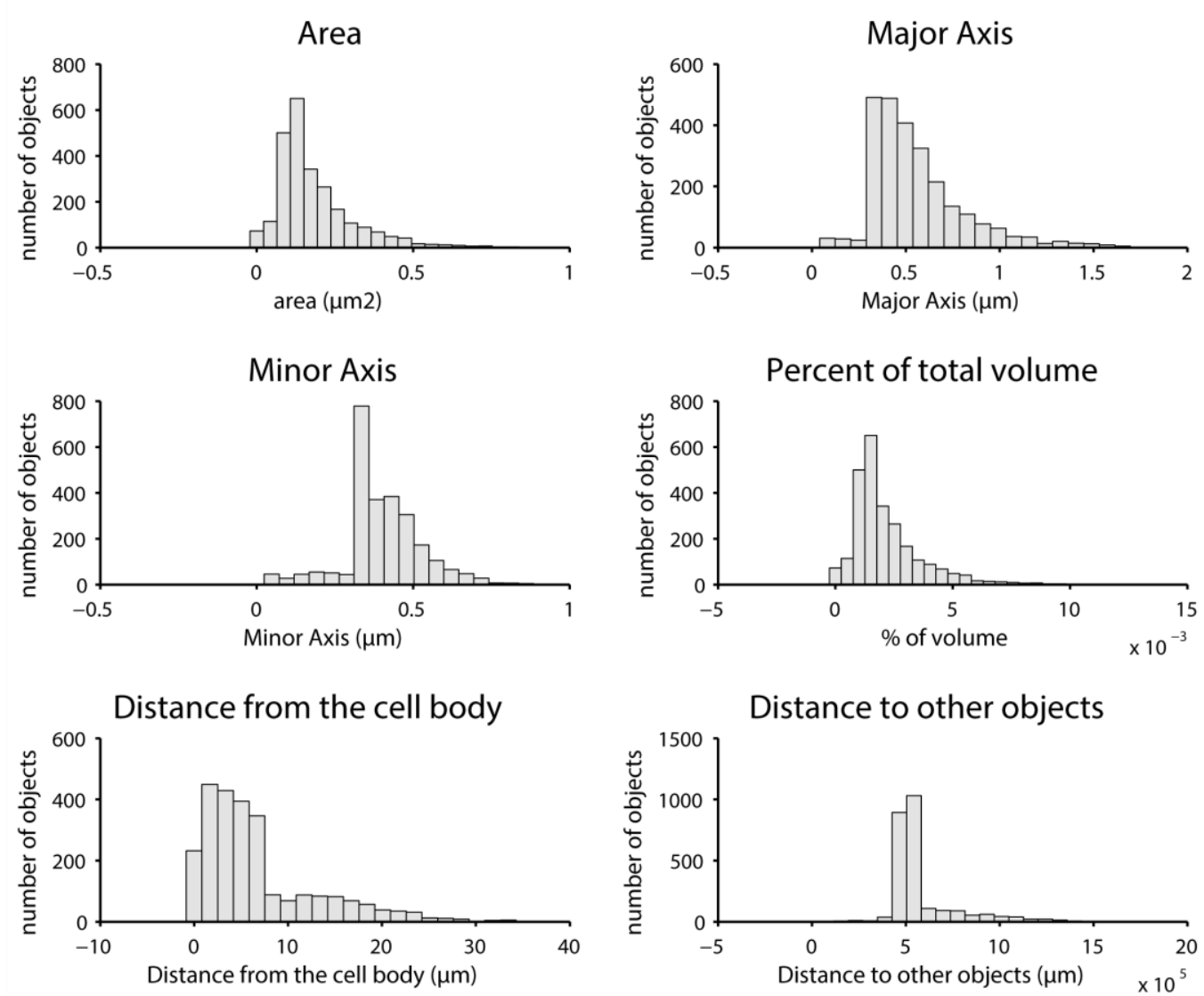

Figure 19: Distribution of catalase. From the objects found during the analysis, l extracted several parameters including the area, the axis, the object volume, the distance to the cell body, and the distance to the neighbouring objects. These parameters are given here in the form of histograms. The bin size was chosen according to the data range. 


\section{clathrin}
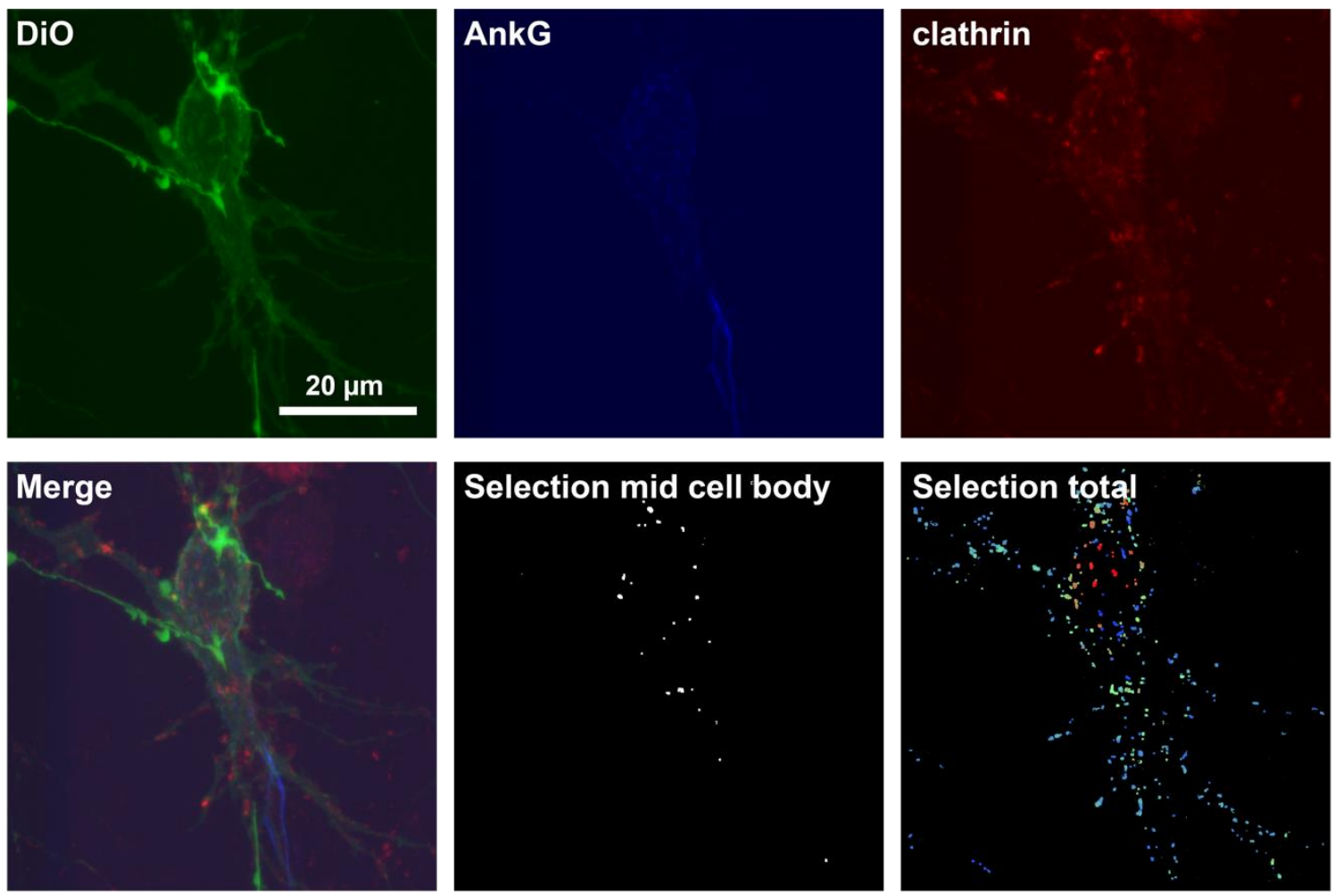

\begin{tabular}{|c|c|c|c|c|c|c|c|c|c|}
\hline properties & $\begin{array}{l}\text { Mean } \\
\text { cell } \\
\text { body }\end{array}$ & $\begin{array}{l}\text { SD cell } \\
\text { body }\end{array}$ & $\begin{array}{l}\text { Mean } \\
\text { axon }\end{array}$ & $\begin{array}{l}\text { SD } \\
\text { axon }\end{array}$ & $\begin{array}{l}\text { Mean } \\
\text { dendrites }\end{array}$ & $\begin{array}{l}\text { SD } \\
\text { dendrites }\end{array}$ & $\begin{array}{l}\text { P value cell } \\
\text { body vs. } \\
\text { axon }\end{array}$ & $\begin{array}{l}\text { P value cell } \\
\text { body vs. } \\
\text { dendrites }\end{array}$ & $\begin{array}{l}\text { P value } \\
\text { axon vs. } \\
\text { dendrites }\end{array}$ \\
\hline Area $\left(\mu \mathrm{m}^{2}\right)$ & 0.198 & 0.122 & 0.165 & 0.141 & 0.131 & 0.122 & $1.16 \mathrm{E}-30$ & $1.36 \mathrm{E}-202$ & 9.57E-24 \\
\hline Major axis $(\mu \mathrm{m})$ & 0.571 & 0.233 & 0.528 & 0.295 & 0.463 & 0.266 & & $2.15 \mathrm{E}-83$ & $1.26 \mathrm{E}-14$ \\
\hline Minor axis $(\mu \mathrm{m})$ & 0.434 & 0.097 & 0.365 & 0.160 & 0.317 & 0.167 & $9.73 E-44$ & $1.09 \mathrm{E}-242$ & $2.92 \mathrm{E}-24$ \\
\hline $\begin{array}{l}\text { Equivalent circle } \\
\text { diameter }(\mu \mathrm{m})\end{array}$ & 0.483 & 0.138 & 0.416 & 0.195 & 0.360 & 0.194 & $1.16 \mathrm{E}-30$ & $1.36 \mathrm{E}-202$ & $9.57 \mathrm{E}-24$ \\
\hline Perimeter $(\mu \mathrm{m})$ & 1.518 & 0.590 & 1.455 & 0.776 & 1.305 & 0.707 & & $3.89 E-49$ & 4.97E-11 \\
\hline Percent of volume (\%) & 0.003 & 0.003 & 0.003 & 0.004 & 0.002 & 0.003 & & $1.75 \mathrm{E}-161$ & $2.73 \mathrm{E}-26$ \\
\hline $\begin{array}{l}\text { Minimum distance from } \\
\text { cell body edge }(\mu \mathrm{m})\end{array}$ & 2.853 & 2.371 & 7.236 & 6.161 & 11.027 & 7.199 & $1.97 \mathrm{E}-137$ & $0.00 \mathrm{E}+00$ & $3.69 \mathrm{E}-90$ \\
\hline $\begin{array}{l}\text { Minimum distance from } \\
\text { nucleus edge }(\mu \mathrm{m})\end{array}$ & 8.127 & 7.339 & 17.362 & 8.686 & 20.558 & 8.603 & $3.88 \mathrm{E}-271$ & $0.00 \mathrm{E}+00$ & $3.57 \mathrm{E}-40$ \\
\hline $\begin{array}{l}\text { Approximate depth in Z } \\
(\mu \mathrm{m})\end{array}$ & 0.434 & 0.097 & 0.365 & 0.160 & 0.317 & 0.167 & $9.73 E-44$ & $1.09 \mathrm{E}-242$ & $2.92 \mathrm{E}-24$ \\
\hline $\begin{array}{l}\text { Minimum distance to the } \\
\text { next object }(\mu \mathrm{m})\end{array}$ & 0.812 & 0.541 & 0.711 & 0.550 & 0.719 & 0.717 & $8.90 E-35$ & $4.01 \mathrm{E}-151$ & \\
\hline
\end{tabular}

Figure 20: Clathrin, characterization in cell bodies, axons, and dendrites. Shown in the top panel is the DiO plasma membrane staining in green, the ankyrinG immunostaining in blue, and the clathrin staining in red. All images were acquired by confocal microscopy taking stacks across entire neuronal cell bodies. The images shown are maximum projections of these stacks. The second row shows a merge image of the three markers. The other two images in the second row represent the objects extracted from the 
organelle staining during the analysis. The middle image shows the objects in the middle section of the z-stack, the third image shows all objects color-coded based on the z-level. The extracted objects were grouped dependent on their presence in the cell body, the axon, or the dendrite and parameters such as the area, and the percent of total volume for each object were extracted. The table shows the mean values and SDs for these parameters in the different regions. The parameters were compared between the different regions using a multiple comparison ranksum Mann-Whitney $U$ test and a Bonferroni correction. Significant differences are indicated in green. 20 neurons from 2 different cultures were analysed.

clathrin
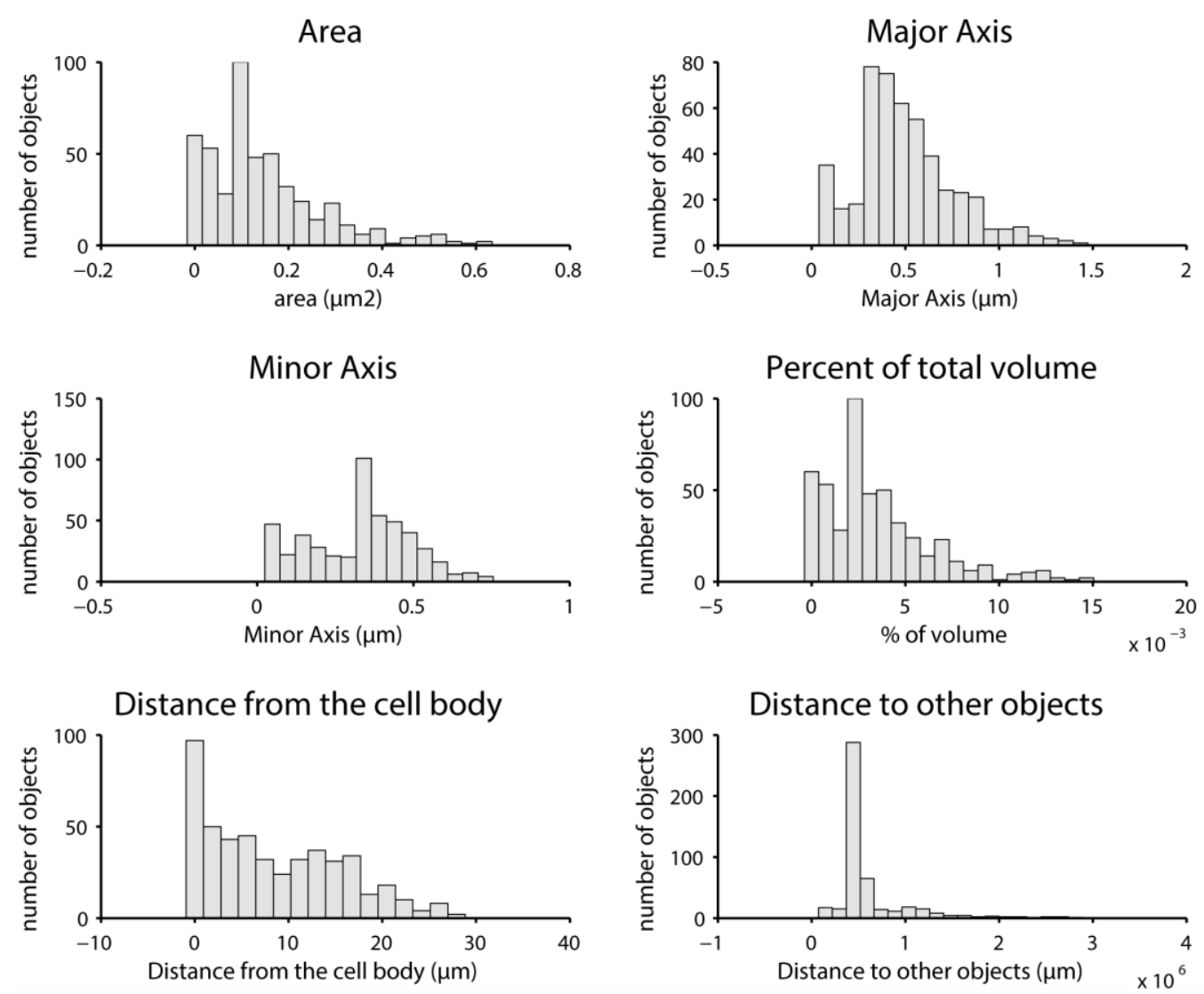

Figure 21: Distribution of clathrin. From the objects found during the analysis, l extracted several parameters including the area, the axis, the object volume, the distance to the cell body, and the distance to the neighbouring objects. These parameters are given here in the form of histograms. The bin size was chosen according to the data range. 


\section{CPT1c}
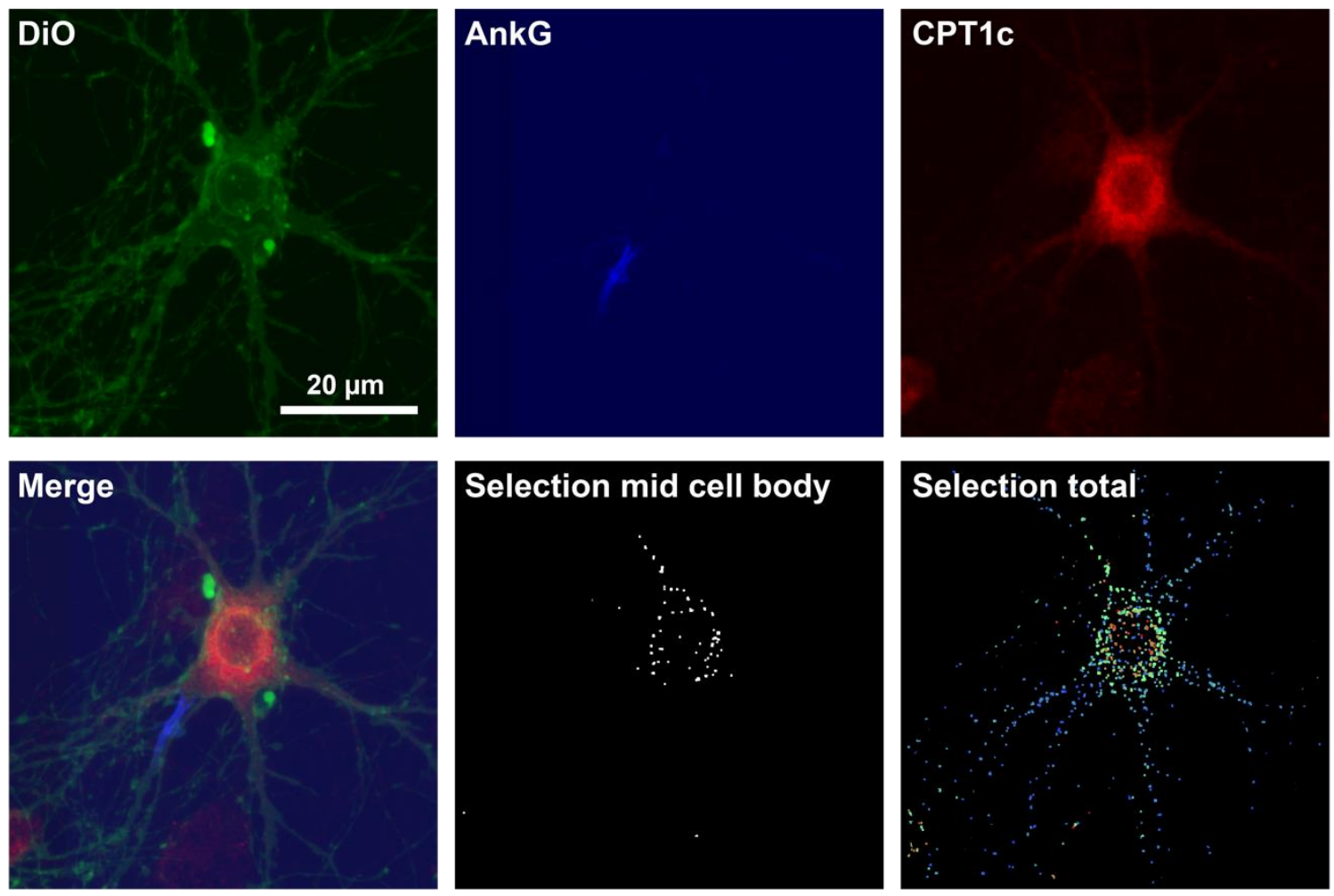

\begin{tabular}{|c|c|c|c|c|c|c|c|c|c|}
\hline properties & $\begin{array}{l}\text { Mean } \\
\text { cell } \\
\text { body }\end{array}$ & $\begin{array}{l}\text { SD cell } \\
\text { body }\end{array}$ & $\begin{array}{l}\text { Mean } \\
\text { axon }\end{array}$ & $\begin{array}{l}\text { SD } \\
\text { axon }\end{array}$ & $\begin{array}{l}\text { Mean } \\
\text { dendrites }\end{array}$ & $\begin{array}{l}\text { SD } \\
\text { dendrites }\end{array}$ & $\begin{array}{l}\text { P value cell } \\
\text { body vs. } \\
\text { axon }\end{array}$ & $\begin{array}{l}\text { P value cell } \\
\text { body vs. } \\
\text { dendrites }\end{array}$ & $\begin{array}{l}\text { P value } \\
\text { axon vs. } \\
\text { dendrites }\end{array}$ \\
\hline Area $\left(\mu \mathrm{m}^{2}\right)$ & 0,152 & 0,077 & 0,147 & 0,085 & 0,115 & 0,074 & & $2,34 \mathrm{E}-154$ & $2,38 \mathrm{E}-24$ \\
\hline Major axis $(\mu \mathrm{m})$ & 0,496 & 0,174 & 0,488 & 0,172 & 0,438 & 0,176 & & $1,01 E-46$ & $6,28 \mathrm{E}-11$ \\
\hline Minor axis $(\mu \mathrm{m})$ & 0,395 & 0,063 & 0,381 & 0,092 & 0,326 & 0,116 & & $2,96 \mathrm{E}-219$ & $1,44 \mathrm{E}-31$ \\
\hline $\begin{array}{l}\text { Equivalent circle } \\
\text { diameter }(\mu \mathrm{m})\end{array}$ & 0,429 & 0,096 & 0,417 & 0,113 & 0,361 & 0,129 & & $2,34 \mathrm{E}-154$ & $2,38 \mathrm{E}-24$ \\
\hline Perimeter $(\mu \mathrm{m})$ & 1,314 & 0,426 & 1,287 & 0,446 & 1,146 & 0,442 & & $2,39 \mathrm{E}-80$ & $9,48 \mathrm{E}-15$ \\
\hline Percent of volume (\%) & 0,003 & 0,002 & 0,003 & 0,001 & 0,002 & 0,001 & & $7,88 \mathrm{E}-163$ & $9,44 \mathrm{E}-24$ \\
\hline $\begin{array}{l}\text { Minimum distance from } \\
\text { cell body edge }(\mu \mathrm{m})\end{array}$ & 2,872 & 1,824 & 6,429 & 5,987 & 13,445 & 9,402 & $9,67 \mathrm{E}-60$ & $0,00 E+00$ & $3,35 \mathrm{E}-91$ \\
\hline $\begin{array}{l}\text { Minimum distance from } \\
\text { nucleus edge }(\mu \mathrm{m})\end{array}$ & 4,197 & 4,101 & 13,479 & 7,470 & 19,566 & 10,415 & $3,43 E-221$ & $0,00 \mathrm{E}+00$ & $4,80 \mathrm{E}-49$ \\
\hline $\begin{array}{l}\text { Approximate depth in Z } \\
(\mu \mathrm{m})\end{array}$ & 0,395 & 0,063 & 0,381 & 0,092 & 0,326 & 0,116 & & $2,96 \mathrm{E}-219$ & $1,44 \mathrm{E}-31$ \\
\hline $\begin{array}{l}\text { Minimum distance to the } \\
\text { next object }(\mu \mathrm{m})\end{array}$ & 0,726 & 0,317 & 0,834 & 0,488 & 1,002 & 0,952 & & & \\
\hline
\end{tabular}

Figure 22: CPT1c, characterization in cell bodies, axons, and dendrites. Shown in the top panel is the DiO plasma membrane staining in green, the ankyring immunostaining in blue, and the CPT1c staining in red. All images were acquired by confocal microscopy taking stacks across entire neuronal cell bodies. The images shown are maximum projections of these stacks. The second row shows a merge image of the three markers. The other two images in the second row represent the objects extracted from the 
organelle staining during the analysis. The middle image shows the objects in the middle section of the z-stack, the third image shows all objects color-coded based on the z-level. The extracted objects were grouped dependent on their presence in the cell body, the axon, or the dendrite and parameters such as the area, and the percent of total volume for each object were extracted. The table shows the mean values and SDs for these parameters in the different regions. The parameters were compared between the different regions using a multiple comparison ranksum Mann-Whitney $U$ test and a Bonferroni correction. Significant differences are indicated in green. 20 neurons from 2 different cultures were analysed.

\section{CPT1C}
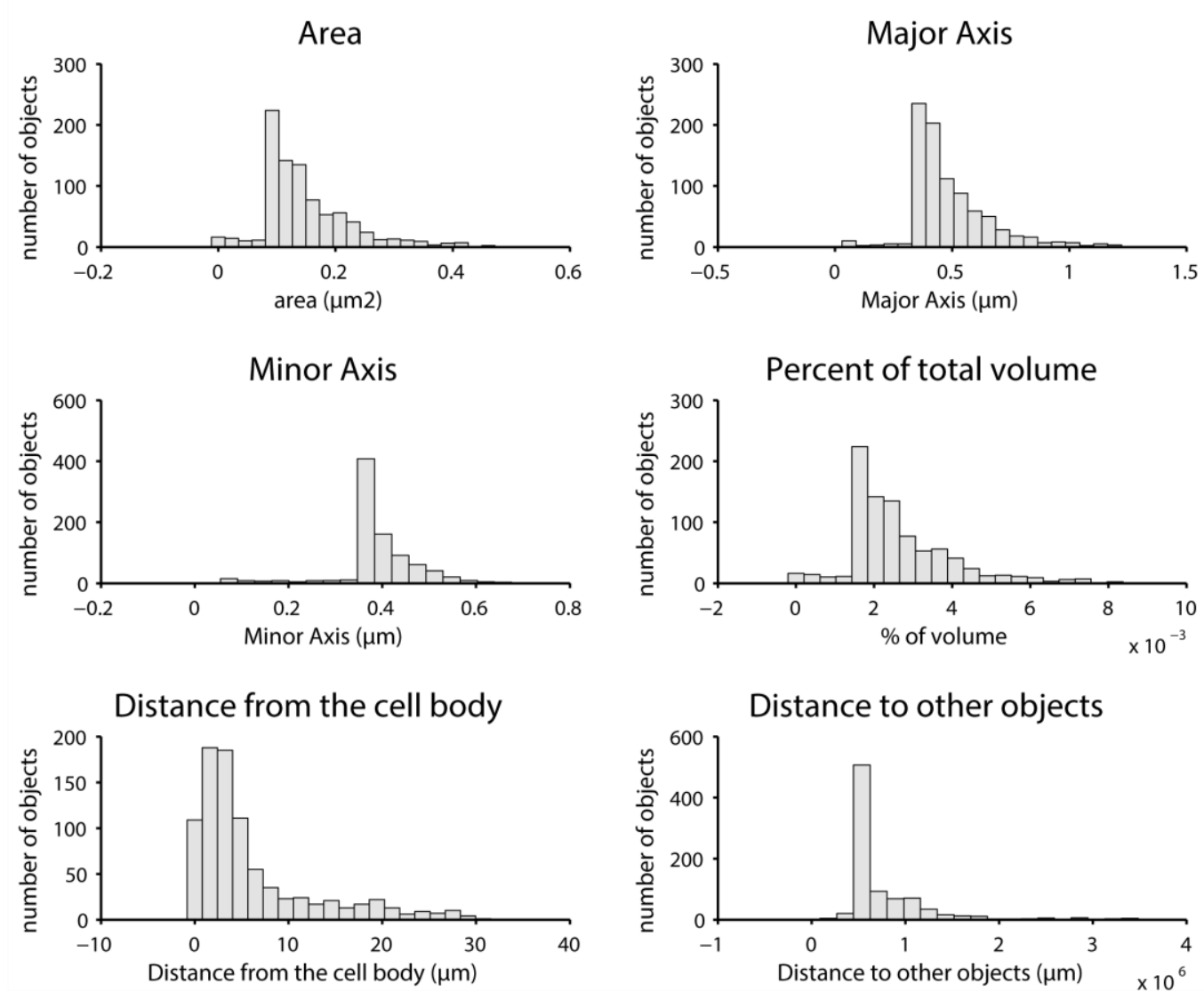

Figure 23: Distribution of CPT1c. From the objects found during the analysis, I extracted several parameters including the area, the axis, the object volume, the distance to the cell body, and the distance to the neighbouring objects. These parameters are given here in the form of histograms. The bin size was chosen according to the data range. 


\section{EEA1}
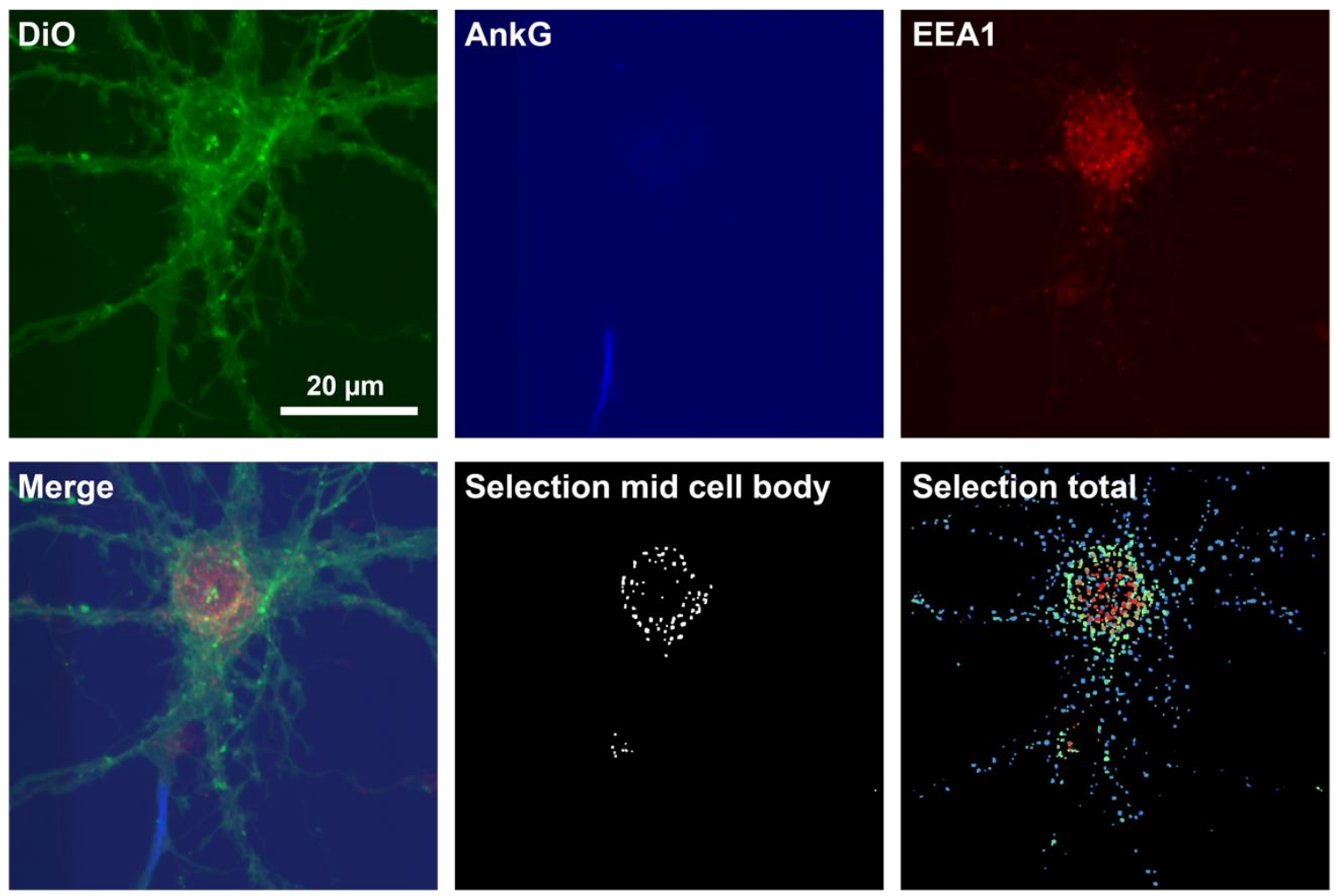

\begin{tabular}{|c|c|c|c|c|c|c|c|c|c|}
\hline properties & $\begin{array}{l}\text { Mean } \\
\text { cell } \\
\text { body }\end{array}$ & $\begin{array}{l}\text { SD cell } \\
\text { body }\end{array}$ & $\begin{array}{l}\text { Mean } \\
\text { axon }\end{array}$ & $\begin{array}{l}\text { SD } \\
\text { axon }\end{array}$ & $\begin{array}{l}\text { Mean } \\
\text { dendrites }\end{array}$ & $\begin{array}{l}\text { SD } \\
\text { dendrites }\end{array}$ & $\begin{array}{l}\text { P value cell } \\
\text { body vs. } \\
\text { axon }\end{array}$ & $\begin{array}{l}\text { P value cell } \\
\text { body vs. } \\
\text { dendrites }\end{array}$ & $\begin{array}{l}\text { P value } \\
\text { axon vs. } \\
\text { dendrites }\end{array}$ \\
\hline Area $\left(\mu \mathrm{m}^{2}\right)$ & 0.217 & 0.125 & 0.184 & 0.125 & 0.170 & 0.124 & $6.39 \mathrm{E}-32$ & $5.53 \mathrm{E}-160$ & \\
\hline Major axis $(\mu \mathrm{m})$ & 0.600 & 0.235 & 0.545 & 0.239 & 0.523 & 0.237 & & $1.93 \mathrm{E}-87$ & \\
\hline Minor axis $(\mu \mathrm{m})$ & 0.454 & 0.100 & 0.413 & 0.134 & 0.387 & 0.149 & & $3.60 \mathrm{E}-180$ & \\
\hline $\begin{array}{l}\text { Equivalent circle } \\
\text { diameter }(\mu \mathrm{m})\end{array}$ & 0.507 & 0.137 & 0.456 & 0.162 & 0.431 & 0.173 & $6.39 E-32$ & $5.53 \mathrm{E}-160$ & \\
\hline Perimeter $(\mu \mathrm{m})$ & 1.600 & 0.592 & 1.483 & 0.641 & 1.431 & 0.620 & & $7.75 \mathrm{E}-68$ & \\
\hline Percent of volume (\%) & 0.002 & 0.002 & 0.004 & 0.003 & 0.003 & 0.003 & $1.83 \mathrm{E}-57$ & 4.79E-35 & \\
\hline $\begin{array}{l}\text { Minimum distance from } \\
\text { cell body edge }(\mu \mathrm{m})\end{array}$ & 12.403 & 12.237 & 6.843 & 6.011 & 9.410 & 6.966 & $8.50 E-57$ & 7.06E-07 & $8.41 \mathrm{E}-44$ \\
\hline $\begin{array}{l}\text { Minimum distance from } \\
\text { nucleus edge }(\mu \mathrm{m})\end{array}$ & 8.641 & 8.573 & 15.422 & 9.469 & 19.069 & 9.462 & 8.09E-198 & $0.00 \mathrm{E}+00$ & $2.95 \mathrm{E}-43$ \\
\hline $\begin{array}{l}\text { Approximate depth in Z } \\
(\mu \mathrm{m})\end{array}$ & 0.454 & 0.100 & 0.413 & 0.134 & 0.387 & 0.149 & & $3.60 \mathrm{E}-180$ & \\
\hline $\begin{array}{l}\text { Minimum distance to the } \\
\text { next object }(\mu \mathrm{m})\end{array}$ & 0.668 & 0.328 & 0.952 & 1.179 & 0.809 & 0.788 & & & \\
\hline
\end{tabular}

Figure 24: EEA1, characterization in cell bodies, axons, and dendrites. Shown in the top panel is the DiO plasma membrane staining in green, the ankyrinG immunostaining in blue, and the EEA1 staining in red. All images were acquired by confocal microscopy taking stacks across entire neuronal cell bodies. The images shown are maximum projections of these stacks. The second row shows a merge image of the three markers. The other two images in the second row represent the objects extracted from the 
organelle staining during the analysis. The middle image shows the objects in the middle section of the z-stack, the third image shows all objects color-coded based on the z-level. The extracted objects were grouped dependent on their presence in the cell body, the axon, or the dendrite and parameters such as the area, and the percent of total volume for each object were extracted. The table shows the mean values and SDs for these parameters in the different regions. The parameters were compared between the different regions using a multiple comparison ranksum Mann-Whitney $U$ test and a Bonferroni correction. Significant differences are indicated in green. 20 neurons from 2 different cultures were analysed.

\section{EEA1}
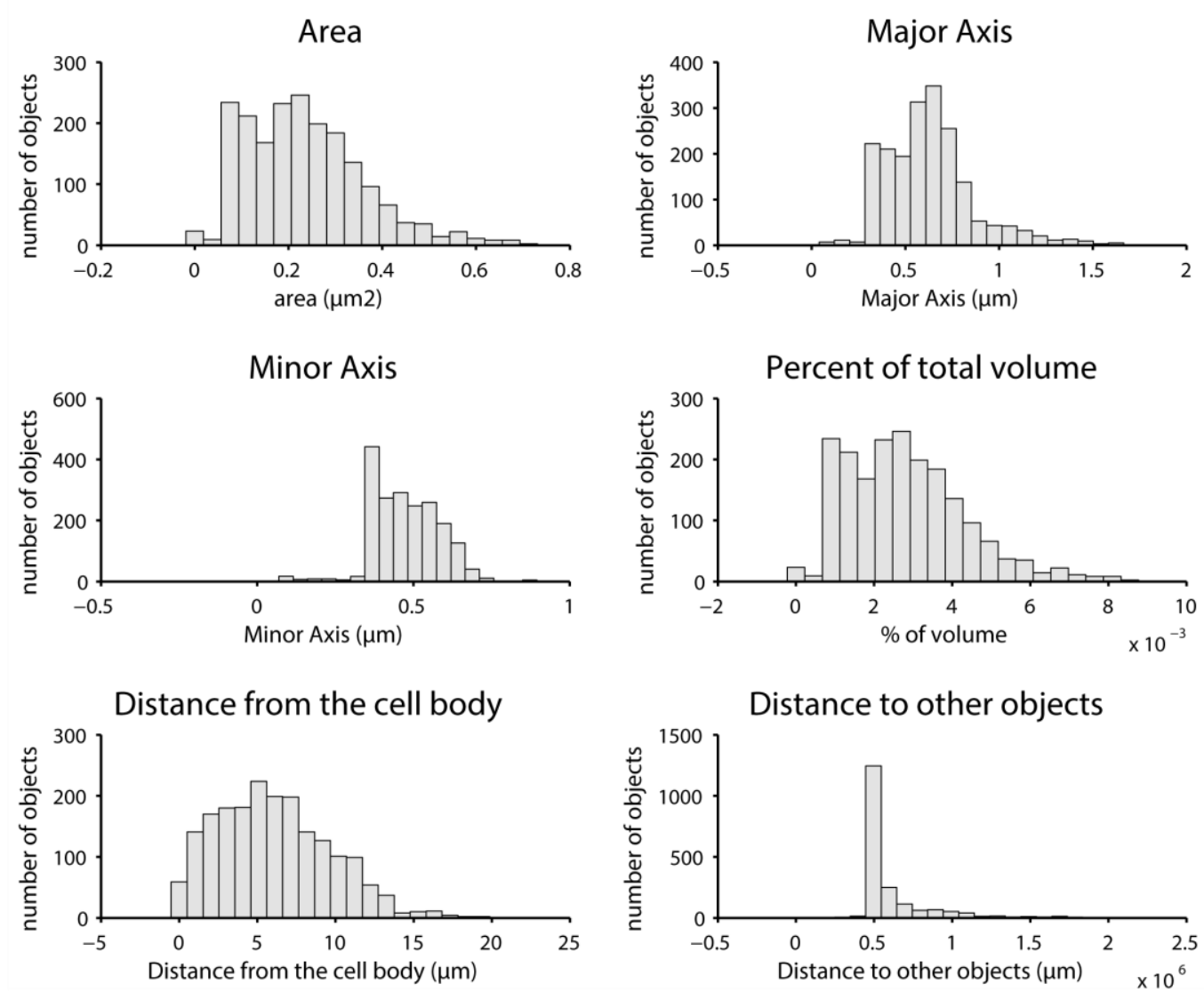

Figure 25: Distribution of EEA1. From the objects found during the analysis, I extracted several parameters including the area, the axis, the object volume, the distance to the cell body, and the distance to the neighbouring objects. These parameters are given here in the form of histograms. The bin size was chosen according to the data range. 


\section{ERp72}
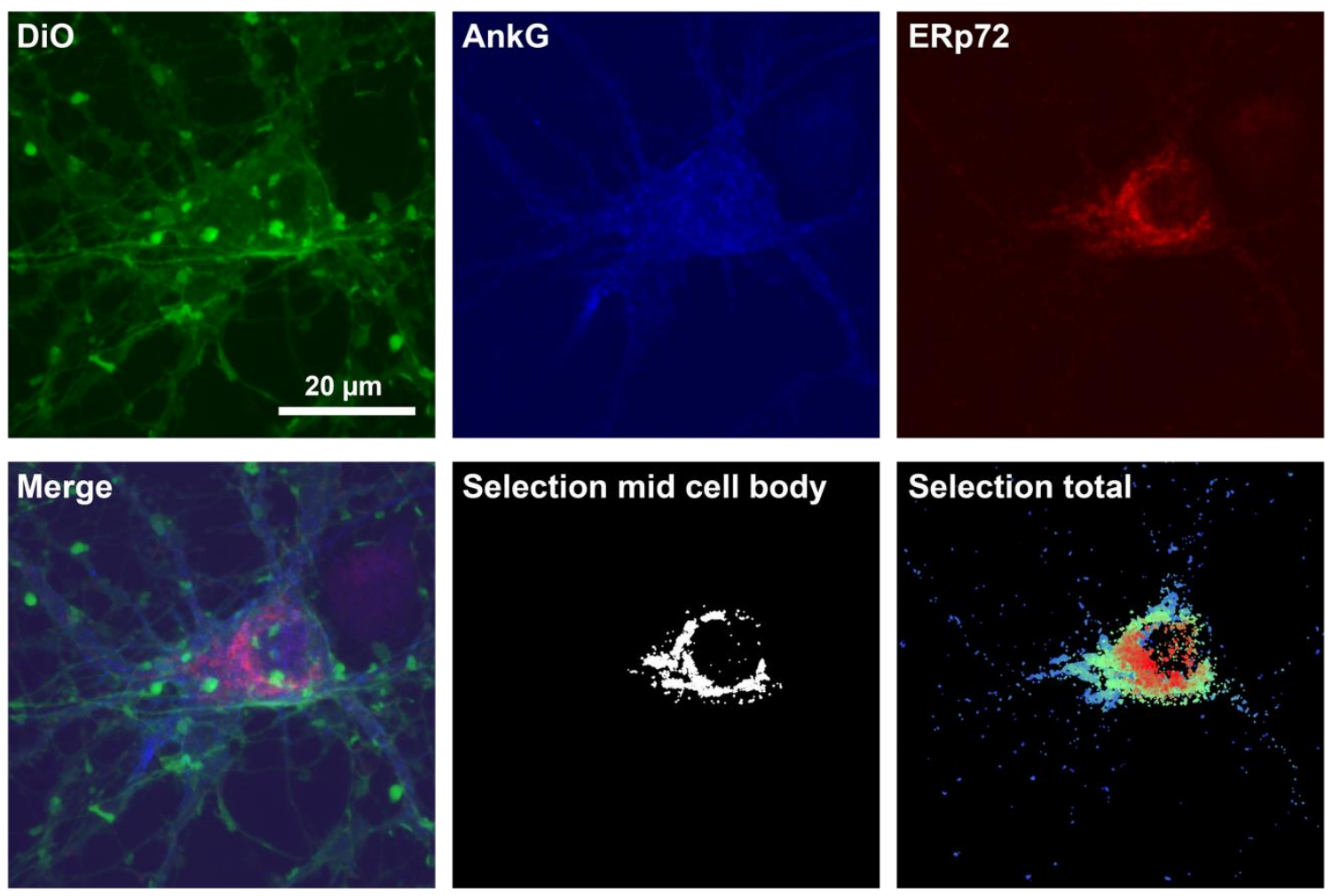

\begin{tabular}{|c|c|c|c|c|c|c|c|c|c|}
\hline properties & $\begin{array}{l}\text { Mean } \\
\text { cell } \\
\text { body }\end{array}$ & $\begin{array}{l}\text { SD cell } \\
\text { body }\end{array}$ & $\begin{array}{l}\text { Mean } \\
\text { axon }\end{array}$ & $\begin{array}{l}\text { SD } \\
\text { axon }\end{array}$ & $\begin{array}{l}\text { Mean } \\
\text { dendrites }\end{array}$ & $\begin{array}{l}\text { SD } \\
\text { dendrites }\end{array}$ & $\begin{array}{l}\text { P value cell } \\
\text { body vs. } \\
\text { axon }\end{array}$ & $\begin{array}{l}\text { P value cell } \\
\text { body vs. } \\
\text { dendrites }\end{array}$ & $\begin{array}{l}\text { P value } \\
\text { axon vs. } \\
\text { dendrites }\end{array}$ \\
\hline Area $\left(\mu \mathrm{m}^{2}\right)$ & 0.412 & 1.639 & 0.153 & 0.252 & 0.118 & 0.123 & $3.98 \mathrm{E}-34$ & $1.55 \mathrm{E}-133$ & $4.91 \mathrm{E}-22$ \\
\hline Major axis $(\mu \mathrm{m})$ & 0.739 & 0.987 & 0.506 & 0.339 & 0.443 & 0.247 & 4.49E-30 & $6.58 \mathrm{E}-106$ & $8.00 \mathrm{E}-16$ \\
\hline Minor axis $(\mu \mathrm{m})$ & 0.471 & 0.444 & 0.358 & 0.154 & 0.325 & 0.126 & $2.15 E-33$ & 4.29E-134 & \\
\hline $\begin{array}{l}\text { Equivalent circle } \\
\text { diameter }(\mu \mathrm{m})\end{array}$ & 0.531 & 0.494 & 0.398 & 0.191 & 0.356 & 0.153 & $3.98 \mathrm{E}-34$ & $1.55 \mathrm{E}-133$ & $4.91 \mathrm{E}-22$ \\
\hline Perimeter $(\mu \mathrm{m})$ & 2.382 & 5.189 & 1.373 & 1.201 & 1.175 & 0.767 & $1.69 \mathrm{E}-33$ & $2.64 \mathrm{E}-118$ & 1.20E-17 \\
\hline Percent of volume (\%) & 0.006 & 0.023 & 0.002 & 0.005 & 0.002 & 0.002 & $1.20 \mathrm{E}-29$ & $3.46 \mathrm{E}-126$ & $1.74 \mathrm{E}-22$ \\
\hline $\begin{array}{l}\text { Minimum distance from } \\
\text { cell body edge }(\mu \mathrm{m})\end{array}$ & 3.767 & 2.150 & 8.208 & 7.199 & 11.492 & 7.921 & 2.17E-163 & $0.00 \mathrm{E}+00$ & 7.70E-66 \\
\hline $\begin{array}{l}\text { Minimum distance from } \\
\text { nucleus edge }(\mu \mathrm{m})\end{array}$ & 8.258 & 8.417 & 21.923 & 9.937 & 23.267 & 10.390 & $0.00 \mathrm{E}+00$ & $0.00 \mathrm{E}+00$ & \\
\hline $\begin{array}{l}\text { Approximate depth in Z } \\
(\mu \mathrm{m})\end{array}$ & 0.471 & 0.444 & 0.358 & 0.154 & 0.325 & 0.126 & $2.15 \mathrm{E}-33$ & $4.29 \mathrm{E}-134$ & \\
\hline $\begin{array}{l}\text { Minimum distance to the } \\
\text { next object }(\mu \mathrm{m})\end{array}$ & 0.667 & 0.259 & 0.791 & 0.530 & 1.067 & 1.178 & $6.68 \mathrm{E}-06$ & $3.32 \mathrm{E}-41$ & $1.33 \mathrm{E}-10$ \\
\hline
\end{tabular}

Figure 26: ERp72, characterization in cell bodies, axons, and dendrites. Shown in the top panel is the DiO plasma membrane staining in green, the ankyring immunostaining in blue, and the ERp72 staining in red. All images were acquired by confocal microscopy taking stacks across entire neuronal cell bodies. The images shown are maximum projections of these stacks. The second row shows a merge image of the three markers. The other two images in the second row represent the objects extracted from the 
organelle staining during the analysis. The middle image shows the objects in the middle section of the z-stack, the third image shows all objects color-coded based on the z-level. The extracted objects were grouped dependent on their presence in the cell body, the axon, or the dendrite and parameters such as the area, and the percent of total volume for each object were extracted. The table shows the mean values and SDs for these parameters in the different regions. The parameters were compared between the different regions using a multiple comparison ranksum Mann-Whitney $U$ test and a Bonferroni correction. Significant differences are indicated in green. 20 neurons from 2 different cultures were analysed.

\section{ERp72}
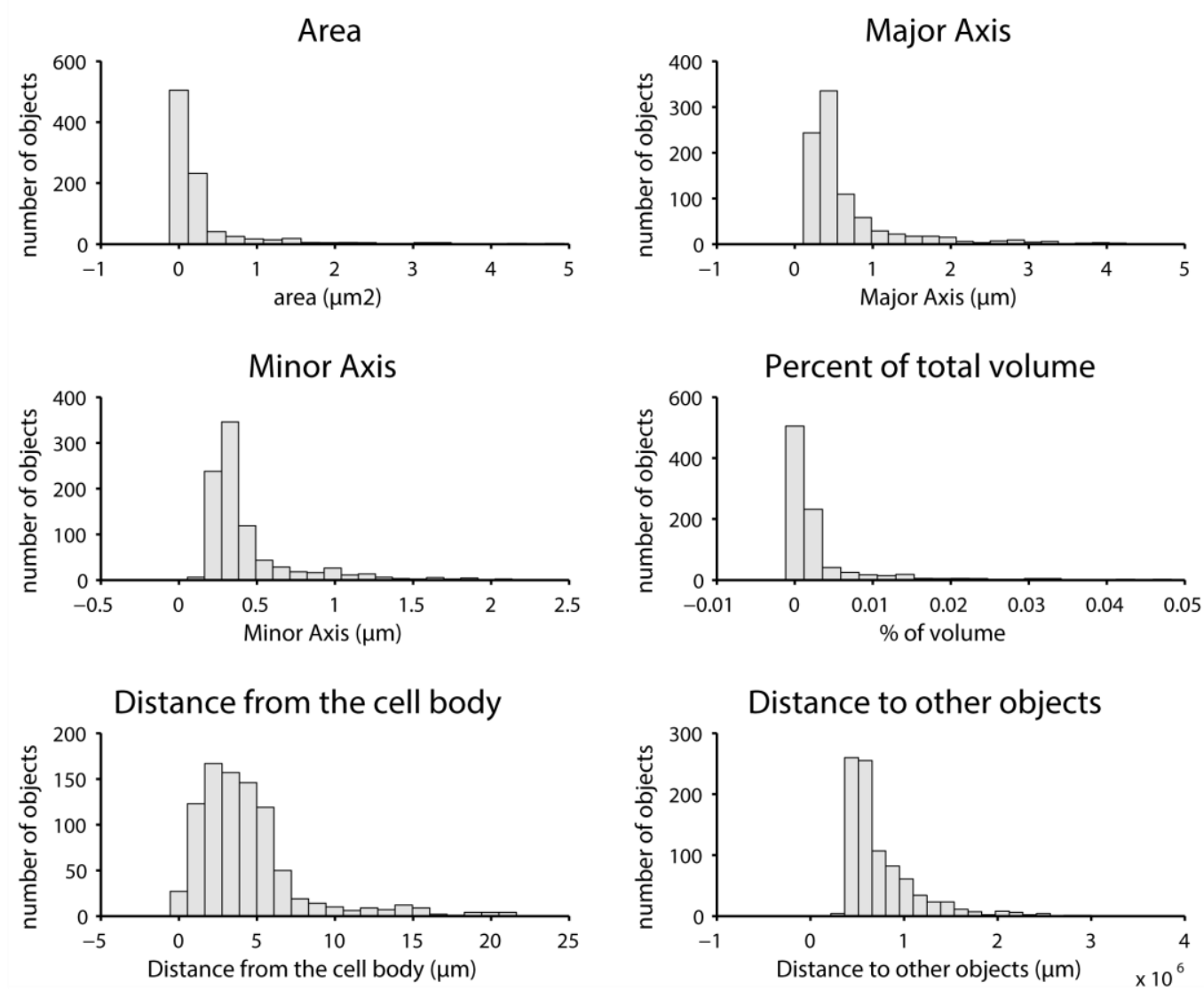

Figure 27: Distribution of ERp72. From the objects found during the analysis, I extracted several parameters including the area, the axis, the object volume, the distance to the cell body, and the distance to the neighbouring objects. These parameters are given here in the form of histograms. The bin size was chosen according to the data range. 


\section{fibrillarin}
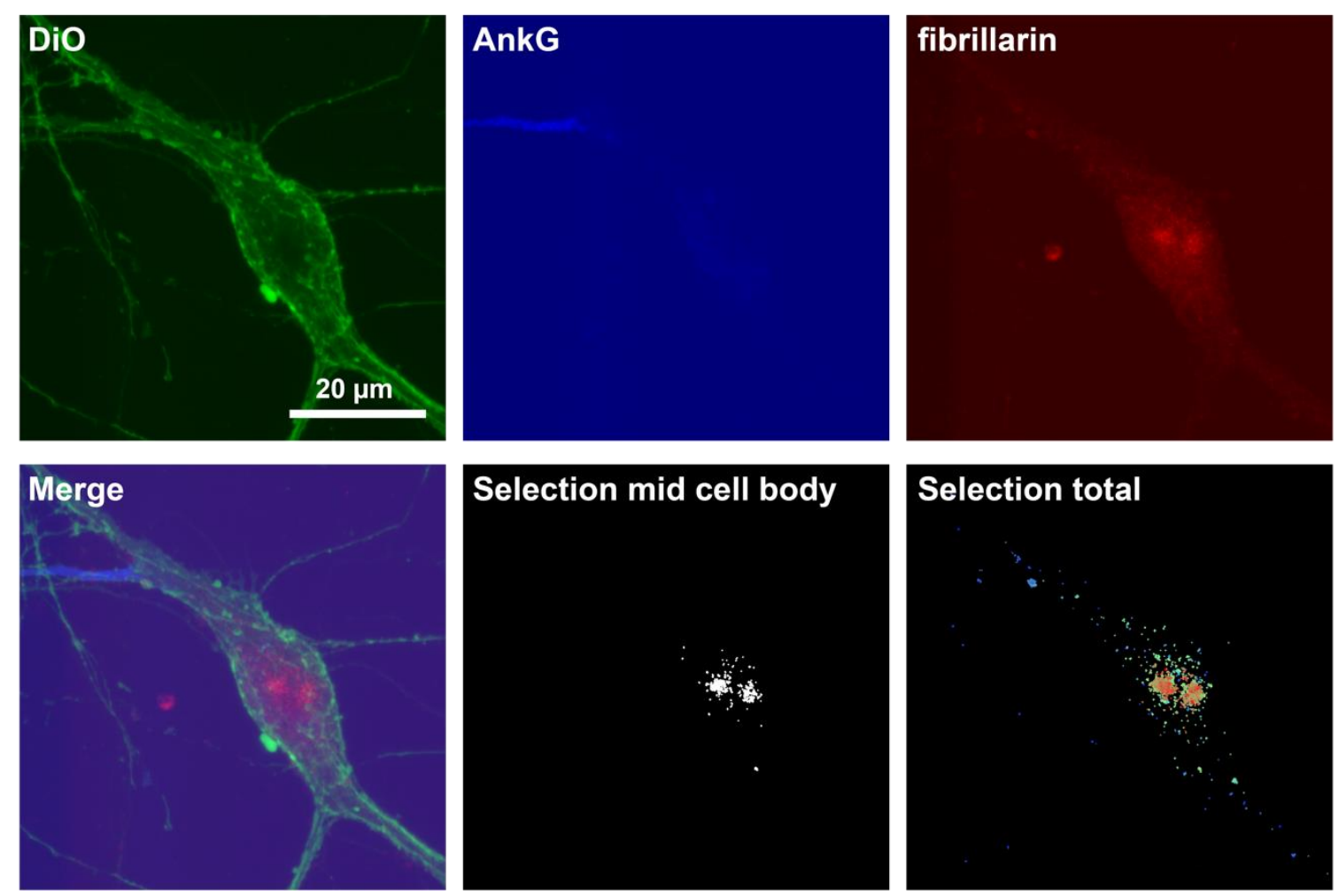

\begin{tabular}{|c|c|c|c|c|c|c|c|c|c|}
\hline properties & $\begin{array}{l}\text { Mean } \\
\text { cell } \\
\text { body }\end{array}$ & $\begin{array}{l}\text { SD cell } \\
\text { body }\end{array}$ & $\begin{array}{l}\text { Mean } \\
\text { axon }\end{array}$ & $\begin{array}{l}\text { SD } \\
\text { axon }\end{array}$ & $\begin{array}{l}\text { Mean } \\
\text { dendrites }\end{array}$ & $\begin{array}{l}\text { SD } \\
\text { dendrites }\end{array}$ & $\begin{array}{l}\text { P value cell } \\
\text { body vs. } \\
\text { axon }\end{array}$ & $\begin{array}{l}\text { P value cell } \\
\text { body vs. } \\
\text { dendrites }\end{array}$ & $\begin{array}{l}\text { P value } \\
\text { axon vs. } \\
\text { dendrites }\end{array}$ \\
\hline Area $\left(\mu \mathrm{m}^{2}\right)$ & 0.294 & 1.352 & 0.154 & 0.166 & 0.196 & 0.690 & & $2.89 \mathrm{E}-31$ & \\
\hline Major axis $(\mu \mathrm{m})$ & 0.593 & 0.650 & 0.515 & 0.249 & 0.508 & 0.470 & & $9.28 \mathrm{E}-14$ & \\
\hline Minor axis $(\mu \mathrm{m})$ & 0.411 & 0.390 & 0.368 & 0.171 & 0.354 & 0.294 & & $5.99 E-41$ & \\
\hline $\begin{array}{l}\text { Equivalent circle } \\
\text { diameter }(\mu \mathrm{m})\end{array}$ & 0.451 & 0.414 & 0.406 & 0.178 & 0.390 & 0.312 & & $2.89 E-31$ & \\
\hline Perimeter $(\mu \mathrm{m})$ & 1.911 & 4.341 & 1.442 & 1.039 & 1.515 & 2.542 & & $2.53 E-16$ & \\
\hline Percent of volume (\%) & 0.004 & 0.017 & 0.002 & 0.003 & 0.003 & 0.010 & & $4.49 \mathrm{E}-34$ & \\
\hline $\begin{array}{l}\text { Minimum distance from } \\
\text { cell body edge }(\mu \mathrm{m})\end{array}$ & 4.567 & 1.992 & 9.009 & 7.221 & 9.016 & 7.222 & $2.71 \mathrm{E}-06$ & $3.41 \mathrm{E}-105$ & \\
\hline $\begin{array}{l}\text { Minimum distance from } \\
\text { nucleus edge }(\mu \mathrm{m})\end{array}$ & 6.066 & 5.363 & 23.172 & 11.245 & 18.988 & 9.512 & $6.43 E-30$ & $0.00 \mathrm{E}+00$ & \\
\hline $\begin{array}{l}\text { Approximate depth in Z } \\
(\mu \mathrm{m})\end{array}$ & 0.411 & 0.390 & 0.368 & 0.171 & 0.354 & 0.294 & & $5.99 E-41$ & \\
\hline $\begin{array}{l}\text { Minimum distance to the } \\
\text { next object }(\mu \mathrm{m})\end{array}$ & 0.678 & 0.383 & 1.813 & 2.264 & 1.447 & 2.064 & 7.25E-06 & $2.56 \mathrm{E}-24$ & \\
\hline
\end{tabular}

Figure 28: Fibrillarin, characterization in cell bodies, axons, and dendrites. Shown in the top panel is the DiO plasma membrane staining in green, the ankyrinG immunostaining in blue, and the fibrillarin staining in red. All images were acquired by confocal microscopy taking stacks across entire neuronal cell bodies. The images shown are maximum projections of these stacks. The second row shows a merge image of the three markers. The other two images in the second row represent the objects extracted from the 
organelle staining during the analysis. The middle image shows the objects in the middle section of the z-stack, the third image shows all objects color-coded based on the z-level. The extracted objects were grouped dependent on their presence in the cell body, the axon, or the dendrite and parameters such as the area, and the percent of total volume for each object were extracted. The table shows the mean values and SDs for these parameters in the different regions. The parameters were compared between the different regions using a multiple comparison ranksum Mann-Whitney $U$ test and a Bonferroni correction. Significant differences are indicated in green. 20 neurons from 2 different cultures were analysed.

fibrillarin
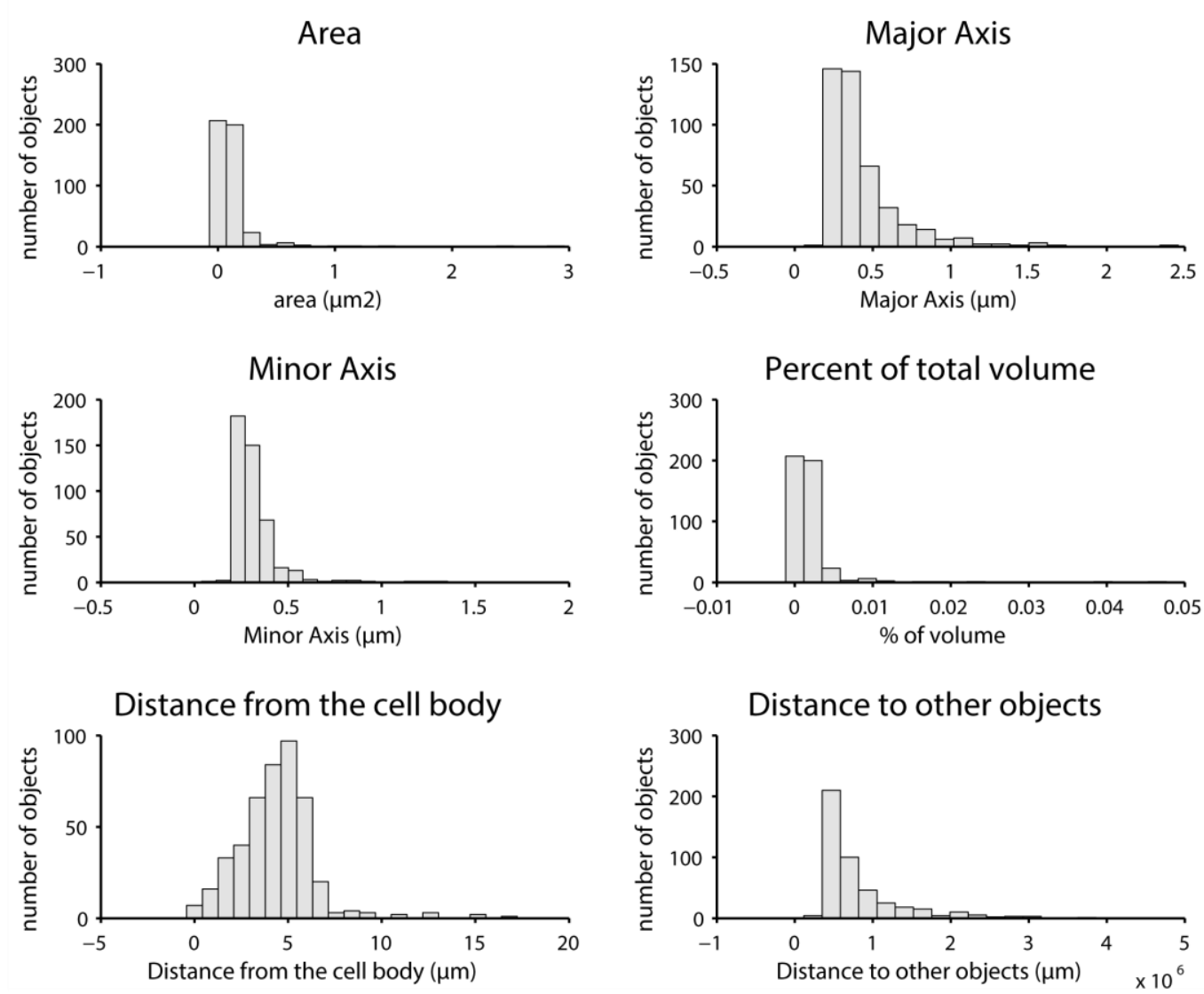

Figure 29: Distribution of fibrillarin. From the objects found during the analysis, I extracted several parameters including the area, the axis, the object volume, the distance to the cell body, and the distance to the neighbouring objects. These parameters are given here in the form of histograms. The bin size was chosen according to the data range. 


\section{GM130}
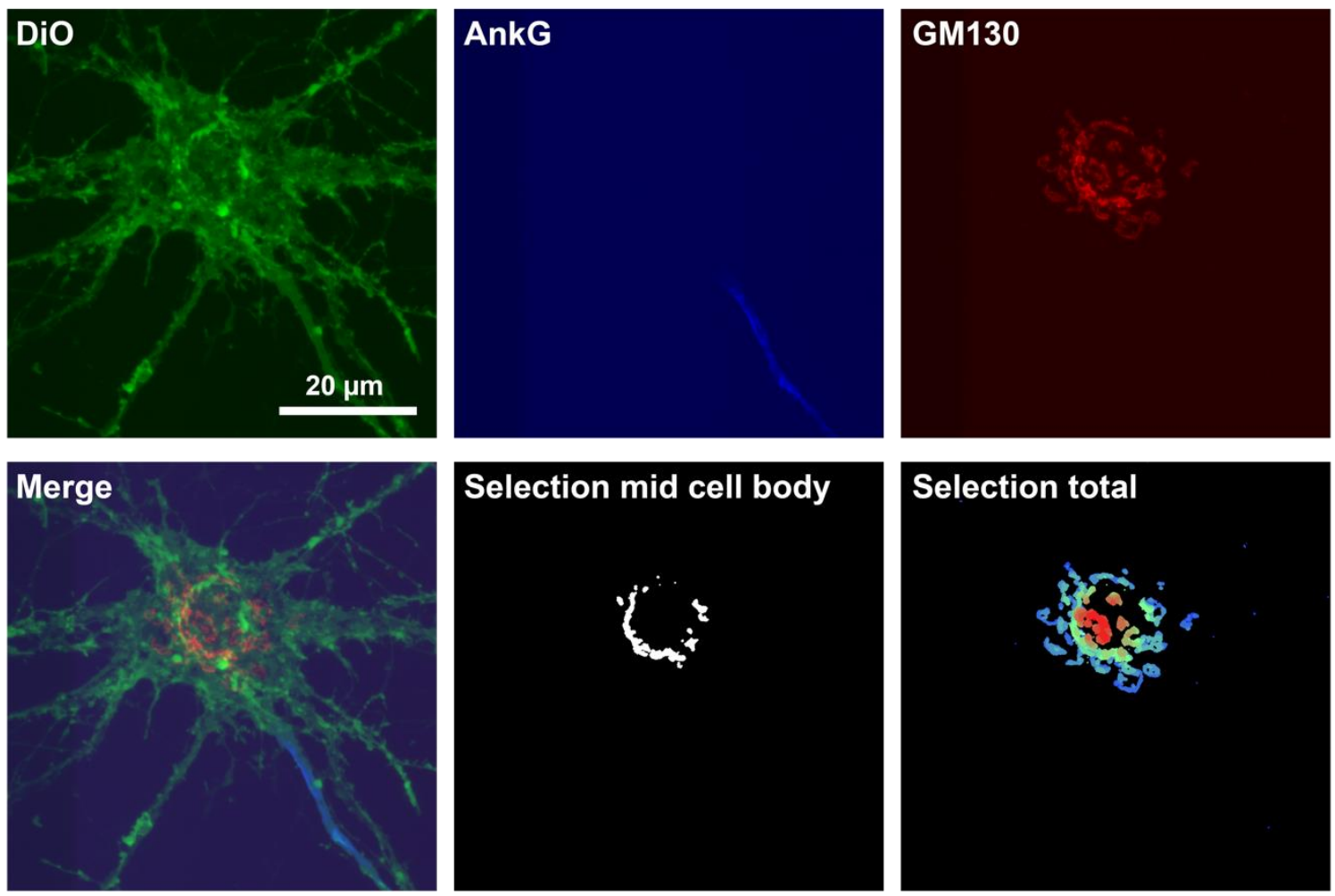

\begin{tabular}{|c|c|c|c|c|c|c|c|c|c|}
\hline properties & $\begin{array}{l}\text { Mean } \\
\text { cell } \\
\text { body }\end{array}$ & $\begin{array}{l}\text { SD cell } \\
\text { body }\end{array}$ & $\begin{array}{l}\text { Mean } \\
\text { axon }\end{array}$ & $\begin{array}{l}\text { SD } \\
\text { axon }\end{array}$ & $\begin{array}{l}\text { Mean } \\
\text { dendrites }\end{array}$ & $\begin{array}{l}\text { SD } \\
\text { dendrites }\end{array}$ & $\begin{array}{l}\text { P value cell } \\
\text { body vs. } \\
\text { axon }\end{array}$ & $\begin{array}{l}\text { P value cell } \\
\text { body vs. } \\
\text { dendrites }\end{array}$ & $\begin{array}{l}\text { P value } \\
\text { axon vs. } \\
\text { dendrites }\end{array}$ \\
\hline Area $\left(\mu \mathrm{m}^{2}\right)$ & 1.071 & 1.529 & 0.419 & 0.659 & 0.287 & 0.373 & & $1.90 \mathrm{E}-83$ & \\
\hline Major axis ( $\mu \mathrm{m})$ & 1.552 & 1.360 & 1.000 & 1.251 & 0.721 & 0.586 & & $2.98 \mathrm{E}-69$ & \\
\hline Minor axis $(\mu \mathrm{m})$ & 0.805 & 0.553 & 0.456 & 0.232 & 0.431 & 0.263 & & $3.70 \mathrm{E}-83$ & \\
\hline $\begin{array}{l}\text { Equivalent circle } \\
\text { diameter }(\mu \mathrm{m})\end{array}$ & 0.990 & 0.620 & 0.585 & 0.450 & 0.509 & 0.327 & & $1.90 \mathrm{E}-83$ & \\
\hline Perimeter $(\mu \mathrm{m})$ & 4.630 & 4.734 & 2.560 & 3.041 & 2.034 & 1.837 & & $4.84 E-68$ & \\
\hline Percent of volume (\%) & 0.014 & 0.022 & 0.007 & 0.013 & 0.004 & 0.006 & & 4.09E-71 & \\
\hline $\begin{array}{l}\text { Minimum distance from } \\
\text { cell body edge }(\mu \mathrm{m})\end{array}$ & 3.972 & 1.809 & 5.298 & 3.815 & 7.420 & 7.260 & & $3.79 \mathrm{E}-10$ & \\
\hline $\begin{array}{l}\text { Minimum distance from } \\
\text { nucleus edge }(\mu \mathrm{m})\end{array}$ & 5.247 & 4.730 & 13.095 & 5.456 & 13.454 & 9.426 & $1.09 \mathrm{E}-08$ & 4.27E-108 & \\
\hline $\begin{array}{l}\text { Approximate depth in Z } \\
(\mu \mathrm{m})\end{array}$ & 0.805 & 0.553 & 0.456 & 0.232 & 0.431 & 0.263 & & $3.70 E-83$ & \\
\hline $\begin{array}{l}\text { Minimum distance to the } \\
\text { next object }(\mu \mathrm{m})\end{array}$ & 0.720 & 0.453 & 3.054 & 4.055 & 2.452 & 4.198 & & & \\
\hline
\end{tabular}

Figure 30: GM130, characterization in cell bodies, axons, and dendrites. Shown in the top panel is the DiO plasma membrane staining in green, the ankyrinG immunostaining in blue, and the GM130 staining in red. All images were acquired by confocal microscopy taking stacks across entire neuronal cell bodies. The images shown are maximum projections of these stacks. The second row shows a merge image of the three markers. The other two images in the second row represent the objects extracted from the 
organelle staining during the analysis. The middle image shows the objects in the middle section of the z-stack, the third image shows all objects color-coded based on the z-level. The extracted objects were grouped dependent on their presence in the cell body, the axon, or the dendrite and parameters such as the area, and the percent of total volume for each object were extracted. The table shows the mean values and SDs for these parameters in the different regions. The parameters were compared between the different regions using a multiple comparison ranksum Mann-Whitney $U$ test and a Bonferroni correction. Significant differences are indicated in green. 20 neurons from 2 different cultures were analysed.

\section{GM130}
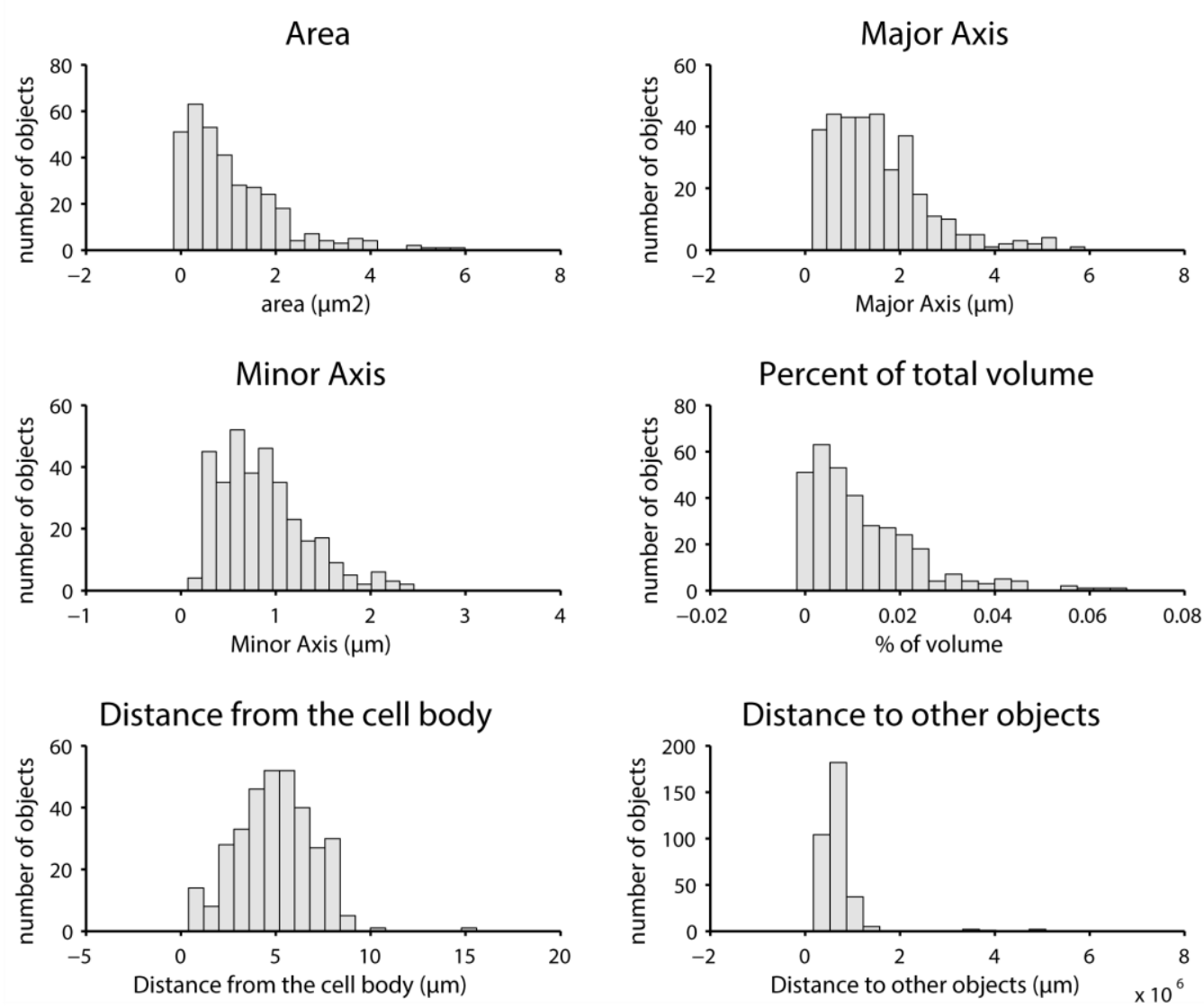

Figure 31: Distribution of GM130. From the objects found during the analysis, I extracted several parameters including the area, the axis, the object volume, the distance to the cell body, and the distance to the neighbouring objects. These parameters are given here in the form of histograms. The bin size was chosen according to the data range. 


\section{homer1}
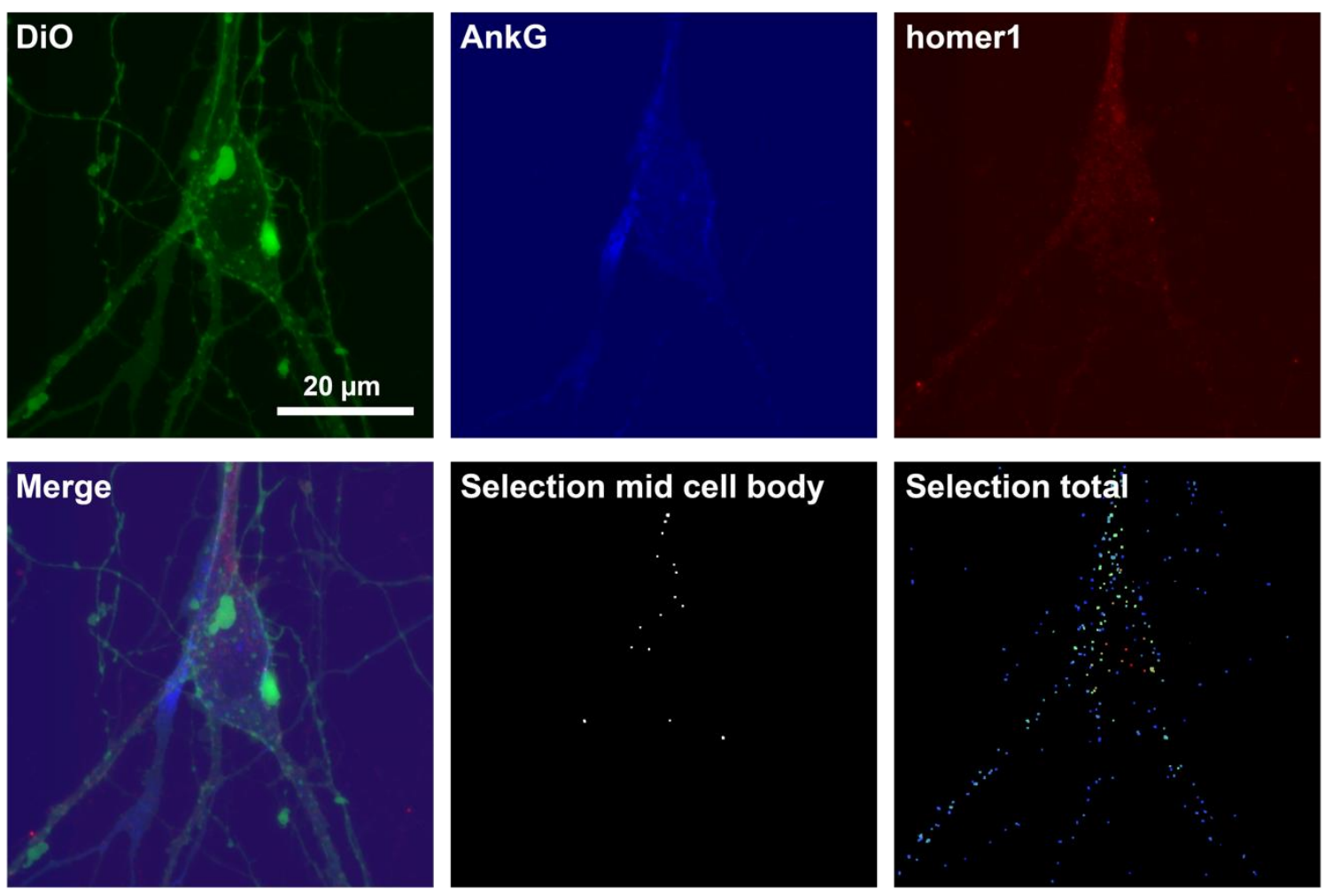

\begin{tabular}{|c|c|c|c|c|c|c|c|c|c|}
\hline properties & $\begin{array}{l}\text { Mean } \\
\text { cell } \\
\text { body }\end{array}$ & $\begin{array}{l}\text { SD cell } \\
\text { body }\end{array}$ & $\begin{array}{l}\text { Mean } \\
\text { axon }\end{array}$ & $\begin{array}{l}\text { SD } \\
\text { axon }\end{array}$ & $\begin{array}{l}\text { Mean } \\
\text { dendrites }\end{array}$ & $\begin{array}{l}\text { SD } \\
\text { dendrites }\end{array}$ & $\begin{array}{l}\text { P value cell } \\
\text { body vs. } \\
\text { axon }\end{array}$ & $\begin{array}{l}\text { P value cell } \\
\text { body vs. } \\
\text { dendrites }\end{array}$ & $\begin{array}{l}\text { P value } \\
\text { axon vs. } \\
\text { dendrites }\end{array}$ \\
\hline Area $\left(\mu \mathrm{m}^{2}\right)$ & 0.142 & 0.067 & 0.169 & 0.101 & 0.152 & 0.093 & $6.59 \mathrm{E}-11$ & & 4.98E-06 \\
\hline Major axis $(\mu \mathrm{m})$ & 0.468 & 0.147 & 0.518 & 0.192 & 0.494 & 0.194 & 3.93E-12 & & \\
\hline Minor axis $(\mu \mathrm{m})$ & 0.391 & 0.060 & 0.408 & 0.099 & 0.382 & 0.104 & & & \\
\hline $\begin{array}{l}\text { Equivalent circle } \\
\text { diameter }(\mu \mathrm{m})\end{array}$ & 0.416 & 0.087 & 0.446 & 0.129 & 0.420 & 0.130 & & & \\
\hline Perimeter $(\mu \mathrm{m})$ & 1.248 & 0.355 & 1.379 & 0.488 & 1.311 & 0.474 & & & \\
\hline Percent of volume (\%) & 0.002 & 0.001 & 0.002 & 0.002 & 0.002 & 0.002 & $6.16 \mathrm{E}-11$ & $1.42 \mathrm{E}-20$ & \\
\hline $\begin{array}{l}\text { Minimum distance from } \\
\text { cell body edge }(\mu \mathrm{m})\end{array}$ & 2.635 & 1.738 & 7.326 & 6.023 & 12.066 & 7.642 & $1.74 \mathrm{E}-102$ & $0.00 \mathrm{E}+00$ & $1.90 \mathrm{E}-55$ \\
\hline $\begin{array}{l}\text { Minimum distance from } \\
\text { nucleus edge }(\mu \mathrm{m})\end{array}$ & 6.633 & 7.977 & 15.668 & 10.198 & 19.946 & 10.914 & 3.70E-149 & $0.00 \mathrm{E}+00$ & $1.29 \mathrm{E}-29$ \\
\hline $\begin{array}{l}\text { Approximate depth in Z } \\
(\mu \mathrm{m})\end{array}$ & 0.391 & 0.060 & 0.408 & 0.099 & 0.382 & 0.104 & & & \\
\hline $\begin{array}{l}\text { Minimum distance to the } \\
\text { next object }(\mu \mathrm{m})\end{array}$ & 0.940 & 0.627 & 0.872 & 0.877 & 1.054 & 1.248 & & $1.08 \mathrm{E}-11$ & \\
\hline
\end{tabular}

Figure 32: Homer1, characterization in cell bodies, axons, and dendrites. Shown in the top panel is the DiO plasma membrane staining in green, the ankyring immunostaining in blue, and the Homer1 staining in red. All images were acquired by confocal microscopy taking stacks across entire neuronal cell bodies. The images shown are maximum projections of these stacks. The second row shows a merge image of the three markers. The other two images in the second row represent the objects extracted from the 
organelle staining during the analysis. The middle image shows the objects in the middle section of the z-stack, the third image shows all objects color-coded based on the z-level. The extracted objects were grouped dependent on their presence in the cell body, the axon, or the dendrite and parameters such as the area, and the percent of total volume for each object were extracted. The table shows the mean values and SDs for these parameters in the different regions. The parameters were compared between the different regions using a multiple comparison ranksum Mann-Whitney $U$ test and a Bonferroni correction. Significant differences are indicated in green. 20 neurons from 2 different cultures were analysed.

homer1
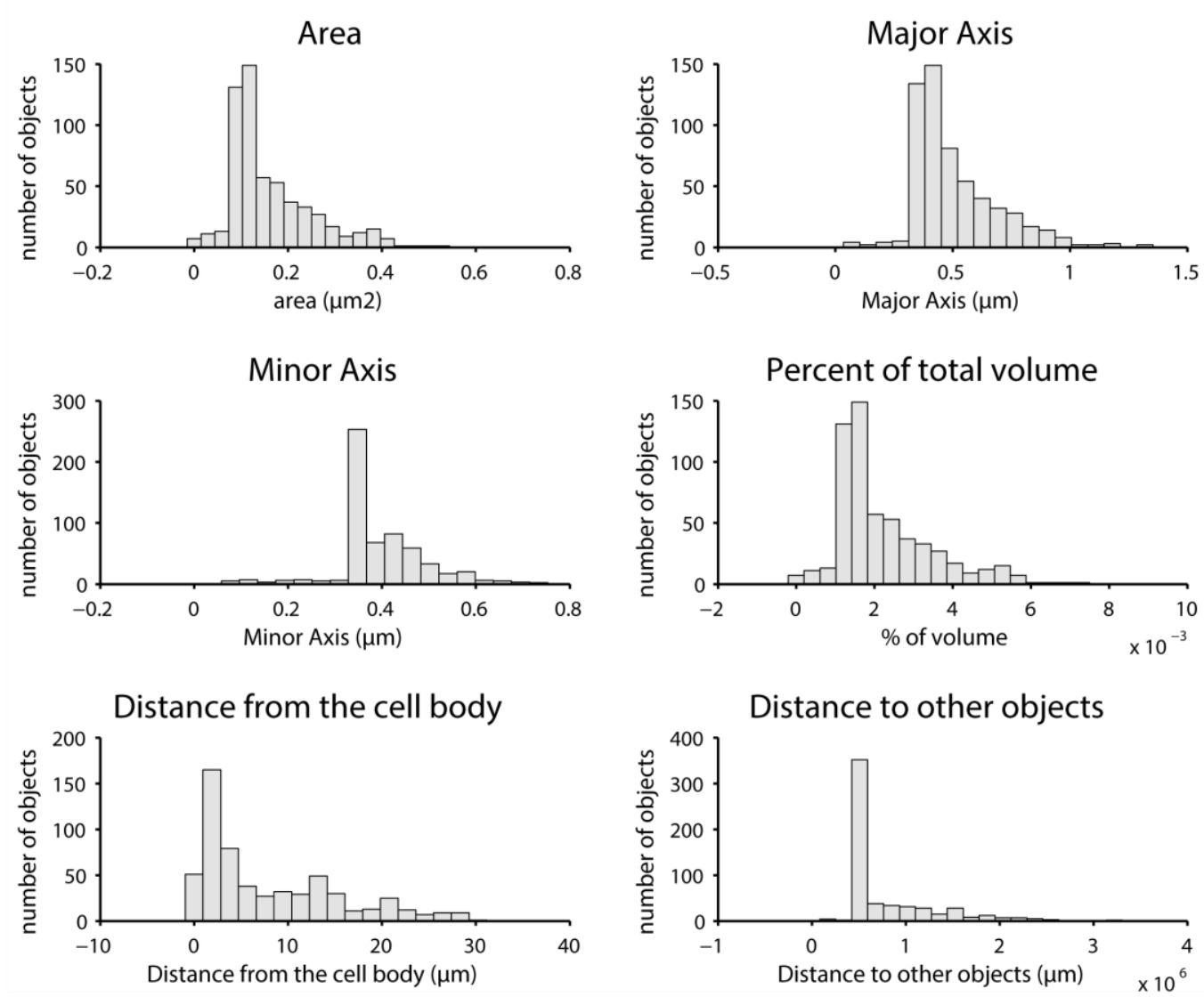

Figure 33: Distribution of Homer1. From the objects found during the analysis, l extracted several parameters including the area, the axis, the object volume, the distance to the cell body, and the distance to the neighbouring objects. These parameters are given here in the form of histograms. The bin size was chosen according to the data range. 


\section{internexin}
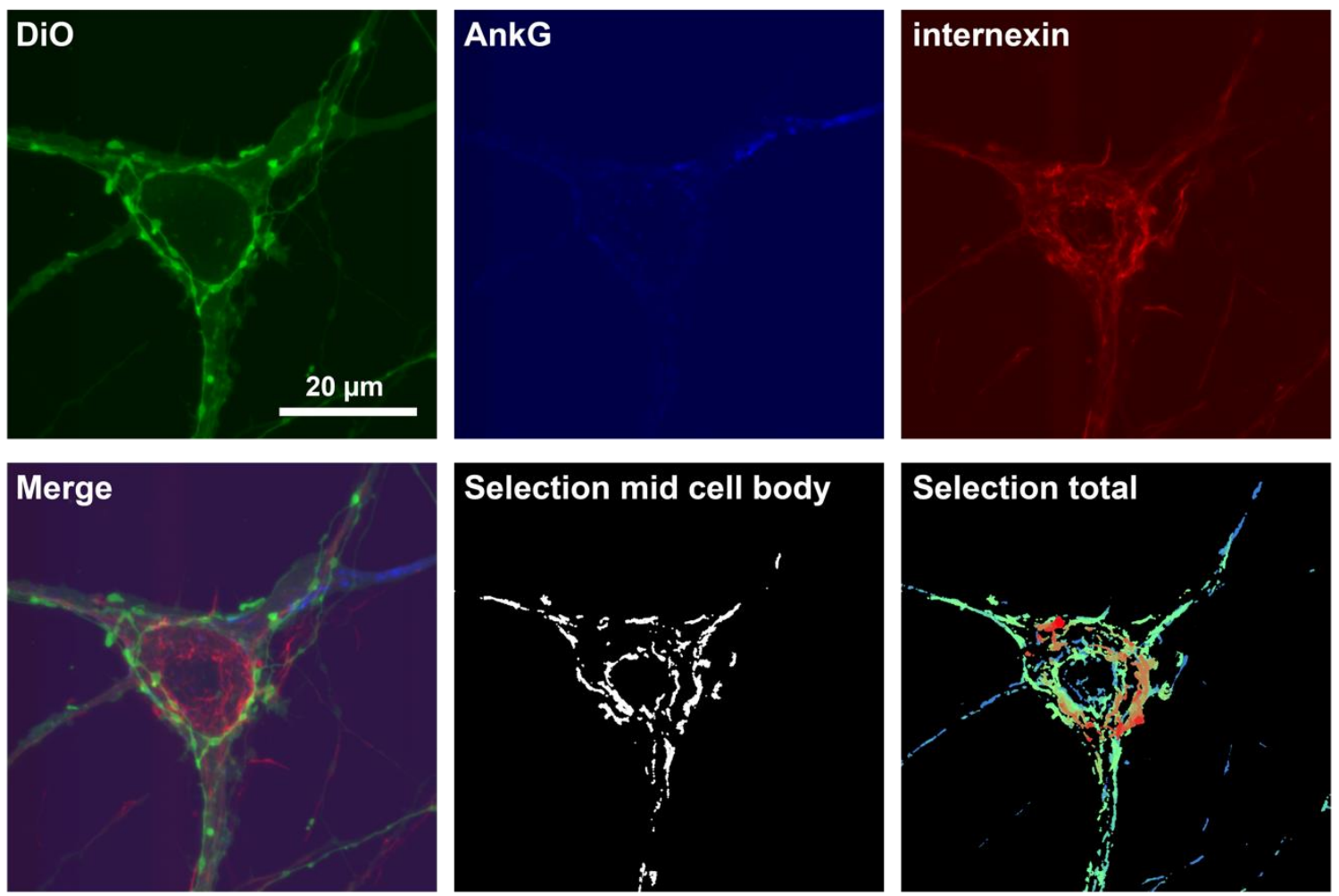

\begin{tabular}{|c|c|c|c|c|c|c|c|c|c|}
\hline properties & $\begin{array}{l}\text { Mean } \\
\text { cell } \\
\text { body }\end{array}$ & $\begin{array}{l}\text { SD cell } \\
\text { body }\end{array}$ & $\begin{array}{l}\text { Mean } \\
\text { axon }\end{array}$ & $\begin{array}{l}\text { SD } \\
\text { axon }\end{array}$ & $\begin{array}{l}\text { Mean } \\
\text { dendrites }\end{array}$ & $\begin{array}{l}\text { SD } \\
\text { dendrites }\end{array}$ & $\begin{array}{l}\text { P value cell } \\
\text { body vs. } \\
\text { axon }\end{array}$ & $\begin{array}{l}\text { P value cell } \\
\text { body vs. } \\
\text { dendrites }\end{array}$ & $\begin{array}{l}\text { P value } \\
\text { axon vs. } \\
\text { dendrites }\end{array}$ \\
\hline Area $\left(\mu \mathrm{m}^{2}\right)$ & 0.857 & 2.488 & 1.064 & 1.938 & 0.395 & 0.879 & & $1.60 \mathrm{E}-114$ & $1.61 \mathrm{E}-40$ \\
\hline Major axis $(\mu \mathrm{m})$ & 1.359 & 1.784 & 2.061 & 2.681 & 1.048 & 1.435 & $2.91 \mathrm{E}-07$ & $3.83 E-53$ & $2.15 \mathrm{E}-34$ \\
\hline Minor axis $(\mu \mathrm{m})$ & 0.604 & 0.676 & 0.564 & 0.536 & 0.367 & 0.315 & & $5.80 \mathrm{E}-179$ & $8.18 \mathrm{E}-38$ \\
\hline $\begin{array}{l}\text { Equivalent circle } \\
\text { diameter }(\mu \mathrm{m})\end{array}$ & 0.762 & 0.714 & 0.874 & 0.770 & 0.522 & 0.480 & & $1.60 \mathrm{E}-114$ & $1.61 \mathrm{E}-40$ \\
\hline Perimeter $(\mu \mathrm{m})$ & 4.024 & 6.926 & 5.520 & 7.567 & 2.924 & 4.011 & $2.09 \mathrm{E}-07$ & $2.45 \mathrm{E}-29$ & $5.83 \mathrm{E}-26$ \\
\hline Percent of volume (\%) & 0.015 & 0.040 & 0.019 & 0.034 & 0.008 & 0.018 & & 5.25E-101 & 2.10E-41 \\
\hline $\begin{array}{l}\text { Minimum distance from } \\
\text { cell body edge }(\mu \mathrm{m})\end{array}$ & 3.123 & 1.949 & 8.562 & 7.256 & 13.329 & 8.387 & $1.18 \mathrm{E}-90$ & $0.00 \mathrm{E}+00$ & 4.94E-53 \\
\hline $\begin{array}{l}\text { Minimum distance from } \\
\text { nucleus edge }(\mu \mathrm{m})\end{array}$ & 5.789 & 5.049 & 17.045 & 9.150 & 22.344 & 9.542 & $6.18 \mathrm{E}-233$ & $0.00 \mathrm{E}+00$ & $2.79 E-44$ \\
\hline $\begin{array}{l}\text { Approximate depth in Z } \\
(\mu \mathrm{m})\end{array}$ & 0.604 & 0.676 & 0.564 & 0.536 & 0.367 & 0.315 & & 5.80E-179 & $8.18 \mathrm{E}-38$ \\
\hline $\begin{array}{l}\text { Minimum distance to the } \\
\text { next object }(\mu \mathrm{m})\end{array}$ & 0.763 & 0.387 & 0.820 & 0.686 & 0.781 & 0.837 & & & \\
\hline
\end{tabular}

Figure 34: Internexin, characterization in cell bodies, axons, and dendrites. Shown in the top panel is the DiO plasma membrane staining in green, the ankyrinG immunostaining in blue, and the internexin staining in red. All images were acquired by confocal microscopy taking stacks across entire neuronal cell bodies. The images shown are maximum projections of these stacks. The second row shows a merge image of the three markers. The other two images in the second row represent the objects extracted from the 
organelle staining during the analysis. The middle image shows the objects in the middle section of the z-stack, the third image shows all objects color-coded based on the z-level. The extracted objects were grouped dependent on their presence in the cell body, the axon, or the dendrite and parameters such as the area, and the percent of total volume for each object were extracted. The table shows the mean values and SDs for these parameters in the different regions. The parameters were compared between the different regions using a multiple comparison ranksum Mann-Whitney $U$ test and a Bonferroni correction. Significant differences are indicated in green. 20 neurons from 2 different cultures were analysed.

internexin
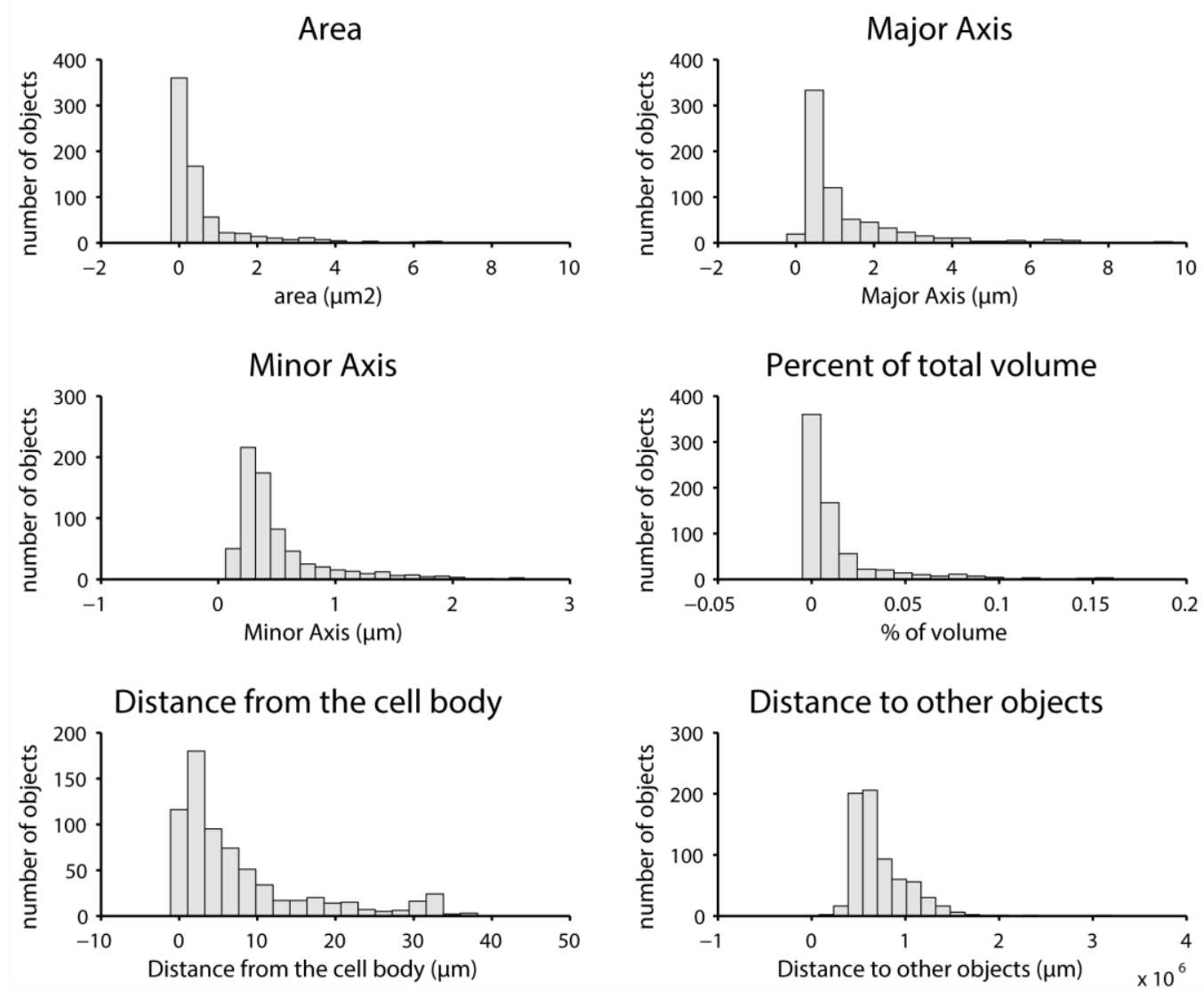

Figure 35: Distribution of Internexin. From the objects found during the analysis, I extracted several parameters including the area, the axis, the object volume, the distance to the cell body, and the distance to the neighbouring objects. These parameters are given here in the form of histograms. The bin size was chosen according to the data range. 


\section{lamp1}
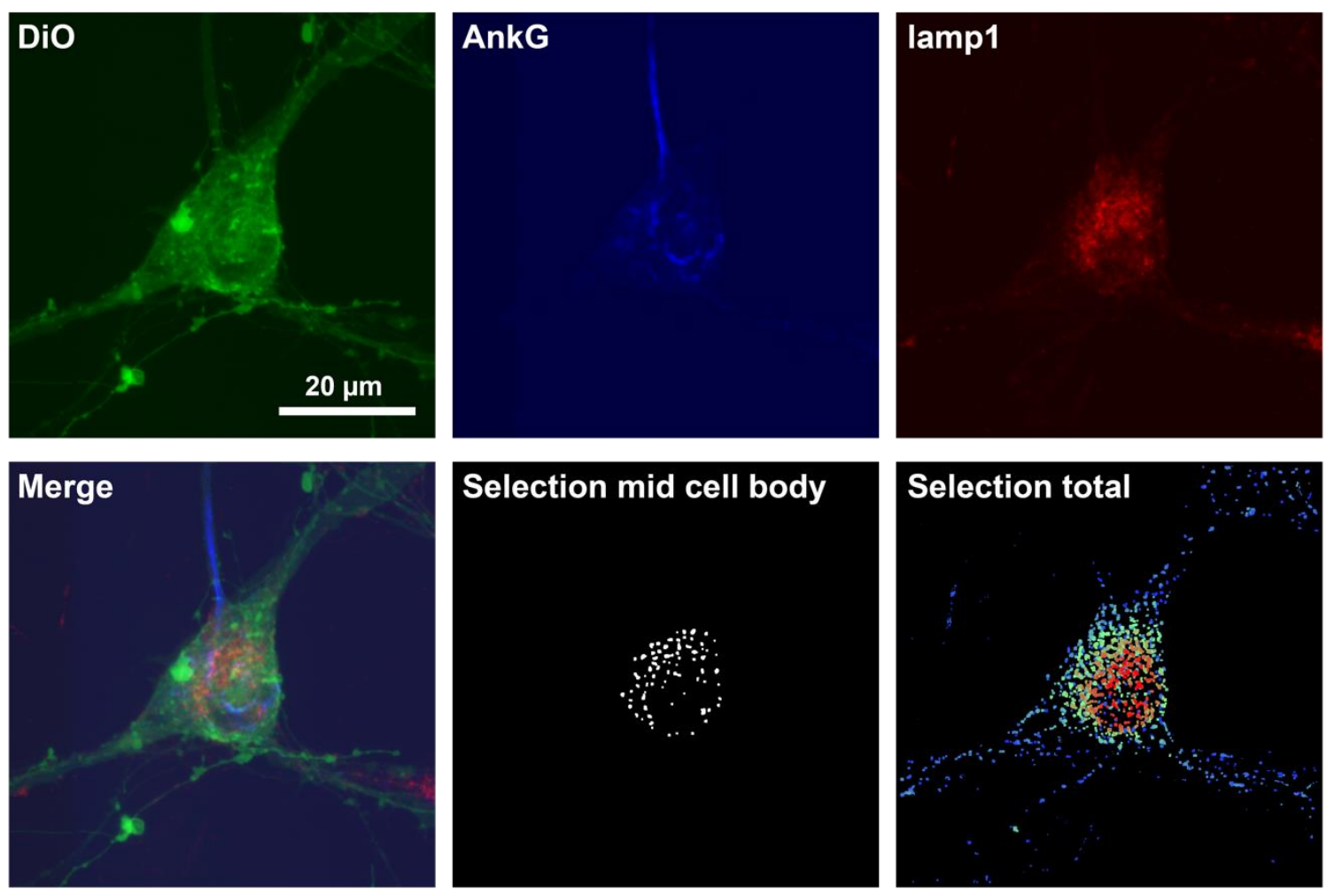

\begin{tabular}{|c|c|c|c|c|c|c|c|c|c|}
\hline properties & $\begin{array}{l}\text { Mean } \\
\text { cell } \\
\text { body }\end{array}$ & $\begin{array}{l}\text { SD cell } \\
\text { body }\end{array}$ & $\begin{array}{l}\text { Mean } \\
\text { axon }\end{array}$ & $\begin{array}{l}\text { SD } \\
\text { axon }\end{array}$ & $\begin{array}{l}\text { Mean } \\
\text { dendrites }\end{array}$ & $\begin{array}{l}\text { SD } \\
\text { dendrites }\end{array}$ & $\begin{array}{l}\text { P value cell } \\
\text { body vs. } \\
\text { axon }\end{array}$ & $\begin{array}{l}\text { P value cell } \\
\text { body vs. } \\
\text { dendrites }\end{array}$ & $\begin{array}{l}\text { P value } \\
\text { axon vs. } \\
\text { dendrites }\end{array}$ \\
\hline Area $\left(\mu \mathrm{m}^{2}\right)$ & 0.278 & 0.211 & 0.198 & 0.167 & 0.139 & 0.119 & $1.74 \mathrm{E}-304$ & $0.00 \mathrm{E}+00$ & $5.44 \mathrm{E}-124$ \\
\hline Major axis $(\mu \mathrm{m})$ & 0.696 & 0.349 & 0.593 & 0.317 & 0.487 & 0.264 & 4.15E-135 & $0.00 \mathrm{E}+00$ & 4.37E-92 \\
\hline Minor axis $(\mu \mathrm{m})$ & 0.493 & 0.141 & 0.399 & 0.159 & 0.330 & 0.155 & $0.00 \mathrm{E}+00$ & $0.00 \mathrm{E}+00$ & $3.23 \mathrm{E}-130$ \\
\hline $\begin{array}{l}\text { Equivalent circle } \\
\text { diameter }(\mu \mathrm{m})\end{array}$ & 0.564 & 0.191 & 0.462 & 0.196 & 0.379 & 0.182 & $1.74 \mathrm{E}-304$ & $0.00 \mathrm{E}+00$ & $5.44 \mathrm{E}-124$ \\
\hline Perimeter $(\mu \mathrm{m})$ & 1.853 & 0.916 & 1.582 & 0.820 & 1.318 & 0.664 & 2.67E-140 & $0.00 \mathrm{E}+00$ & $5.63 \mathrm{E}-80$ \\
\hline Percent of volume (\%) & 0.004 & 0.003 & 0.004 & 0.004 & 0.002 & 0.002 & & $0.00 \mathrm{E}+00$ & $1.53 \mathrm{E}-137$ \\
\hline $\begin{array}{l}\text { Minimum distance from } \\
\text { cell body edge }(\mu \mathrm{m})\end{array}$ & 3.984 & 2.227 & 7.993 & 6.725 & 10.765 & 7.495 & $0.00 \mathrm{E}+00$ & $0.00 \mathrm{E}+00$ & $7.06 \mathrm{E}-113$ \\
\hline $\begin{array}{l}\text { Minimum distance from } \\
\text { nucleus edge }(\mu \mathrm{m})\end{array}$ & 5.320 & 4.418 & 17.598 & 8.128 & 20.345 & 8.480 & $0.00 \mathrm{E}+00$ & $0.00 \mathrm{E}+00$ & $1.68 \mathrm{E}-86$ \\
\hline $\begin{array}{l}\text { Approximate depth in Z } \\
(\mu \mathrm{m})\end{array}$ & 0.493 & 0.141 & 0.399 & 0.159 & 0.330 & 0.155 & $0.00 \mathrm{E}+00$ & $0.00 \mathrm{E}+00$ & $3.23 \mathrm{E}-130$ \\
\hline $\begin{array}{l}\text { Minimum distance to the } \\
\text { next object }(\mu \mathrm{m})\end{array}$ & 0.602 & 0.185 & 0.616 & 0.295 & 0.751 & 0.680 & & $1.36 \mathrm{E}-07$ & \\
\hline
\end{tabular}

Figure 36: LAMP1, characterization in cell bodies, axons, and dendrites. Shown in the top panel is the DiO plasma membrane staining in green, the ankyring immunostaining in blue, and the LAMP1 staining in red. All images were acquired by confocal microscopy taking stacks across entire neuronal cell bodies. The images shown are maximum projections of these stacks. The second row shows a merge image of the three markers. The other two images in the second row represent the objects extracted from the 
organelle staining during the analysis. The middle image shows the objects in the middle section of the z-stack, the third image shows all objects color-coded based on the z-level. The extracted objects were grouped dependent on their presence in the cell body, the axon, or the dendrite and parameters such as the area, and the percent of total volume for each object were extracted. The table shows the mean values and SDs for these parameters in the different regions. The parameters were compared between the different regions using a multiple comparison ranksum Mann-Whitney $U$ test and a Bonferroni correction. Significant differences are indicated in green. 20 neurons from 2 different cultures were analysed.

\section{LAMP1}
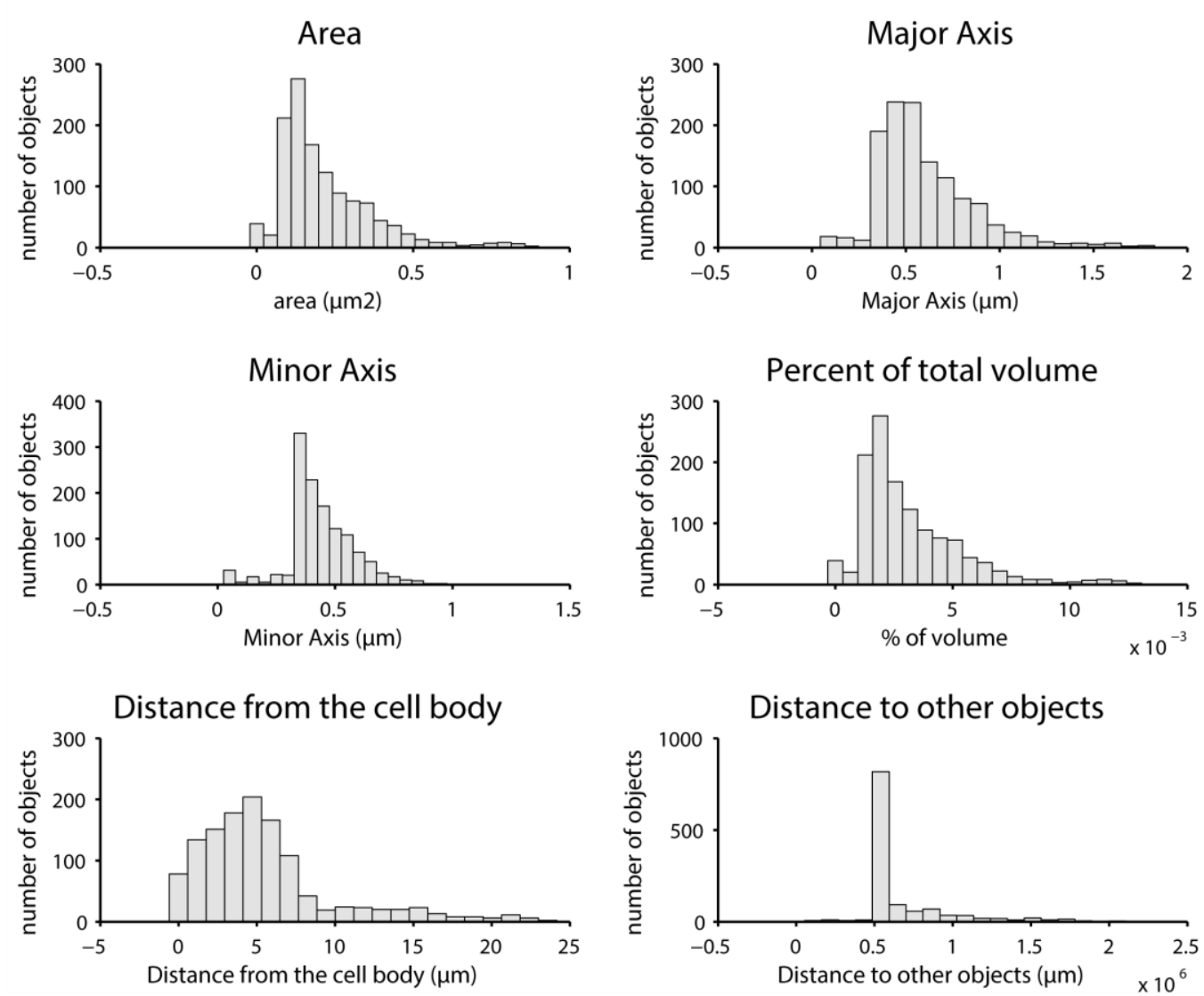

Figure 37: Distribution of LAMP1. From the objects found during the analysis, l extracted several parameters including the area, the axis, the object volume, the distance to the cell body, and the distance to the neighbouring objects. These parameters are given here in the form of histograms. The bin size was chosen according to the data range. 


\section{map2}
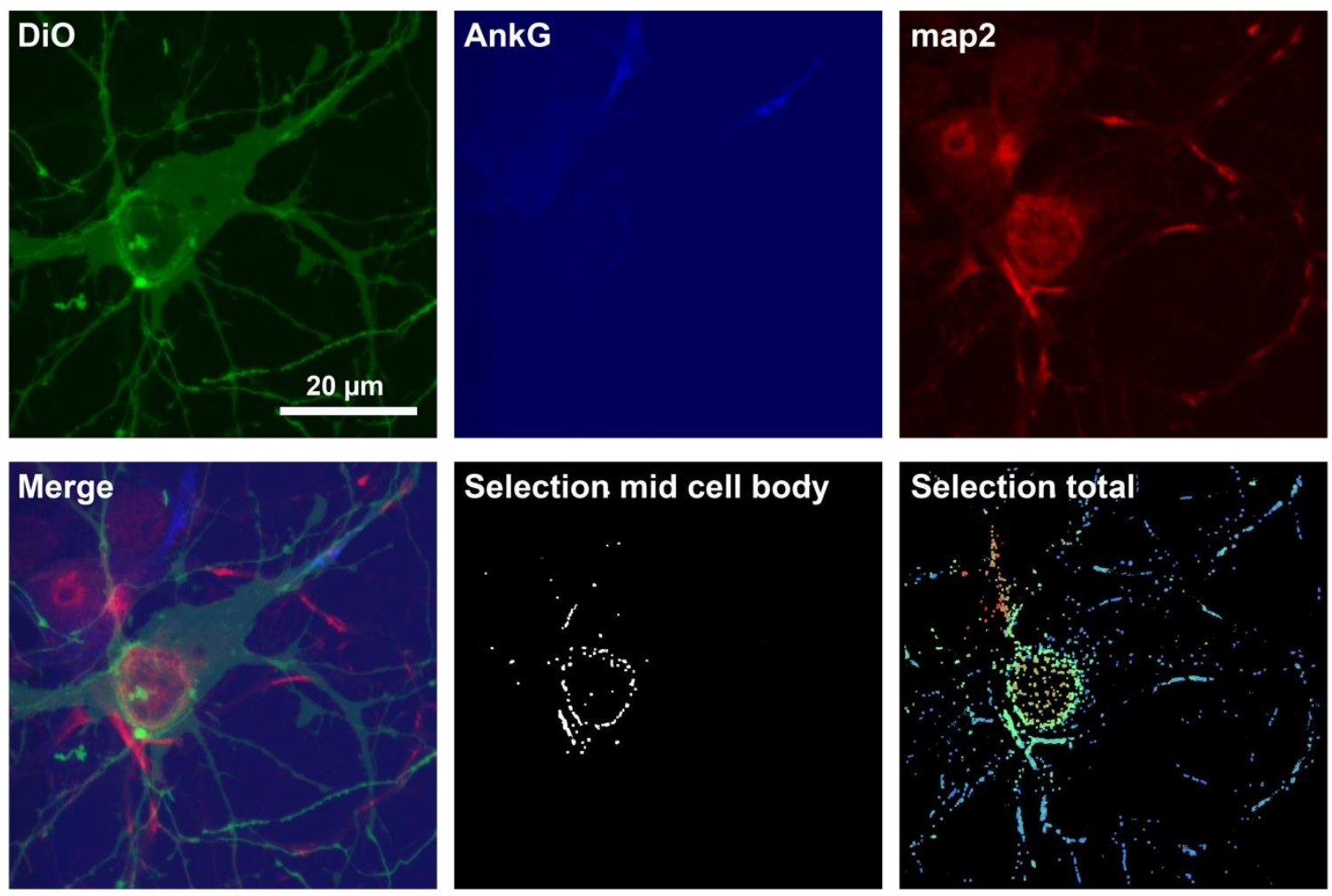

\begin{tabular}{|c|c|c|c|c|c|c|c|c|c|}
\hline properties & $\begin{array}{l}\text { Mean } \\
\text { cell } \\
\text { body }\end{array}$ & $\begin{array}{l}\text { SD cell } \\
\text { body }\end{array}$ & $\begin{array}{l}\text { Mean } \\
\text { axon }\end{array}$ & $\begin{array}{l}\text { SD } \\
\text { axon }\end{array}$ & $\begin{array}{l}\text { Mean } \\
\text { dendrites }\end{array}$ & $\begin{array}{l}\text { SD } \\
\text { dendrites }\end{array}$ & $\begin{array}{l}\text { P value cell } \\
\text { body vs. } \\
\text { axon }\end{array}$ & $\begin{array}{l}\text { P value cell } \\
\text { body vs. } \\
\text { dendrites }\end{array}$ & $\begin{array}{l}\text { P value } \\
\text { axon vs. } \\
\text { dendrites }\end{array}$ \\
\hline Area $\left(\mu \mathrm{m}^{2}\right)$ & 0,275 & 0,450 & 0,189 & 0,228 & 0,160 & 0,189 & $9,18 \mathrm{E}-14$ & $7,82 \mathrm{E}-221$ & 2,88E-09 \\
\hline Major axis $(\mu \mathrm{m})$ & 0,726 & 0,781 & 0,582 & 0,483 & 0,528 & 0,409 & 2,07E-09 & $1,83 \mathrm{E}-121$ & \\
\hline Minor axis $(\mu \mathrm{m})$ & 0,449 & 0,163 & 0,390 & 0,113 & 0,344 & 0,145 & $8,09 E-15$ & $1,75 E-274$ & $9,04 \mathrm{E}-13$ \\
\hline $\begin{array}{l}\text { Equivalent circle } \\
\text { diameter }(\mu \mathrm{m})\end{array}$ & 0,529 & 0,265 & 0,450 & 0,196 & 0,401 & 0,207 & $9,18 \mathrm{E}-14$ & $7,82 \mathrm{E}-221$ & $2,88 \mathrm{E}-09$ \\
\hline Perimeter $(\mu \mathrm{m})$ & 1,884 & 1,885 & 1,529 & 1,074 & 1,421 & 0,975 & $3,59 \mathrm{E}-08$ & $2,77 E-97$ & \\
\hline Percent of volume (\%) & 0,004 & 0,006 & 0,003 & 0,003 & 0,002 & 0,003 & $2,56 \mathrm{E}-08$ & 2,91E-209 & $8,96 \mathrm{E}-13$ \\
\hline $\begin{array}{l}\text { Minimum distance from } \\
\text { cell body edge }(\mu \mathrm{m})\end{array}$ & 3,837 & 2,286 & 7,931 & 5,455 & 10,760 & 7,327 & $6,98 \mathrm{E}-68$ & $0,00 E+00$ & $3,01 \mathrm{E}-16$ \\
\hline $\begin{array}{l}\text { Minimum distance from } \\
\text { nucleus edge }(\mu \mathrm{m})\end{array}$ & 7,391 & 5,748 & 19,669 & 8,286 & 21,416 & 8,470 & $5,20 \mathrm{E}-200$ & $0,00 E+00$ & \\
\hline $\begin{array}{l}\text { Approximate depth in Z } \\
(\mu \mathrm{m})\end{array}$ & 0,449 & 0,163 & 0,390 & 0,113 & 0,344 & 0,145 & $8,09 E-15$ & $1,75 \mathrm{E}-274$ & $9,04 \mathrm{E}-13$ \\
\hline $\begin{array}{l}\text { Minimum distance to the } \\
\text { next object }(\mu \mathrm{m})\end{array}$ & 0,745 & 0,380 & 0,880 & 0,667 & 0,881 & 0,777 & & & \\
\hline
\end{tabular}

Figure 38: MAP2, characterization in cell bodies, axons, and dendrites. Shown in the top panel is the DiO plasma membrane staining in green, the ankyring immunostaining in blue, and the MAP2 staining in red. All images were acquired by confocal microscopy taking stacks across entire neuronal cell bodies. The images shown are maximum projections of these stacks. The second row shows a merge image of the three markers. The other two images in the second row represent the objects extracted from the 
organelle staining during the analysis. The middle image shows the objects in the middle section of the z-stack, the third image shows all objects color-coded based on the z-level. The extracted objects were grouped dependent on their presence in the cell body, the axon, or the dendrite and parameters such as the area, and the percent of total volume for each object were extracted. The table shows the mean values and SDs for these parameters in the different regions. The parameters were compared between the different regions using a multiple comparison ranksum Mann-Whitney $U$ test and a Bonferroni correction. Significant differences are indicated in green. 20 neurons from 2 different cultures were analysed.

\section{MAP2}
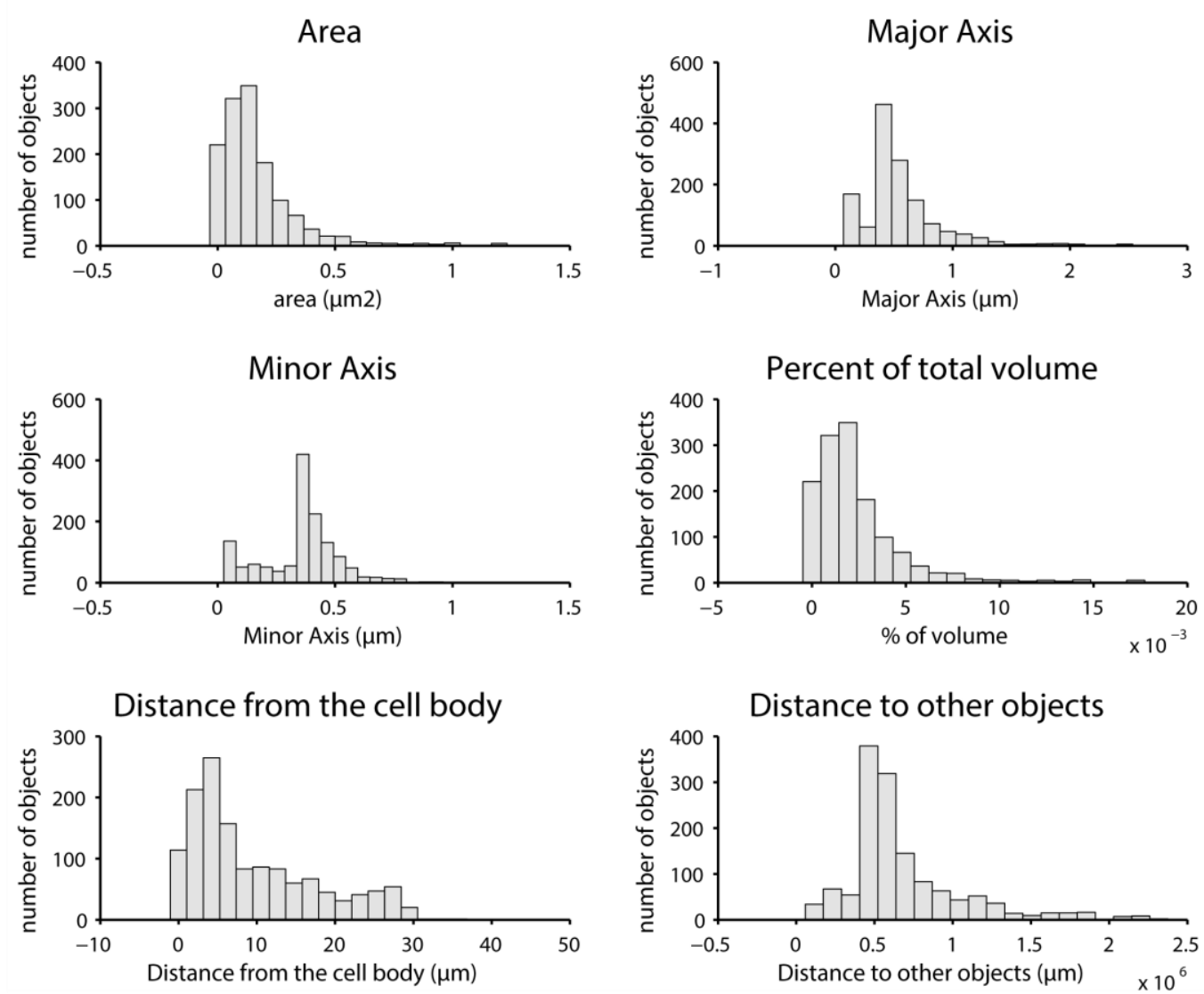

Figure 39: Distribution of MAP2. From the objects found during the analysis, I extracted several parameters including the area, the axis, the object volume, the distance to the cell body, and the distance to the neighbouring objects. These parameters are given here in the form of histograms. The bin size was chosen according to the data range. 


\section{PDI}
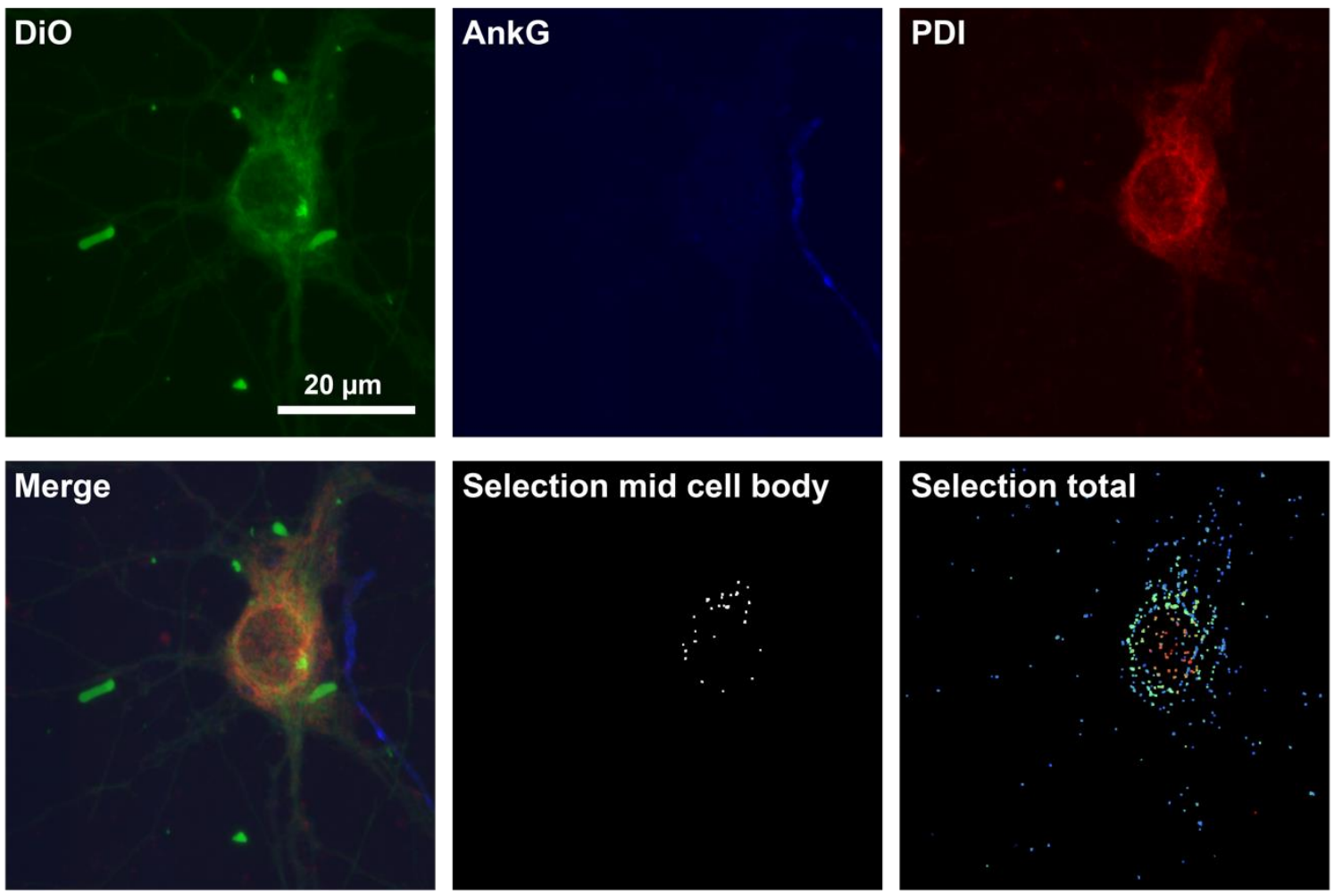

\begin{tabular}{|c|c|c|c|c|c|c|c|c|c|}
\hline properties & $\begin{array}{l}\text { Mean } \\
\text { cell } \\
\text { body }\end{array}$ & $\begin{array}{l}\text { SD cell } \\
\text { body }\end{array}$ & $\begin{array}{l}\text { Mean } \\
\text { axon }\end{array}$ & $\begin{array}{l}\text { SD } \\
\text { axon }\end{array}$ & $\begin{array}{l}\text { Mean } \\
\text { dendrites }\end{array}$ & $\begin{array}{l}\text { SD } \\
\text { dendrites }\end{array}$ & $\begin{array}{l}\text { P value cell } \\
\text { body vs. } \\
\text { axon }\end{array}$ & $\begin{array}{l}\text { P value cell } \\
\text { body vs. } \\
\text { dendrites }\end{array}$ & $\begin{array}{l}\text { P value } \\
\text { axon vs. } \\
\text { dendrites }\end{array}$ \\
\hline Area $\left(\mu \mathrm{m}^{2}\right)$ & 0,176 & 0,125 & 0,132 & 0,095 & 0,100 & 0,092 & $1,51 \mathrm{E}-19$ & $6,93 \mathrm{E}-127$ & $4,37 \mathrm{E}-12$ \\
\hline Major axis $(\mu \mathrm{m})$ & 0,541 & 0,245 & 0,453 & 0,212 & 0,388 & 0,218 & $1,02 \mathrm{E}-11$ & $2,66 \mathrm{E}-80$ & $2,97 \mathrm{E}-08$ \\
\hline Minor axis $(\mu \mathrm{m})$ & 0,413 & 0,085 & 0,352 & 0,139 & 0,286 & 0,155 & $7,99 \mathrm{E}-17$ & $3,30 \mathrm{E}-130$ & $1,90 \mathrm{E}-13$ \\
\hline $\begin{array}{l}\text { Equivalent circle } \\
\text { diameter }(\mu \mathrm{m})\end{array}$ & 0,456 & 0,128 & 0,379 & 0,156 & 0,313 & 0,171 & $1,51 \mathrm{E}-19$ & $6,93 \mathrm{E}-127$ & 4,37E-12 \\
\hline Perimeter $(\mu \mathrm{m})$ & 1,432 & 0,615 & 1,272 & 0,587 & 1,111 & 0,617 & $3,37 \mathrm{E}-07$ & $3,11 E-51$ & $1,60 \mathrm{E}-06$ \\
\hline Percent of volume (\%) & 0,003 & 0,002 & 0,003 & 0,003 & 0,002 & 0,003 & & $9,09 E-85$ & $1,35 E-15$ \\
\hline $\begin{array}{l}\text { Minimum distance from } \\
\text { cell body edge }(\mu \mathrm{m})\end{array}$ & 3,494 & 2,033 & 9,806 & 5,696 & 9,798 & 7,169 & $2,95 \mathrm{E}-106$ & 1,91E-193 & \\
\hline $\begin{array}{l}\text { Minimum distance from } \\
\text { nucleus edge }(\mu \mathrm{m})\end{array}$ & 4,365 & 4,182 & 18,029 & 6,454 & 17,340 & 8,788 & $1,66 \mathrm{E}-208$ & $0,00 E+00$ & \\
\hline $\begin{array}{l}\text { Approximate depth in Z } \\
(\mu \mathrm{m})\end{array}$ & 0,413 & 0,085 & 0,352 & 0,139 & 0,286 & 0,155 & $7,99 \mathrm{E}-17$ & $3,30 \mathrm{E}-130$ & $1,90 \mathrm{E}-13$ \\
\hline $\begin{array}{l}\text { Minimum distance to the } \\
\text { next object }(\mu \mathrm{m})\end{array}$ & 0,758 & 0,476 & 1,036 & 1,657 & 1,001 & 1,765 & $4,88 \mathrm{E}-06$ & $2,82 E-52$ & \\
\hline
\end{tabular}

Figure 40: PDI, characterization in cell bodies, axons, and dendrites. Shown in the top panel is the DiO plasma membrane staining in green, the ankyring immunostaining in blue, and the PDI staining in red. All images were acquired by confocal microscopy taking stacks across entire neuronal cell bodies. The images shown are maximum projections of these stacks. The second row shows a merge image of the three markers. The other two images in the second row represent the objects extracted from the organelle staining 
during the analysis. The middle image shows the objects in the middle section of the zstack, the third image shows all objects color-coded based on the z-level. The extracted objects were grouped dependent on their presence in the cell body, the axon, or the dendrite and parameters such as the area, and the percent of total volume for each object were extracted. The table shows the mean values and SDs for these parameters in the different regions. The parameters were compared between the different regions using a multiple comparison ranksum Mann-Whitney $U$ test and a Bonferroni correction. Significant differences are indicated in green. 20 neurons from 2 different cultures were analysed.

PDI
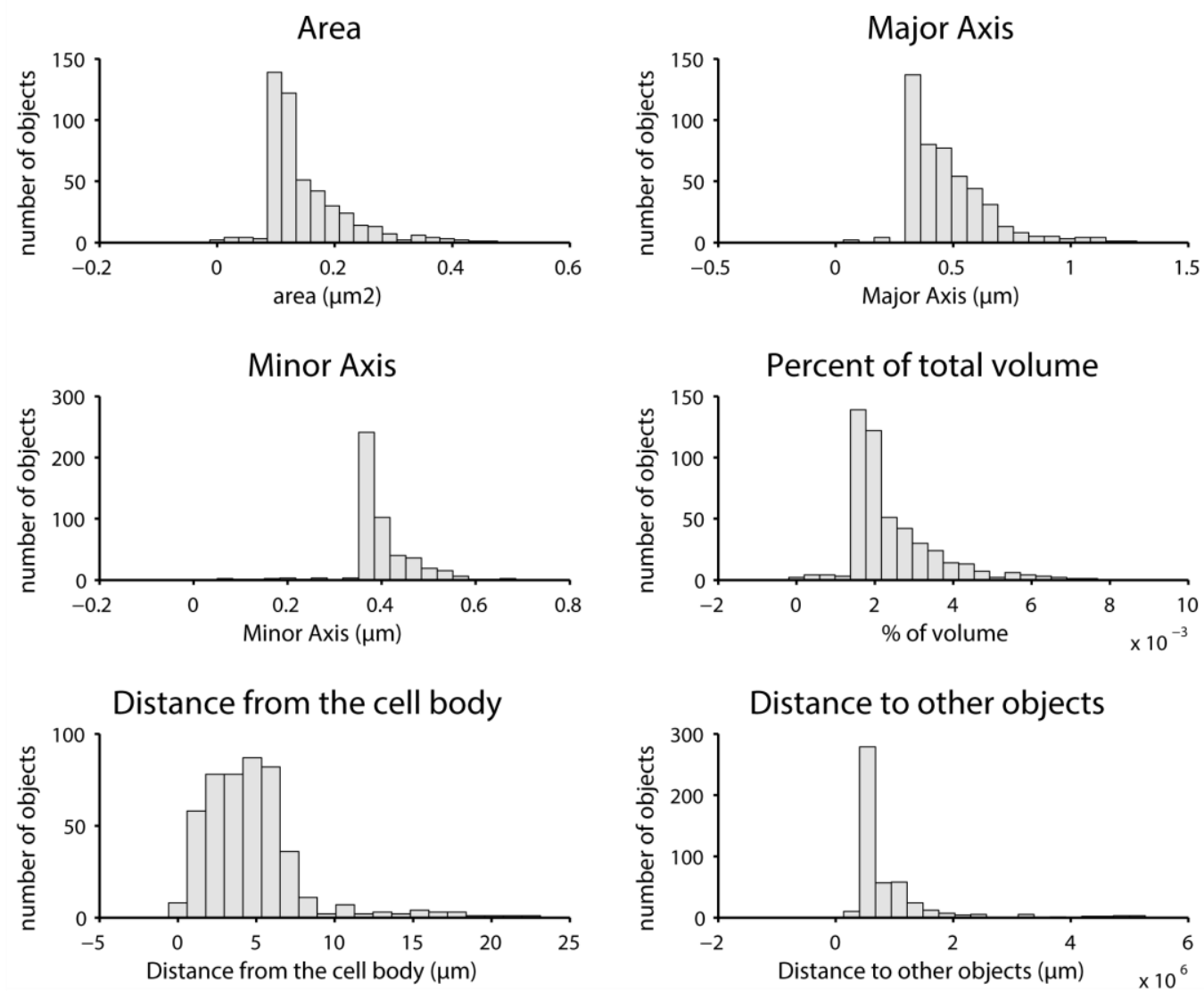

Figure 41: Distribution of PDI. From the objects found during the analysis, I extracted several parameters including the area, the axis, the object volume, the distance to the cell body, and the distance to the neighbouring objects. These parameters are given here in the form of histograms. The bin size was chosen according to the data range. 


\section{PMP70}
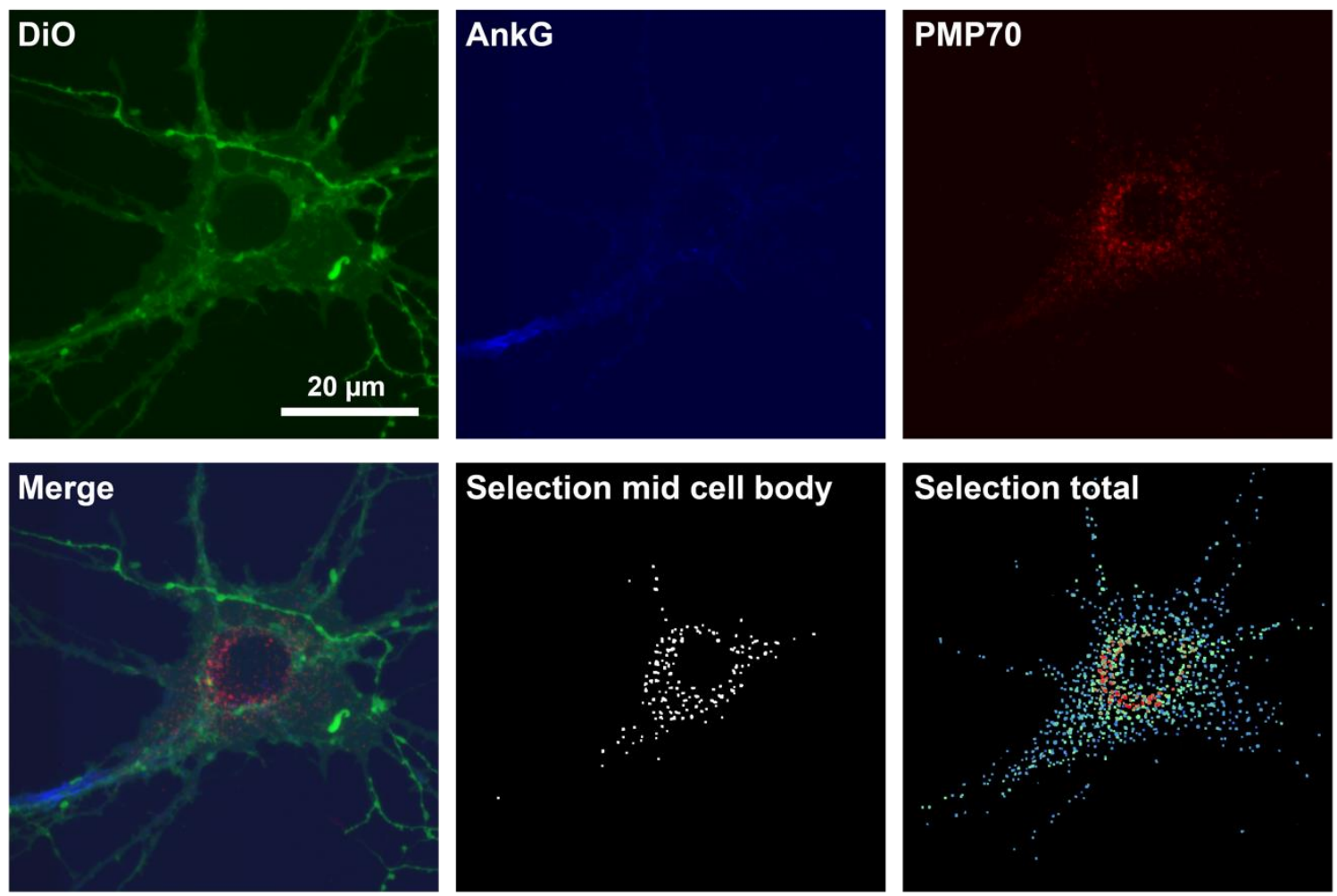

\begin{tabular}{|c|c|c|c|c|c|c|c|c|c|}
\hline properties & $\begin{array}{l}\text { Mean } \\
\text { cell } \\
\text { body }\end{array}$ & $\begin{array}{l}\text { SD cell } \\
\text { body }\end{array}$ & $\begin{array}{l}\text { Mean } \\
\text { axon }\end{array}$ & $\begin{array}{l}\text { SD } \\
\text { axon }\end{array}$ & $\begin{array}{l}\text { Mean } \\
\text { dendrites }\end{array}$ & $\begin{array}{l}\text { SD } \\
\text { dendrites }\end{array}$ & $\begin{array}{l}\text { P value cell } \\
\text { body vs. } \\
\text { axon }\end{array}$ & $\begin{array}{l}\text { P value cell } \\
\text { body vs. } \\
\text { dendrites }\end{array}$ & $\begin{array}{l}\text { P value } \\
\text { axon vs. } \\
\text { dendrites }\end{array}$ \\
\hline Area $\left(\mu \mathrm{m}^{2}\right)$ & 0.180 & 0.087 & 0.151 & 0.066 & 0.135 & 0.077 & $7.22 \mathrm{E}-14$ & 3.77E-128 & 3.07E-06 \\
\hline Major axis $(\mu \mathrm{m})$ & 0.544 & 0.189 & 0.494 & 0.156 & 0.457 & 0.170 & & $4.01 \mathrm{E}-83$ & \\
\hline Minor axis $(\mu \mathrm{m})$ & 0.426 & 0.071 & 0.394 & 0.072 & 0.364 & 0.117 & & 2.24E-125 & \\
\hline $\begin{array}{l}\text { Equivalent circle } \\
\text { diameter }(\mu \mathrm{m})\end{array}$ & 0.467 & 0.105 & 0.428 & 0.095 & 0.393 & 0.131 & & 3.77E-128 & \\
\hline Perimeter $(\mu \mathrm{m})$ & 1.443 & 0.457 & 1.314 & 0.368 & 1.249 & 0.418 & & $1.83 \mathrm{E}-69$ & \\
\hline Percent of volume (\%) & 0.002 & 0.002 & 0.003 & 0.001 & 0.002 & 0.001 & & 2.01E-09 & 2.14E-16 \\
\hline $\begin{array}{l}\text { Minimum distance from } \\
\text { cell body edge }(\mu \mathrm{m})\end{array}$ & 8.351 & 9.695 & 6.298 & 5.656 & 8.565 & 6.913 & & & 1.67E-12 \\
\hline $\begin{array}{l}\text { Minimum distance from } \\
\text { nucleus edge }(\mu \mathrm{m})\end{array}$ & 7.526 & 6.635 & 19.526 & 8.849 & 19.678 & 7.849 & $6.41 \mathrm{E}-181$ & $0.00 \mathrm{E}+00$ & \\
\hline $\begin{array}{l}\text { Approximate depth in Z } \\
(\mu \mathrm{m})\end{array}$ & 0.426 & 0.071 & 0.394 & 0.072 & 0.364 & 0.117 & & $2.24 \mathrm{E}-125$ & \\
\hline $\begin{array}{l}\text { Minimum distance to the } \\
\text { next object }(\mu \mathrm{m})\end{array}$ & 0.577 & 0.218 & 0.682 & 0.414 & 0.872 & 1.127 & & 4.95E-05 & \\
\hline
\end{tabular}

Figure 42: PMP70, characterization in cell bodies, axons, and dendrites. Shown in the top panel is the DiO plasma membrane staining in green, the ankyring immunostaining in blue, and the PMP70 staining in red. All images were acquired by confocal microscopy taking stacks across entire neuronal cell bodies. The images shown are maximum projections of these stacks. The second row shows a merge image of the three markers. The other two images in the second row represent the objects extracted from the 
organelle staining during the analysis. The middle image shows the objects in the middle section of the z-stack, the third image shows all objects color-coded based on the z-level. The extracted objects were grouped dependent on their presence in the cell body, the axon, or the dendrite and parameters such as the area, and the percent of total volume for each object were extracted. The table shows the mean values and SDs for these parameters in the different regions. The parameters were compared between the different regions using a multiple comparison ranksum Mann-Whitney $U$ test and a Bonferroni correction. Significant differences are indicated in green. 20 neurons from 2 different cultures were analysed.

\section{PMP70}
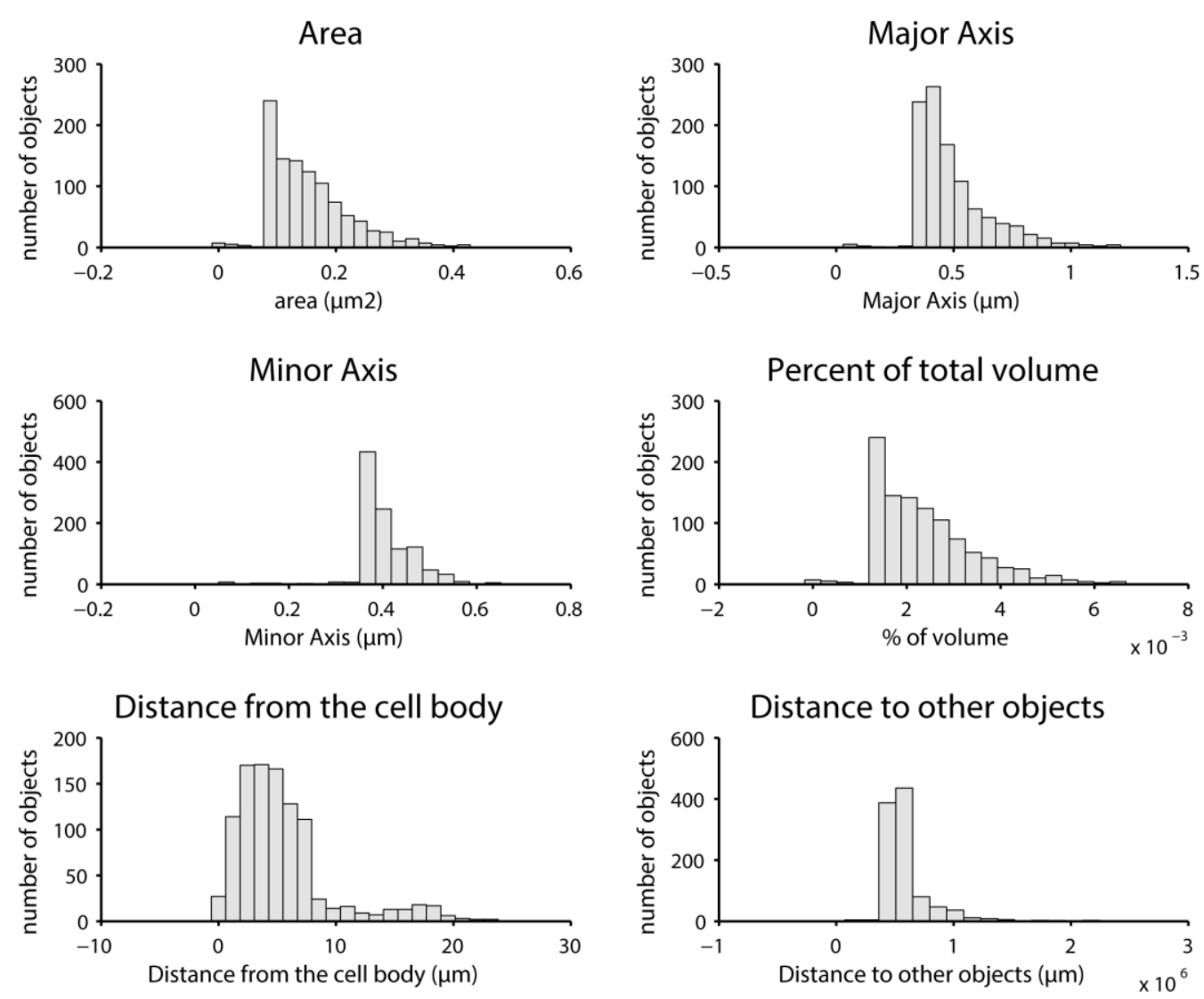

Figure 43: Distribution of PMP70. From the objects found during the analysis, I extracted several parameters including the area, the axis, the object volume, the distance to the cell body, and the distance to the neighbouring objects. These parameters are given here in the form of histograms. The bin size was chosen according to the data range. 


\section{rab5}
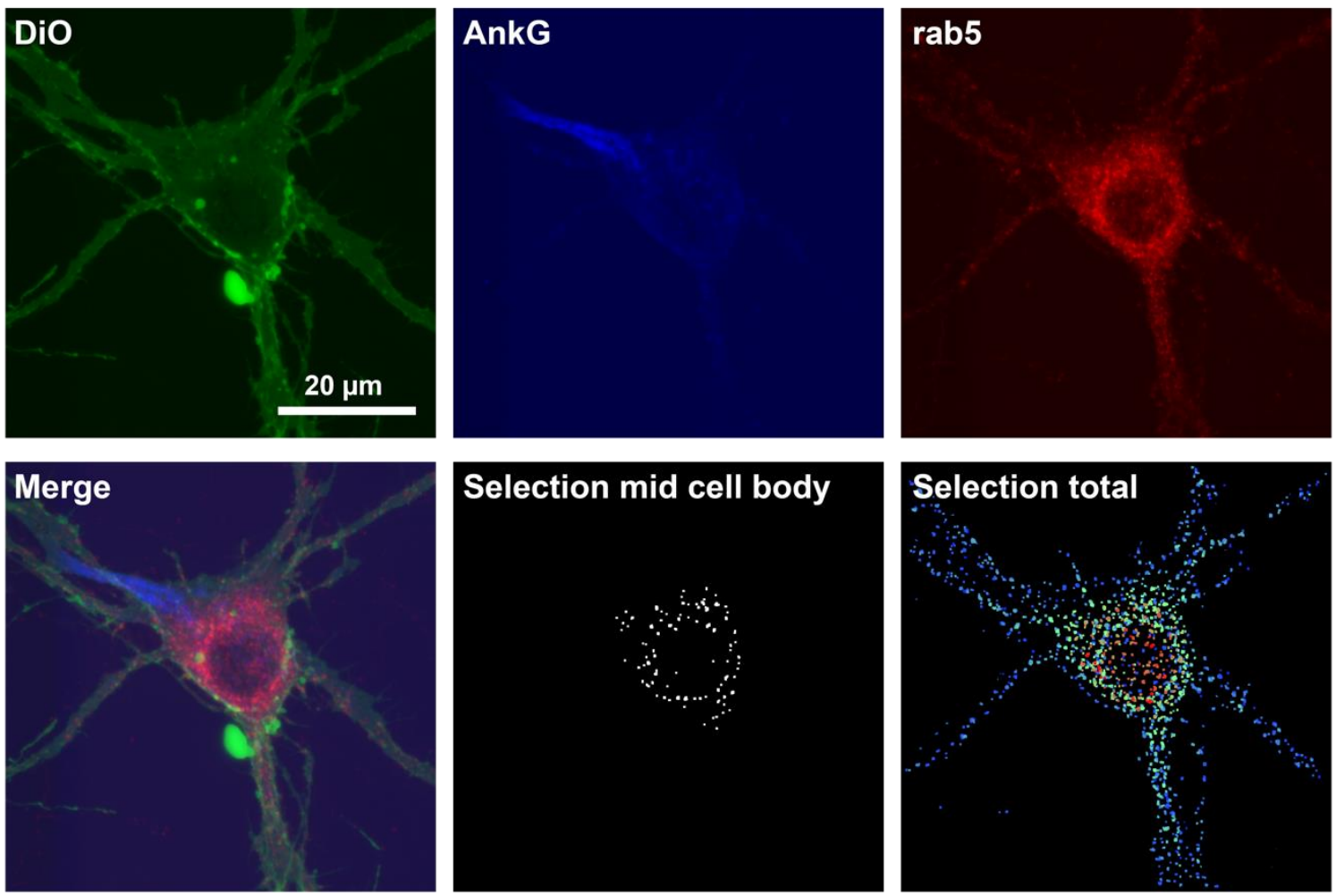

\begin{tabular}{|c|c|c|c|c|c|c|c|c|c|}
\hline properties & $\begin{array}{l}\text { Mean } \\
\text { cell } \\
\text { body }\end{array}$ & $\begin{array}{l}\text { SD cell } \\
\text { body }\end{array}$ & $\begin{array}{l}\text { Mean } \\
\text { axon }\end{array}$ & $\begin{array}{l}\text { SD } \\
\text { axon }\end{array}$ & $\begin{array}{l}\text { Mean } \\
\text { dendrites }\end{array}$ & $\begin{array}{l}\text { SD } \\
\text { dendrites }\end{array}$ & $\begin{array}{l}\text { P value cell } \\
\text { body vs. } \\
\text { axon }\end{array}$ & $\begin{array}{l}\text { P value cell } \\
\text { body vs. } \\
\text { dendrites }\end{array}$ & $\begin{array}{l}\text { P value } \\
\text { axon vs. } \\
\text { dendrites }\end{array}$ \\
\hline Area $\left(\mu \mathrm{m}^{2}\right)$ & 0.165 & 0.078 & 0.150 & 0.092 & 0.138 & 0.081 & & $1.24 \mathrm{E}-108$ & \\
\hline Major axis $(\mu \mathrm{m})$ & 0.516 & 0.167 & 0.492 & 0.182 & 0.469 & 0.172 & & & \\
\hline Minor axis $(\mu \mathrm{m})$ & 0.410 & 0.068 & 0.382 & 0.105 & 0.364 & 0.113 & & $2.83 \mathrm{E}-132$ & \\
\hline $\begin{array}{l}\text { Equivalent circle } \\
\text { diameter }(\mu \mathrm{m})\end{array}$ & 0.447 & 0.098 & 0.418 & 0.126 & 0.398 & 0.128 & & $1.24 \mathrm{E}-108$ & \\
\hline Perimeter $(\mu \mathrm{m})$ & 1.368 & 0.409 & 1.313 & 0.457 & 1.251 & 0.435 & & & \\
\hline Percent of volume (\%) & 0.003 & 0.002 & 0.003 & 0.002 & 0.002 & 0.002 & & & \\
\hline $\begin{array}{l}\text { Minimum distance from } \\
\text { cell body edge }(\mu \mathrm{m})\end{array}$ & 3.517 & 2.236 & 7.677 & 6.189 & 10.925 & 7.616 & $2.77 \mathrm{E}-260$ & $0.00 \mathrm{E}+00$ & $2.24 \mathrm{E}-93$ \\
\hline $\begin{array}{l}\text { Minimum distance from } \\
\text { nucleus edge }(\mu \mathrm{m})\end{array}$ & 6.547 & 5.546 & 16.644 & 9.189 & 20.835 & 9.020 & $0.00 \mathrm{E}+00$ & $0.00 \mathrm{E}+00$ & $2.36 \mathrm{E}-89$ \\
\hline $\begin{array}{l}\text { Approximate depth in Z } \\
(\mu \mathrm{m})\end{array}$ & 0.410 & 0.068 & 0.382 & 0.105 & 0.364 & 0.113 & & $2.83 \mathrm{E}-132$ & \\
\hline $\begin{array}{l}\text { Minimum distance to the } \\
\text { next object }(\mu \mathrm{m})\end{array}$ & 0.679 & 0.256 & 0.773 & 0.458 & 0.923 & 0.849 & $1.73 \mathrm{E}-06$ & $5.38 \mathrm{E}-18$ & \\
\hline
\end{tabular}

Figure 44: Rab5, characterization in cell bodies, axons, and dendrites. Shown in the top panel is the DiO plasma membrane staining in green, the ankyrinG immunostaining in blue, and the Rab5 staining in red. All images were acquired by confocal microscopy taking stacks across entire neuronal cell bodies. The images shown are maximum projections of these stacks. The second row shows a merge image of the three markers. The other two images in the second row represent the objects extracted from the 
organelle staining during the analysis. The middle image shows the objects in the middle section of the z-stack, the third image shows all objects color-coded based on the z-level. The extracted objects were grouped dependent on their presence in the cell body, the axon, or the dendrite and parameters such as the area, and the percent of total volume for each object were extracted. The table shows the mean values and SDs for these parameters in the different regions. The parameters were compared between the different regions using a multiple comparison ranksum Mann-Whitney $U$ test and a Bonferroni correction. Significant differences are indicated in green. 20 neurons from 2 different cultures were analysed.

rab5
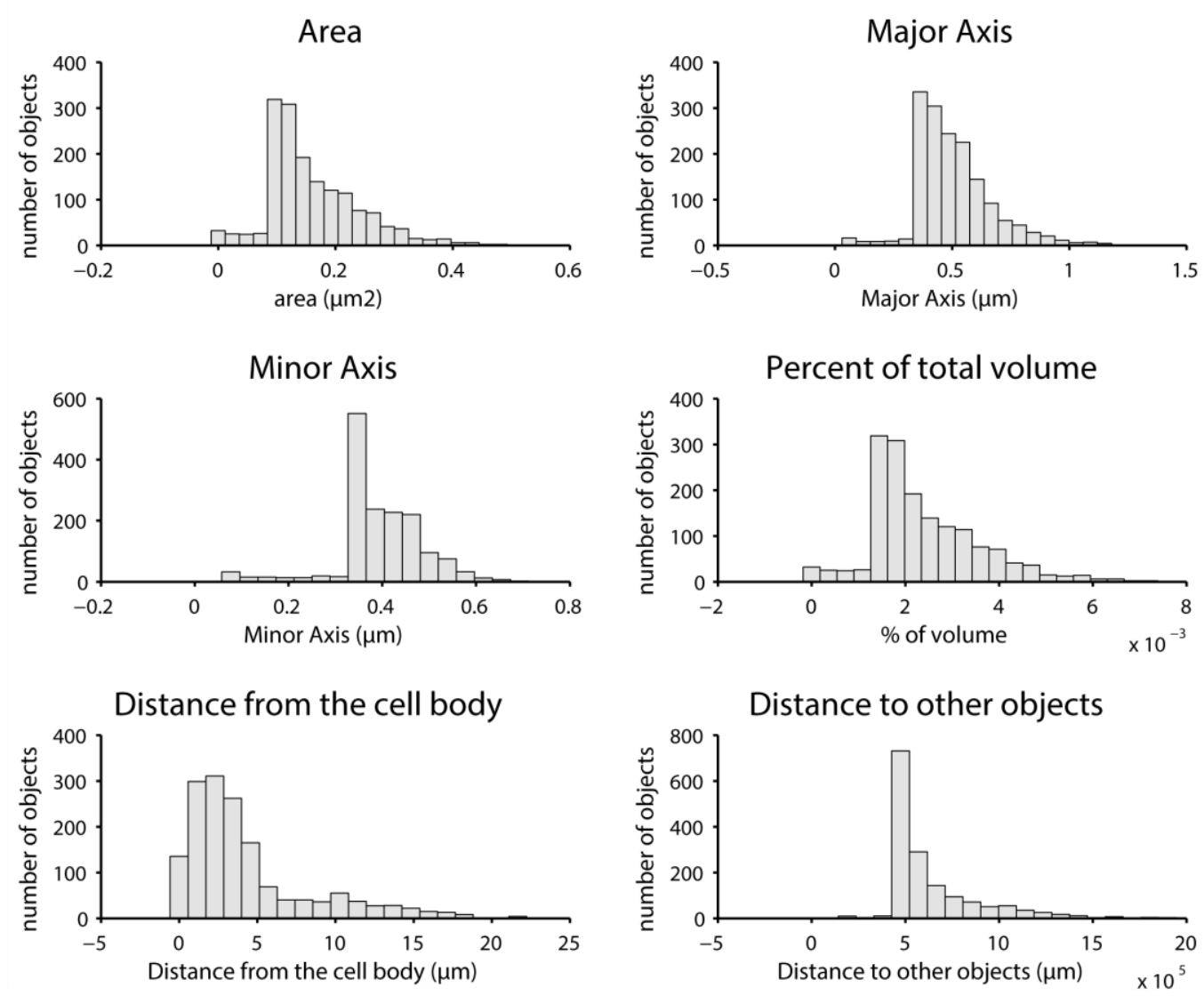

Figure 45: Distribution of Rab5. From the objects found during the analysis, I extracted several parameters including the area, the axis, the object volume, the distance to the cell body, and the distance to the neighbouring objects. These parameters are given here in the form of histograms. The bin size was chosen according to the data range. 


\section{rab7}
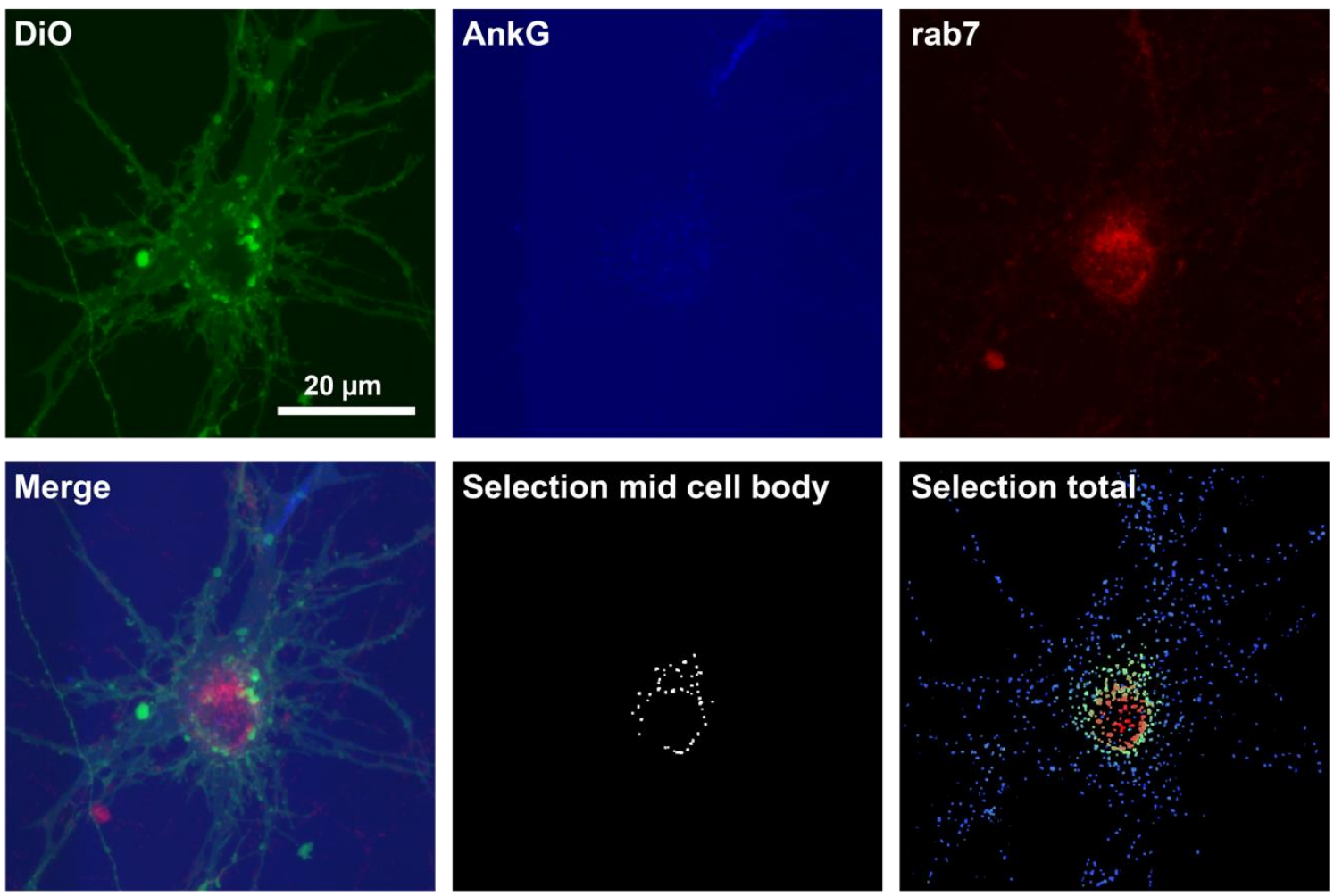

\begin{tabular}{|c|c|c|c|c|c|c|c|c|c|}
\hline properties & $\begin{array}{l}\text { Mean } \\
\text { cell } \\
\text { body }\end{array}$ & $\begin{array}{l}\text { SD cell } \\
\text { body }\end{array}$ & $\begin{array}{l}\text { Mean } \\
\text { axon }\end{array}$ & $\begin{array}{l}\text { SD } \\
\text { axon }\end{array}$ & $\begin{array}{l}\text { Mean } \\
\text { dendrites }\end{array}$ & $\begin{array}{l}\text { SD } \\
\text { dendrites }\end{array}$ & $\begin{array}{l}\text { P value cell } \\
\text { body vs. } \\
\text { axon }\end{array}$ & $\begin{array}{l}\text { P value cell } \\
\text { body vs. } \\
\text { dendrites }\end{array}$ & $\begin{array}{l}\text { P value } \\
\text { axon vs. } \\
\text { dendrites }\end{array}$ \\
\hline Area $\left(\mu \mathrm{m}^{2}\right)$ & 0.194 & 0.178 & 0.163 & 0.212 & 0.128 & 0.094 & $2.56 \mathrm{E}-43$ & $0.00 \mathrm{E}+00$ & $2.24 \mathrm{E}-46$ \\
\hline Major axis $(\mu \mathrm{m})$ & 0.569 & 0.292 & 0.513 & 0.253 & 0.464 & 0.214 & $1.05 \mathrm{E}-19$ & $1.91 \mathrm{E}-164$ & \\
\hline Minor axis $(\mu \mathrm{m})$ & 0.425 & 0.109 & 0.382 & 0.143 & 0.335 & 0.127 & $2.31 \mathrm{E}-55$ & $0.00 \mathrm{E}+00$ & $8.76 \mathrm{E}-59$ \\
\hline $\begin{array}{l}\text { Equivalent circle } \\
\text { diameter }(\mu \mathrm{m})\end{array}$ & 0.473 & 0.153 & 0.424 & 0.166 & 0.375 & 0.147 & $2.56 \mathrm{E}-43$ & $0.00 \mathrm{E}+00$ & $2.24 \mathrm{E}-46$ \\
\hline Perimeter $(\mu \mathrm{m})$ & 1.507 & 0.752 & 1.367 & 0.674 & 1.228 & 0.540 & & $2.08 \mathrm{E}-199$ & $2.28 \mathrm{E}-27$ \\
\hline Percent of volume (\%) & 0.003 & 0.003 & 0.002 & 0.003 & 0.002 & 0.002 & 1.37E-43 & $0.00 \mathrm{E}+00$ & $1.01 \mathrm{E}-36$ \\
\hline $\begin{array}{l}\text { Minimum distance from } \\
\text { cell body edge }(\mu \mathrm{m})\end{array}$ & 3.646 & 2.338 & 8.359 & 7.180 & 11.867 & 7.902 & $5.32 \mathrm{E}-177$ & $0.00 \mathrm{E}+00$ & 1.37E-109 \\
\hline $\begin{array}{l}\text { Minimum distance from } \\
\text { nucleus edge }(\mu \mathrm{m})\end{array}$ & 7.183 & 5.656 & 17.287 & 8.757 & 20.308 & 8.756 & $0.00 \mathrm{E}+00$ & $0.00 \mathrm{E}+00$ & $1.09 \mathrm{E}-56$ \\
\hline $\begin{array}{l}\text { Approximate depth in Z } \\
(\mu \mathrm{m})\end{array}$ & 0.425 & 0.109 & 0.382 & 0.143 & 0.335 & 0.127 & 2.31E-55 & $0.00 \mathrm{E}+00$ & $8.76 \mathrm{E}-59$ \\
\hline $\begin{array}{l}\text { Minimum distance to the } \\
\text { next object }(\mu \mathrm{m})\end{array}$ & 0.710 & 0.331 & 0.830 & 0.734 & 0.816 & 0.746 & & 6.69E-11 & \\
\hline
\end{tabular}

Figure 46: Rab7, characterization in cell bodies, axons, and dendrites. Shown in the top panel is the DiO plasma membrane staining in green, the ankyrinG immunostaining in blue, and the Rab7 staining in red. All images were acquired by confocal microscopy taking stacks across entire neuronal cell bodies. The images shown are maximum projections of these stacks. The second row shows a merge image of the three markers. The other two images in the second row represent the objects extracted from the 
organelle staining during the analysis. The middle image shows the objects in the middle section of the z-stack, the third image shows all objects color-coded based on the z-level. The extracted objects were grouped dependent on their presence in the cell body, the axon, or the dendrite and parameters such as the area, and the percent of total volume for each object were extracted. The table shows the mean values and SDs for these parameters in the different regions. The parameters were compared between the different regions using a multiple comparison ranksum Mann-Whitney $U$ test and a Bonferroni correction. Significant differences are indicated in green. 20 neurons from 2 different cultures were analysed.

rab7
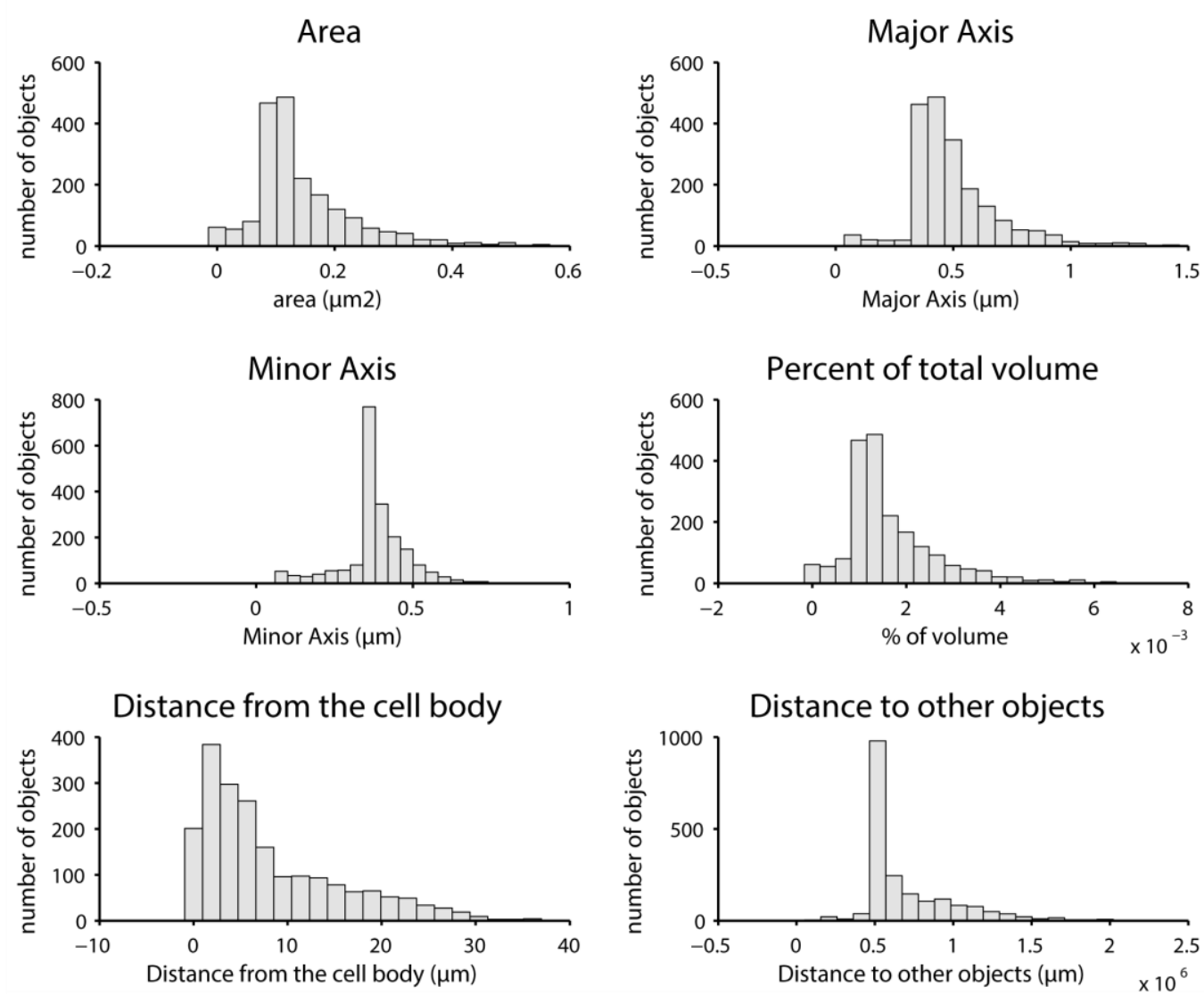

Figure 47: Distribution of Rab7. From the objects found during the analysis, I extracted several parameters including the area, the axis, the object volume, the distance to the cell body, and the distance to the neighbouring objects. These parameters are given here in the form of histograms. The bin size was chosen according to the data range. 


\section{rab11a}
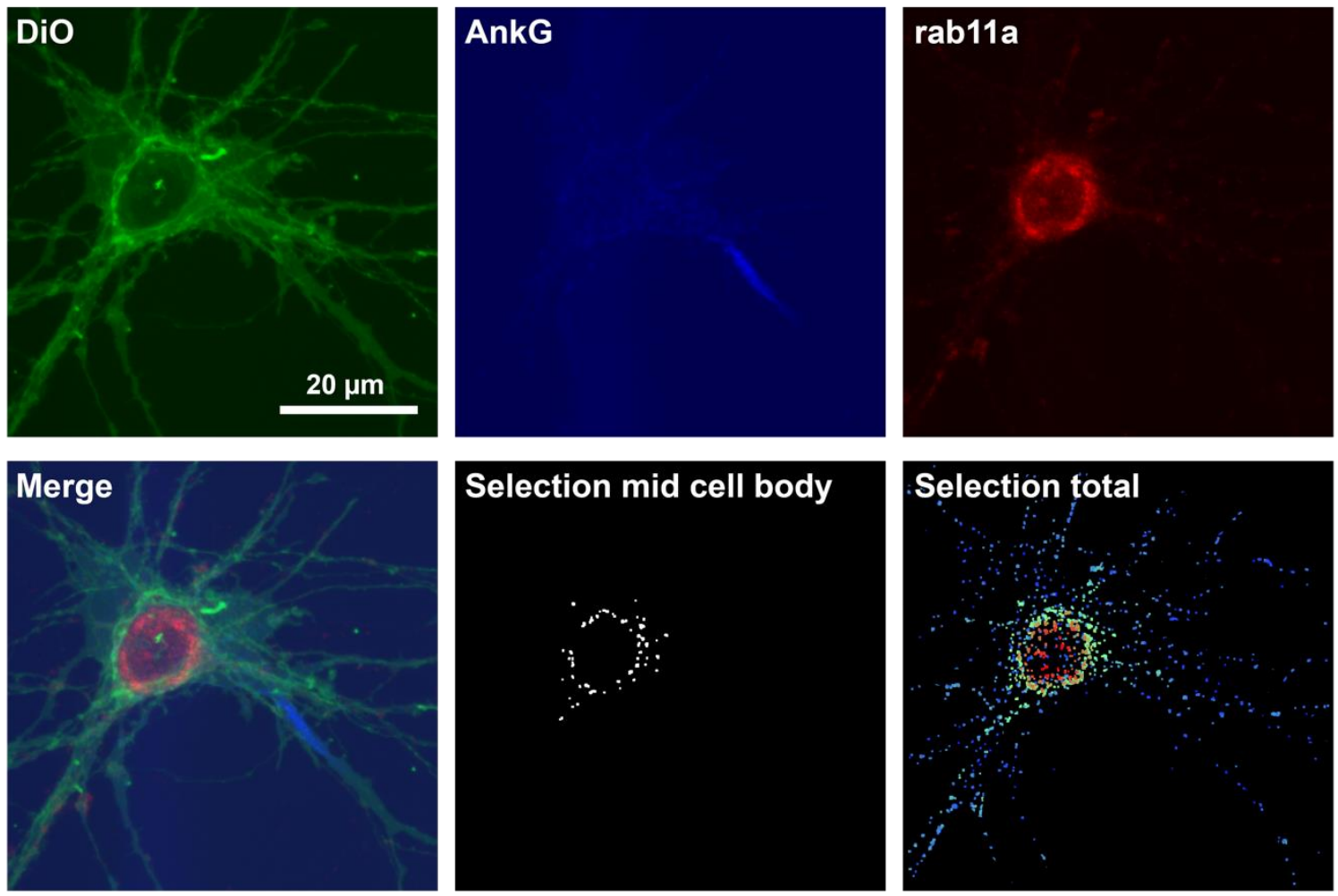

\begin{tabular}{|c|c|c|c|c|c|c|c|c|c|}
\hline properties & $\begin{array}{l}\text { Mean } \\
\text { cell } \\
\text { body }\end{array}$ & $\begin{array}{l}\text { SD cell } \\
\text { body }\end{array}$ & $\begin{array}{l}\text { Mean } \\
\text { axon }\end{array}$ & $\begin{array}{l}\text { SD } \\
\text { axon }\end{array}$ & $\begin{array}{l}\text { Mean } \\
\text { dendrites }\end{array}$ & $\begin{array}{l}\text { SD } \\
\text { dendrites }\end{array}$ & $\begin{array}{l}\text { P value cell } \\
\text { body vs. } \\
\text { axon }\end{array}$ & $\begin{array}{l}\text { P value cell } \\
\text { body vs. } \\
\text { dendrites }\end{array}$ & $\begin{array}{l}\text { P value } \\
\text { axon vs. } \\
\text { dendrites }\end{array}$ \\
\hline Area $\left(\mu \mathrm{m}^{2}\right)$ & 0.164 & 0.092 & 0.147 & 0.082 & 0.125 & 0.091 & & $6.03 \mathrm{E}-164$ & $5.07 \mathrm{E}-15$ \\
\hline Major axis ( $\mu \mathrm{m})$ & 0.517 & 0.194 & 0.492 & 0.187 & 0.450 & 0.209 & & $4.08 \mathrm{E}-69$ & \\
\hline Minor axis $(\mu \mathrm{m})$ & 0.406 & 0.075 & 0.378 & 0.092 & 0.337 & 0.123 & & $1.48 \mathrm{E}-210$ & $4.89 \mathrm{E}-16$ \\
\hline $\begin{array}{l}\text { Equivalent circle } \\
\text { diameter }(\mu \mathrm{m})\end{array}$ & 0.444 & 0.109 & 0.416 & 0.118 & 0.372 & 0.143 & & $6.03 \mathrm{E}-164$ & 5.07E-15 \\
\hline Perimeter $(\mu \mathrm{m})$ & 1.372 & 0.495 & 1.303 & 0.464 & 1.213 & 0.522 & & $1.24 \mathrm{E}-68$ & \\
\hline Percent of volume (\%) & 0.002 & 0.001 & 0.002 & 0.001 & 0.002 & 0.001 & $9.91 \mathrm{E}-13$ & & $5.77 \mathrm{E}-15$ \\
\hline $\begin{array}{l}\text { Minimum distance from } \\
\text { cell body edge }(\mu \mathrm{m})\end{array}$ & 11.237 & 13.247 & 5.961 & 5.039 & 9.713 & 7.123 & $1.11 \mathrm{E}-08$ & $5.29 \mathrm{E}-21$ & $1.33 \mathrm{E}-35$ \\
\hline $\begin{array}{l}\text { Minimum distance from } \\
\text { nucleus edge }(\mu \mathrm{m})\end{array}$ & 8.832 & 9.008 & 19.068 & 8.889 & 20.590 & 8.596 & 7.44E-152 & $0.00 \mathrm{E}+00$ & \\
\hline $\begin{array}{l}\text { Approximate depth in Z } \\
(\mu \mathrm{m})\end{array}$ & 0.406 & 0.075 & 0.378 & 0.092 & 0.337 & 0.123 & & $1.48 \mathrm{E}-210$ & $4.89 \mathrm{E}-16$ \\
\hline $\begin{array}{l}\text { Minimum distance to the } \\
\text { next object }(\mu \mathrm{m})\end{array}$ & 0.835 & 0.608 & 0.855 & 0.580 & 0.887 & 0.724 & & & \\
\hline
\end{tabular}

Figure 48: Rab11a, characterization in cell bodies, axons, and dendrites. Shown in the top panel is the DiO plasma membrane staining in green, the ankyrinG immunostaining in blue, and the Rab11a staining in red. All images were acquired by confocal microscopy taking stacks across entire neuronal cell bodies. The images shown are maximum projections of these stacks. The second row shows a merge image of the three markers. The other two images in the second row represent the objects extracted from the 
organelle staining during the analysis. The middle image shows the objects in the middle section of the z-stack, the third image shows all objects color-coded based on the z-level. The extracted objects were grouped dependent on their presence in the cell body, the axon, or the dendrite and parameters such as the area, and the percent of total volume for each object were extracted. The table shows the mean values and SDs for these parameters in the different regions. The parameters were compared between the different regions using a multiple comparison ranksum Mann-Whitney $U$ test and a Bonferroni correction. Significant differences are indicated in green. 20 neurons from 2 different cultures were analysed.

\section{rab11a}
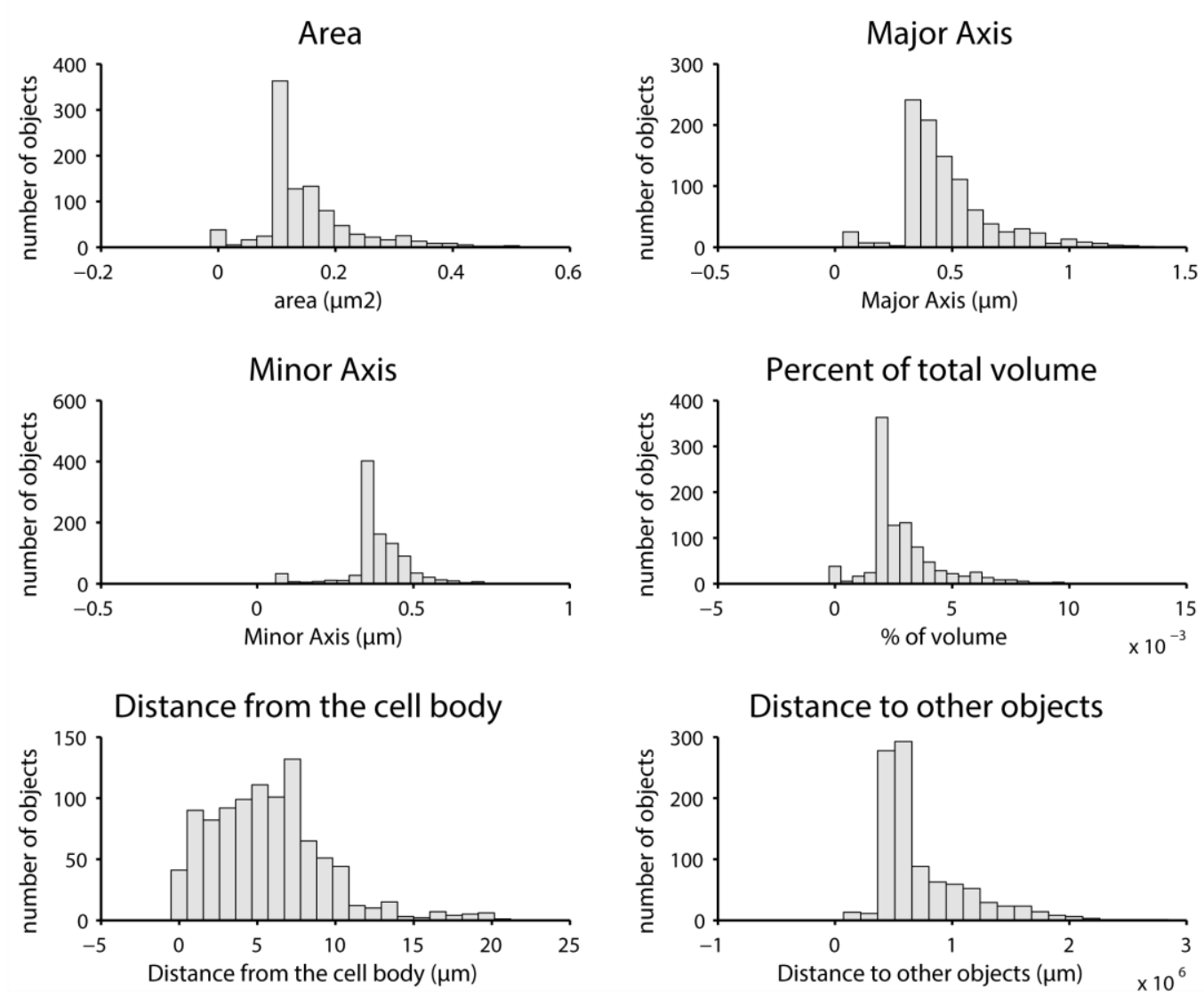

Figure 49: Distribution of Rab11a. From the objects found during the analysis, I extracted several parameters including the area, the axis, the object volume, the distance to the cell body, and the distance to the neighbouring objects. These parameters are given here in the form of histograms. The bin size was chosen according to the data range. 


\section{ribophorin1}
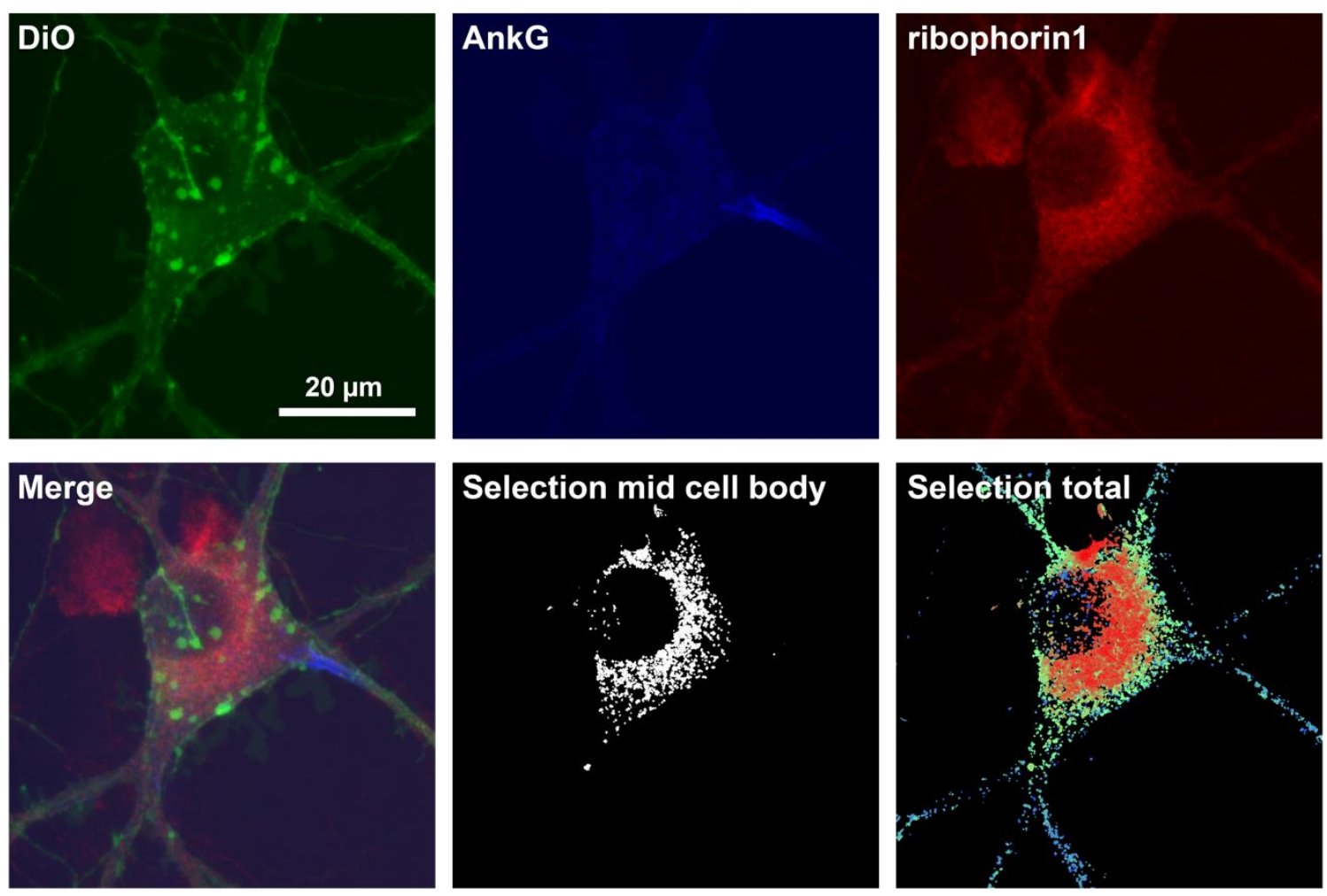

\begin{tabular}{|c|c|c|c|c|c|c|c|c|c|}
\hline properties & $\begin{array}{l}\text { Mean } \\
\text { cell } \\
\text { body }\end{array}$ & $\begin{array}{l}\text { SD cell } \\
\text { body }\end{array}$ & $\begin{array}{l}\text { Mean } \\
\text { axon }\end{array}$ & $\begin{array}{l}\text { SD } \\
\text { axon }\end{array}$ & $\begin{array}{l}\text { Mean } \\
\text { dendrites }\end{array}$ & $\begin{array}{l}\text { SD } \\
\text { dendrites }\end{array}$ & $\begin{array}{l}\text { P value cell } \\
\text { body vs. } \\
\text { axon }\end{array}$ & $\begin{array}{l}\text { P value cell } \\
\text { body vs. } \\
\text { dendrites }\end{array}$ & $\begin{array}{l}\text { P value } \\
\text { axon vs. } \\
\text { dendrites }\end{array}$ \\
\hline Area $\left(\mu \mathrm{m}^{2}\right)$ & 0.515 & 4.064 & 0.683 & 5.291 & 0.140 & 0.274 & $1.02 \mathrm{E}-12$ & $0.00 \mathrm{E}+00$ & $5.39 \mathrm{E}-50$ \\
\hline Major axis $(\mu \mathrm{m})$ & 0.726 & 1.208 & 0.736 & 1.499 & 0.486 & 0.447 & & $1.96 \mathrm{E}-274$ & 1.17E-34 \\
\hline Minor axis $(\mu \mathrm{m})$ & 0.461 & 0.674 & 0.455 & 0.821 & 0.310 & 0.188 & & $0.00 \mathrm{E}+00$ & $7.00 \mathrm{E}-56$ \\
\hline $\begin{array}{l}\text { Equivalent circle } \\
\text { diameter }(\mu \mathrm{m})\end{array}$ & 0.509 & 0.630 & 0.505 & 0.784 & 0.352 & 0.233 & & $0.00 \mathrm{E}+00$ & $5.39 \mathrm{E}-50$ \\
\hline Perimeter $(\mu \mathrm{m})$ & 2.514 & 8.441 & 2.863 & 11.811 & 1.400 & 1.543 & & $2.45 \mathrm{E}-187$ & 3.07E-24 \\
\hline Percent of volume (\%) & 0.007 & 0.059 & 0.014 & 0.131 & 0.002 & 0.005 & 5.34E-07 & 7.35E-266 & 3.39E-31 \\
\hline $\begin{array}{l}\text { Minimum distance from } \\
\text { cell body edge }(\mu \mathrm{m})\end{array}$ & 3.644 & 2.102 & 6.866 & 6.590 & 10.758 & 7.574 & $7.49 E-82$ & $0.00 \mathrm{E}+00$ & 4.33E-154 \\
\hline $\begin{array}{l}\text { Minimum distance from } \\
\text { nucleus edge }(\mu \mathrm{m})\end{array}$ & 6.851 & 6.412 & 16.942 & 9.439 & 20.300 & 9.509 & $0.00 \mathrm{E}+00$ & $0.00 \mathrm{E}+00$ & $8.41 \mathrm{E}-62$ \\
\hline $\begin{array}{l}\text { Approximate depth in Z } \\
(\mu \mathrm{m})\end{array}$ & 0.461 & 0.674 & 0.455 & 0.821 & 0.310 & 0.188 & & $0.00 \mathrm{E}+00$ & 7.00E-56 \\
\hline $\begin{array}{l}\text { Minimum distance to the } \\
\text { next object }(\mu \mathrm{m})\end{array}$ & 0.616 & 0.200 & 0.644 & 0.311 & 0.701 & 0.525 & & 4.63E-16 & \\
\hline
\end{tabular}

Figure 50: Ribophorin1, characterization in cell bodies, axons, and dendrites. Shown in the top panel is the DiO plasma membrane staining in green, the ankyring immunostaining in blue, and the ribophorin1 staining in red. All images were acquired by confocal microscopy taking stacks across entire neuronal cell bodies. The images shown are maximum projections of these stacks. The second row shows a merge image of the three markers. The other two images in the second row represent the objects extracted 
from the organelle staining during the analysis. The middle image shows the objects in the middle section of the z-stack, the third image shows all objects color-coded based on the z-level. The extracted objects were grouped dependent on their presence in the cell body, the axon, or the dendrite and parameters such as the area, and the percent of total volume for each object were extracted. The table shows the mean values and SDs for these parameters in the different regions. The parameters were compared between the different regions using a multiple comparison ranksum Mann-Whitney $U$ test and a Bonferroni correction. Significant differences are indicated in green. 20 neurons from 2 different cultures were analysed.

ribophorin1
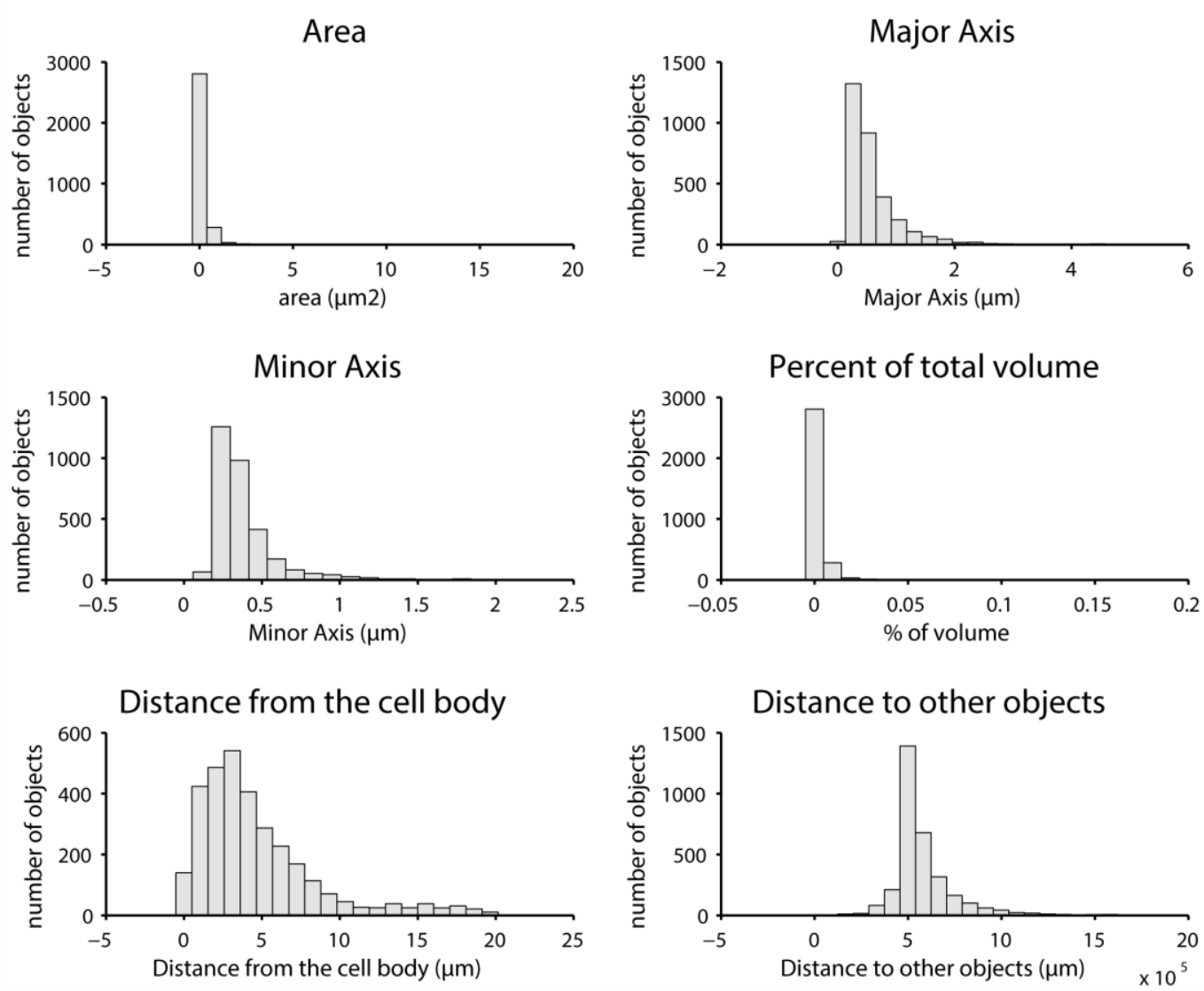

Figure 51: Distribution of ribophorin1. From the objects found during the analysis, I extracted several parameters including the area, the axis, the object volume, the distance to the cell body, and the distance to the neighbouring objects. These parameters are given here in the form of histograms. The bin size was chosen according to the data range. 


\section{ribosomal protein S3}
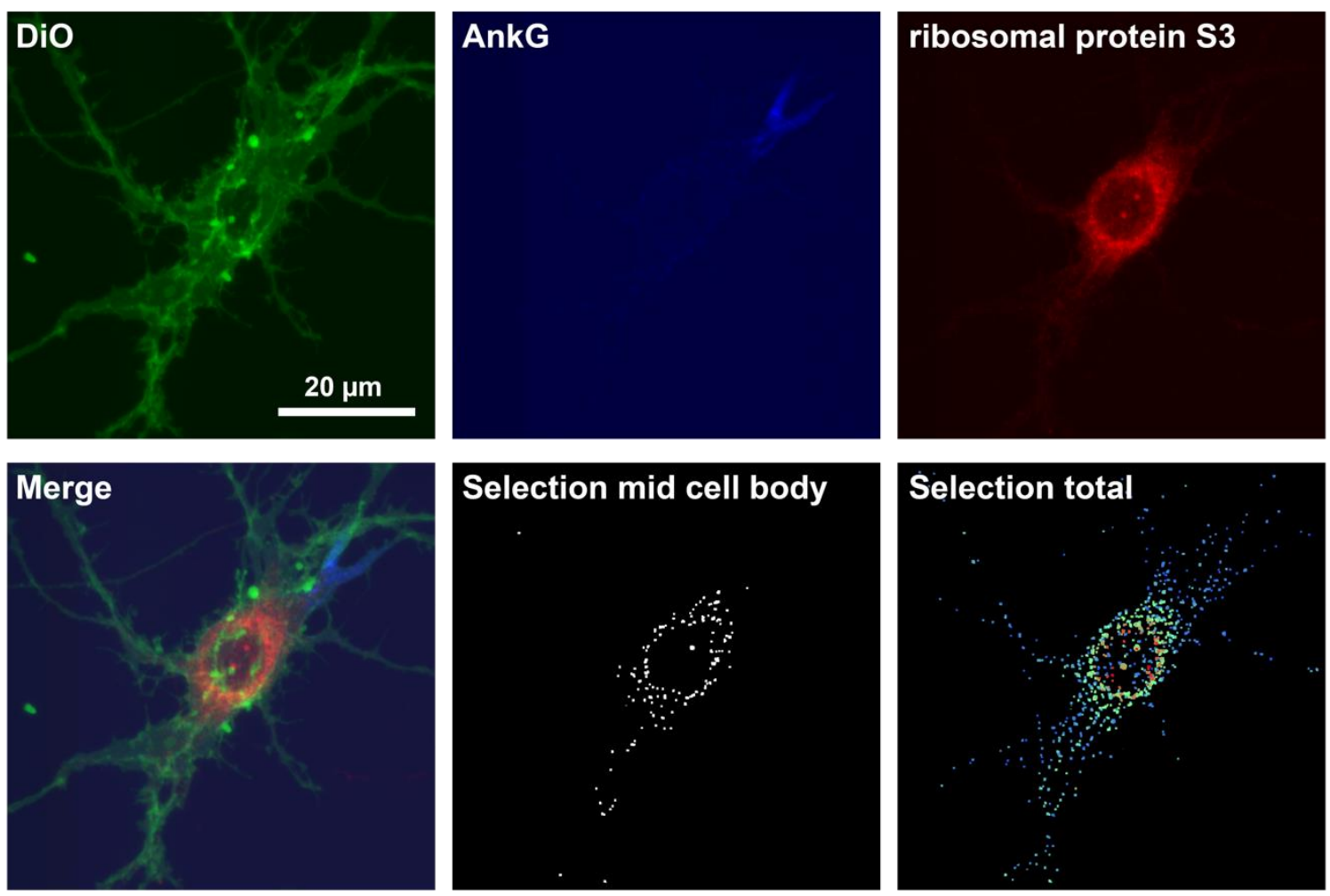

\begin{tabular}{|c|c|c|c|c|c|c|c|c|c|}
\hline properties & $\begin{array}{l}\text { Mean } \\
\text { cell } \\
\text { body }\end{array}$ & $\begin{array}{l}\text { SD cell } \\
\text { body }\end{array}$ & $\begin{array}{l}\text { Mean } \\
\text { axon }\end{array}$ & $\begin{array}{l}\text { SD } \\
\text { axon }\end{array}$ & $\begin{array}{l}\text { Mean } \\
\text { dendrites }\end{array}$ & $\begin{array}{l}\text { SD } \\
\text { dendrites }\end{array}$ & $\begin{array}{l}\text { P value cell } \\
\text { body vs. } \\
\text { axon }\end{array}$ & $\begin{array}{l}\text { P value cell } \\
\text { body vs. } \\
\text { dendrites }\end{array}$ & $\begin{array}{l}\text { P value } \\
\text { axon vs. } \\
\text { dendrites }\end{array}$ \\
\hline Area $\left(\mu \mathrm{m}^{2}\right)$ & 0.152 & 0.086 & 0.128 & 0.065 & 0.115 & 0.066 & $2.40 \mathrm{E}-36$ & $1.08 \mathrm{E}-204$ & $6.10 \mathrm{E}-17$ \\
\hline Major axis $(\mu \mathrm{m})$ & 0.494 & 0.174 & 0.455 & 0.160 & 0.430 & 0.159 & & $6.49 \mathrm{E}-84$ & \\
\hline Minor axis $(\mu \mathrm{m})$ & 0.396 & 0.070 & 0.357 & 0.091 & 0.334 & 0.108 & $1.98 \mathrm{E}-50$ & 1.47E-267 & \\
\hline $\begin{array}{l}\text { Equivalent circle } \\
\text { diameter }(\mu \mathrm{m})\end{array}$ & 0.429 & 0.100 & 0.388 & 0.108 & 0.364 & 0.120 & & $1.08 \mathrm{E}-204$ & \\
\hline Perimeter $(\mu \mathrm{m})$ & 1.310 & 0.442 & 1.207 & 0.383 & 1.144 & 0.393 & & 2.64E-106 & \\
\hline Percent of volume (\%) & 0.003 & 0.002 & 0.002 & 0.002 & 0.002 & 0.002 & $1.05 \mathrm{E}-25$ & $8.53 \mathrm{E}-134$ & \\
\hline $\begin{array}{l}\text { Minimum distance from } \\
\text { cell body edge }(\mu \mathrm{m})\end{array}$ & 3.160 & 2.042 & 7.557 & 6.723 & 11.211 & 7.751 & $1.02 \mathrm{E}-197$ & $0.00 \mathrm{E}+00$ & $6.75 \mathrm{E}-100$ \\
\hline $\begin{array}{l}\text { Minimum distance from } \\
\text { nucleus edge }(\mu \mathrm{m})\end{array}$ & 5.012 & 4.485 & 15.815 & 8.186 & 19.036 & 8.832 & $0.00 E+00$ & $0.00 \mathrm{E}+00$ & $4.94 \mathrm{E}-53$ \\
\hline $\begin{array}{l}\text { Approximate depth in Z } \\
(\mu \mathrm{m})\end{array}$ & 0.396 & 0.070 & 0.357 & 0.091 & 0.334 & 0.108 & $1.98 \mathrm{E}-50$ & 1.47E-267 & \\
\hline $\begin{array}{l}\text { Minimum distance to the } \\
\text { next object }(\mu \mathrm{m})\end{array}$ & 0.771 & 5.160 & 0.770 & 0.453 & 0.910 & 0.730 & & $9.61 \mathrm{E}-35$ & \\
\hline
\end{tabular}

Figure 52: Ribosomal protein S3, characterization in cell bodies, axons, and dendrites. Shown in the top panel is the DiO plasma membrane staining in green, the ankyrinG immunostaining in blue, and the ribosomal protein S3 staining in red. All images were acquired by confocal microscopy taking stacks across entire neuronal cell bodies. The images shown are maximum projections of these stacks. The second row shows a merge image of the three markers. The other two images in the second row represent the objects 
extracted from the organelle staining during the analysis. The middle image shows the objects in the middle section of the z-stack, the third image shows all objects color-coded based on the z-level. The extracted objects were grouped dependent on their presence in the cell body, the axon, or the dendrite and parameters such as the area, and the percent of total volume for each object were extracted. The table shows the mean values and SDs for these parameters in the different regions. The parameters were compared between the different regions using a multiple comparison ranksum Mann-Whitney $U$ test and a Bonferroni correction. Significant differences are indicated in green. 20 neurons from 2 different cultures were analysed.

\section{ribosomal protein S3}
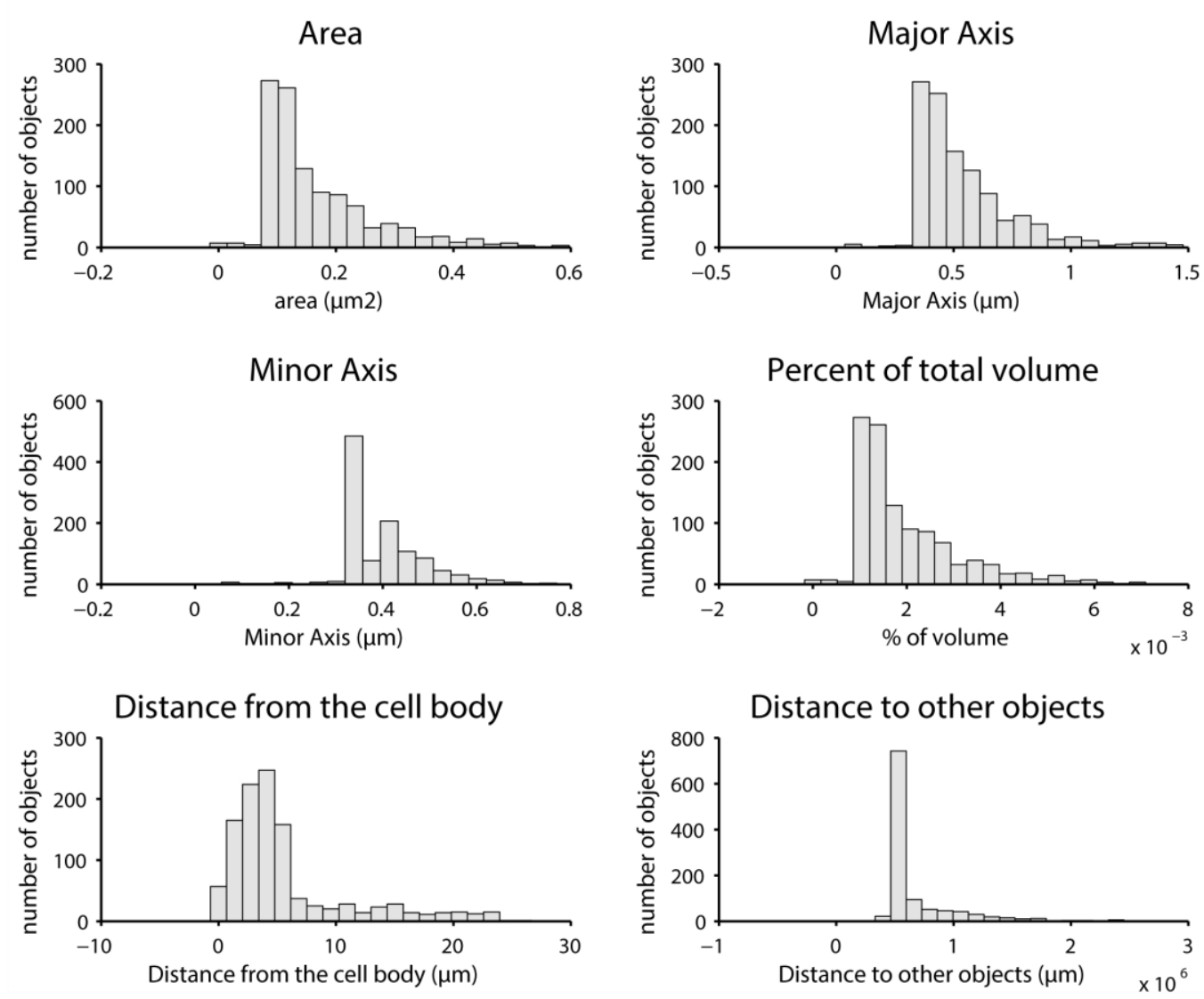

Figure 53: Distribution of ribosomal protein S3. From the objects found during the analysis, I extracted several parameters including the area, the axis, the object volume, the distance to the cell body, and the distance to the neighbouring objects. These parameters are given here in the form of histograms. The bin size was chosen according to the data range. 


\section{ribosomal protein $\mathbf{S 6}$}
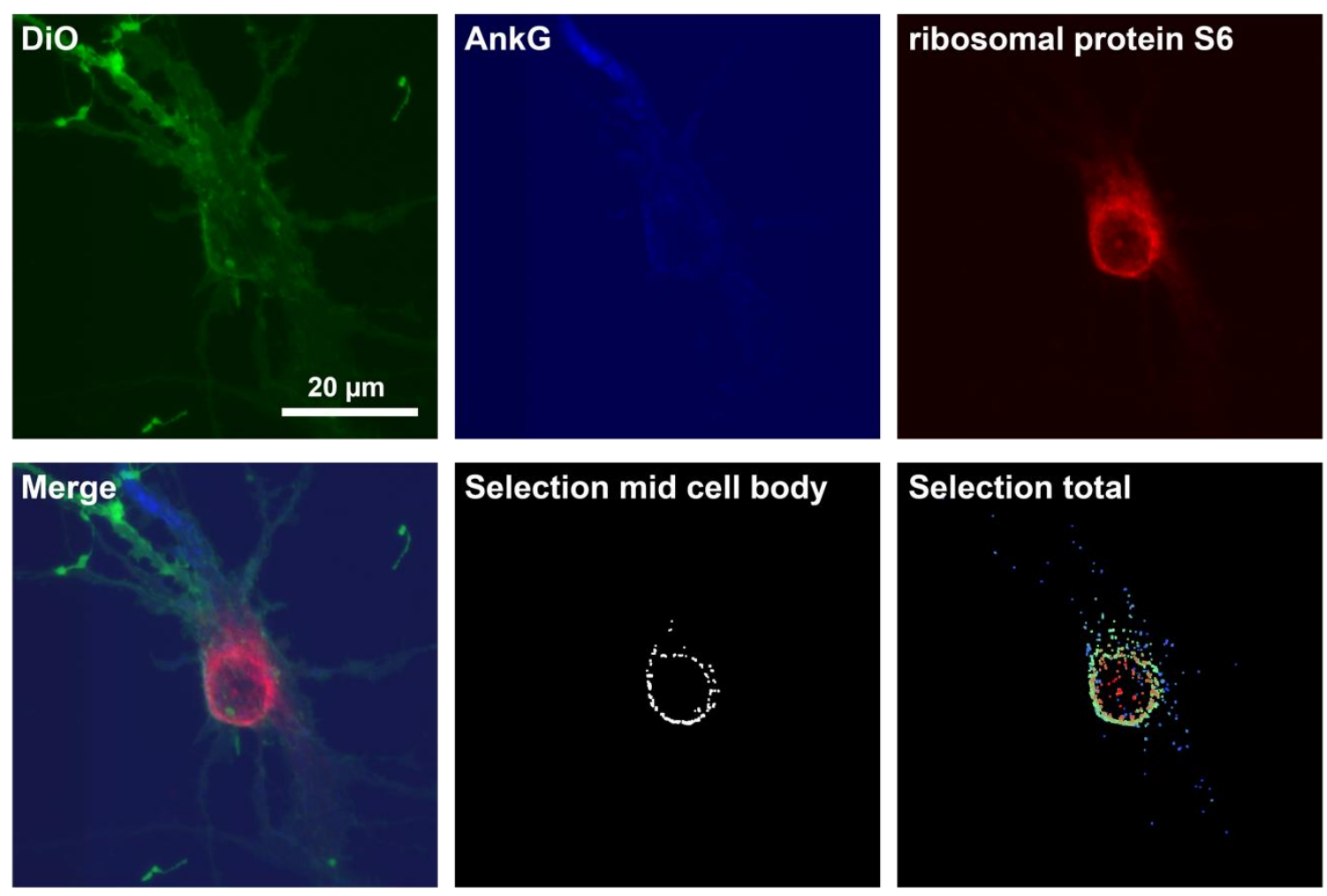

\begin{tabular}{|c|c|c|c|c|c|c|c|c|c|}
\hline properties & $\begin{array}{l}\text { Mean } \\
\text { cell } \\
\text { body }\end{array}$ & $\begin{array}{l}\text { SD cell } \\
\text { body }\end{array}$ & $\begin{array}{l}\text { Mean } \\
\text { axon }\end{array}$ & $\begin{array}{l}\text { SD } \\
\text { axon }\end{array}$ & $\begin{array}{l}\text { Mean } \\
\text { dendrites }\end{array}$ & $\begin{array}{l}\text { SD } \\
\text { dendrites }\end{array}$ & $\begin{array}{l}\text { P value cell } \\
\text { body vs. } \\
\text { axon }\end{array}$ & $\begin{array}{l}\text { P value cell } \\
\text { body vs. } \\
\text { dendrites }\end{array}$ & $\begin{array}{l}\text { P value } \\
\text { axon vs. } \\
\text { dendrites }\end{array}$ \\
\hline Area $\left(\mu \mathrm{m}^{2}\right)$ & 0.162 & 0.140 & 0.126 & 0.066 & 0.123 & 0.071 & & $2.36 \mathrm{E}-24$ & \\
\hline Major axis $(\mu \mathrm{m})$ & 0.512 & 0.290 & 0.443 & 0.152 & 0.440 & 0.174 & & $3.53 \mathrm{E}-15$ & \\
\hline Minor axis $(\mu \mathrm{m})$ & 0.399 & 0.076 & 0.359 & 0.089 & 0.356 & 0.094 & $1.59 \mathrm{E}-05$ & $2.34 \mathrm{E}-26$ & \\
\hline $\begin{array}{l}\text { Equivalent circle } \\
\text { diameter }(\mu \mathrm{m})\end{array}$ & 0.435 & 0.128 & 0.385 & 0.108 & 0.380 & 0.112 & & $2.36 \mathrm{E}-24$ & \\
\hline Perimeter $(\mu \mathrm{m})$ & 1.356 & 0.707 & 1.184 & 0.396 & 1.197 & 0.441 & & $2.58 \mathrm{E}-14$ & \\
\hline Percent of volume (\%) & 0.002 & 0.003 & 0.002 & 0.001 & 0.002 & 0.001 & & & $3.03 E-05$ \\
\hline $\begin{array}{l}\text { Minimum distance from } \\
\text { cell body edge }(\mu \mathrm{m})\end{array}$ & 7.435 & 12.420 & 5.228 & 4.666 & 8.001 & 6.584 & & & $1.93 \mathrm{E}-05$ \\
\hline $\begin{array}{l}\text { Minimum distance from } \\
\text { nucleus edge }(\mu \mathrm{m})\end{array}$ & 6.510 & 7.844 & 13.598 & 8.167 & 16.356 & 7.887 & 4.95E-19 & $6.47 \mathrm{E}-168$ & \\
\hline $\begin{array}{l}\text { Approximate depth in Z } \\
(\mu \mathrm{m})\end{array}$ & 0.399 & 0.076 & 0.359 & 0.089 & 0.356 & 0.094 & $1.59 \mathrm{E}-05$ & $2.34 \mathrm{E}-26$ & \\
\hline $\begin{array}{l}\text { Minimum distance to the } \\
\text { next object }(\mu \mathrm{m})\end{array}$ & 0.936 & 0.826 & 1.434 & 1.595 & 2.189 & 2.730 & & $1.21 \mathrm{E}-20$ & \\
\hline
\end{tabular}

Figure 54: Ribosomal protein S6, characterization in cell bodies, axons, and dendrites. Shown in the top panel is the DiO plasma membrane staining in green, the ankyrinG immunostaining in blue, and the ribosomal protein 56 staining in red. All images were acquired by confocal microscopy taking stacks across entire neuronal cell bodies. The images shown are maximum projections of these stacks. The second row shows a merge image of the three markers. The other two images in the second row represent the objects 
extracted from the organelle staining during the analysis. The middle image shows the objects in the middle section of the z-stack, the third image shows all objects color-coded based on the z-level. The extracted objects were grouped dependent on their presence in the cell body, the axon, or the dendrite and parameters such as the area, and the percent of total volume for each object were extracted. The table shows the mean values and SDs for these parameters in the different regions. The parameters were compared between the different regions using a multiple comparison ranksum Mann-Whitney $U$ test and a Bonferroni correction. Significant differences are indicated in green. 20 neurons from 2 different cultures were analysed.

ribosomal protein S6
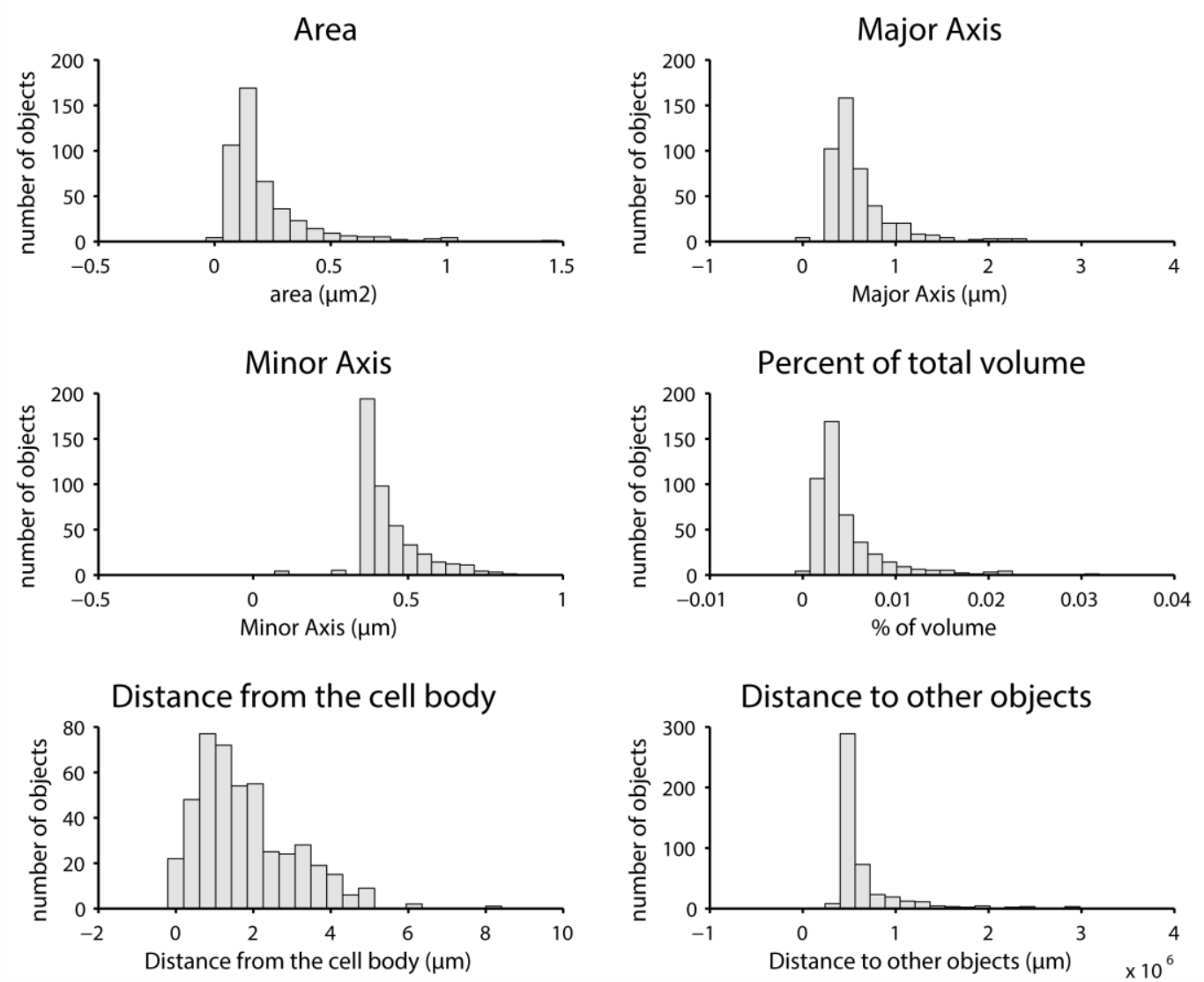

Figure 55: Distribution of ribosomal protein S6. From the objects found during the analysis, I extracted several parameters including the area, the axis, the object volume, the distance to the cell body, and the distance to the neighbouring objects. These parameters are given here in the form of histograms. The bin size was chosen according to the data range. 


\section{synaptophysin}
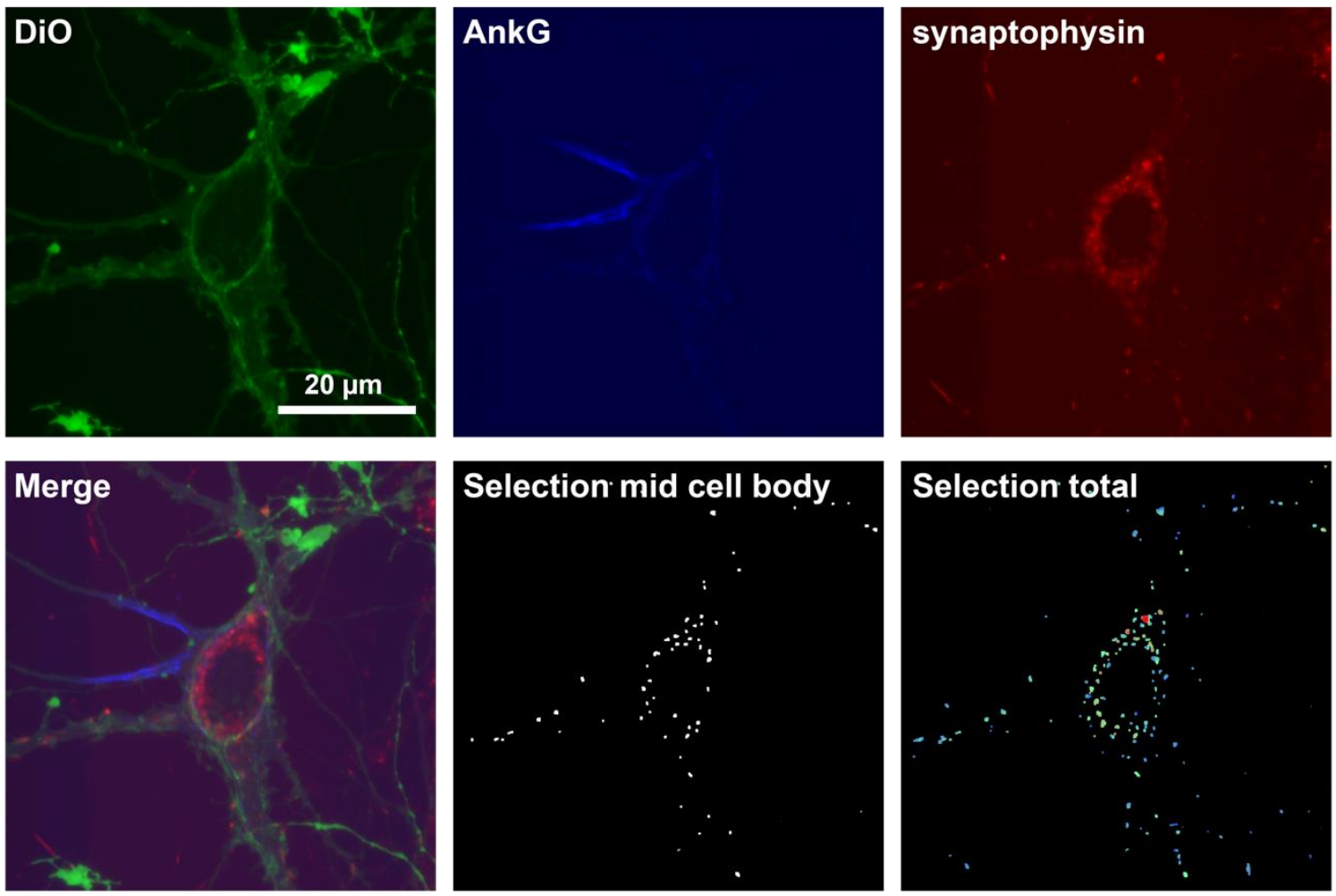

\begin{tabular}{|c|c|c|c|c|c|c|c|c|c|}
\hline properties & $\begin{array}{l}\text { Mean } \\
\text { cell } \\
\text { body }\end{array}$ & $\begin{array}{l}\text { SD cell } \\
\text { body }\end{array}$ & $\begin{array}{l}\text { Mean } \\
\text { axon }\end{array}$ & $\begin{array}{l}\text { SD } \\
\text { axon }\end{array}$ & $\begin{array}{l}\text { Mean } \\
\text { dendrites }\end{array}$ & $\begin{array}{l}\text { SD } \\
\text { dendrites }\end{array}$ & $\begin{array}{l}\text { P value cell } \\
\text { body vs. } \\
\text { axon }\end{array}$ & $\begin{array}{l}\text { P value cell } \\
\text { body vs. } \\
\text { dendrites }\end{array}$ & $\begin{array}{l}\text { P value } \\
\text { axon vs. } \\
\text { dendrites }\end{array}$ \\
\hline Area $\left(\mu \mathrm{m}^{2}\right)$ & 0.290 & 0.216 & 0.233 & 0.203 & 0.182 & 0.155 & $9.41 \mathrm{E}-72$ & $2.14 \mathrm{E}-146$ & $5.41 \mathrm{E}-26$ \\
\hline Major axis $(\mu \mathrm{m})$ & 0.730 & 0.376 & 0.663 & 0.386 & 0.576 & 0.312 & & $7.98 \mathrm{E}-70$ & $4.10 \mathrm{E}-23$ \\
\hline Minor axis $(\mu \mathrm{m})$ & 0.490 & 0.136 & 0.410 & 0.183 & 0.368 & 0.165 & $4.58 \mathrm{E}-106$ & 3.64E-189 & $8.82 \mathrm{E}-26$ \\
\hline $\begin{array}{l}\text { Equivalent circle } \\
\text { diameter }(\mu \mathrm{m})\end{array}$ & 0.575 & 0.197 & 0.492 & 0.233 & 0.437 & 0.204 & $9.41 \mathrm{E}-72$ & $2.14 \mathrm{E}-146$ & $5.41 \mathrm{E}-26$ \\
\hline Perimeter $(\mu \mathrm{m})$ & 1.900 & 0.926 & 1.753 & 0.943 & 1.530 & 0.766 & & $9.34 \mathrm{E}-67$ & $2.11 \mathrm{E}-25$ \\
\hline Percent of volume (\%) & 0.003 & 0.003 & 0.003 & 0.002 & 0.002 & 0.002 & $1.04 \mathrm{E}-91$ & 1.19E-94 & \\
\hline $\begin{array}{l}\text { Minimum distance from } \\
\text { cell body edge }(\mu \mathrm{m})\end{array}$ & 3.265 & 2.330 & 9.513 & 7.244 & 10.732 & 7.314 & $0.00 \mathrm{E}+00$ & $0.00 \mathrm{E}+00$ & $1.40 \mathrm{E}-15$ \\
\hline $\begin{array}{l}\text { Minimum distance from } \\
\text { nucleus edge }(\mu \mathrm{m})\end{array}$ & 5.222 & 4.507 & 17.951 & 8.491 & 19.937 & 8.626 & $0.00 \mathrm{E}+00$ & $0.00 \mathrm{E}+00$ & $1.11 \mathrm{E}-26$ \\
\hline $\begin{array}{l}\text { Approximate depth in Z } \\
(\mu \mathrm{m})\end{array}$ & 0.490 & 0.136 & 0.410 & 0.183 & 0.368 & 0.165 & $4.58 \mathrm{E}-106$ & $3.64 \mathrm{E}-189$ & $8.82 \mathrm{E}-26$ \\
\hline $\begin{array}{l}\text { Minimum distance to the } \\
\text { next object }(\mu \mathrm{m})\end{array}$ & 0.674 & 0.405 & 0.668 & 0.482 & 0.771 & 0.886 & & $2.88 \mathrm{E}-44$ & $4.81 \mathrm{E}-35$ \\
\hline
\end{tabular}

Figure 56: Synaptophysin, characterization in cell bodies, axons, and dendrites. Shown in the top panel is the DiO plasma membrane staining in green, the ankyring immunostaining in blue, and the synaptophysin staining in red. All images were acquired by confocal microscopy taking stacks across entire neuronal cell bodies. The images shown are maximum projections of these stacks. The second row shows a merge image of the three markers. The other two images in the second row represent the objects extracted 
from the organelle staining during the analysis. The middle image shows the objects in the middle section of the z-stack, the third image shows all objects color-coded based on the z-level. The extracted objects were grouped dependent on their presence in the cell body, the axon, or the dendrite and parameters such as the area, and the percent of total volume for each object were extracted. The table shows the mean values and SDs for these parameters in the different regions. The parameters were compared between the different regions using a multiple comparison ranksum Mann-Whitney $U$ test and a Bonferroni correction. Significant differences are indicated in green. 20 neurons from 2 different cultures were analysed.

synaptophysin

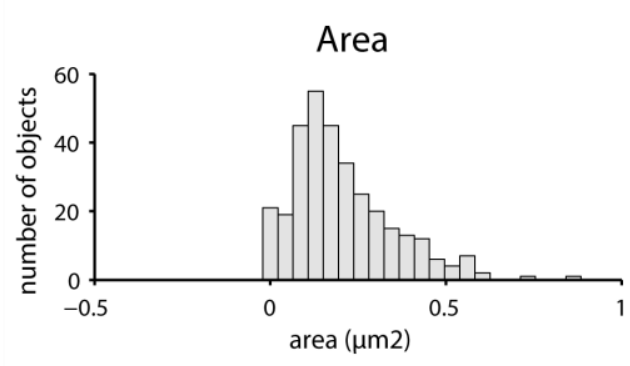

Minor Axis

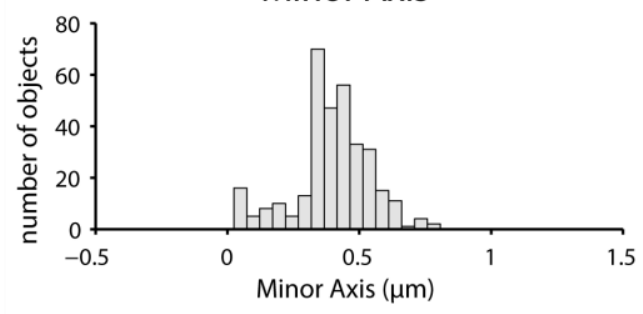

Distance from the cell body

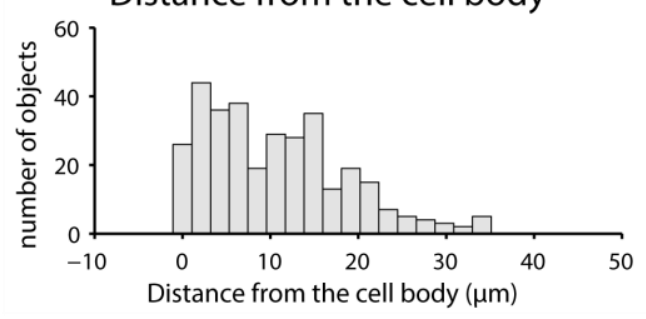

Major Axis

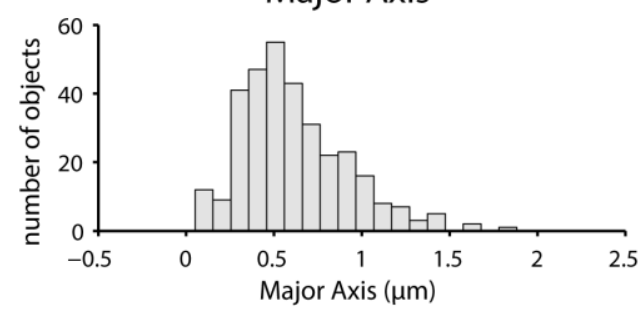

Percent of total volume

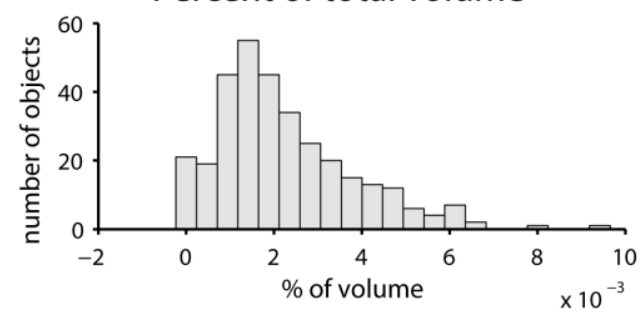

Distance to other objects

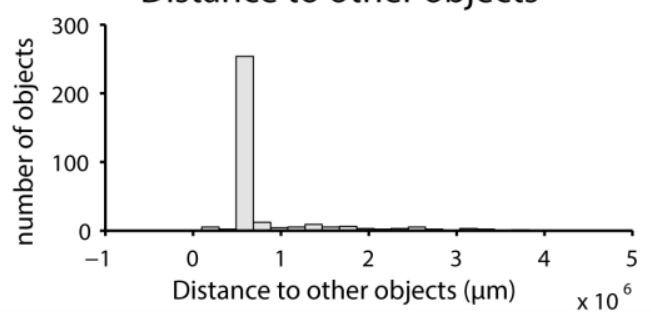

Figure 57: Distribution of synaptophysin. From the objects found during the analysis, I extracted several parameters including the area, the axis, the object volume, the distance to the cell body, and the distance to the neighbouring objects. These parameters are given here in the form of histograms. The bin size was chosen according to the data range. 


\section{transferrin receptor}
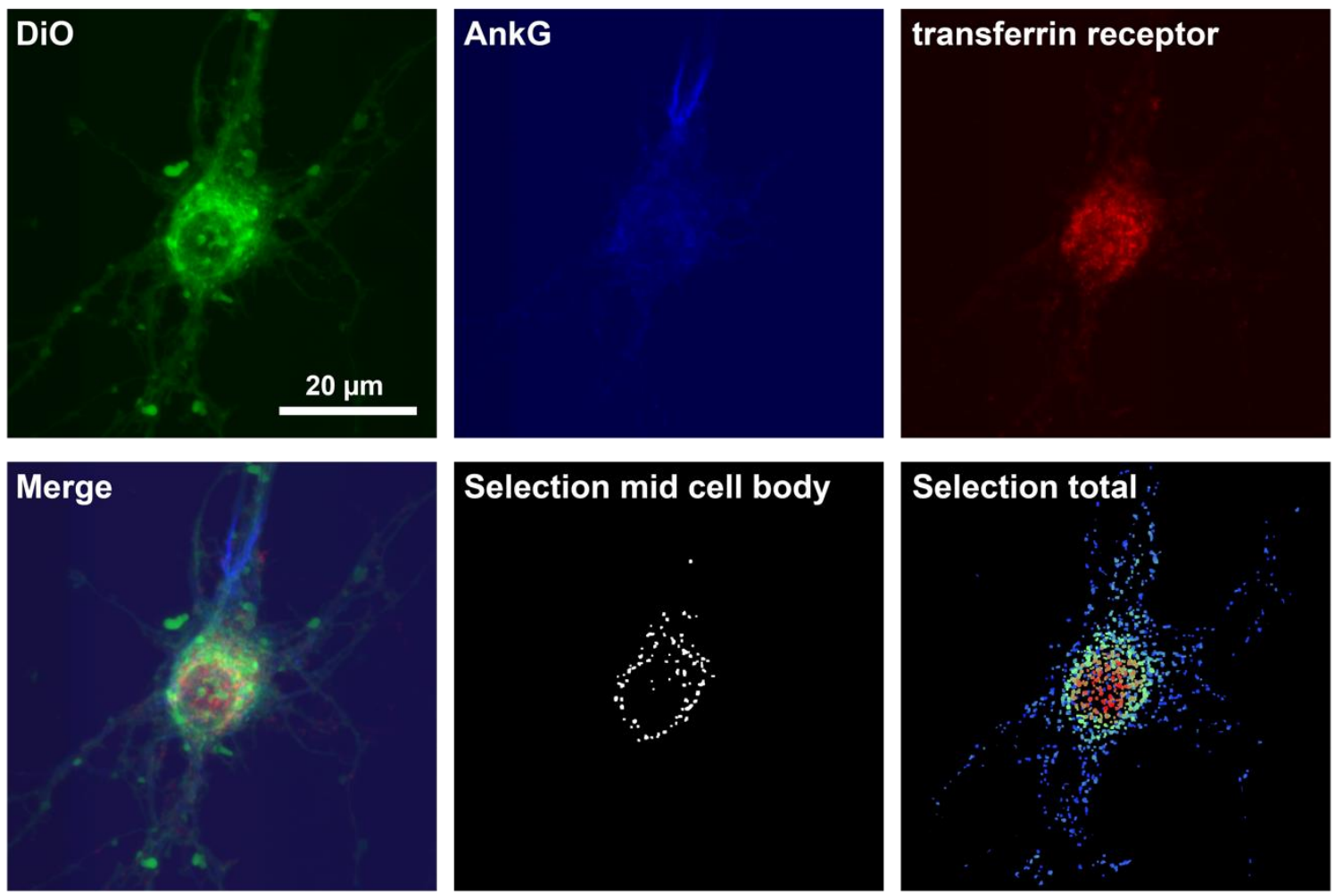

\begin{tabular}{|c|c|c|c|c|c|c|c|c|c|}
\hline properties & $\begin{array}{l}\text { Mean } \\
\text { cell } \\
\text { body }\end{array}$ & $\begin{array}{l}\text { SD cell } \\
\text { body }\end{array}$ & $\begin{array}{l}\text { Mean } \\
\text { axon }\end{array}$ & $\begin{array}{l}\text { SD } \\
\text { axon }\end{array}$ & $\begin{array}{l}\text { Mean } \\
\text { dendrites }\end{array}$ & $\begin{array}{l}\text { SD } \\
\text { dendrites }\end{array}$ & $\begin{array}{l}\text { P value cell } \\
\text { body vs. } \\
\text { axon }\end{array}$ & $\begin{array}{l}\text { P value cell } \\
\text { body vs. } \\
\text { dendrites }\end{array}$ & $\begin{array}{l}\text { P value } \\
\text { axon vs. } \\
\text { dendrites }\end{array}$ \\
\hline Area $\left(\mu \mathrm{m}^{2}\right)$ & 0.219 & 0.165 & 0.190 & 0.116 & 0.155 & 0.120 & $5.20 \mathrm{E}-10$ & $6.70 \mathrm{E}-190$ & $5.66 \mathrm{E}-33$ \\
\hline Major axis $(\mu \mathrm{m})$ & 0.615 & 0.288 & 0.577 & 0.250 & 0.510 & 0.249 & & $6.54 \mathrm{E}-105$ & 4.89E-20 \\
\hline Minor axis $(\mu \mathrm{m})$ & 0.446 & 0.110 & 0.416 & 0.103 & 0.364 & 0.138 & & $2.58 \mathrm{E}-228$ & $6.60 \mathrm{E}-37$ \\
\hline $\begin{array}{l}\text { Equivalent circle } \\
\text { diameter }(\mu \mathrm{m})\end{array}$ & 0.505 & 0.155 & 0.471 & 0.142 & 0.412 & 0.167 & & $6.70 \mathrm{E}-190$ & $5.66 \mathrm{E}-33$ \\
\hline Perimeter $(\mu \mathrm{m})$ & 1.628 & 0.752 & 1.522 & 0.619 & 1.365 & 0.627 & & $1.92 \mathrm{E}-99$ & $7.94 \mathrm{E}-19$ \\
\hline Percent of volume (\%) & 0.002 & 0.002 & 0.004 & 0.004 & 0.003 & 0.003 & $9.74 \mathrm{E}-106$ & & $4.32 E-58$ \\
\hline $\begin{array}{l}\text { Minimum distance from } \\
\text { cell body edge }(\mu \mathrm{m})\end{array}$ & 13.175 & 13.582 & 5.734 & 5.816 & 9.056 & 6.912 & 6.97E-111 & $2.04 \mathrm{E}-11$ & 1.23E-78 \\
\hline $\begin{array}{l}\text { Minimum distance from } \\
\text { nucleus edge }(\mu \mathrm{m})\end{array}$ & 9.735 & 10.636 & 17.036 & 9.551 & 20.655 & 8.989 & $6.87 \mathrm{E}-229$ & $0.00 \mathrm{E}+00$ & $1.79 \mathrm{E}-42$ \\
\hline $\begin{array}{l}\text { Approximate depth in Z } \\
(\mu \mathrm{m})\end{array}$ & 0.446 & 0.110 & 0.416 & 0.103 & 0.364 & 0.138 & & $2.58 \mathrm{E}-228$ & $6.60 \mathrm{E}-37$ \\
\hline $\begin{array}{l}\text { Minimum distance to the } \\
\text { next object }(\mu \mathrm{m})\end{array}$ & 0.704 & 0.462 & 0.763 & 0.428 & 0.811 & 0.657 & & & \\
\hline
\end{tabular}

Figure 58: Transferrin receptor, characterization in cell bodies, axons, and dendrites. Shown in the top panel is the DiO plasma membrane staining in green, the ankyrinG immunostaining in blue, and the transferrin receptor staining in red. All images were acquired by confocal microscopy taking stacks across entire neuronal cell bodies. The images shown are maximum projections of these stacks. The second row shows a merge image of the three markers. The other two images in the second row represent the objects 
extracted from the organelle staining during the analysis. The middle image shows the objects in the middle section of the z-stack, the third image shows all objects color-coded based on the z-level. The extracted objects were grouped dependent on their presence in the cell body, the axon, or the dendrite and parameters such as the area, and the percent of total volume for each object were extracted. The table shows the mean values and SDs for these parameters in the different regions. The parameters were compared between the different regions using a multiple comparison ranksum Mann-Whitney $U$ test and a Bonferroni correction. Significant differences are indicated in green. 20 neurons from 2 different cultures were analysed.

\section{transferrin receptor}
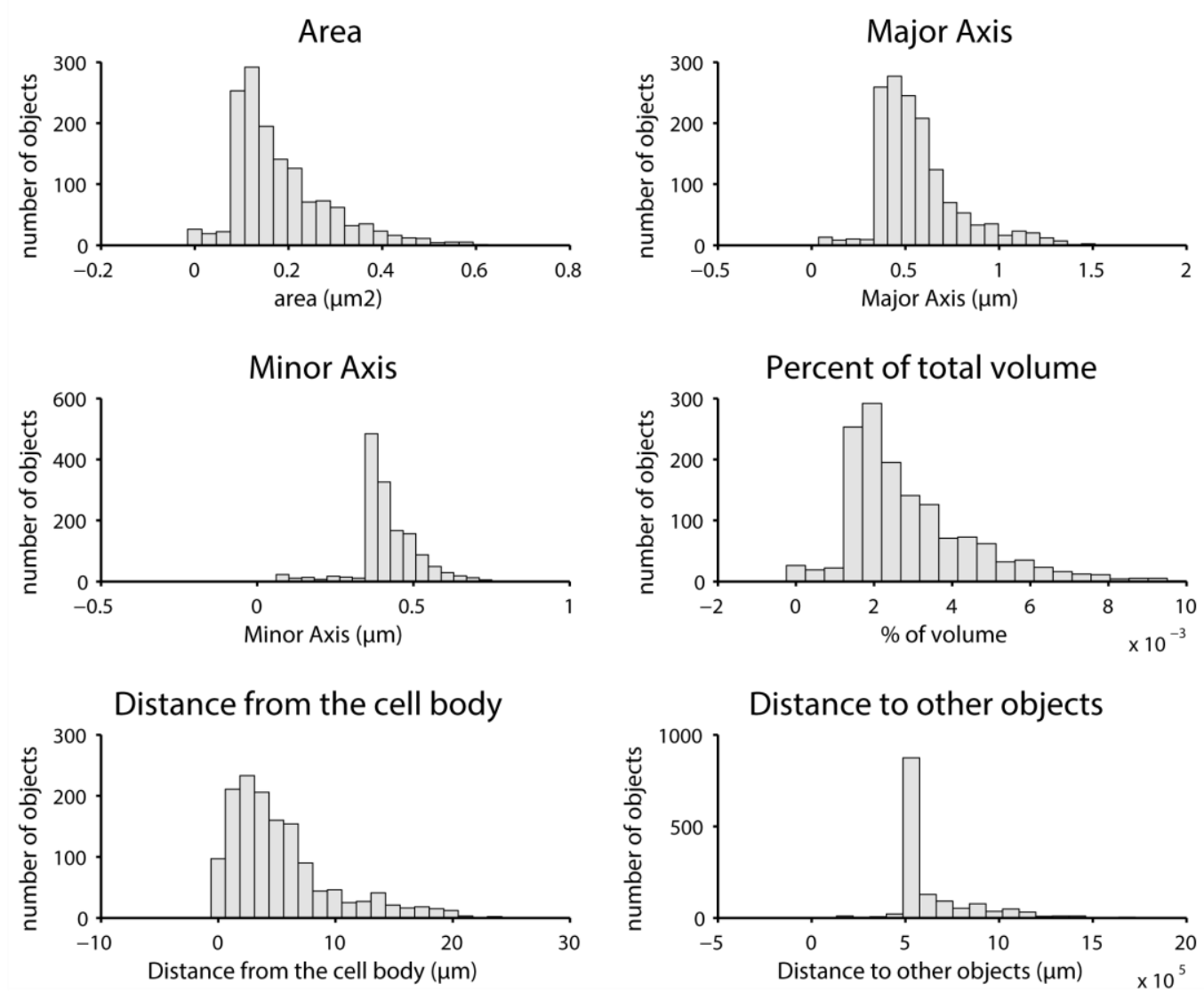

Figure 59: Distribution of transferrin receptor. From the objects found during the analysis, I extracted several parameters including the area, the axis, the object volume, the distance to the cell body, and the distance to the neighbouring objects. These parameters are given here in the form of histograms. The bin size was chosen according to the data range. 


\section{TGN38}
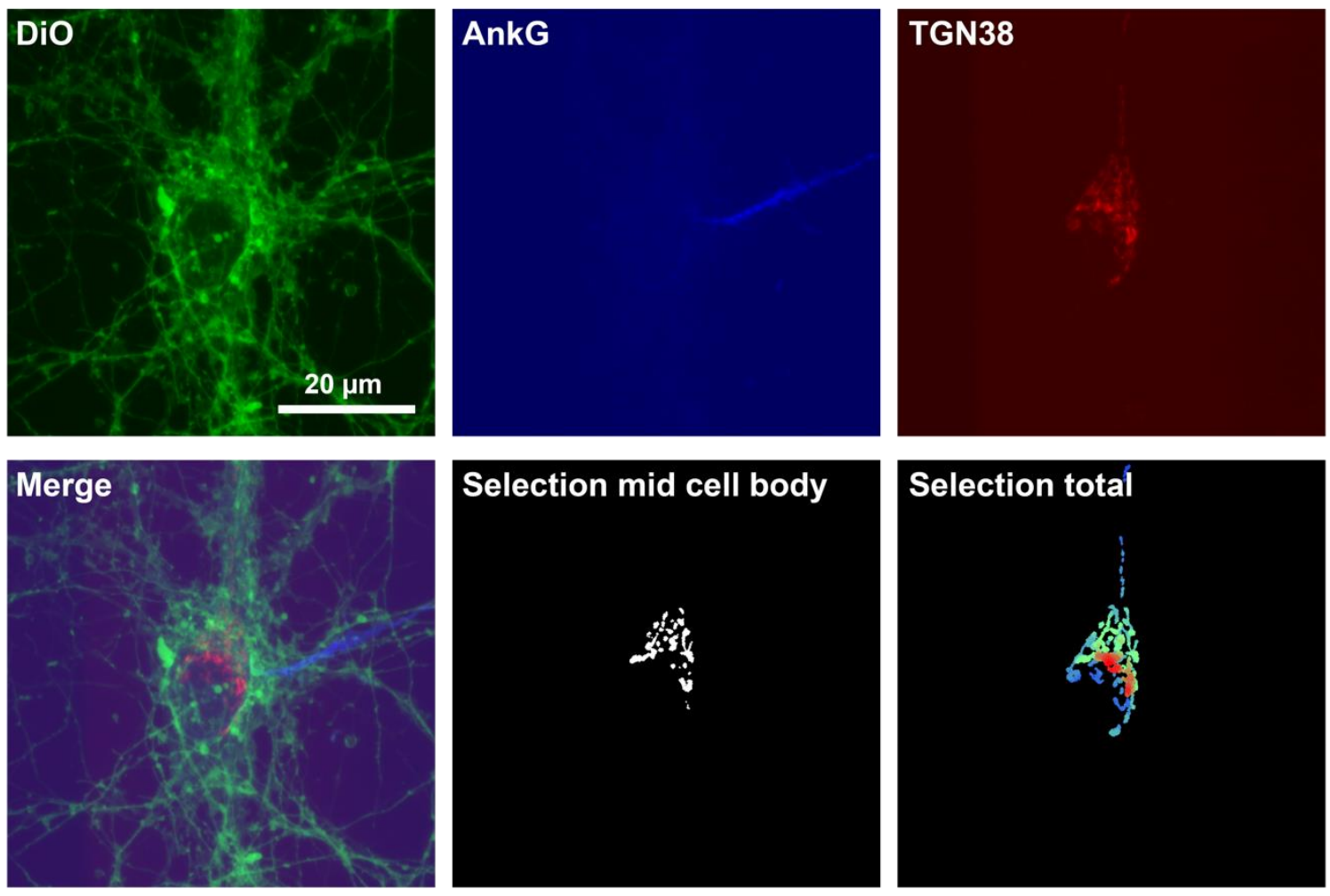

\begin{tabular}{|c|c|c|c|c|c|c|c|c|c|}
\hline properties & $\begin{array}{l}\text { Mean } \\
\text { cell } \\
\text { body }\end{array}$ & $\begin{array}{l}\text { SD cell } \\
\text { body }\end{array}$ & $\begin{array}{l}\text { Mean } \\
\text { axon }\end{array}$ & $\begin{array}{l}\text { SD } \\
\text { axon }\end{array}$ & $\begin{array}{l}\text { Mean } \\
\text { dendrites }\end{array}$ & $\begin{array}{l}\text { SD } \\
\text { dendrites }\end{array}$ & $\begin{array}{l}\text { P value cell } \\
\text { body vs. } \\
\text { axon }\end{array}$ & $\begin{array}{l}\text { P value cell } \\
\text { body vs. } \\
\text { dendrites }\end{array}$ & $\begin{array}{l}\text { P value } \\
\text { axon vs. } \\
\text { dendrites }\end{array}$ \\
\hline Area $\left(\mu \mathrm{m}^{2}\right)$ & 1.262 & 2.544 & 0.346 & 0.430 & 0.459 & 0.814 & $3.55 \mathrm{E}-19$ & $3.74 \mathrm{E}-82$ & \\
\hline Major axis $(\mu \mathrm{m})$ & 1.510 & 1.491 & 0.760 & 0.678 & 0.845 & 0.823 & 8.30E-15 & $1.89 \mathrm{E}-66$ & \\
\hline Minor axis $(\mu \mathrm{m})$ & 0.850 & 0.674 & 0.445 & 0.341 & 0.508 & 0.396 & 9.56E-19 & $9.85 E-81$ & \\
\hline $\begin{array}{l}\text { Equivalent circle } \\
\text { diameter }(\mu \mathrm{m})\end{array}$ & 1.020 & 0.753 & 0.521 & 0.412 & 0.595 & 0.479 & $3.55 \mathrm{E}-19$ & $3.74 \mathrm{E}-82$ & \\
\hline Perimeter $(\mu \mathrm{m})$ & 4.762 & 5.762 & 2.863 & 2.187 & 2.807 & 2.740 & & $2.13 E-37$ & \\
\hline Percent of volume (\%) & 0.017 & 0.037 & 0.003 & 0.004 & 0.005 & 0.010 & $4.84 \mathrm{E}-23$ & $6.63 E-93$ & \\
\hline $\begin{array}{l}\text { Minimum distance from } \\
\text { cell body edge }(\mu \mathrm{m})\end{array}$ & 3.968 & 2.002 & 3.816 & 3.166 & 5.743 & 4.359 & & $7.61 \mathrm{E}-26$ & 4.55E-08 \\
\hline $\begin{array}{l}\text { Minimum distance from } \\
\text { nucleus edge }(\mu \mathrm{m})\end{array}$ & 5.023 & 5.034 & 10.897 & 6.363 & 13.487 & 6.915 & $1.50 \mathrm{E}-28$ & $1.24 \mathrm{E}-234$ & \\
\hline $\begin{array}{l}\text { Approximate depth in Z } \\
(\mu \mathrm{m})\end{array}$ & 0.850 & 0.674 & 0.445 & 0.341 & 0.508 & 0.396 & 9.56E-19 & $9.85 \mathrm{E}-81$ & \\
\hline $\begin{array}{l}\text { Minimum distance to the } \\
\text { next object }(\mu \mathrm{m})\end{array}$ & 0.649 & 0.340 & 0.524 & 0.537 & 0.911 & 2.493 & $1.11 \mathrm{E}-16$ & $2.21 \mathrm{E}-49$ & \\
\hline
\end{tabular}

Figure 60: TGN38, characterization in cell bodies, axons, and dendrites. Shown in the top panel is the DiO plasma membrane staining in green, the ankyrinG immunostaining in blue, and the TGN38 staining in red. All images were acquired by confocal microscopy taking stacks across entire neuronal cell bodies. The images shown are maximum projections of these stacks. The second row shows a merge image of the three markers. The other two images in the second row represent the objects extracted from the 
organelle staining during the analysis. The middle image shows the objects in the middle section of the z-stack, the third image shows all objects color-coded based on the z-level. The extracted objects were grouped dependent on their presence in the cell body, the axon, or the dendrite and parameters such as the area, and the percent of total volume for each object were extracted. The table shows the mean values and SDs for these parameters in the different regions. The parameters were compared between the different regions using a multiple comparison ranksum Mann-Whitney $U$ test and a Bonferroni correction. Significant differences are indicated in green. 20 neurons from 2 different cultures were analysed.

\section{TGN38}
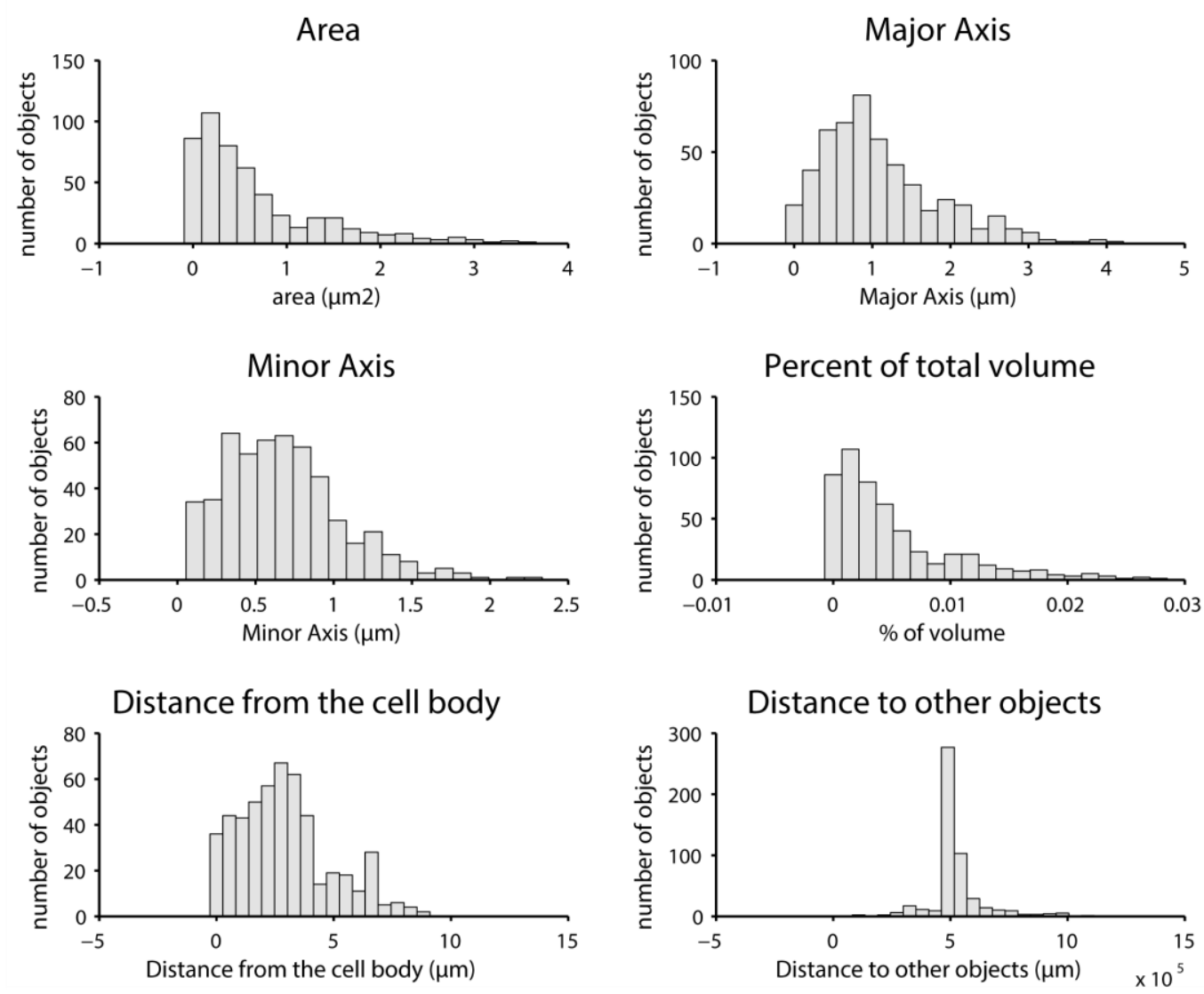

Figure 61: Distribution of TGN38. From the objects found during the analysis, I extracted several parameters including the area, the axis, the object volume, the distance to the cell body, and the distance to the neighbouring objects. These parameters are given here in the form of histograms. The bin size was chosen according to the data range. 


\section{tomm20 other}
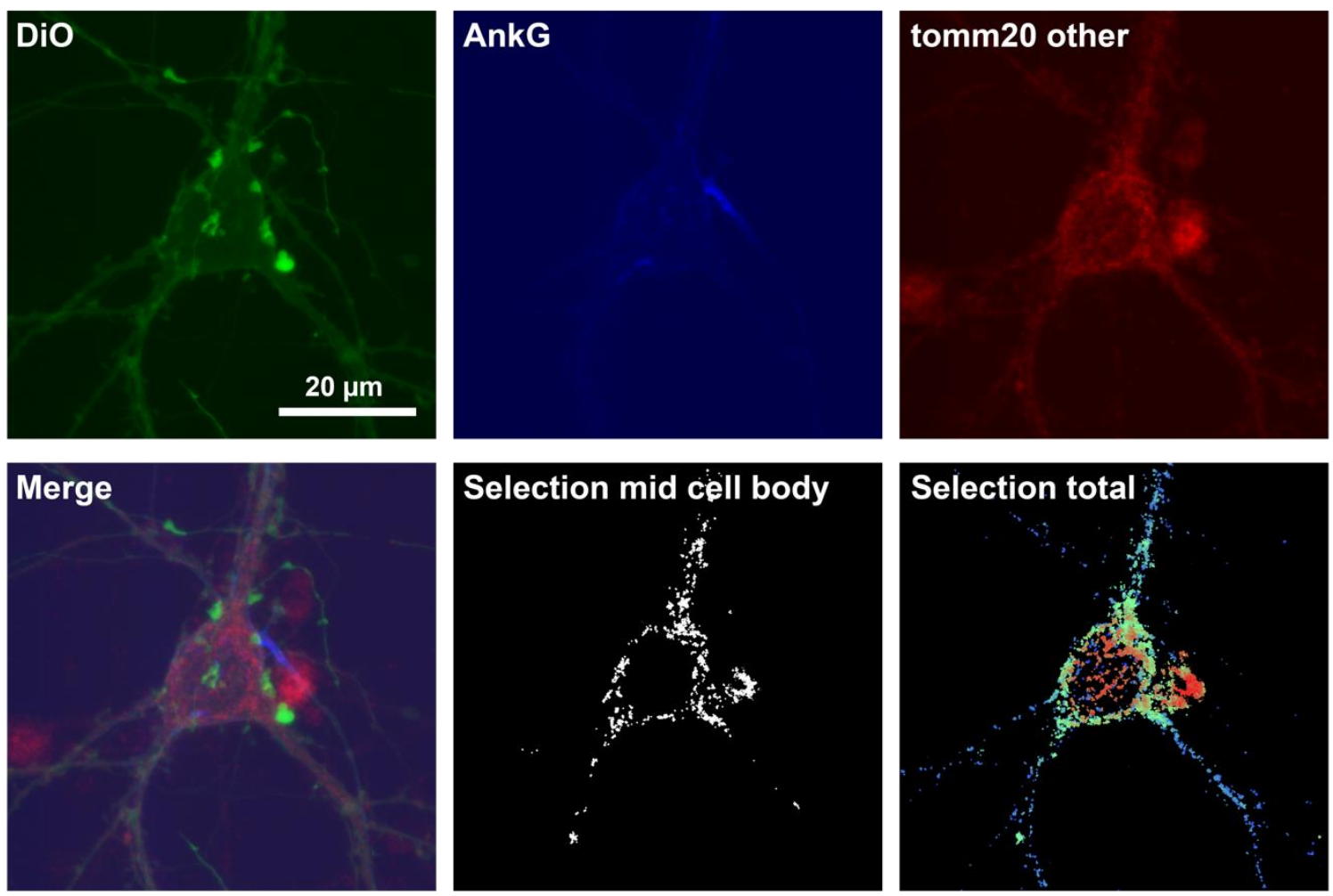

\begin{tabular}{|c|c|c|c|c|c|c|c|c|c|}
\hline properties & $\begin{array}{l}\text { Mean } \\
\text { cell } \\
\text { body }\end{array}$ & $\begin{array}{l}\text { SD cell } \\
\text { body }\end{array}$ & $\begin{array}{l}\text { Mean } \\
\text { axon }\end{array}$ & $\begin{array}{l}\text { SD } \\
\text { axon }\end{array}$ & $\begin{array}{l}\text { Mean } \\
\text { dendrites }\end{array}$ & $\begin{array}{l}\text { SD } \\
\text { dendrites }\end{array}$ & $\begin{array}{l}\text { P value cell } \\
\text { body vs. } \\
\text { axon }\end{array}$ & $\begin{array}{l}\text { P value cell } \\
\text { body vs. } \\
\text { dendrites }\end{array}$ & $\begin{array}{l}\text { P value } \\
\text { axon vs. } \\
\text { dendrites }\end{array}$ \\
\hline Area $\left(\mu \mathrm{m}^{2}\right)$ & 0.986 & 5.955 & 0.689 & 4.534 & 0.143 & 0.231 & $3.79 \mathrm{E}-19$ & $5.38 \mathrm{E}-178$ & $1.21 \mathrm{E}-40$ \\
\hline Major axis $(\mu \mathrm{m})$ & 0.967 & 1.754 & 0.839 & 1.643 & 0.496 & 0.391 & $4.56 \mathrm{E}-12$ & $2.75 \mathrm{E}-130$ & $1.43 \mathrm{E}-34$ \\
\hline Minor axis $(\mu \mathrm{m})$ & 0.585 & 0.950 & 0.488 & 0.862 & 0.331 & 0.163 & $5.34 \mathrm{E}-23$ & $2.78 \mathrm{E}-198$ & $1.08 \mathrm{E}-42$ \\
\hline $\begin{array}{l}\text { Equivalent circle } \\
\text { diameter }(\mu \mathrm{m})\end{array}$ & 0.646 & 0.915 & 0.547 & 0.760 & 0.373 & 0.209 & $3.79 E-19$ & $5.38 \mathrm{E}-178$ & $1.21 \mathrm{E}-40$ \\
\hline Perimeter $(\mu \mathrm{m})$ & 3.749 & 11.679 & 2.977 & 9.850 & 1.352 & 1.303 & 3.54E-11 & 5.51E-146 & 1.15E-42 \\
\hline Percent of volume (\%) & 0.014 & 0.080 & 0.010 & 0.067 & 0.002 & 0.005 & $1.82 \mathrm{E}-14$ & $2.73 \mathrm{E}-115$ & $1.02 \mathrm{E}-25$ \\
\hline $\begin{array}{l}\text { Minimum distance from } \\
\text { cell body edge }(\mu \mathrm{m})\end{array}$ & 3.398 & 1.995 & 7.761 & 6.690 & 11.881 & 7.639 & 3.09E-206 & $0.00 \mathrm{E}+00$ & 1.39E-124 \\
\hline $\begin{array}{l}\text { Minimum distance from } \\
\text { nucleus edge }(\mu \mathrm{m})\end{array}$ & 4.803 & 4.309 & 15.785 & 9.910 & 20.132 & 9.656 & $0.00 \mathrm{E}+00$ & $0.00 \mathrm{E}+00$ & $1.81 \mathrm{E}-79$ \\
\hline $\begin{array}{l}\text { Approximate depth in Z } \\
(\mu \mathrm{m})\end{array}$ & 0.585 & 0.950 & 0.488 & 0.862 & 0.331 & 0.163 & $5.34 \mathrm{E}-23$ & $2.78 \mathrm{E}-198$ & $1.08 \mathrm{E}-42$ \\
\hline $\begin{array}{l}\text { Minimum distance to the } \\
\text { next object }(\mu \mathrm{m})\end{array}$ & 0.655 & 0.239 & 0.720 & 0.508 & 0.890 & 1.010 & & & \\
\hline
\end{tabular}

Figure 62: TOMM20 b-alternative marker, characterization in cell bodies, axons, and dendrites. Shown in the top panel is the DiO plasma membrane staining in green, the ankyring immunostaining in blue, and the TOMM2O $b$ staining in red. All images were acquired by confocal microscopy taking stacks across entire neuronal cell bodies. The images shown are maximum projections of these stacks. The second row shows a merge image of the three markers. The other two images in the second row represent the objects 
extracted from the organelle staining during the analysis. The middle image shows the objects in the middle section of the z-stack, the third image shows all objects color-coded based on the z-level. The extracted objects were grouped dependent on their presence in the cell body, the axon, or the dendrite and parameters such as the area, and the percent of total volume for each object were extracted. The table shows the mean values and SDs for these parameters in the different regions. The parameters were compared between the different regions using a multiple comparison ranksum Mann-Whitney $U$ test and a Bonferroni correction. Significant differences are indicated in green. 20 neurons from 2 different cultures were analysed.

TOMM-20 b
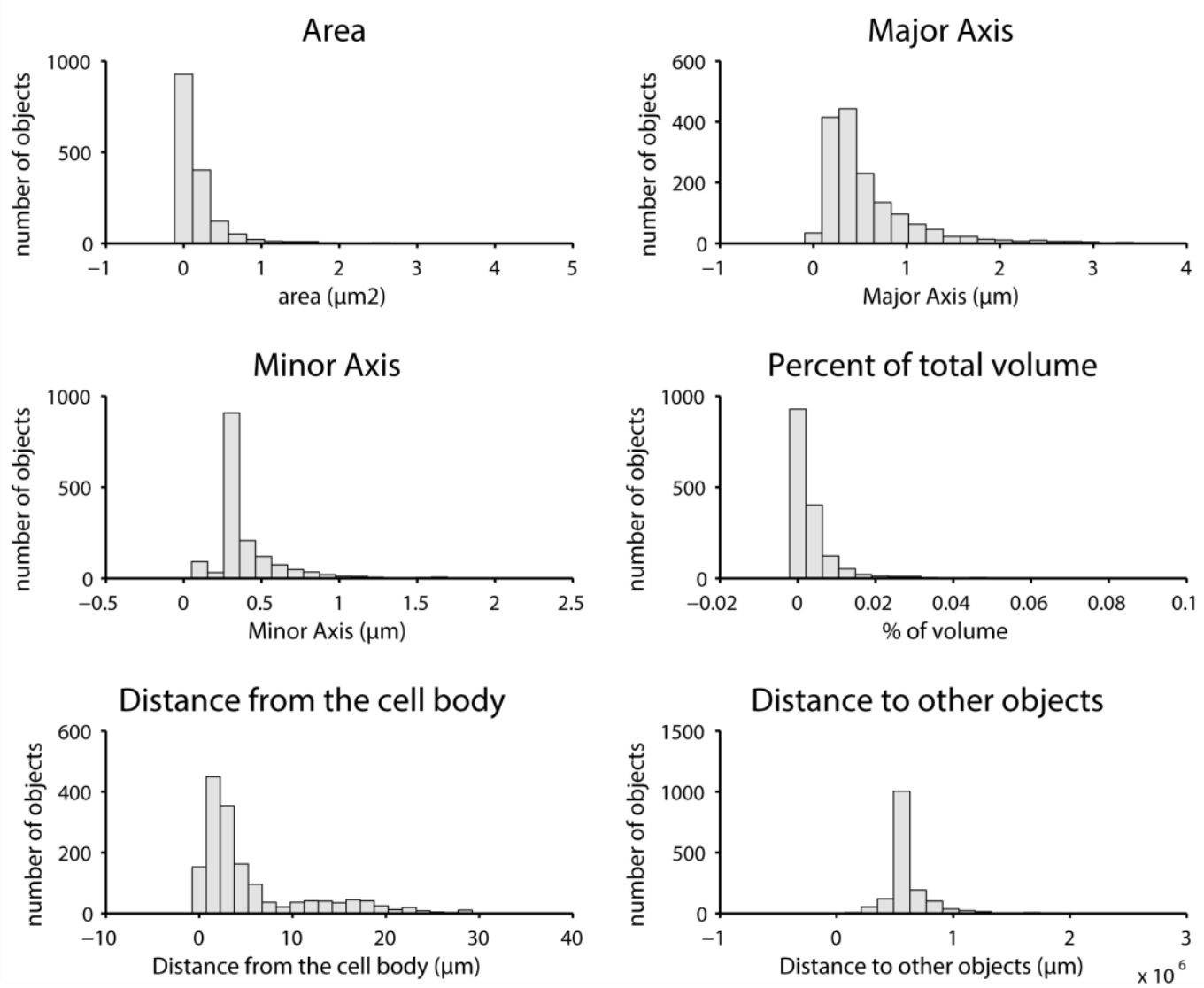

Figure 63: Distribution of TOMM20 b. From the objects found during the analysis, I extracted several parameters including the area, the axis, the object volume, the distance to the cell body, and the distance to the neighbouring objects. These parameters are given here in the form of histograms. The bin size was chosen according to the data range. 


\section{tomm20}
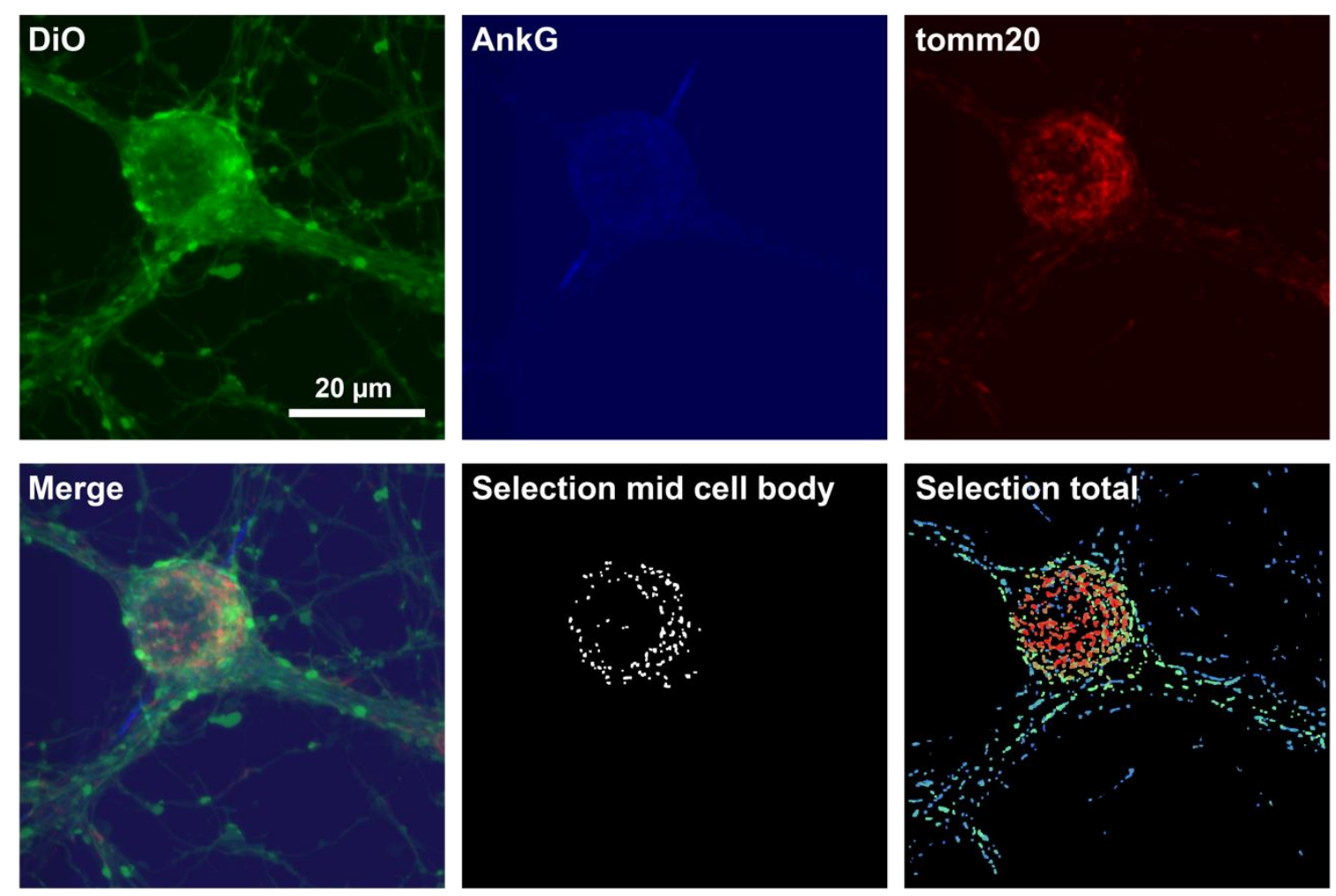

\begin{tabular}{|c|c|c|c|c|c|c|c|c|c|}
\hline properties & $\begin{array}{l}\text { Mean } \\
\text { cell } \\
\text { body }\end{array}$ & $\begin{array}{l}\text { SD cell } \\
\text { body }\end{array}$ & $\begin{array}{l}\text { Mean } \\
\text { axon }\end{array}$ & $\begin{array}{l}\text { SD } \\
\text { axon }\end{array}$ & $\begin{array}{l}\text { Mean } \\
\text { dendrites }\end{array}$ & $\begin{array}{l}\text { SD } \\
\text { dendrites }\end{array}$ & $\begin{array}{l}\text { P value cell } \\
\text { body vs. } \\
\text { axon }\end{array}$ & $\begin{array}{l}\text { P value cell } \\
\text { body vs. } \\
\text { dendrites }\end{array}$ & $\begin{array}{l}\text { P value } \\
\text { axon vs. } \\
\text { dendrites }\end{array}$ \\
\hline Area $\left(\mu \mathrm{m}^{2}\right)$ & 0,301 & 0,256 & 0,299 & 0,278 & 0,222 & 0,214 & & $9,72 \mathrm{E}-72$ & $5,73 \mathrm{E}-21$ \\
\hline Major axis $(\mu \mathrm{m})$ & 0,784 & 0,485 & 0,828 & 0,593 & 0,668 & 0,473 & & $1,59 \mathrm{E}-37$ & $9,96 \mathrm{E}-20$ \\
\hline Minor axis $(\mu \mathrm{m})$ & 0,481 & 0,140 & 0,455 & 0,152 & 0,407 & 0,133 & & $1,03 E-100$ & $2,08 \mathrm{E}-17$ \\
\hline $\begin{array}{l}\text { Equivalent circle } \\
\text { diameter }(\mu \mathrm{m})\end{array}$ & 0,580 & 0,216 & 0,569 & 0,239 & 0,492 & 0,203 & & $9,72 \mathrm{E}-72$ & $5,73 E-21$ \\
\hline Perimeter $(\mu \mathrm{m})$ & 2,026 & 1,196 & 2,154 & 1,438 & 1,716 & 1,078 & & $4,59 E-41$ & $3,91 \mathrm{E}-23$ \\
\hline Percent of volume (\%) & 0,003 & 0,003 & 0,004 & 0,003 & 0,003 & 0,003 & $2,03 \mathrm{E}-05$ & $5,05 E-34$ & $3,75 E-26$ \\
\hline $\begin{array}{l}\text { Minimum distance from } \\
\text { cell body edge }(\mu \mathrm{m})\end{array}$ & 3,126 & 2,110 & 7,876 & 9,327 & 10,411 & 7,493 & $5,13 E-16$ & $0,00 E+00$ & $1,76 \mathrm{E}-44$ \\
\hline $\begin{array}{l}\text { Minimum distance from } \\
\text { nucleus edge }(\mu \mathrm{m})\end{array}$ & 7,249 & 6,807 & 18,330 & 13,208 & 21,164 & 10,153 & $1,71 \mathrm{E}-149$ & $0,00 E+00$ & $4,93 E-24$ \\
\hline $\begin{array}{l}\text { Approximate depth in Z } \\
(\mu \mathrm{m})\end{array}$ & 0,481 & 0,140 & 0,455 & 0,152 & 0,407 & 0,133 & & $1,03 E-100$ & $2,08 \mathrm{E}-17$ \\
\hline $\begin{array}{l}\text { Minimum distance to the } \\
\text { next object }(\mu \mathrm{m})\end{array}$ & 0,616 & 0,235 & 0,590 & 0,242 & 0,683 & 0,587 & & $1,74 \mathrm{E}-18$ & \\
\hline
\end{tabular}

Figure 64: TOMM20, characterization in cell bodies, axons, and dendrites. Shown in the top panel is the DiO plasma membrane staining in green, the ankyrinG immunostaining in blue, and the TOMM20 staining in red. All images were acquired by confocal microscopy taking stacks across entire neuronal cell bodies. The images shown are maximum projections of these stacks. The second row shows a merge image of the three markers. The other two images in the second row represent the objects extracted from the 
organelle staining during the analysis. The middle image shows the objects in the middle section of the z-stack, the third image shows all objects color-coded based on the z-level. The extracted objects were grouped dependent on their presence in the cell body, the axon, or the dendrite and parameters such as the area, and the percent of total volume for each object were extracted. The table shows the mean values and SDs for these parameters in the different regions. The parameters were compared between the different regions using a multiple comparison ranksum Mann-Whitney $U$ test and a Bonferroni correction. Significant differences are indicated in green. 20 neurons from 2 different cultures were analysed.

TOMM-20
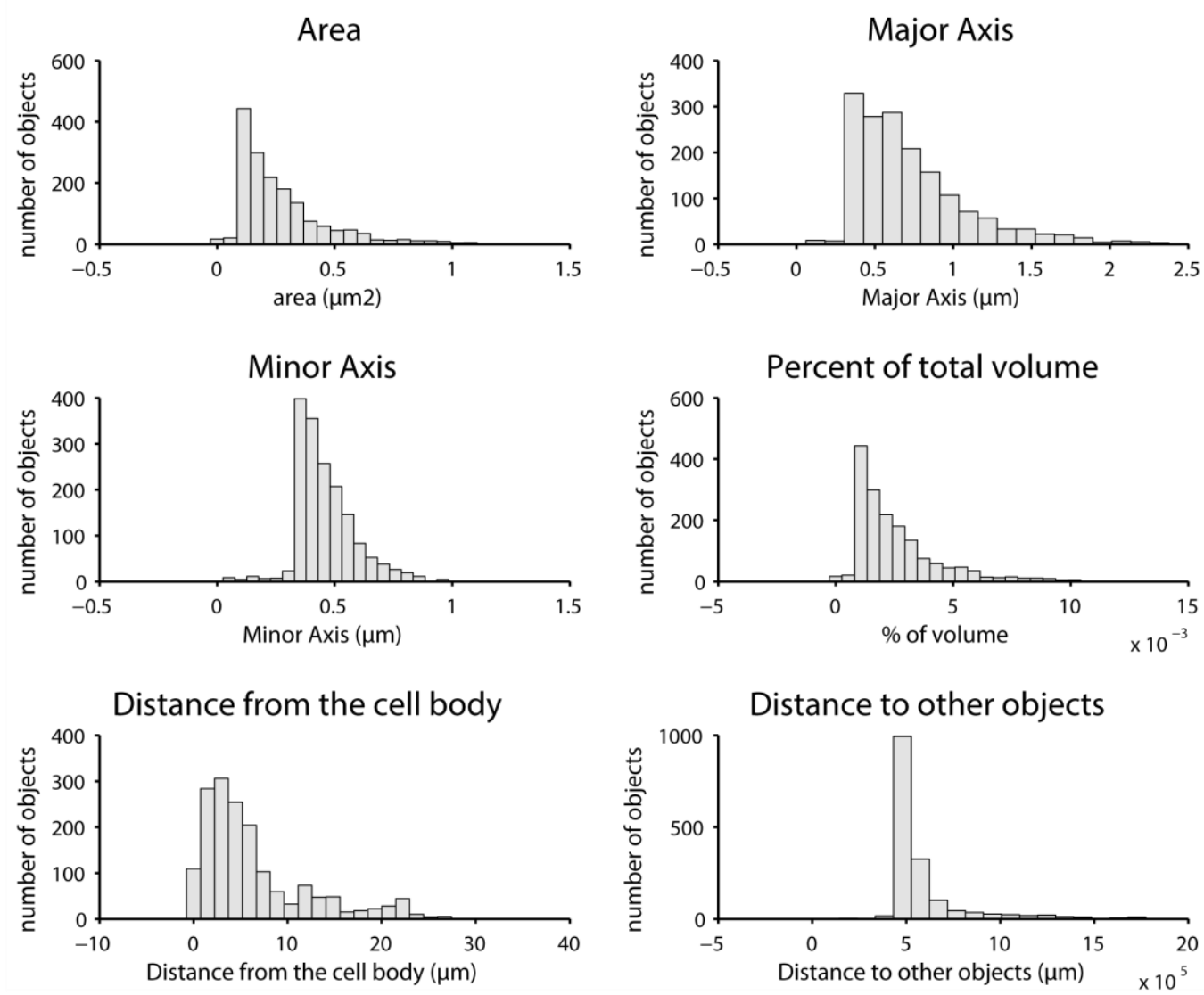

Figure 65: Distribution of TOMM20. From the objects found during the analysis, I extracted several parameters including the area, the axis, the object volume, the distance to the cell body, and the distance to the neighbouring objects. These parameters are given here in the form of histograms. The bin size was chosen according to the data range. 


\section{VAMP-2}
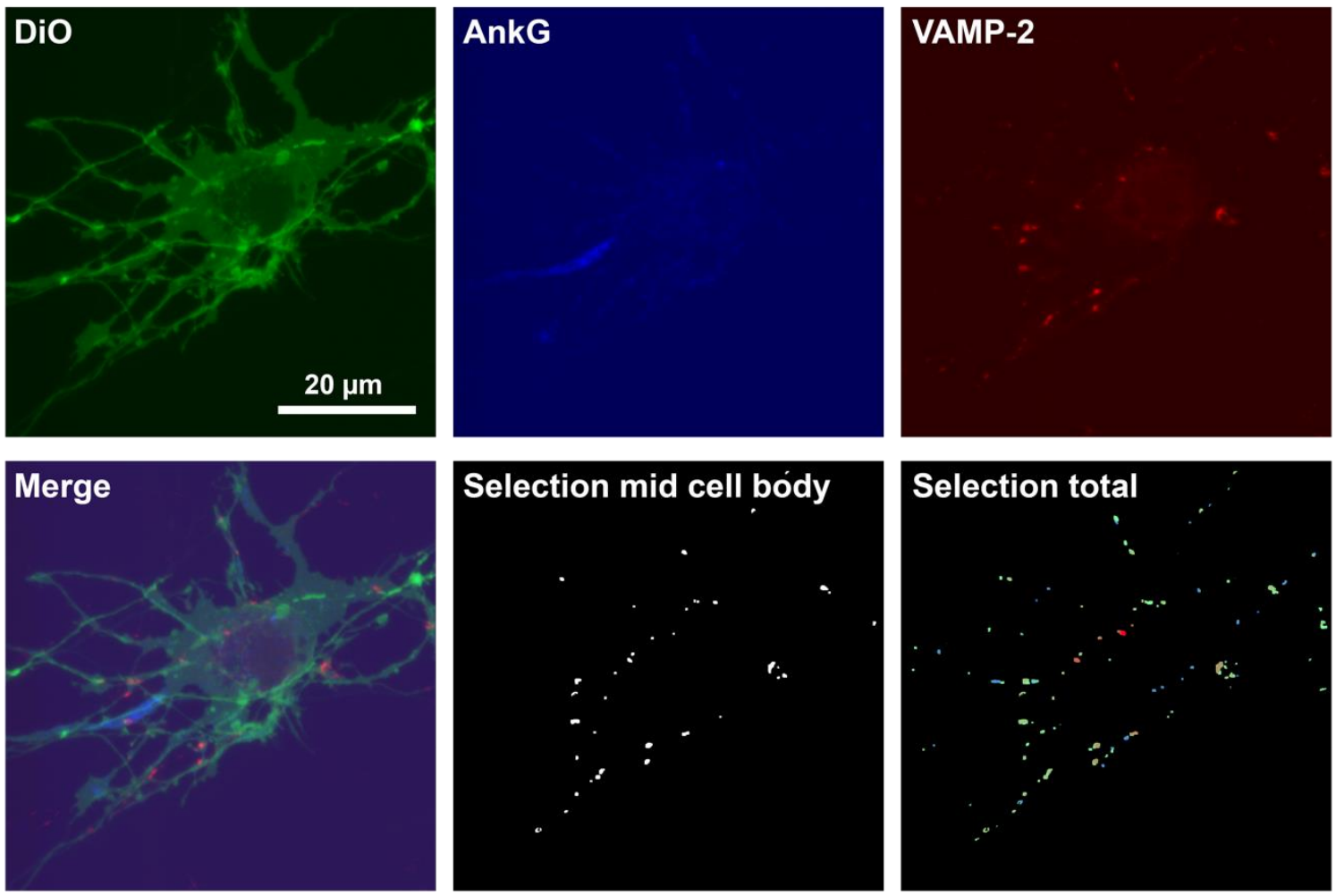

\begin{tabular}{|c|c|c|c|c|c|c|c|c|c|}
\hline properties & $\begin{array}{l}\text { Mean } \\
\text { cell } \\
\text { body }\end{array}$ & $\begin{array}{l}\text { SD cell } \\
\text { body }\end{array}$ & $\begin{array}{l}\text { Mean } \\
\text { axon }\end{array}$ & $\begin{array}{l}\text { SD } \\
\text { axon }\end{array}$ & $\begin{array}{l}\text { Mean } \\
\text { dendrites }\end{array}$ & $\begin{array}{l}\text { SD } \\
\text { dendrites }\end{array}$ & $\begin{array}{l}\text { P value cell } \\
\text { body vs. } \\
\text { axon }\end{array}$ & $\begin{array}{l}\text { P value cell } \\
\text { body vs. } \\
\text { dendrites }\end{array}$ & $\begin{array}{l}\text { P value } \\
\text { axon vs. } \\
\text { dendrites }\end{array}$ \\
\hline Area $\left(\mu \mathrm{m}^{2}\right)$ & 0.258 & 0.179 & 0.266 & 0.212 & 0.199 & 0.164 & & $1.11 \mathrm{E}-62$ & $6.80 \mathrm{E}-15$ \\
\hline Major axis $(\mu \mathrm{m})$ & 0.681 & 0.340 & 0.710 & 0.410 & 0.595 & 0.329 & & 1.07E-26 & 1.29E-10 \\
\hline Minor axis $(\mu \mathrm{m})$ & 0.470 & 0.114 & 0.447 & 0.159 & 0.388 & 0.166 & & $3.75 \mathrm{E}-86$ & $8.61 \mathrm{E}-16$ \\
\hline $\begin{array}{l}\text { Equivalent circle } \\
\text { diameter }(\mu \mathrm{m})\end{array}$ & 0.546 & 0.173 & 0.537 & 0.223 & 0.457 & 0.210 & & $1.11 \mathrm{E}-62$ & $6.80 \mathrm{E}-15$ \\
\hline Perimeter $(\mu \mathrm{m})$ & 1.768 & 0.795 & 1.872 & 0.981 & 1.596 & 0.807 & & $1.84 \mathrm{E}-18$ & $3.20 \mathrm{E}-10$ \\
\hline Percent of volume (\%) & 0.004 & 0.003 & 0.004 & 0.004 & 0.003 & 0.003 & & $1.50 \mathrm{E}-59$ & $6.86 \mathrm{E}-15$ \\
\hline $\begin{array}{l}\text { Minimum distance from } \\
\text { cell body edge }(\mu \mathrm{m})\end{array}$ & 2.846 & 2.057 & 7.369 & 5.970 & 11.159 & 7.211 & $6.03 E-72$ & $0.00 \mathrm{E}+00$ & $2.80 \mathrm{E}-37$ \\
\hline $\begin{array}{l}\text { Minimum distance from } \\
\text { nucleus edge }(\mu \mathrm{m})\end{array}$ & 7.731 & 7.642 & 16.921 & 9.106 & 19.860 & 10.289 & 3.93E-119 & $0.00 \mathrm{E}+00$ & 8.32E-12 \\
\hline $\begin{array}{l}\text { Approximate depth in Z } \\
(\mu \mathrm{m})\end{array}$ & 0.470 & 0.114 & 0.447 & 0.159 & 0.388 & 0.166 & & $3.75 E-86$ & 8.61E-16 \\
\hline $\begin{array}{l}\text { Minimum distance to the } \\
\text { next object }(\mu \mathrm{m})\end{array}$ & 0.728 & 0.500 & 0.771 & 0.656 & 0.839 & 0.970 & & 1.60E-09 & \\
\hline
\end{tabular}

Figure 66: VAMP2, characterization in cell bodies, axons, and dendrites. Shown in the top panel is the DiO plasma membrane staining in green, the ankyrinG immunostaining in blue, and the VAMP2 staining in red. All images were acquired by confocal microscopy taking stacks across entire neuronal cell bodies. The images shown are maximum projections of these stacks. The second row shows a merge image of the three markers. The other two images in the second row represent the objects extracted from the 
organelle staining during the analysis. The middle image shows the objects in the middle section of the z-stack, the third image shows all objects color-coded based on the z-level. The extracted objects were grouped dependent on their presence in the cell body, the axon, or the dendrite and parameters such as the area, and the percent of total volume for each object were extracted. The table shows the mean values and SDs for these parameters in the different regions. The parameters were compared between the different regions using a multiple comparison ranksum Mann-Whitney $U$ test and a Bonferroni correction. Significant differences are indicated in green. 20 neurons from 2 different cultures were analysed.

VAMP-2
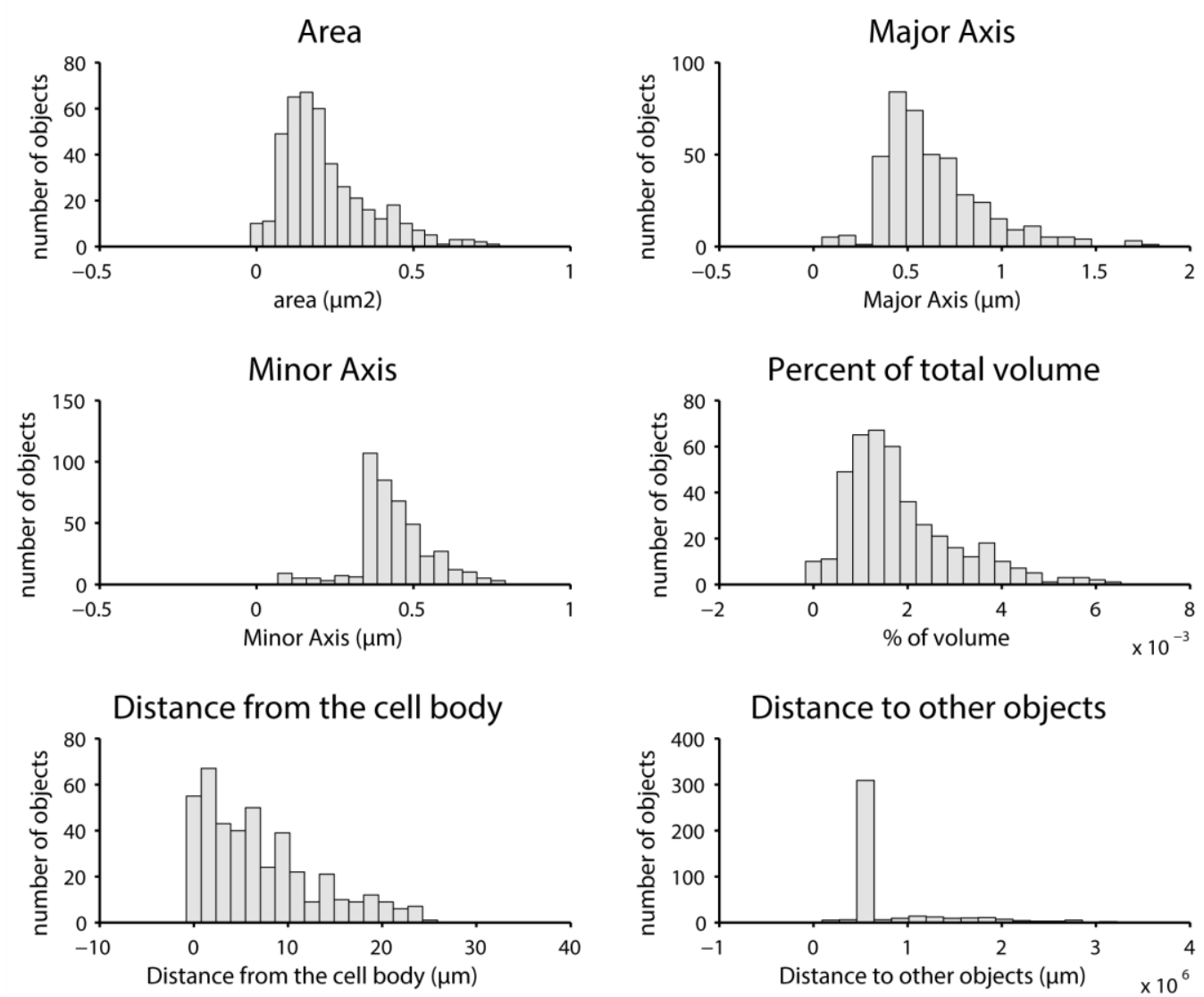

Figure 67: Distribution of VAMP2. From the objects found during the analysis, I extracted several parameters including the area, the axis, the object volume, the distance to the cell body, and the distance to the neighbouring objects. These parameters are given here in the form of histograms. The bin size was chosen according to the data range. 


\section{vGLUT}
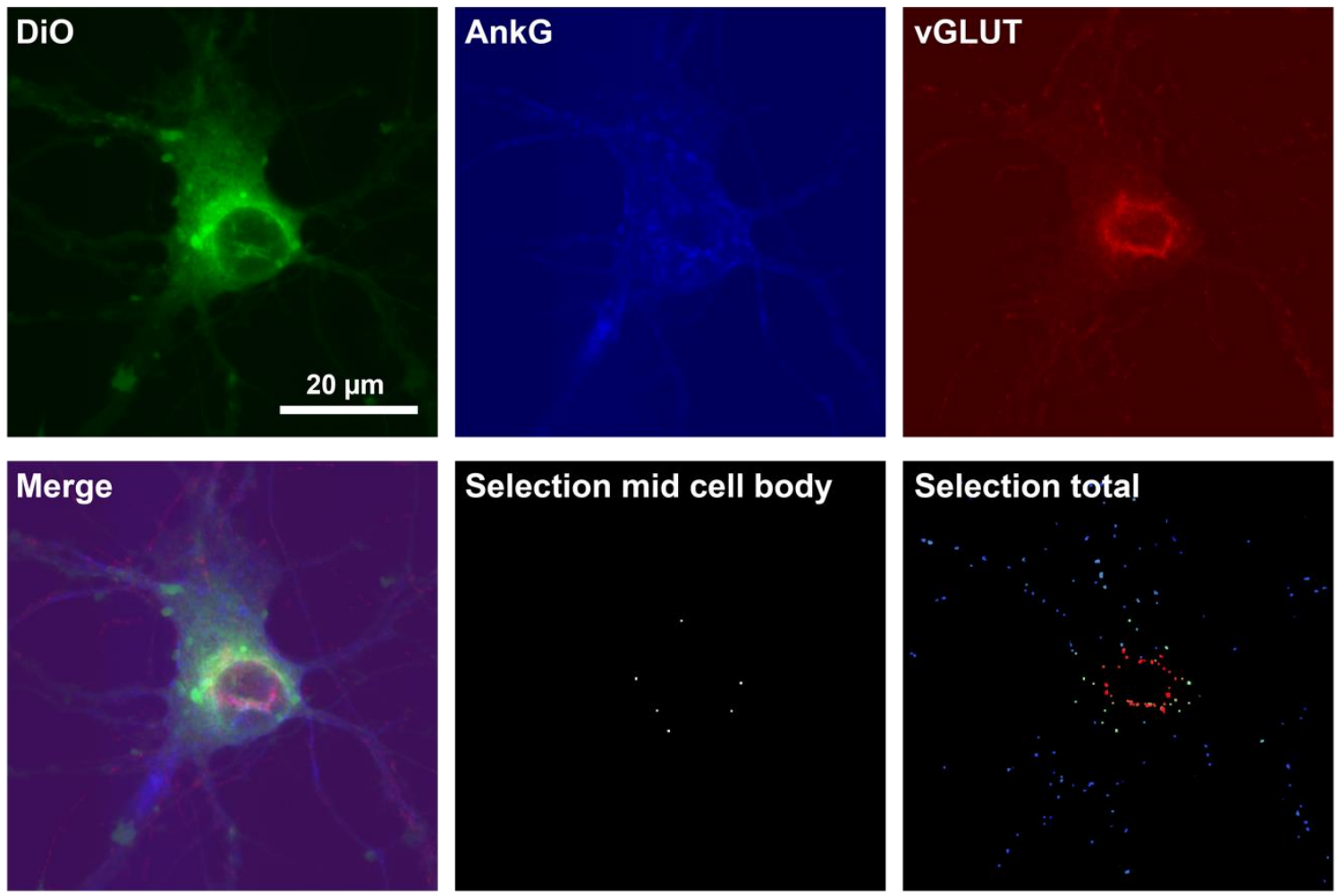

\begin{tabular}{|c|c|c|c|c|c|c|c|c|c|}
\hline properties & $\begin{array}{l}\text { Mean } \\
\text { cell } \\
\text { body }\end{array}$ & $\begin{array}{l}\text { SD cell } \\
\text { body }\end{array}$ & $\begin{array}{l}\text { Mean } \\
\text { axon }\end{array}$ & $\begin{array}{l}\text { SD } \\
\text { axon }\end{array}$ & $\begin{array}{l}\text { Mean } \\
\text { dendrites }\end{array}$ & $\begin{array}{l}\text { SD } \\
\text { dendrites }\end{array}$ & $\begin{array}{l}\text { P value cell } \\
\text { body vs. } \\
\text { axon }\end{array}$ & $\begin{array}{l}\text { P value cell } \\
\text { body vs. } \\
\text { dendrites }\end{array}$ & $\begin{array}{l}\text { P value } \\
\text { axon vs. } \\
\text { dendrites }\end{array}$ \\
\hline Area $\left(\mu \mathrm{m}^{2}\right)$ & 0.175 & 0.106 & 0.160 & 0.118 & 0.111 & 0.089 & & $0.00 \mathrm{E}+00$ & $1.13 \mathrm{E}-113$ \\
\hline Major axis $(\mu \mathrm{m})$ & 0.536 & 0.216 & 0.524 & 0.251 & 0.437 & 0.212 & & $3.48 \mathrm{E}-120$ & $1.57 \mathrm{E}-62$ \\
\hline Minor axis $(\mu \mathrm{m})$ & 0.415 & 0.080 & 0.373 & 0.131 & 0.303 & 0.136 & $1.22 \mathrm{E}-78$ & $0.00 \mathrm{E}+00$ & 3.86E-132 \\
\hline $\begin{array}{l}\text { Equivalent circle } \\
\text { diameter }(\mu \mathrm{m})\end{array}$ & 0.457 & 0.119 & 0.422 & 0.160 & 0.344 & 0.153 & & $0.00 \mathrm{E}+00$ & $1.13 \mathrm{E}-113$ \\
\hline Perimeter $(\mu \mathrm{m})$ & 1.418 & 0.535 & 1.395 & 0.642 & 1.154 & 0.538 & & $7.20 \mathrm{E}-154$ & 5.57E-77 \\
\hline Percent of volume (\%) & 0.002 & 0.002 & 0.002 & 0.002 & 0.002 & 0.001 & & $1.89 \mathrm{E}-200$ & 1.48E-73 \\
\hline $\begin{array}{l}\text { Minimum distance from } \\
\text { cell body edge }(\mu \mathrm{m})\end{array}$ & 3.551 & 2.177 & 8.127 & 6.889 & 12.204 & 7.423 & $0.00 \mathrm{E}+00$ & $0.00 \mathrm{E}+00$ & $4.01 \mathrm{E}-152$ \\
\hline $\begin{array}{l}\text { Minimum distance from } \\
\text { nucleus edge }(\mu \mathrm{m})\end{array}$ & 5.143 & 5.553 & 16.837 & 8.173 & 20.133 & 8.449 & $0.00 \mathrm{E}+00$ & $0.00 \mathrm{E}+00$ & 5.17E-71 \\
\hline $\begin{array}{l}\text { Approximate depth in Z } \\
(\mu \mathrm{m})\end{array}$ & 0.415 & 0.080 & 0.373 & 0.131 & 0.303 & 0.136 & $1.22 \mathrm{E}-78$ & $0.00 \mathrm{E}+00$ & 3.86E-132 \\
\hline $\begin{array}{l}\text { Minimum distance to the } \\
\text { next object }(\mu \mathrm{m})\end{array}$ & 0.634 & 0.260 & 0.648 & 0.380 & 0.959 & 1.049 & & & 8.39E-08 \\
\hline
\end{tabular}

Figure 68: vGLUT, characterization in cell bodies, axons, and dendrites. Shown in the top panel is the DiO plasma membrane staining in green, the ankyring immunostaining in blue, and the vGLUT staining in red. All images were acquired by confocal microscopy taking stacks across entire neuronal cell bodies. The images shown are maximum projections of these stacks. The second row shows a merge image of the three markers. The other two images in the second row represent the objects extracted from the 
organelle staining during the analysis. The middle image shows the objects in the middle section of the z-stack, the third image shows all objects color-coded based on the z-level. The extracted objects were grouped dependent on their presence in the cell body, the axon, or the dendrite and parameters such as the area, and the percent of total volume for each object were extracted. The table shows the mean values and SDs for these parameters in the different regions. The parameters were compared between the different regions using a multiple comparison ranksum Mann-Whitney $U$ test and a Bonferroni correction. Significant differences are indicated in green. 20 neurons from 2 different cultures were analysed.

\section{vGLUT}
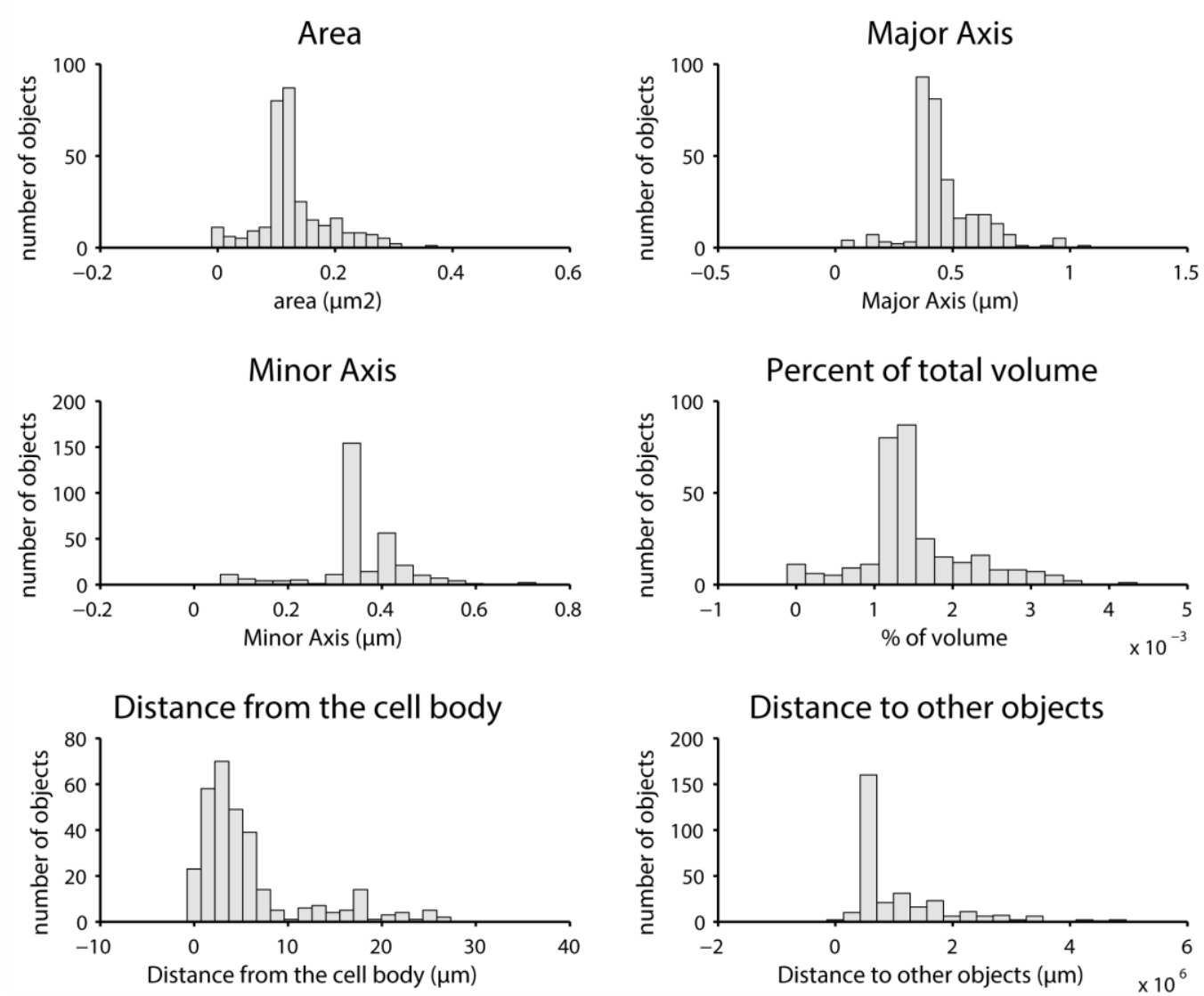

Figure 69: Distribution of vGLUT. From the objects found during the analysis, I extracted several parameters including the area, the axis, the object volume, the distance to the cell body, and the distance to the neighbouring objects. These parameters are given here in the form of histograms. The bin size was chosen according to the data range. 


\section{vimentin}
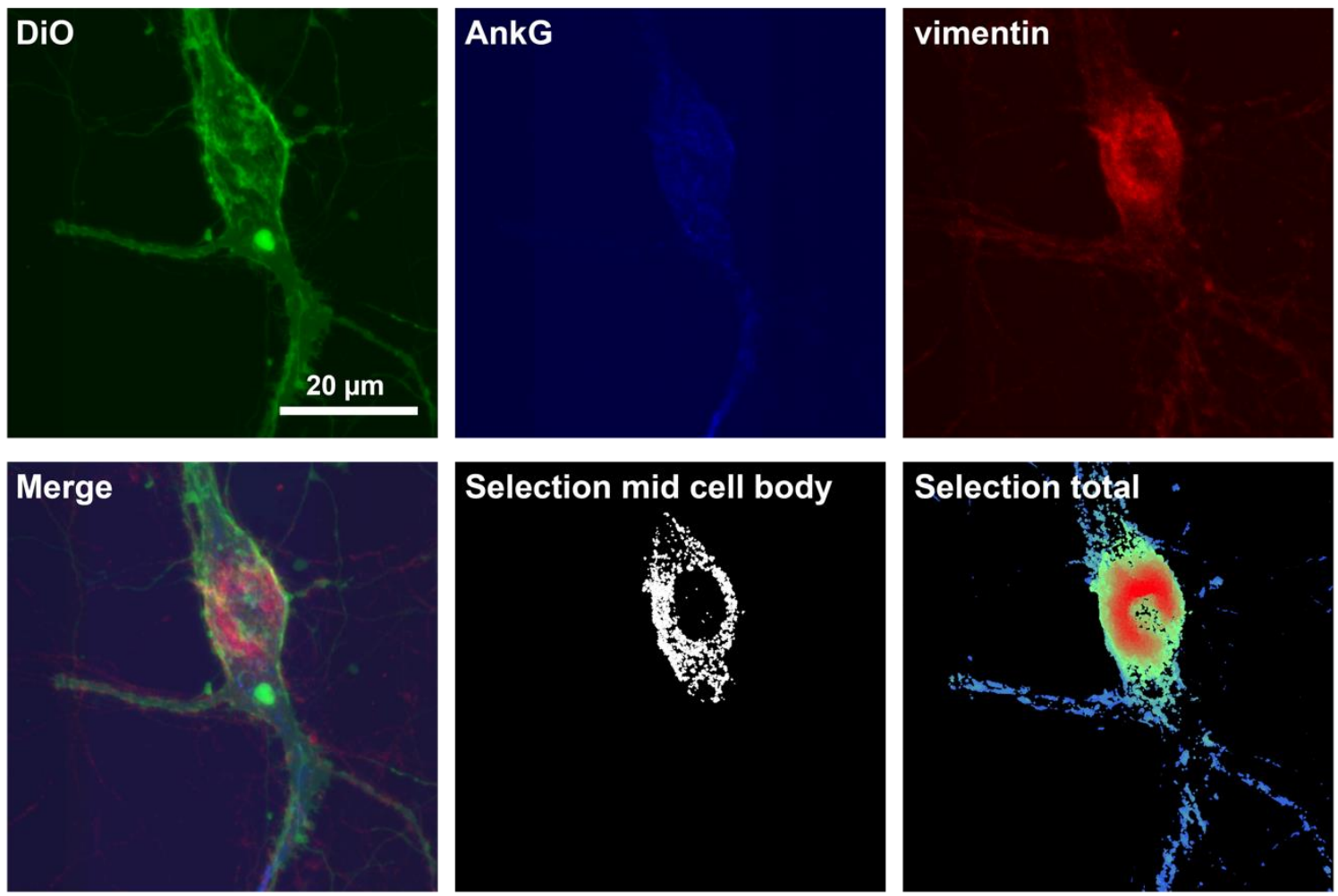

\begin{tabular}{|c|c|c|c|c|c|c|c|c|c|}
\hline properties & $\begin{array}{l}\text { Mean } \\
\text { cell } \\
\text { body }\end{array}$ & $\begin{array}{l}\text { SD cell } \\
\text { body }\end{array}$ & $\begin{array}{l}\text { Mean } \\
\text { axon }\end{array}$ & $\begin{array}{l}\text { SD } \\
\text { axon }\end{array}$ & $\begin{array}{l}\text { Mean } \\
\text { dendrites }\end{array}$ & $\begin{array}{l}\text { SD } \\
\text { dendrites }\end{array}$ & $\begin{array}{l}\text { P value cell } \\
\text { body vs. } \\
\text { axon }\end{array}$ & $\begin{array}{l}\text { P value cell } \\
\text { body vs. } \\
\text { dendrites }\end{array}$ & $\begin{array}{l}\text { P value } \\
\text { axon vs. } \\
\text { dendrites }\end{array}$ \\
\hline Area $\left(\mu \mathrm{m}^{2}\right)$ & 1.212 & 8.203 & 0.915 & 6.842 & 0.157 & 0.280 & & $6.49 \mathrm{E}-188$ & $1.56 \mathrm{E}-106$ \\
\hline Major axis ( $\mu \mathrm{m})$ & 0.920 & 1.902 & 0.979 & 1.847 & 0.540 & 0.489 & & $5.32 \mathrm{E}-71$ & $1.41 \mathrm{E}-69$ \\
\hline Minor axis $(\mu \mathrm{m})$ & 0.561 & 1.085 & 0.520 & 0.839 & 0.315 & 0.194 & & $1.06 \mathrm{E}-270$ & $2.69 \mathrm{E}-129$ \\
\hline $\begin{array}{l}\text { Equivalent circle } \\
\text { diameter }(\mu \mathrm{m})\end{array}$ & 0.621 & 1.076 & 0.609 & 0.891 & 0.372 & 0.247 & & $6.49 \mathrm{E}-188$ & $1.56 \mathrm{E}-106$ \\
\hline Perimeter $(\mu \mathrm{m})$ & 3.484 & 12.131 & 3.623 & 12.153 & 1.477 & 1.565 & & 4.37E-93 & $3.78 \mathrm{E}-83$ \\
\hline Percent of volume (\%) & 0.018 & 0.131 & 0.014 & 0.111 & 0.002 & 0.004 & & $2.10 \mathrm{E}-159$ & $1.13 \mathrm{E}-120$ \\
\hline $\begin{array}{l}\text { Minimum distance from } \\
\text { cell body edge }(\mu \mathrm{m})\end{array}$ & 2.900 & 1.754 & 8.880 & 7.699 & 14.086 & 8.425 & $0.00 \mathrm{E}+00$ & $0.00 \mathrm{E}+00$ & $9.83 E-216$ \\
\hline $\begin{array}{l}\text { Minimum distance from } \\
\text { nucleus edge }(\mu \mathrm{m})\end{array}$ & 4.970 & 5.381 & 15.280 & 8.595 & 21.243 & 9.119 & $0.00 \mathrm{E}+00$ & $0.00 \mathrm{E}+00$ & $2.45 \mathrm{E}-223$ \\
\hline $\begin{array}{l}\text { Approximate depth in Z } \\
(\mu \mathrm{m})\end{array}$ & 0.561 & 1.085 & 0.520 & 0.839 & 0.315 & 0.194 & & $1.06 \mathrm{E}-270$ & $2.69 \mathrm{E}-129$ \\
\hline $\begin{array}{l}\text { Minimum distance to the } \\
\text { next object }(\mu \mathrm{m})\end{array}$ & 0.631 & 0.216 & 0.620 & 0.224 & 0.675 & 0.472 & & & \\
\hline
\end{tabular}

Figure 70: Vimentin, characterization in cell bodies, axons, and dendrites. Shown in the top panel is the DiO plasma membrane staining in green, the ankyrinG immunostaining in blue, and the vimentin staining in red. All images were acquired by confocal microscopy taking stacks across entire neuronal cell bodies. The images shown are maximum projections of these stacks. The second row shows a merge image of the three markers. The other two images in the second row represent the objects extracted from the 
organelle staining during the analysis. The middle image shows the objects in the middle section of the z-stack, the third image shows all objects color-coded based on the z-level. The extracted objects were grouped dependent on their presence in the cell body, the axon, or the dendrite and parameters such as the area, and the percent of total volume for each object were extracted. The table shows the mean values and SDs for these parameters in the different regions. The parameters were compared between the different regions using a multiple comparison ranksum Mann-Whitney $U$ test and a Bonferroni correction. Significant differences are indicated in green. 20 neurons from 2 different cultures were analysed.

vimentin
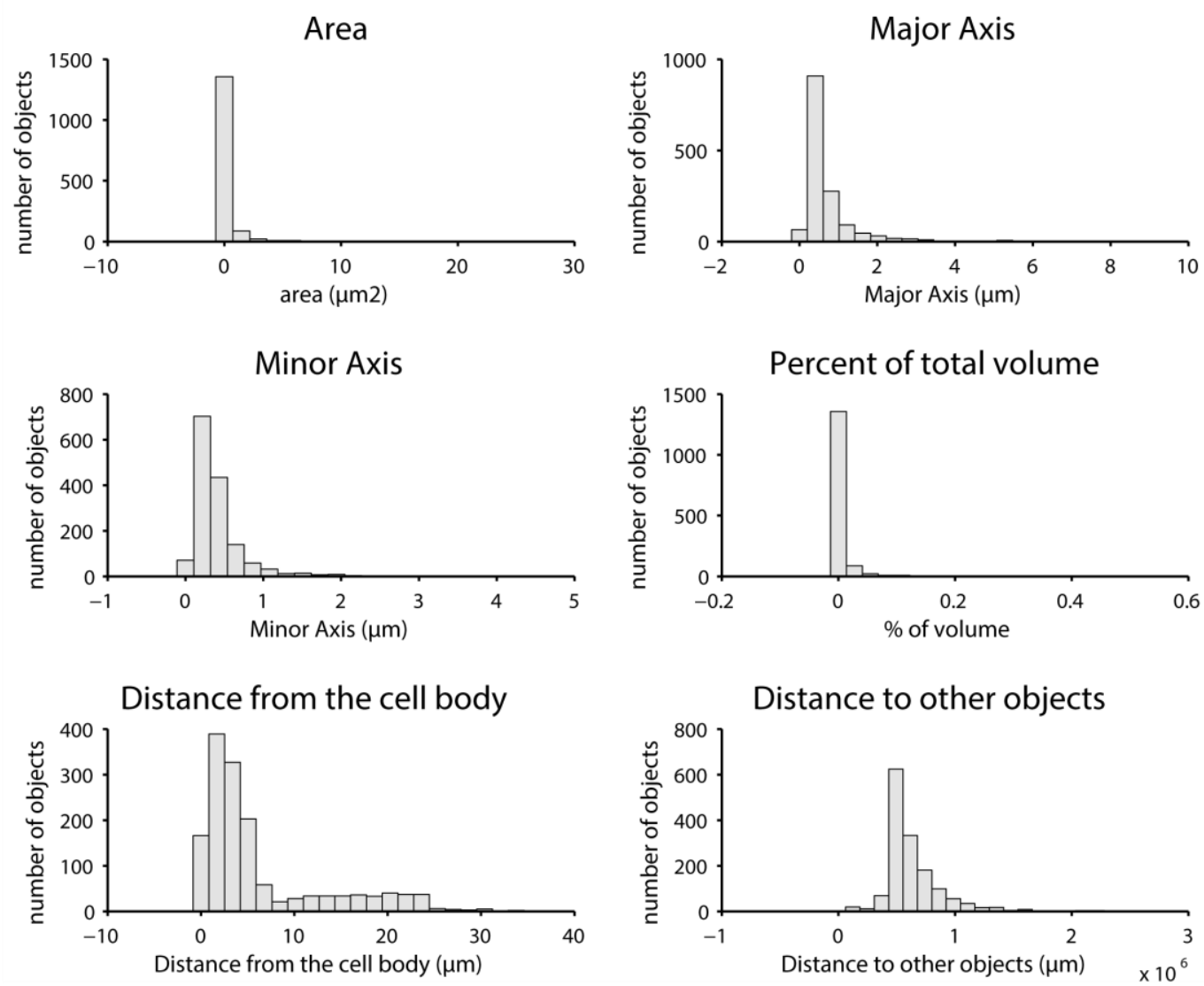

Figure 71: Distribution of vimentin. From the objects found during the analysis, I extracted several parameters including the area, the axis, the object volume, the distance to the cell body, and the distance to the neighbouring objects. These parameters are given here in the form of histograms. The bin size was chosen according to the data range. 
Neuronal organelles occupy most of the cell body volume

Apart from the distribution parameters that I extracted from the confocal image analysis of the organelle markers, I wanted to determine the sizes of these organelles, especially in relation to the cell body.

From the distribution analysis, I knew the average percentage that an organelle object takes up of the cell body. I also determined the number of organelle objects per cell body (Figure 72A). This number ranged from around 100 for TGN-38 (Golgi marker) objects to 2000 objects for LAMP1 (lysosome marker). I used the numbers and the average percentage taken up by the objects to calculate the total volume the markers take up in the cell body (Figure 72B). For most organelle markers, the percentage they take up of the cell body was between $0.5 \%$ and $7 \%$. Some of the markers, namely brevican, ribophorin1, TOMM20 b (a second antibody I tested), and vimentin took up more than $10 \%$ of the total cell body volume (Figure $72 \mathrm{C}$ ). The brevican, TOMM20 b, and vimentin immunostainings were not particularly good. They either did not look very specific or were very noisy. Thus, I excluded them from any further analysis.

I used the plasma membrane staining with DiO to determine the volume of all the analysed cell bodies (Figure 72D). The mean volume of a neuronal cell body in the Banker culture was $3700.23 \pm 70.61 \mu^{3}$. Taken together with the total neurite volume calculated before, the total volume of a neuron in the Banker culture was $45108.2 \pm$ $18255.4 \mu \mathrm{m}^{3}$. The cell body occupied about $8.2 \%$ of the total neuronal volume.

From the percentage each organelle takes up of the cell body, I calculated the overall organelle volumes. The treemap shown in Figure 73 represents the volumes as box sizes. The cytoplasm, the ER, and the nucleus occupy most of the cell body. 
A
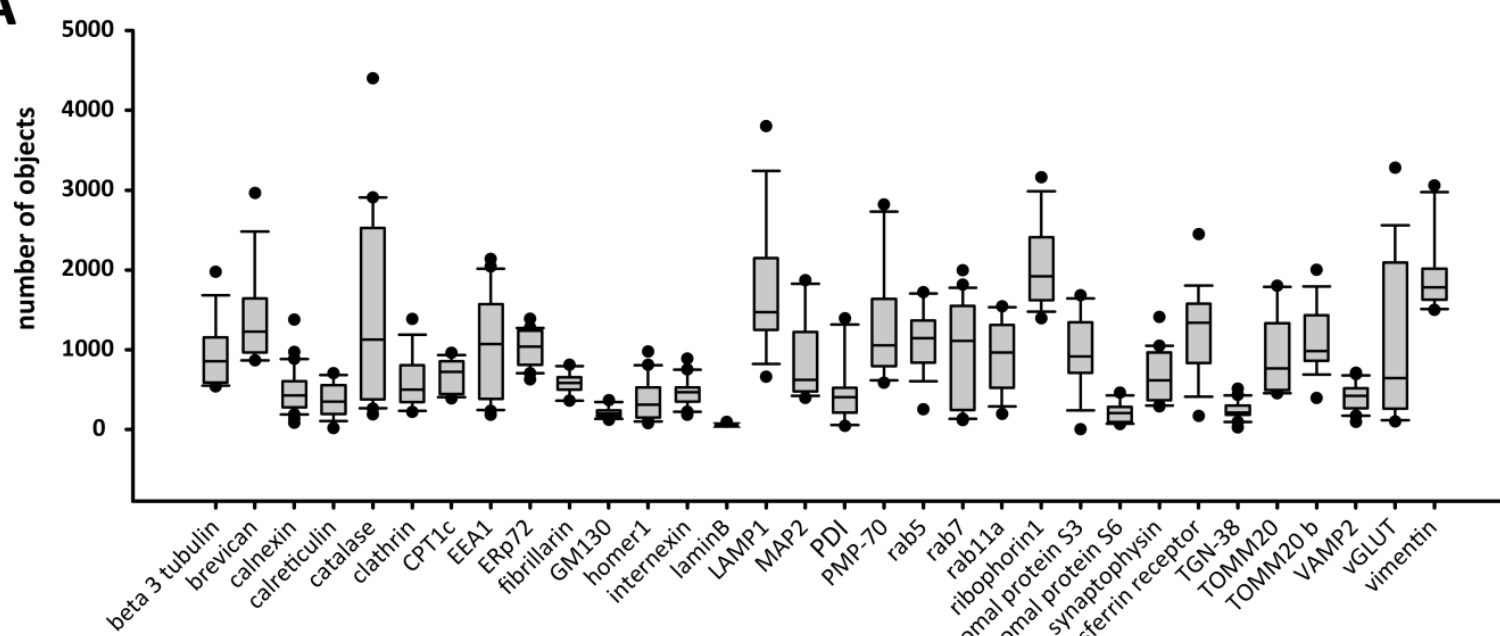

B

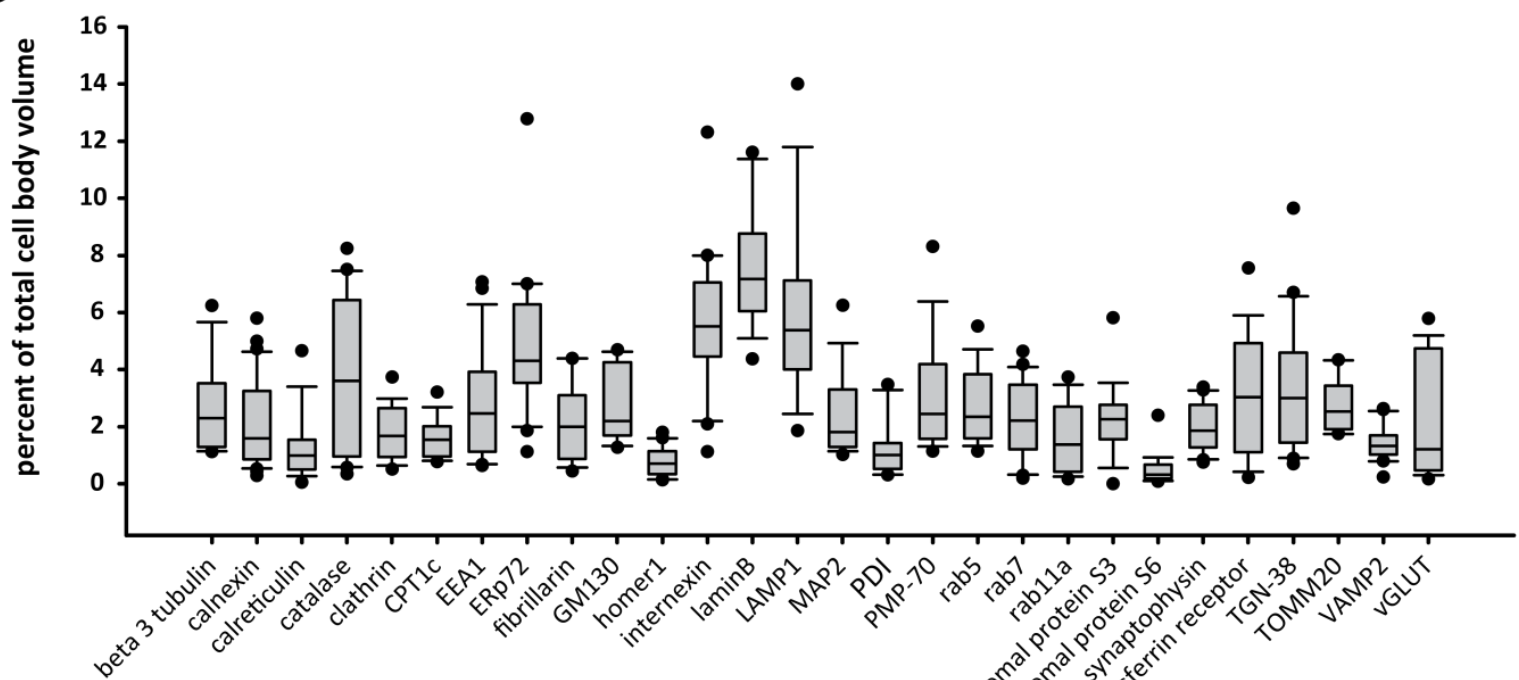

C

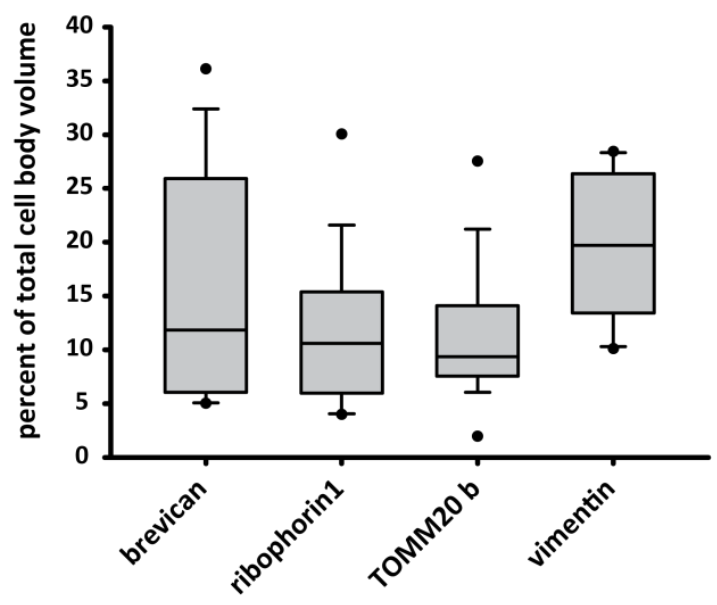

D

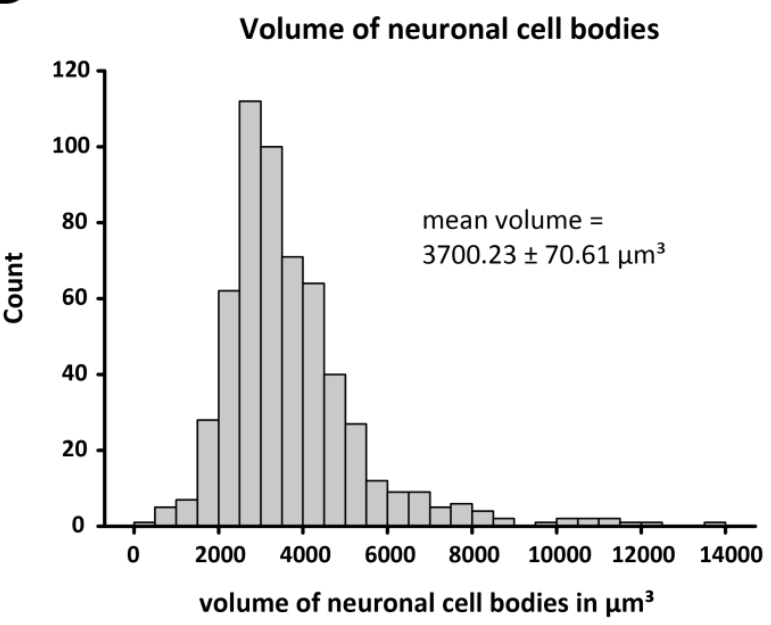

Figure 72: Volumes of the neuronal cell bodies and its organelles and compartments. Neurons had been labelled with a fluorescent membrane dye, DiO, an antibody against the AIS marker ankyrinG, and against an organelle compartment marker of interest. I 
analysed the organelle signals and determined the number of objects and their volume. $\boldsymbol{A}$ For each organelle marker the number of objects per cell is given. The number of objects ranges from below 100 to a couple of thousands per cell. The box plot shows the median, the $25^{\text {th }}$ and $75^{\text {th }}$ percentile are represented by the lower and upper boundaries of the box. The lower and upper whiskers show the $10^{\text {th }}$ and $90^{\text {th }}$ percentile respectively. $\boldsymbol{B}$ The percentage that the organelles/compartments take up of the cell body volume. Most organelles take up between $1 \%$ and $7 \%$ of the cell body. C Some organelles take up more than $10 \%$ of the total cell body volume. D The DiO signal was analysed to determine the cell body size. The mean volume per cell body is $3700.23 \pm 70.61 \mu \mathrm{m}^{3}$ (mean \pm SEM).

\section{Volume of Organelles}

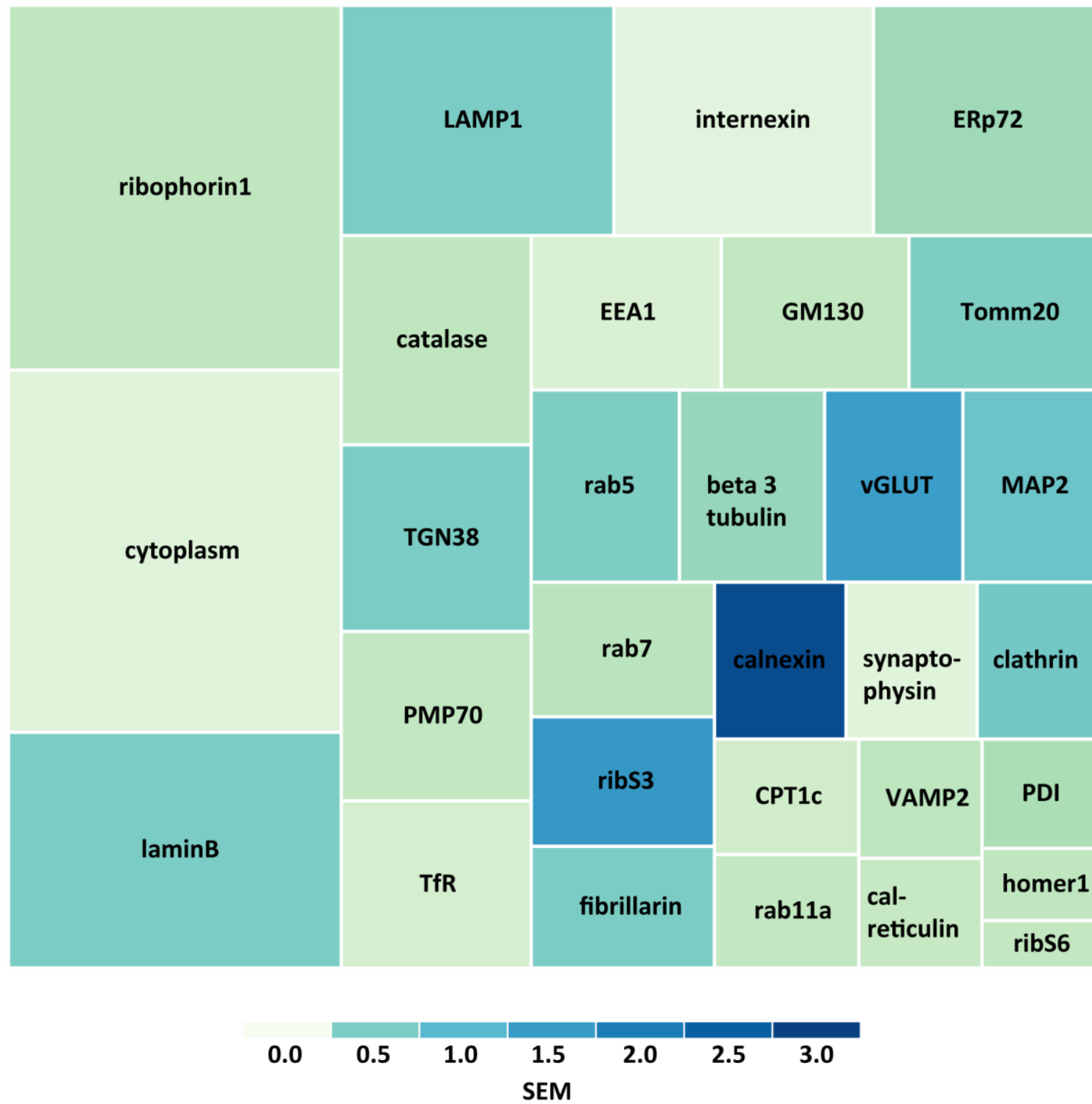


Figure 73: Organelle/compartment volumes in neuronal cell bodies. The boxes represent the proportion each organelle/compartment is taking up in the neuronal cell body. I used the mean values of the measurements shown in Figure 72B. The color codes for the SEM. The cytoplasm, the ER, and the nucleus take up most of the space in the cell body.

FIB-SEM measurements enabled the reconstruction of entire neuronal cell bodies, of nuclei, and mitochondria

Since confocal microscopy is inherently diffraction-limited, it is not ideal for size estimations of smaller organelles such as SVs or for densely packed structures, such as ER networks or cytoskeletal elements, as they cannot be separated (Lakadamyali et al., 2012; Shim et al., 2012; Xu et al., 2013). Thus, I combined the confocal measurements with electron microscopy and super resolution microscopy. Electron microscopy has an outstanding resolution (Kosinski et al., 2016). It also provides very good structural information and allows the identification of many organelles and compartments. One problem with EM is that the imaging area is relatively small. Thus I again focused on the cell body. In order to be able to image entire neuronal cell bodies I used FIB-SEM (Knott et al., 2008, 2011). I took image stacks through 10 neuronal cell bodies with a lateral pixel size of $5 \mathrm{~nm}$, and an axial pixel size of $50 \mathrm{~nm}$. Figure 74A shows an example of the centre of a cell body. The nucleus, nucleoli, mitochondria, and vacuoles were identifiable. Smaller organelles, such as SVs or thinner tubes like ER membranes were not easily visible. I decided to segment the plasma membrane, the nucleus, and mitochondria. Even though there are more and more automated, algorithm-based reconstruction/ segmentation methods being developed, manual segmentations are still the goldstandard (Plaza et al., 2014). This is very labour-intensive and not feasible for the large dataset, consisting of about 4000 individual image slices, on which this study is based. Thus, we developed a filter-based algorithm to automatically segment mitochondria (Figure 74D and Figure 75). I compared this to a fully manual reconstruction of mitochondria of the same neuron (manual reconstruction shown in Figure 74B and C). In the manual reconstruction, the mitochondria, with a volume of $30.33 \mu \mathrm{m}^{3}$ took up $6.2 \%$ of the entire cell body. The mitochondrial volume determined by the algorithm was 40.6 $\mu \mathrm{m}^{3}$, which is $8.8 \%$ of the total cell body volume. This is only a minor difference. Thus, the 
remaining cells were analysed using the algorithm. The reconstructions of these segmentations are shown in Figure 75.

A

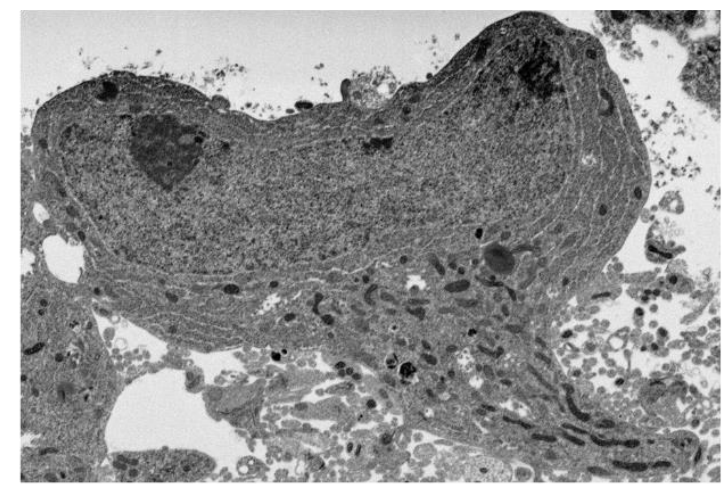

C

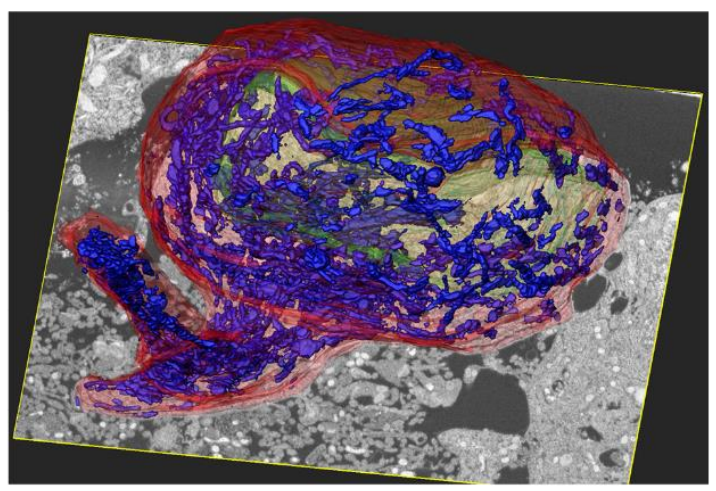

B

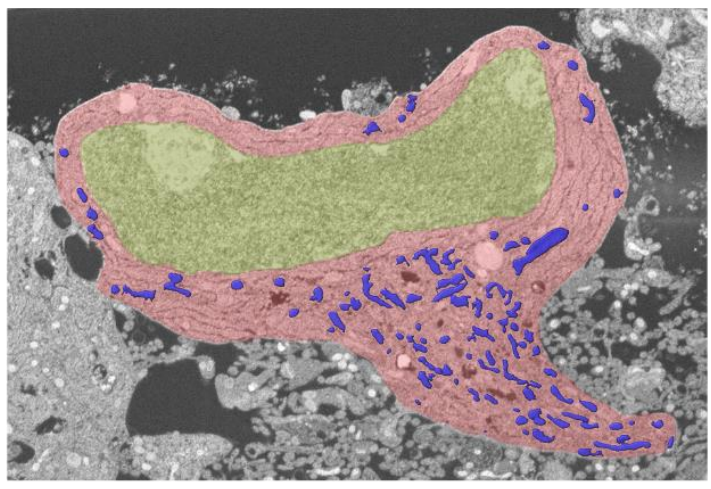

D

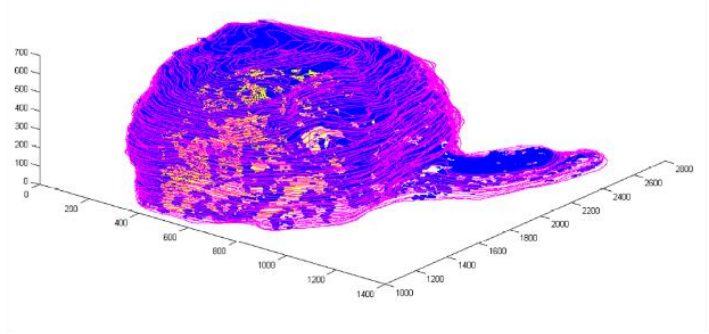

Figure 74: FIB-SEM recording of entire neuronal cell bodies. FIB-SEM was used to take SEM images of FIB sectioned, chemically fixed and embedded neuronal cell bodies. $\boldsymbol{A}$ Representative SEM image of a cell body section. The LUT has been inverted. The nucleus takes up most of the cell body space. Two nucleoli are visible (darker contrast). The cytoplasm contains many mitochondria (darker tubes). Due to the low contrast of the SEM measurements, it was difficult to reliably identify other organelles. B One neuronal cell body was manually segmented. The yellow area represents the nucleus, the red area the cytoplasm, and the blue regions the mitochondria. $\boldsymbol{C}$ shows a reconstruction of the entire imaged and manually traced cell body (the color scheme is retained). The mitochondrial network extends throughout the cytoplasm. $D$ Since manual reconstruction would not be feasible for all the cells, I tried to segment the mitochondria automatically using a filterbased algorithm. The figure shows a full reconstruction of the same cell body as in A-C, the mitochondria being automatically reconstructed. 


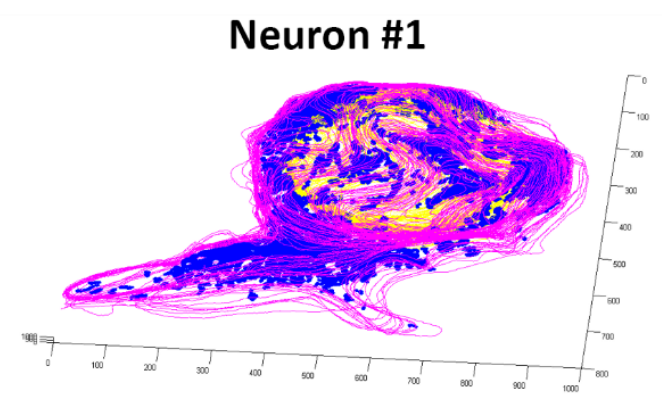

Neuron \#3

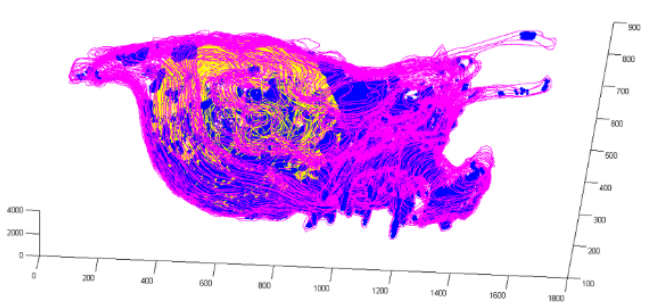

Neuron \#5

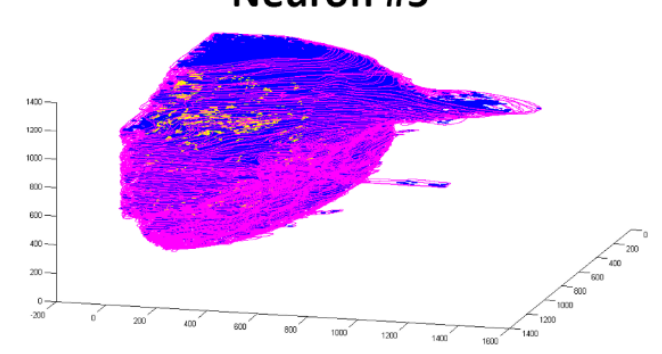

Neuron \#7

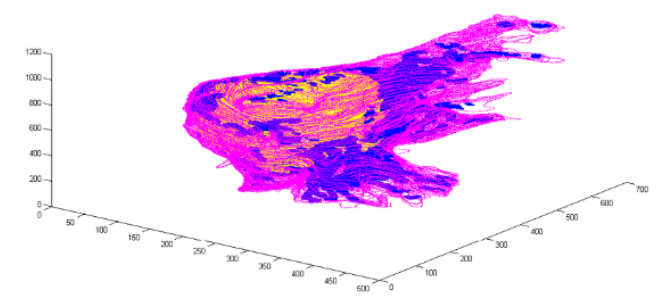

Neuron \#2

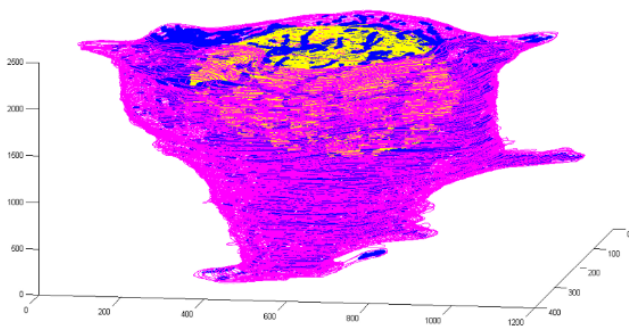

Neuron \#4

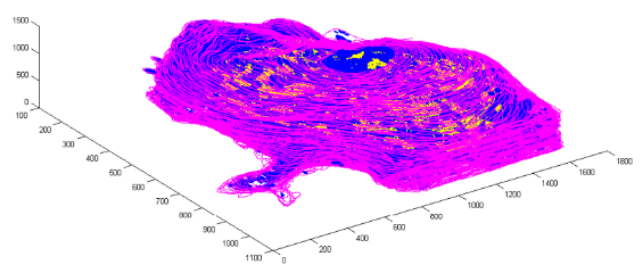

Neuron \#6

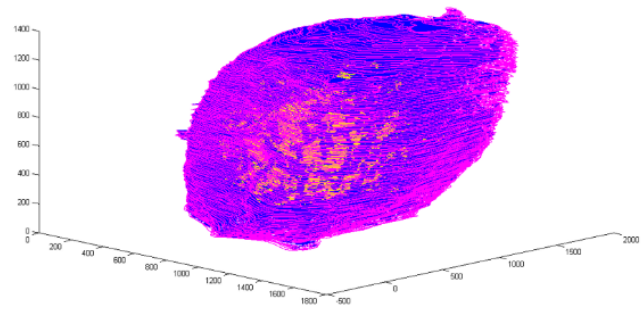

Neuron \#8

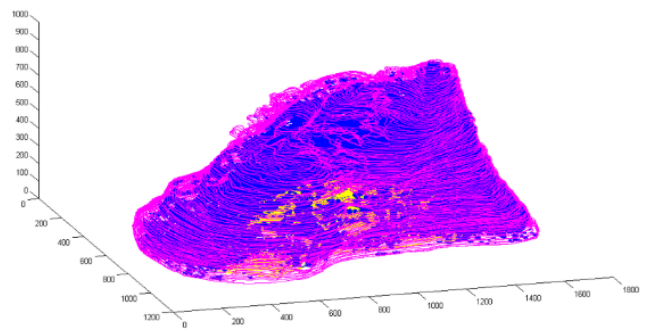

Figure 75: Half-automatized segmentations of neuronal cell bodies imaged by FIB-SEM. Shown are reconstructions of all the neuronal cell bodies imaged with FIB-SEM. The nucleus (yellow), as well as the plasma membrane (magenta) were segmented manually. The mitochondria (blue) were segmented using a filter-based macro/algorithm. 


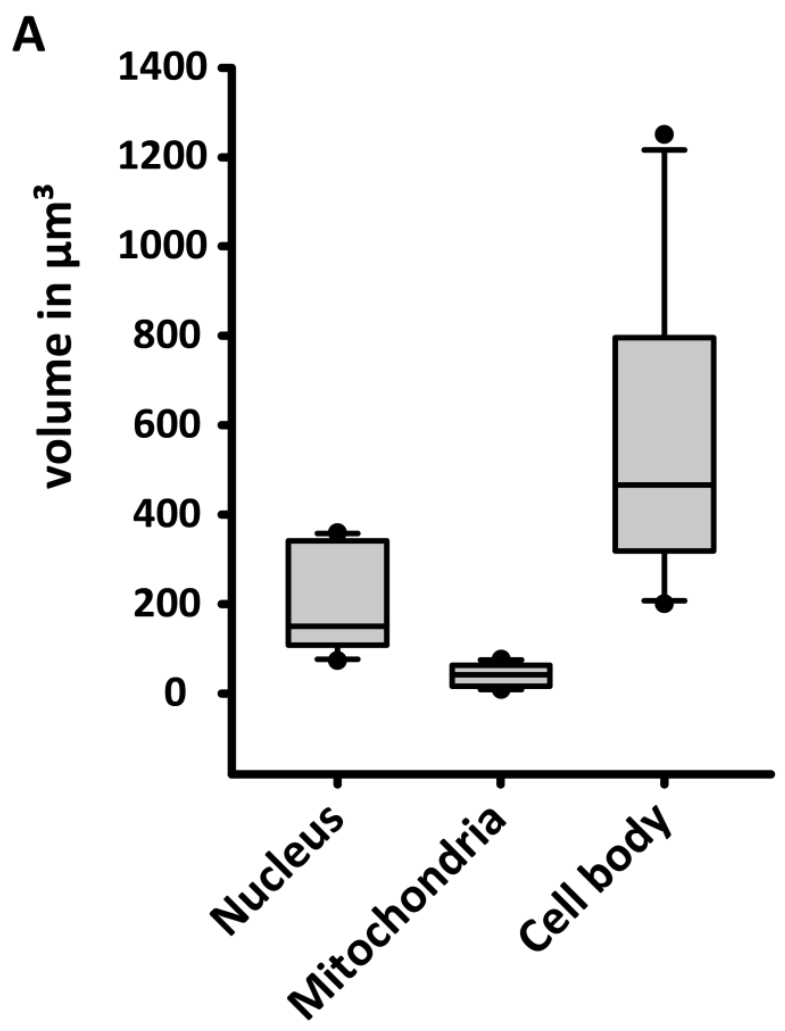

B

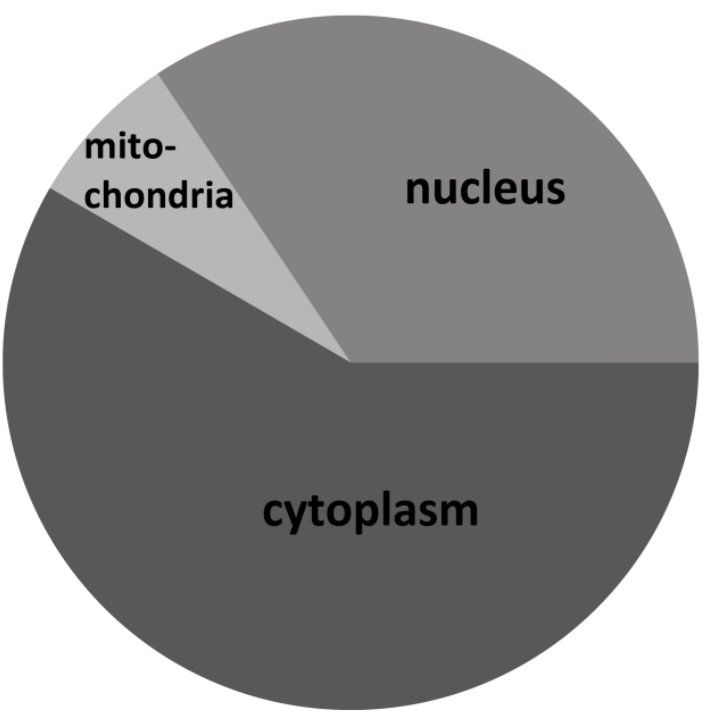

volume nucleus $=193.86 \pm 35.33 \mu \mathrm{m}^{3}$ volume mitochondria $=40.98 \pm 7.15 \mu \mathrm{m}^{3}$ volume cell body $=564.24 \pm 101.52 \mu \mathrm{m}^{3}$

proportion of nucleus $=36.31 \pm 3.79 \%$ proportion of mitochondria $=7.31 \pm 0.82 \%$

Figure 76: Neuronal cell body, nucleus, and mitochondria volumes determined by FIBSEM measurements. A From the semi-automatically segmented FIB-SEM reconstructions of neuronal cell bodies (see Figure 75), I calculated the volume of the cell bodies, of nuclei, and mitochondria. The box plot shows the median, the $25^{\text {th }}$ and $75^{\text {th }}$ percentile are represented by the lower and upper boundaries of the box. The lower and upper whiskers show the $10^{\text {th }}$ and $90^{\text {th }}$ percentile, respectively. B Pie chart showing the proportions of nuclei, mitochondria, and cytoplasm (containing all the other non-specified organelles) to the cell body. The values used are mean values from the volume measurements. The table gives the mean values \pm the SEM for all the measurements. The nucleus takes up about $36 \%$ of the cell body, mitochondria around $7 \%$.

From the EM segmentations of these ten neurons, I extracted the volumes of the cell bodies, the nuclei, and the mitochondria. The results are given in Figure 76 . The mean cell body volume was $564.24 \pm 101.52 \mu \mathrm{m}^{3}$. This is much below the value $(3700.23 \pm 70.61$ $\mu \mathrm{m}^{3}$ ) obtained from the DiO signal imaged with the confocal microscope. To incorporate the shrinkage factor caused by the chemical fixation for EM, I multiplied the volume by a factor of 1.24 (Bastacky et al., 1985). 
Shrinkage adjusted cell body volume $=$ cell body volume $\mathrm{x}$ shrinkage factor

$=564.24 \pm 101.52 \mu \mathrm{m}^{3} \times 1.24=699.66 \pm 125.88 \mu \mathrm{m}^{3}$

Another contribution to this difference might be that the FIB-SEM reconstruction are often limited to one third of the entire cell body (see Figure 75). Lastly, in the confocal measurements the DiO signal might include the start of some neurites, which might increase the volume slightly. This might explain the 5 fold difference in the cell body volume obtained from the confocal and the FIB-SEM measurements. This, apart from the shrinkage, should not affect the volume measurements of the nuclei, nor of the mitochondria.

The mean volume of the mitochondria per cell was $40.98 \pm 7.15 \mu \mathrm{m}^{3}$ (shrinkage adjusted: $50.85 \pm 8.87 \mu \mathrm{m}^{3}$ ). The nuclei took up $193.86 \pm 35.33 \mu \mathrm{m}^{3}$ (shrinkage adjusted: $240.39 \pm$ $43.81 \mu^{3}$ ). A fraction of $36.31 \pm 3.79 \%$ of the cell body was occupied by the nucleus. Mitochondria occupied on average $7.31 \pm 0.82 \%$ of the cell body (Figure 76B).

3D-dSTORM can improve volumetric measurements and can serve as a replacement for classical EM studies

As it was not possible to identify many organelles apart from mitochondria in the FIB-SEM recordings, I also performed super-resolution microscopy experiments using 3D-dSTORM in combination with an alpha shape analysis to refine the volumetric analysis of different organelles. Here, the difficulty was to find good molecular markers that are specific to the organelle of interest and that are expressed throughout the membrane of the organelle. This is necessary to ensure the correct identity of the organelle and a complete coverage of its surface. After extensive testing of different markers, I settled on the clathrin heavy chain (clathrin-coated vesicles), LAMP1 (lysosomal marker), Rab11a (recycling endosome marker), the transferrin receptor (early endosomes), and PMP70 (peroxisomes). In Figure 77, I present an exemplary recoding of PMP70 to illustrate the 3D-dSTORM experiments and the subsequent volume analysis. 
Using the 3D-STORM setup, I was able to resolve the organelles much better. In an epifluorescence image of peroxisomes, the signals were rather diffuse and overlapped (Figure 77A). The corresponding image that had been reconstructed from the 3D-dSTORM recording shows a much better separation of the peroxisomes, showing round/elliptical structures with a diameter of around $200 \mathrm{~nm}$. This is similar to previous findings (Holtzman et al., 1973). As one can see in the image, the PMP70 signal is not fully homogenous. This is probably due to the molecules not being evenly distributed on the membrane or due to them not being entirely labelled. This can pose a challenge for the volumetric analysis. Using for example the point density of the localizations (which we started off with), is either including noise or removing the outer layers of the peroxisomes (Figure $77 \mathrm{C}$, top middle panel). Using alpha shapes, as described above, helped to circumvent this issue (Edelsbrunner and Mücke, 1994; Edelsbrunner et al., 1983; Nicovich et al., 2017; Tang et al., 2016). The noise that was still present in the point density separation is excluded during the alpha shape analysis (Figure 77C, top right panel). I tested several alpha shape radii for my data and decided to use a $20 \mathrm{~nm}$ radius, fitting the resolution of the dSTORM system used. In the bottom left panel of Figure $77 \mathrm{C}$, the actual alpha shape-determined peroxisome is shown. It is easy to extract the volumetric parameters from the shape, which is not biased by making prior assumptions on the shape itself (like it would be when using a fit). It would also be possible to fit the shapes, but this is not necessary for extracting the parameters (see bottom right panel of Figure 77C for a 3D-Gaussian fit of the peroxisome alpha shape).

The complete volumetric analysis of the clathrin heavy chain (clathrin-coated vesicles, LAMP1 (lysosomal marker), Rab11a (recycling endosome marker), the transferrin receptor (early endosomes), and PMP70 (peroxisomes) is shown in Figure 78. I plotted the distribution of the volumes of each of the organelles analysed. Mostly, the distribution was slightly skewed with a tail to larger objects. 
A

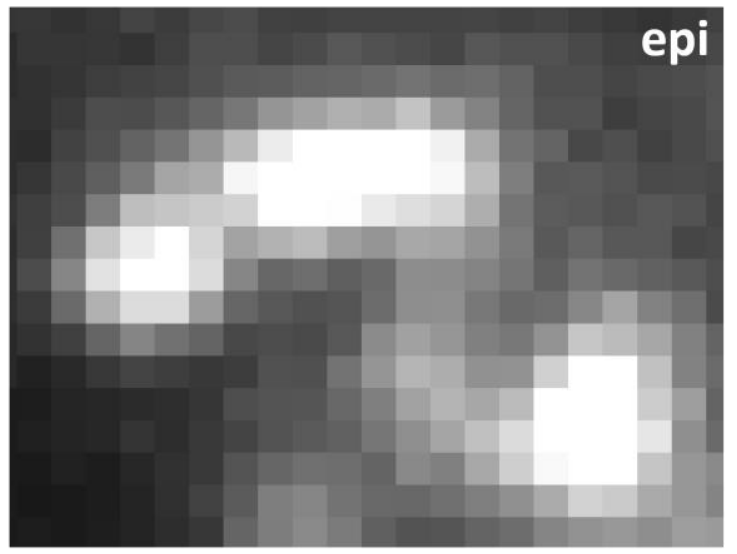

C

raw localizations (ungrouped (corrected))

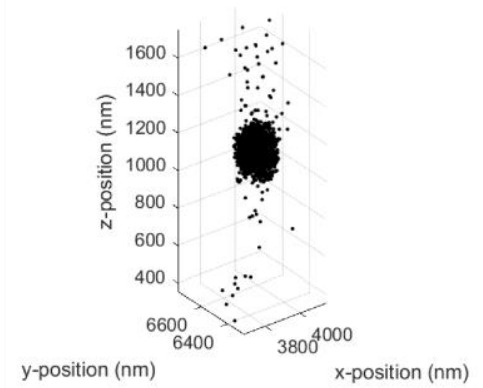

$r_{\alpha}=20 \mathrm{~nm}, \mathrm{v}_{\alpha}=0.00471 \mu \mathrm{m}^{-3}$

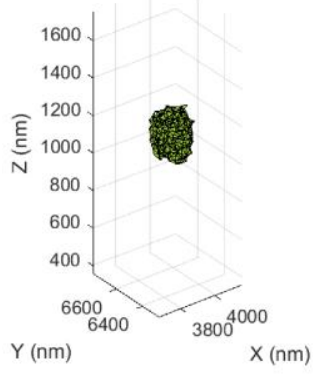

B
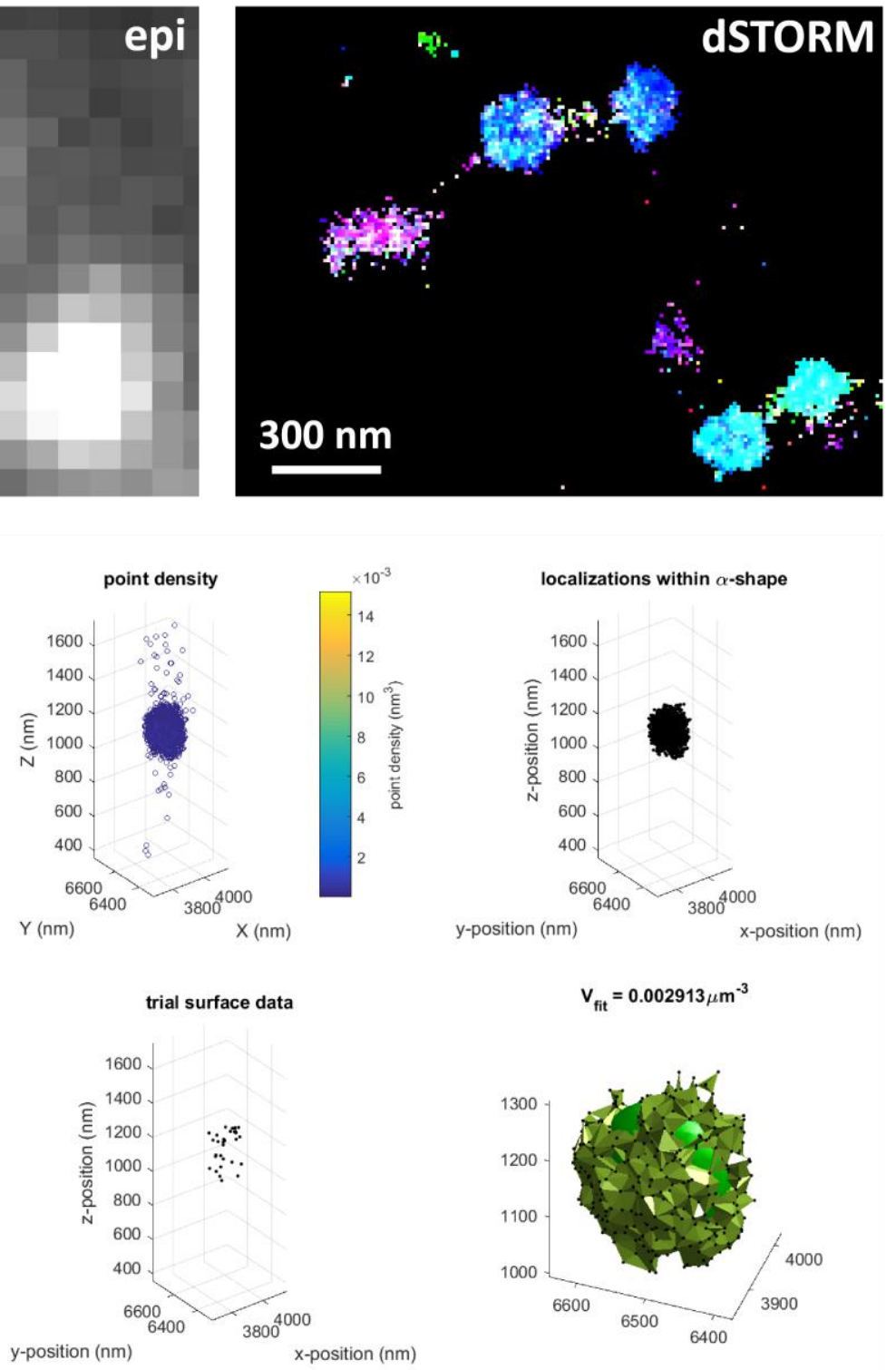

localizations within $\alpha$-shape

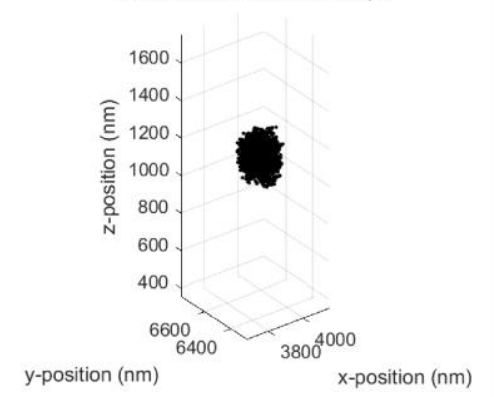

$V_{\text {fit }}=0.002913 \mu \mathrm{m}^{-3}$

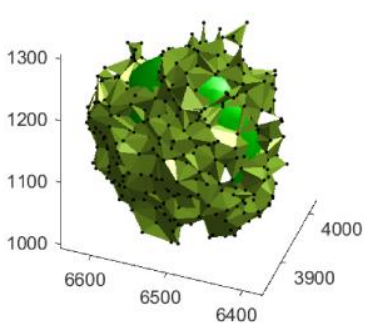

Figure 77: 3D-dSTORM imaging and volume analysis of neuronal organelles. 3DdSTORM has an improved resolution when compared to conventional fluorescence microscopy. This enables a better volume estimation. A Epifluorescent image of PMP70, a peroxisome marker. B Corresponding 3D-dSTORM image. The axial dimension is colorcoded. The different peroxisomes can only be properly resolved in the dSTORM setup. The peroxisomes have a round/elliptical shape. $\mathrm{CI}$ used alpha shapes to define the borders of the peroxisomes. From the border, the volume can be calculated with a high precision. It is more accurate than point density based filtering, which is prone to catch noise. The alpha shape based analysis was used to analyse several organelle markers. 
A

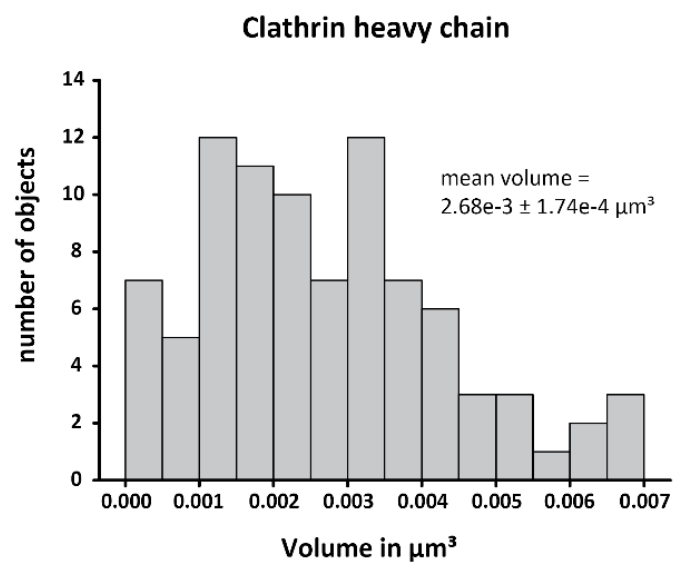

C

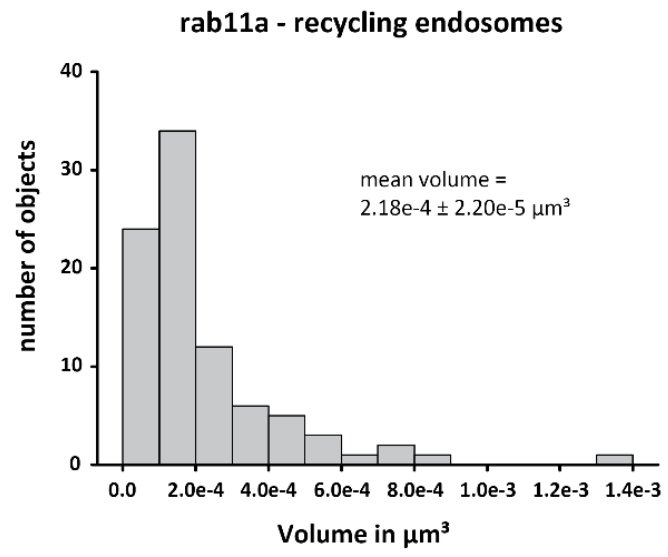

$\mathbf{E}$

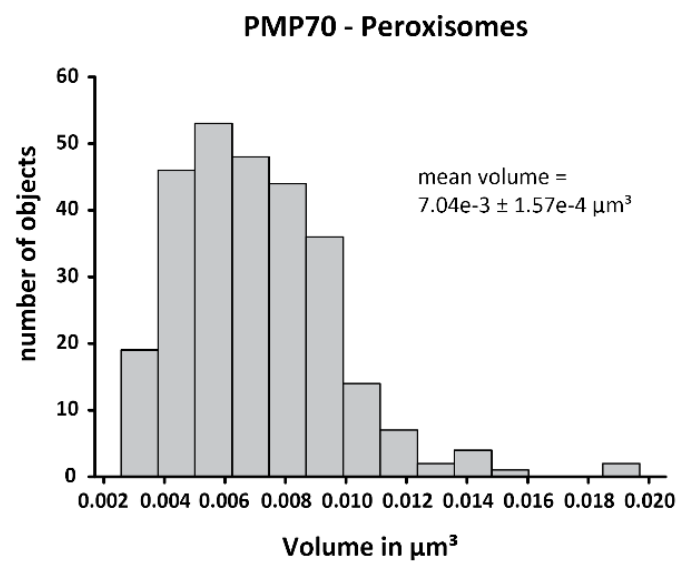

B

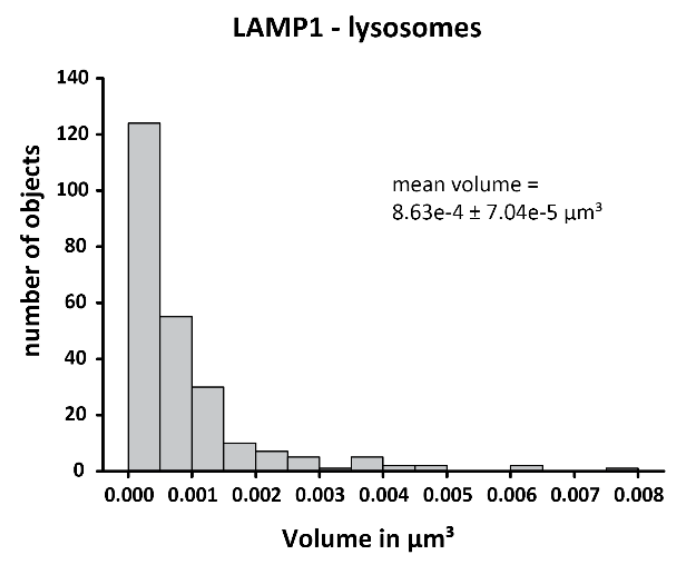

D

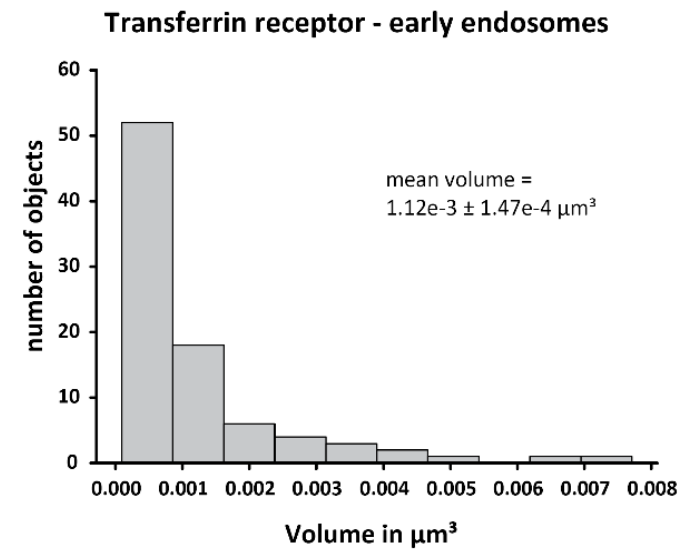

$\mathbf{F}$

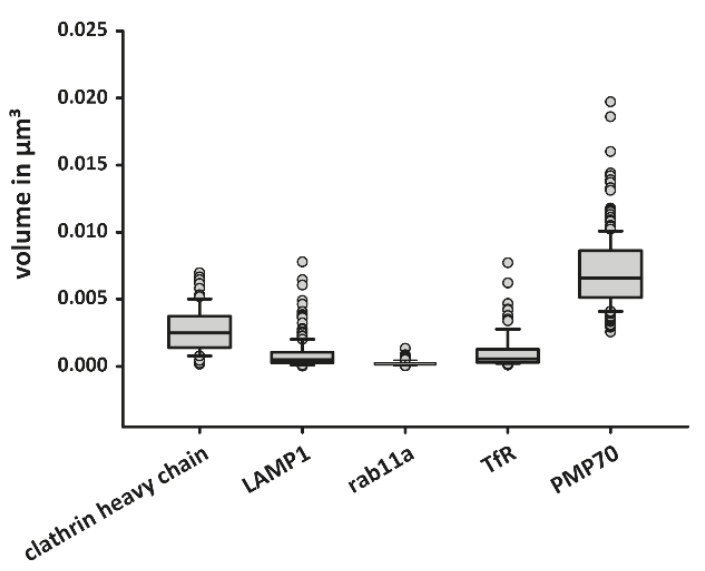

Figure 78: Improved volume estimations of neuronal organelles by using 3D-dSTORM. 3D-dSTORM measurements were used to extract volume parameters for several organelles. Alpha shapes were used to define the borders of the organelles. An alpha shape radius of $20 \mathrm{~nm}$ was used throughout the analysis. Objects were manually selected. A-E Histograms showing the volume distribution of the organelles that had been imaged and analysed. For each organelle, the mean volume \pm the SEM are given. $\boldsymbol{F}$ Volume 
comparison of the different organelles. The box plot shows the median, the $25^{\text {th }}$ and $75^{\text {th }}$ percentile are represented by the lower and upper boundaries of the box. The lower and upper whiskers show the $10^{\text {th }}$ and $90^{\text {th }}$ percentile respectively.

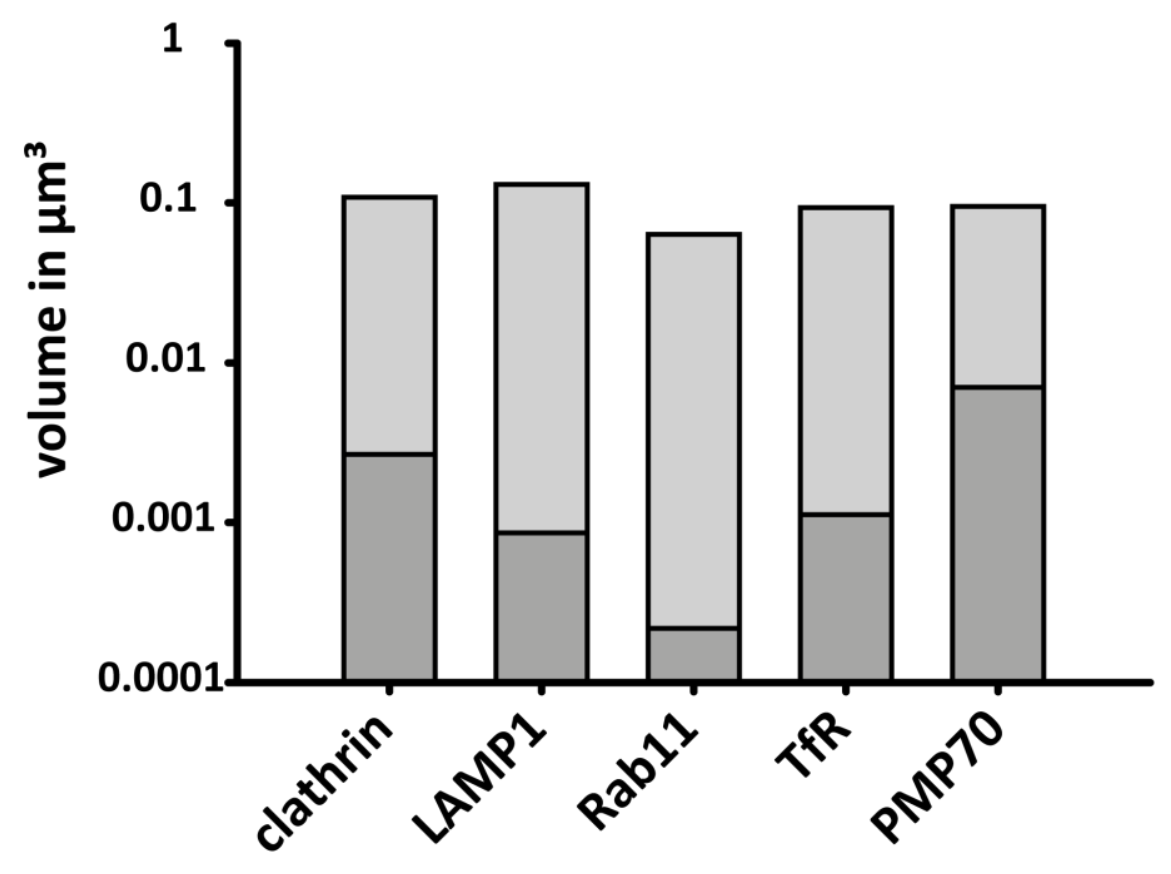

Figure 79: dSTORM measurements improve the volumetric analysis of organelles. The figure shows the volumes of clathrin coated vesicles (clathrin), lysosomes (LAMP1), recycling endosomes (Rab11), transferrin receptor positive endosomes (TfR), and peroxisomes (PMP70) as determined by confocal microscopy (entire column) and 3DdSTORM (dark grey). The volumes determined by dSTORM are one to two orders of magnitude below the confocal volumes. The figure represents the means. The scale is logarithmic.

I compared the volumes obtained from the 3D-dSTORM experiments with the ones from confocal microscopy (Figures 72 and 73). The volumes obtained with 3D-dSTORM were up to two orders of magnitude smaller than the ones determined by confocal. The values obtained by confocal microscopy are close to the theoretical resolution limit that can be obtained (around $0.06 \mu \mathrm{m}^{3}$ ) with our setup. Peroxisomes, which were described to have a diameter of $200 \mathrm{~nm}$, would (Holtzman et al., 1973), if assuming a round shape, have a volume of $0.004 \mu^{3}$, which is much below the limits of our confocal setup. The mean volume of peroxisomes determined by 3D-dSTORM was $0.007 \mu \mathrm{m}^{3}$, which is much closer to the assumed volume. 
One aspect of why we are interested in generating a quantitative neuronal model is to improve our understanding of the synaptic vesicle cycle and its regulation. Especially, the production and import of new synaptic proteins is not well understood (Rizzoli, 2014). It is known that protein expression is required for synaptic plasticity, but how is this regulated (Ehlers, 2003; Kang and Schuman, 1996; Schanzenbächer et al., 2016)? Does the synaptic activity influence the import of new proteins? Do synapses receive new components consecutively, without any influence on how active they are? While our model, once we start to fit in the protein copy numbers and the protein distributions, will help us to understand the stoichiometry of certain functional pathways, it does not directly allow us to assess these questions (Wilhelm et al., 2014). Thus, I also carried out functional experiments, for which I used a combination of isotopic and optical imaging to look at the protein turnover in synapses and its relation to synaptic activity (Saka et al., 2014; Truckenbrodt et al., 2018).

I incubated neurons with an essential amino acid, leucine, containing the rare, stable isotope of nitrogen, ${ }^{15} \mathrm{~N} .{ }^{15} \mathrm{~N}$-leucine is incorporated into newly made proteins just like its normal isoform (Figure 80A) (Steinhauser and Lechene, 2013). Its location can be imaged with the nanoSIMS. The ratio between the secondary ions, ${ }^{15} \mathrm{~N}^{12} \mathrm{C}$ and ${ }^{14} \mathrm{~N}^{12} \mathrm{C}$ then provides the fold incorporation over the natural abundance of ${ }^{15} \mathrm{~N}^{12} \mathrm{C}$ and can be used as a measure of local protein turnover. I combined the SIMS measurement with an immunostaining against the pre- (synaptophysin) and postsynapse (homer1) (Figure 80C) (Brakeman et al., 1997; Takamori et al., 2006). 

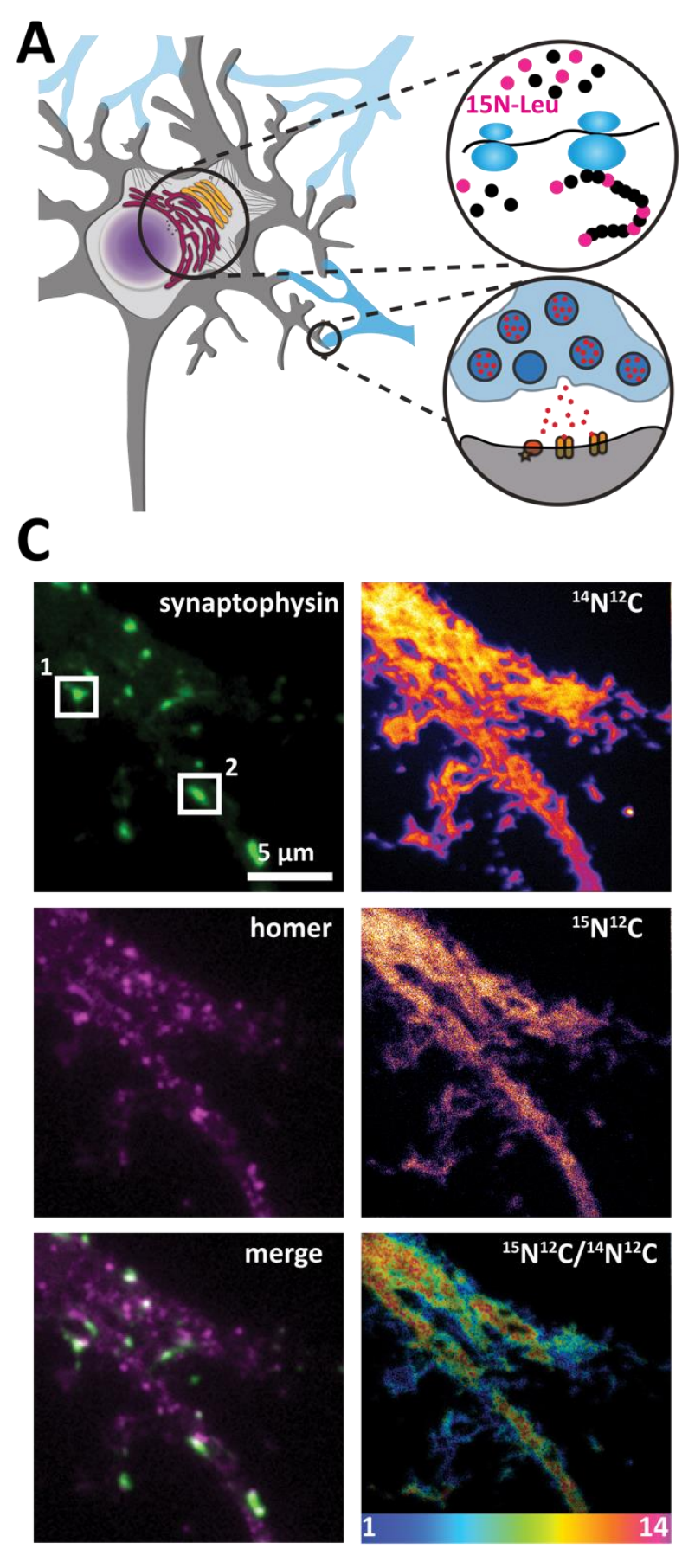

B Fluorescence Microscopy

NanoSIMS
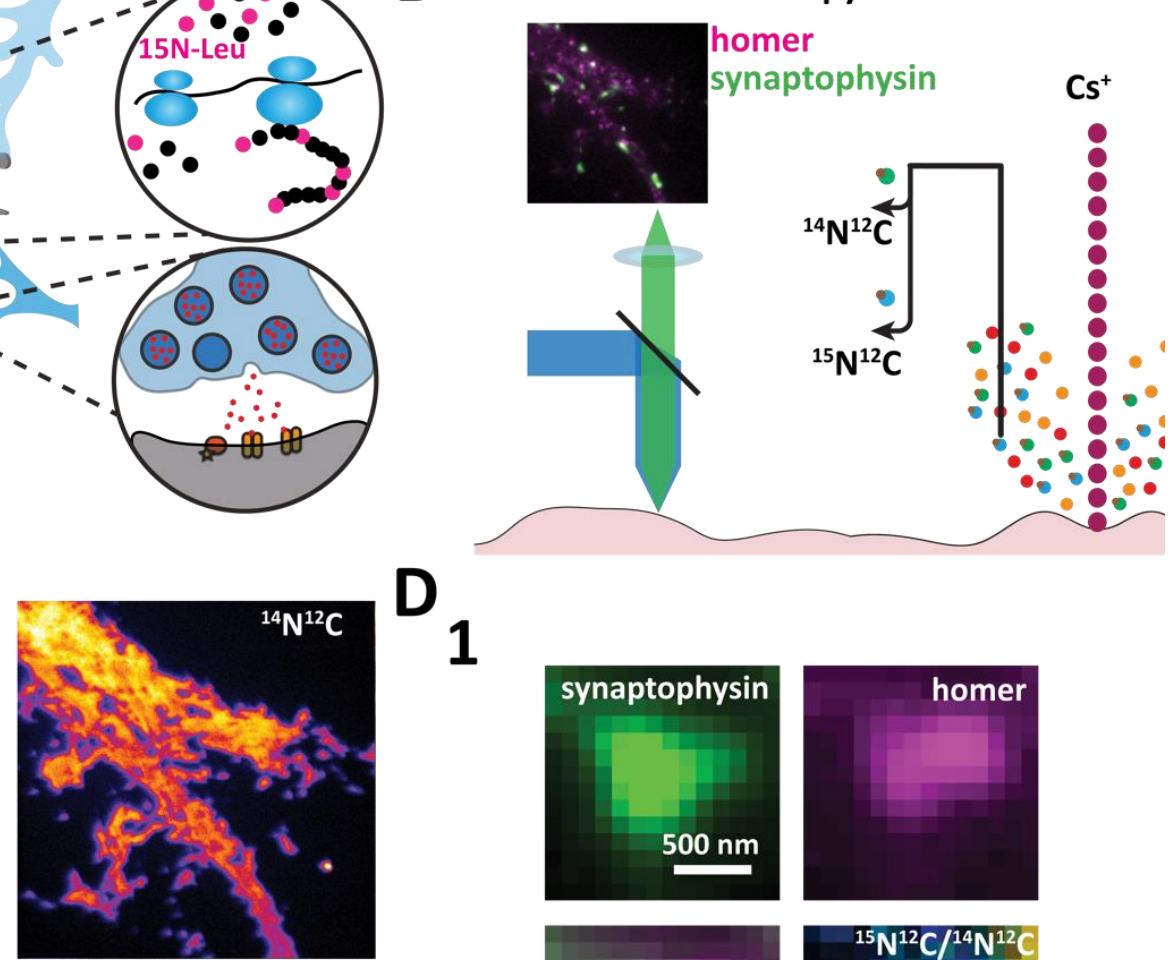

D
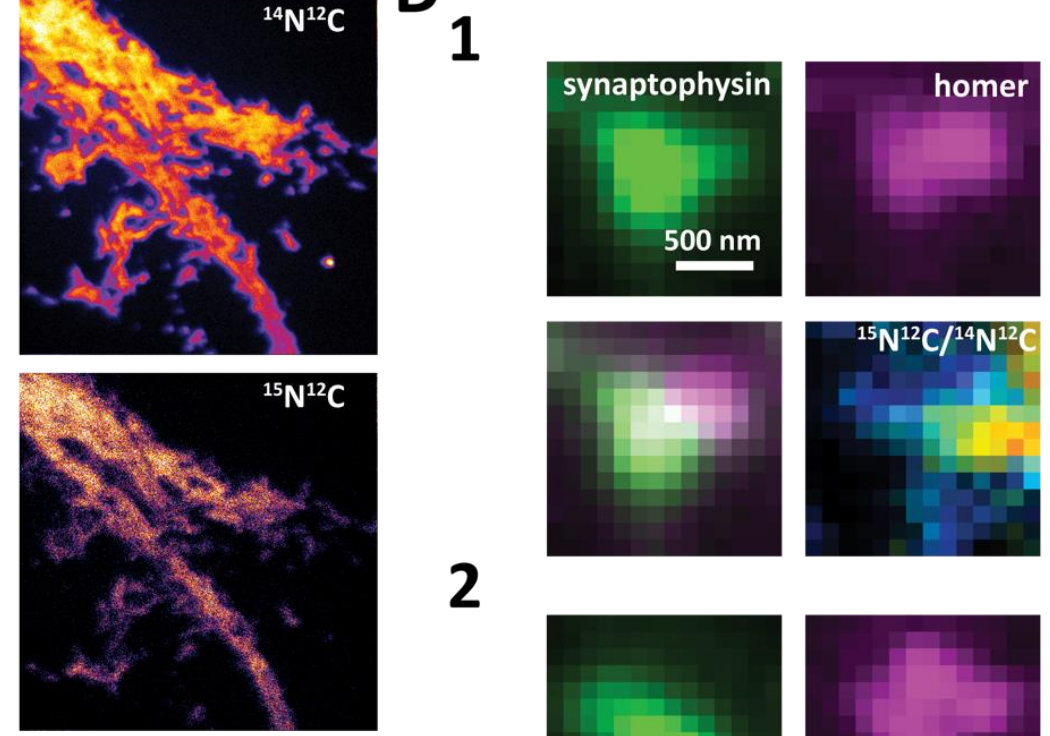

2
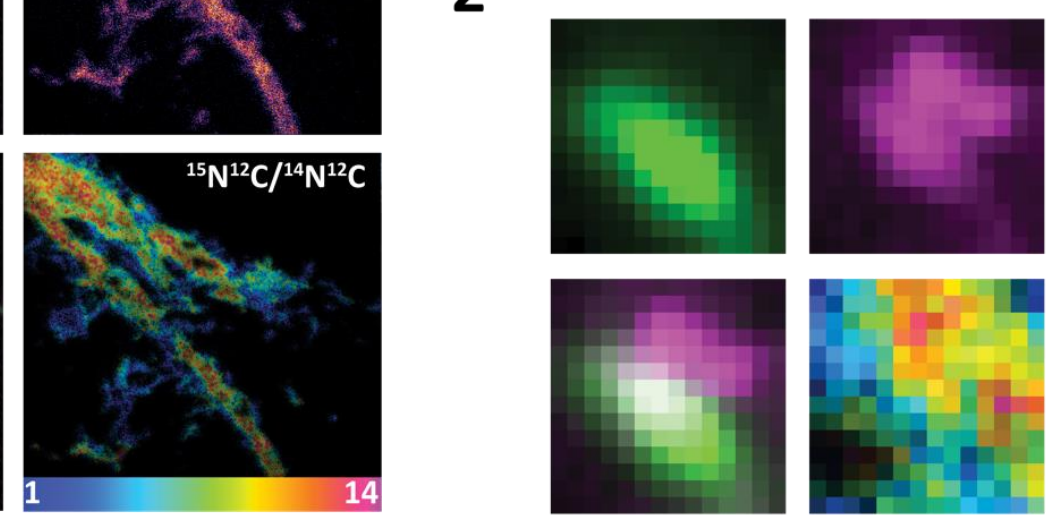

E

F
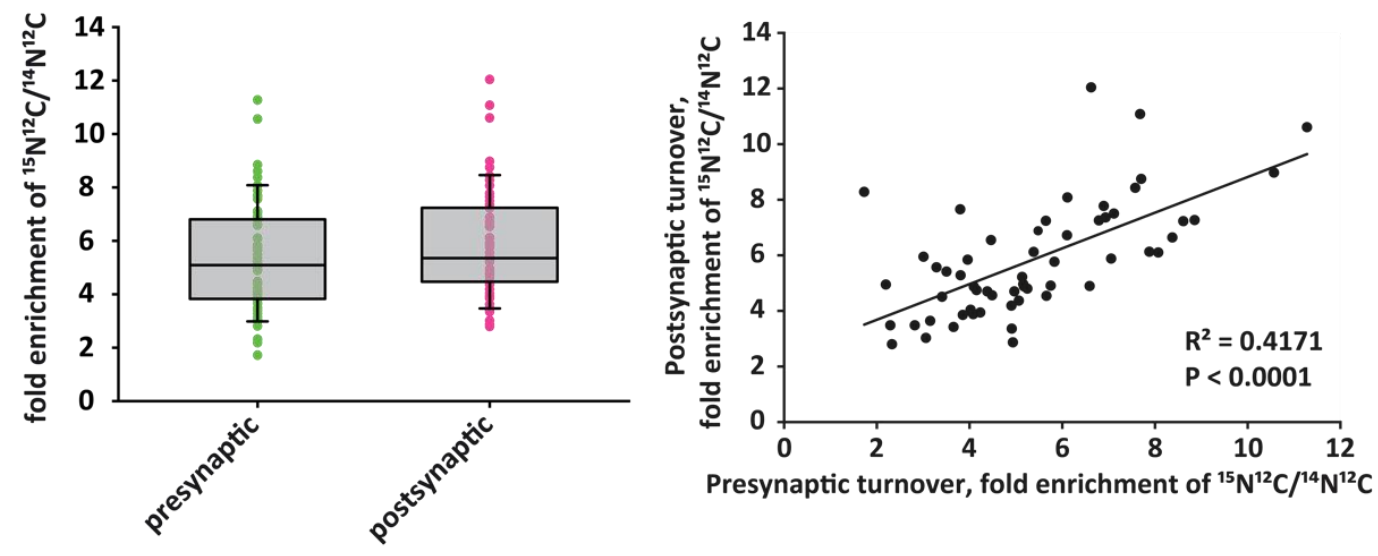
Figure 80: Pre- and postsynaptic protein turnover are positively correlated to each other. A In order to look at the relationship of synaptic protein turnover with synaptic activity in cultured hippocampal neurons, I labelled newly made proteins with ${ }^{15} \mathrm{~N}$-leucine and exocytosing SVs with synaptotagmin antibodies. B I employed a combination of fluorescence microscopy and nanoscale secondary ion mass spectrometry to specifically look at the incorporation of ${ }^{15} \mathrm{~N}$-leucine at synapses. $C$ Example of a neuron treated with ${ }^{15} \mathrm{~N}$-leucine. Presynaptic (synaptophysin) and postsynaptic (Homer1) areas have been immunostained. The pre-and postsynaptic labels allow for an identification of the synapse location. On the right panel, the isotope distributions of ${ }^{14} \mathrm{~N}^{12} \mathrm{C}$ and ${ }^{15} \mathrm{~N}^{12} \mathrm{C}$ are shown. The ratio of ${ }^{15} \mathrm{~N}^{12} \mathrm{C} /{ }^{14} \mathrm{~N}^{12} \mathrm{C}$ represents the incorporation of ${ }^{15} \mathrm{~N}$-leucine above the natural abundance. One can see a heterogeneous distribution of ${ }^{15} \mathrm{~N}$-leucine incorporation. $D$ Close-up of two synapses. $\boldsymbol{E}$ The enrichment of ${ }^{15} \mathrm{~N}$-leucine in pre-and postsynapses is relatively similar, and on average 5 to 6 fold above the natural abundance of ${ }^{15} \mathrm{~N}$. F Preand postsynaptic ${ }^{15} \mathrm{~N}$-leucine incorporation is positively correlated.

Using COIN (Saka et al., 2014), I first imaged the samples with a fluorescence microscope and then the same areas with the nanoSIMS. The images were fused/overlaid and the protein turnover in the pre- and postsynaptic area was determined (Figure 80D-F). In general the pre- and postsynaptic turnovers are well correlated, with the presynaptic turnover being higher in synapses that had a higher postsynaptic turnover (Figure 80F). The postsynaptic turnover was overall slightly higher than the presynaptic protein turnover (Figure 80E). The mean fold enrichment (to the natural abundance of ${ }^{15} \mathrm{~N}$ ) of ${ }^{15} \mathrm{~N}$ was around 5 to 6 times. Leucine makes about $9-10 \%$ of all amino acids in proteins. Thus, a fold change of 5 times corresponds to a $50 \%$ exchange of proteins. The change here is relative and means both a degradation of old proteins and production of new proteins. 
A

Control

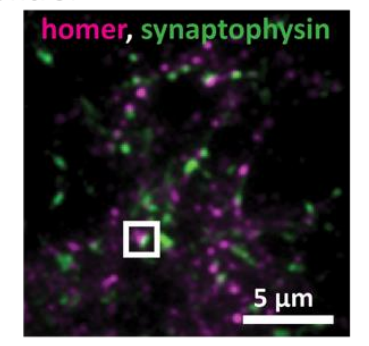

$+\mathrm{TTX}$

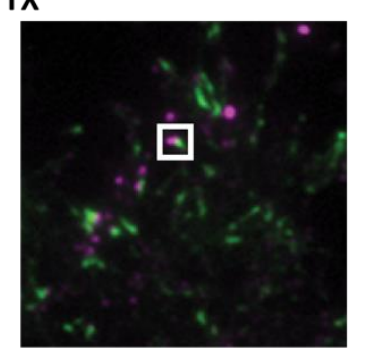

$+\mathrm{BIC}$
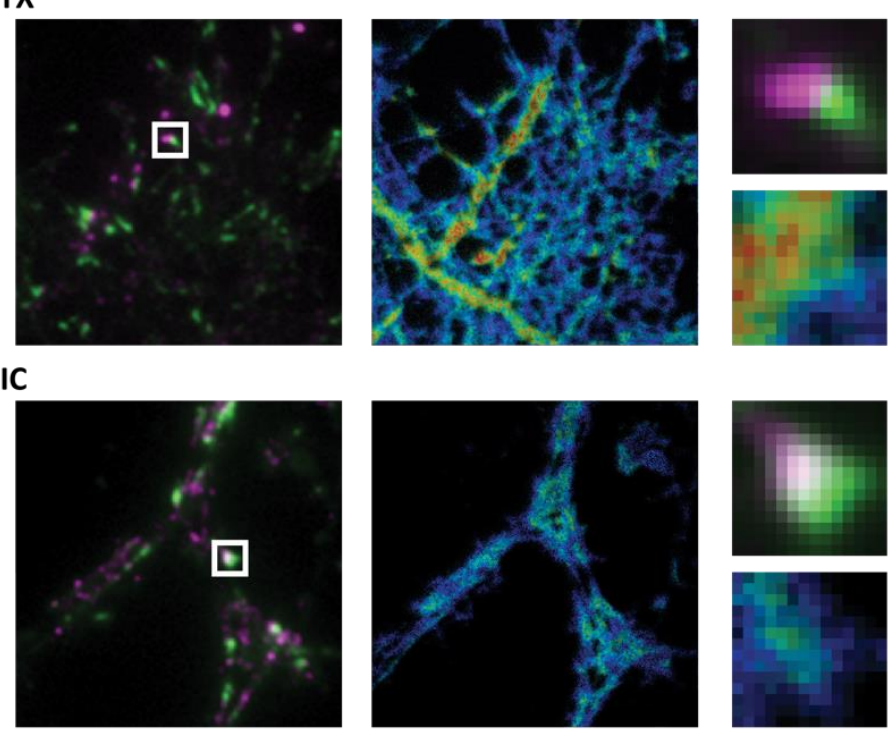

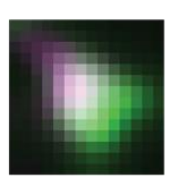

B

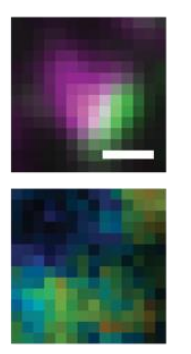

Presynaptic protein turnover

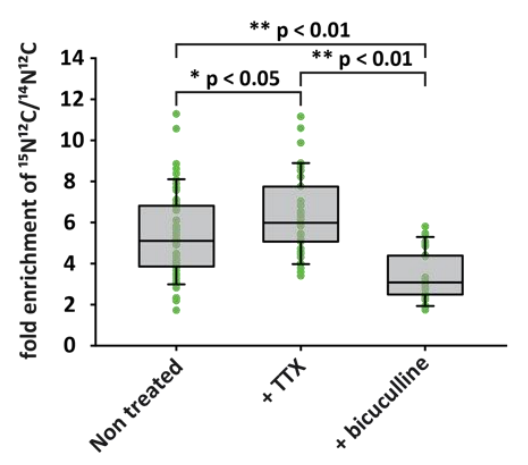

Postsynaptic protein turnover

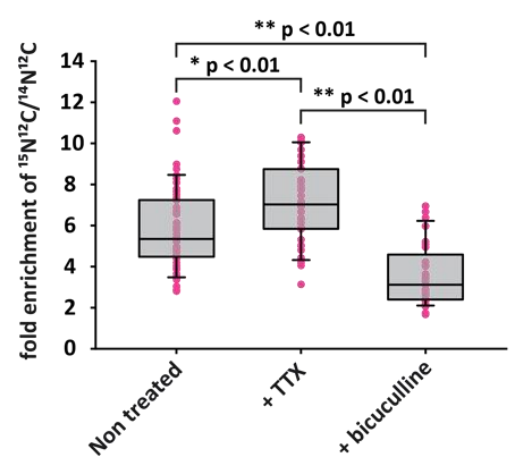

C
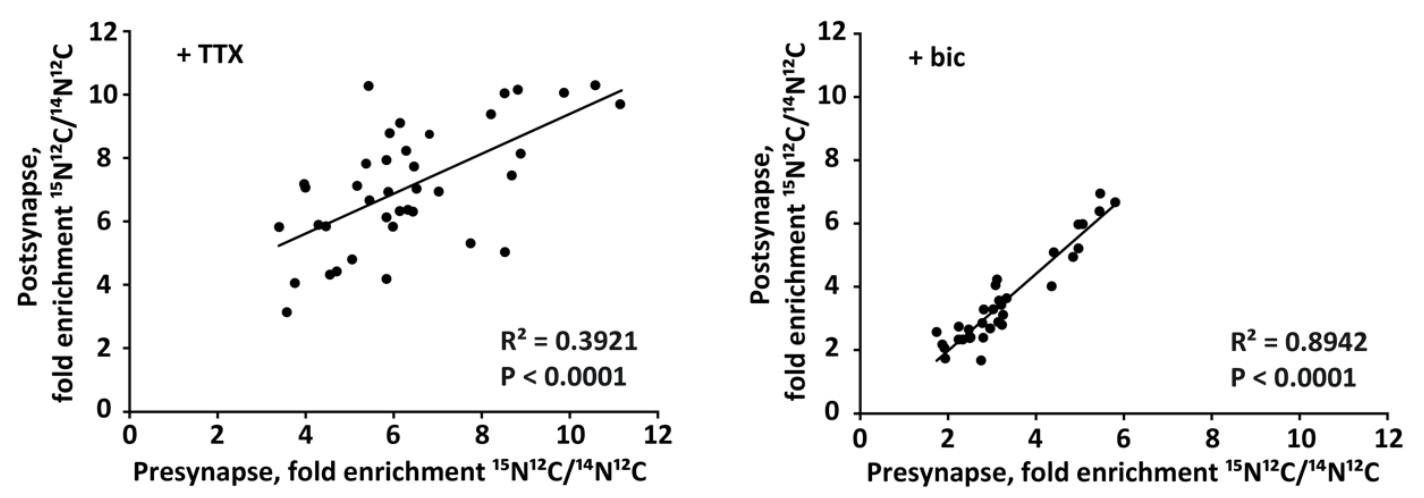

Figure 81: Modulating synaptic activity affects pre- and postsynaptic protein turnover.

To chronically change the activity of the neurons in culture, I subjected the neurons to either TTX (tetrodotoxin, inhibits action potentials by blocking voltage gated sodium channels) or bicuculline (GABA receptor antagonist, blocks GABAergic neurotransmission and raises the activity level of the culture). A shows exemplary cells and synaptic regions for each condition. Note the protein turnover differences in the synaptic regions. $\boldsymbol{B}$ Quantification of protein turnover of 30 to 60 pre-and postsynaptic regions per condition. Both, in pre- and postsynapses, chronic TTX treatment increased the protein turnover, whereas bicuculline was reducing it. The data is plotted as typical box plots showing the 
median, the 25th and 75th percentile (box boundaries), and the 10th and 90th percentile (whiskers). I carried out an ANOVA with a Bonferroni correction. C Pre- and postsynaptic protein turnover remained correlated after TTX and bicuculline treatments.

Does synaptic activity have an impact on the synaptic protein turnover? In order to study this, I chronically changed the activity of the cells in the culture. I used TTX to block voltage-gated sodium channels. This blocks action potentials and silences most of the neuronal activity and the network activity of the culture (see Figure 84). Spontaneous SV release is still possible. Bicuculline was used to increase the activity of the culture. It acts as a GABA receptor antagonist and by that stops inhibitory neurotransmission (see Figure 84), increasing the overall activity of the culture. I again labelled newly produced proteins with ${ }^{15} \mathrm{~N}$-leucine and checked the protein turnover in pre- and postsynapses. Both, preand postsynaptic protein turnover, increase upon chronic exposure to TTX (Figure 81B). This is not completely unexpected. The cells might try to counteract the decreased activity by producing more components for transmission, as has been described before (O'Brien et al., 1998; Turrigiano et al., 1998). This has been linked to transcription and translation (Ibata et al., 2008; Schanzenbächer et al., 2016). A chronic increase in synaptic activity by bicuculline treatment elicited the opposite effect, namely a significant decrease in both pre- and postsynaptic protein turnover. Again, a down-scaling of synaptic responses has been described before (O'Brien et al., 1998; Turrigiano et al., 1998). Both treatments show that on the synapse level the protein turnover is also scaled up or down as a response to suppressed or stimulated activity, respectively. The correlation between pre- and postsynaptic turnover is maintained (Figure 81C). 
A

$+15 \mathrm{~N}$-Leucine

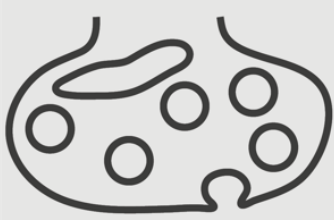

B
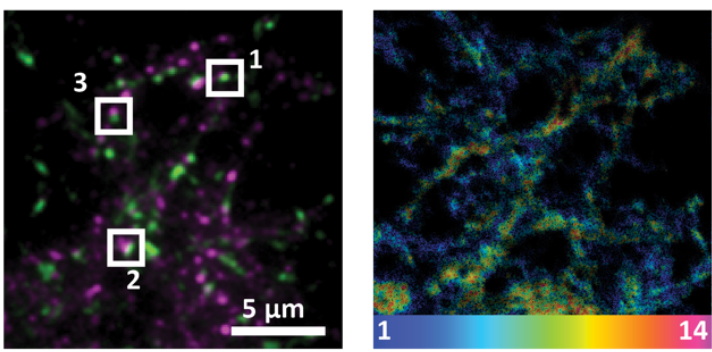

C

Presynaptic protein turnover

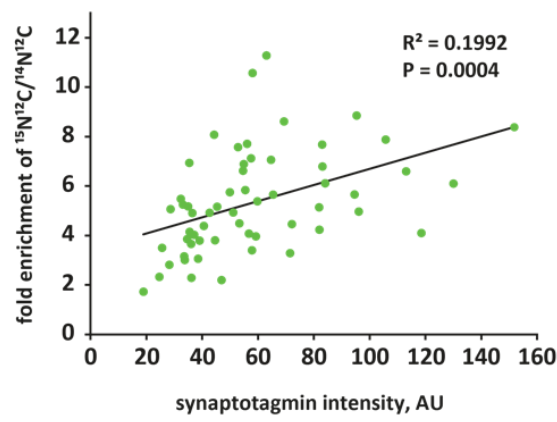

D

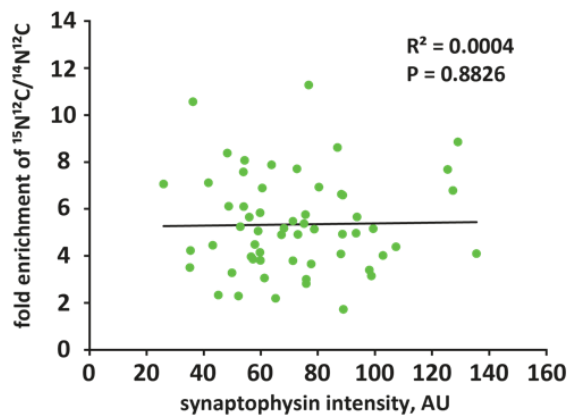

E

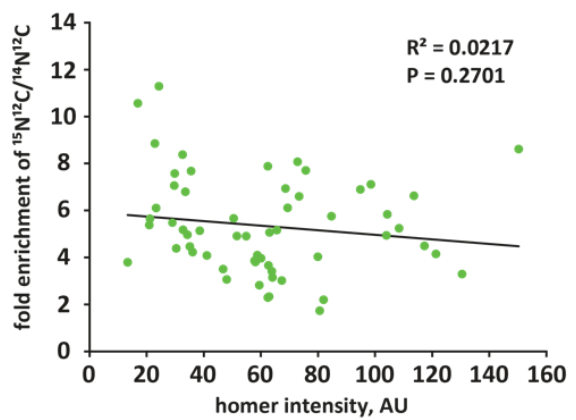

antibody

+ anti synaptotagmin
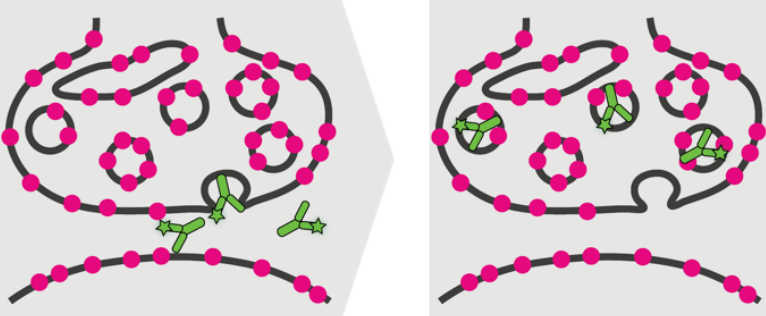

1

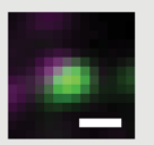

2
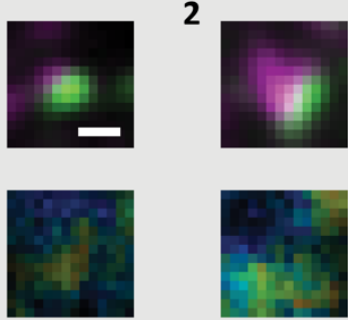

Postsynaptic protein turnover
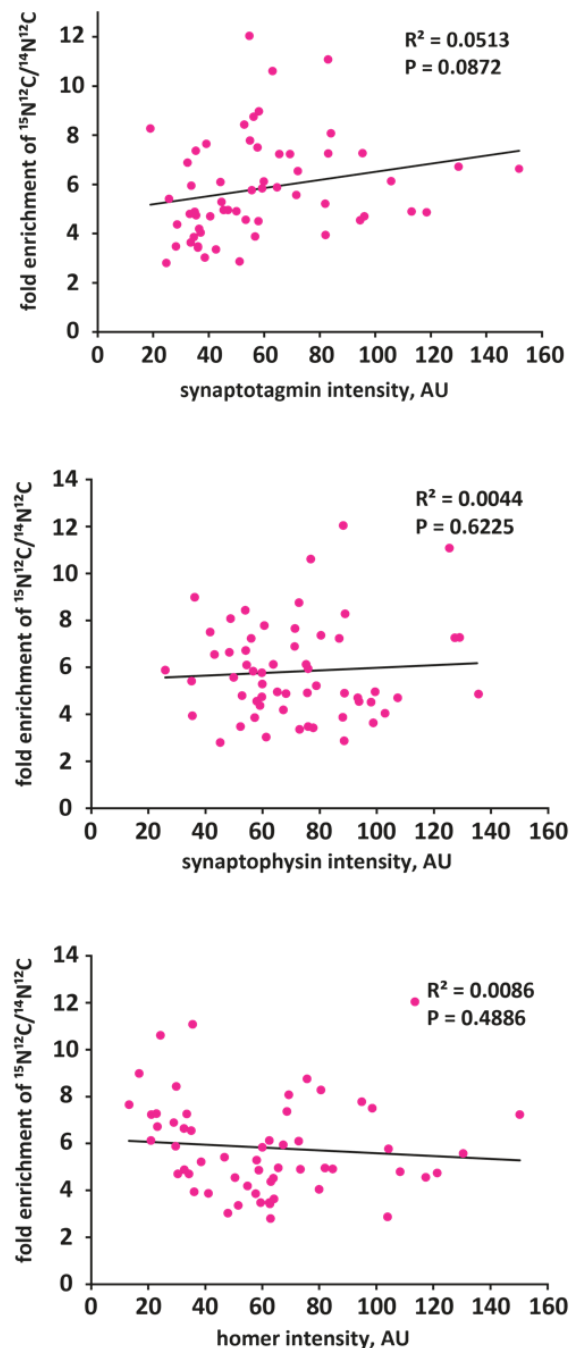
Figure 82: Pre-, but not postsynaptic protein turnover is correlated to synaptic activity. Chronic modulation of synaptic activity changes pre- and postsynaptic protein turnover. Do normal differences in synaptic activity have an effect on synaptic protein turnover, too? In order to find this out, I compared synaptic activity to pre- and postsynaptic protein turnover on the single synapse level. A Newly produced proteins were labelled with ${ }^{15} \mathrm{~N}$ leucine. Exocytosing synaptic vesicles were labelled with a primary labelled antibody against the lumenal domain of synaptotagmin1. After the live-labelling, the cells were fixed and the pre-and postsynapses were labelled. B Exemplary images showing the protein turnover signal, the pre- and postsynaptic markers synaptophysin and homer1, and the signal of the synaptic activity marker synaptotagmin1. C Pre-but not postsynaptic protein turnover is correlated to synaptic activity. $D$ The protein turnover on the other hand is not correlated to the size of the presynapse, as measured by the intensity of the synaptophysin staining. $\boldsymbol{E}$ The size of the postsynapse, Homer1 intensity, was not correlated to the protein turnover, either. The staining intensities were normalized across experiments. The data was taken from three independent experiments. Around 50 synaptic regions were analysed.

The chronic activity changes elicited by TTX and bicuculline have an effect on the protein turnover of the pre- and postsynapse. While this is in accordance with previous studies on homeostatic scaling, these paradigms are not very close to the ranges of activity that synapses usually have. The changes elicited are likely very strong and do not reflect the regulations very well. Thus, I wanted to check how the actual, natural activity of the synapses of our cultured neurons affect the local synaptic protein turnover. I used a primary labelled antibody against the lumenal domain of synaptotagmin, which I added to the neurons for the last hour of protein labelling (Figure 82A). The antibody binds recycling vesicles during this hour and the amount of labelling reflects the number of SVs that were active. As such, it can be used as an estimate for synaptic activity (Kraszewski et al., 1995; Truckenbrodt et al., 2018; Wilhelm et al., 2010). This form of activity labelling was compatible with the previous experimental procedure and allowed me to not only look at the pre- and postsynaptic protein turnover, but to relate it to its synaptic activity.

I found that the presynaptic turnover correlated with synaptic activity. The more active a synapse was, the higher was the turnover. This correlation was not or at least less visible on the postsynaptic side (Figure $82 \mathrm{C}$ ). I then checked whether the pre- or postsynaptic 
protein turnover is in some way related to the size of the SV cluster size in the presynapse, given by the intensity of the synaptophysin signal or to the size of the homer1 structure in the postsynapse. For both cases, no correlation was present (Figure $82 \mathrm{D}$ and $\mathrm{E})$.

\section{Presynaptic protein turnover Postsynaptic protein turnover}

+ TTX
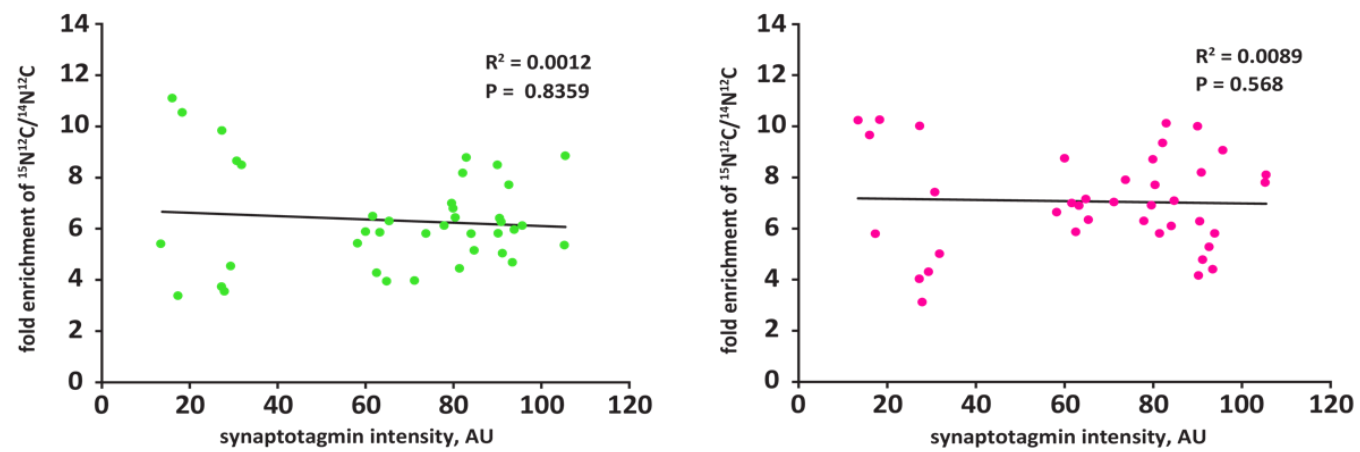

+ bic
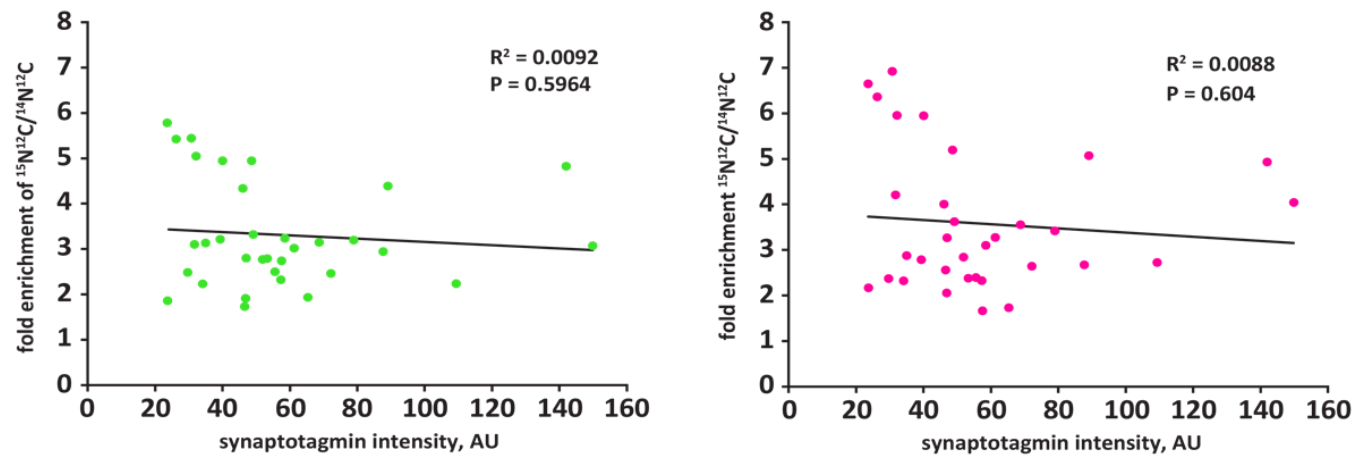

Figure 83: Modulating synaptic activity deregulates activity-turnover coupling. The presynaptic turnover correlation to synaptic activity was lost for cells chronically treated with TTX or bicuculline. The treatments were carried-out as described in Figure 81. Both, for TTX and bicuculline treatments, the relationships between the synaptic activity of a single synapse and the protein turnover in the corresponding presynapse is lost. Overall, the turnover is changed, but it is not anymore coupled to the individual synaptic activity.

In the presence of TTX or bicuculline, the correlation between presynaptic turnover and synaptic activity was abolished (Figure 83). Since both drugs drastically change the cells, it is very likely that the normal regulation of protein turnover is not functional here (Schanzenbächer et al., 2016). Does the inhibition of protein synthesis in turn have an 
effect on synaptic activity? In order to check this, I blocked translation with cycloheximide and looked at the amount of SV cycling. Indeed, over time (after 3 hours) the synaptic activity is significantly reduced (Figure 84 , bottom panel). 
+ TTX

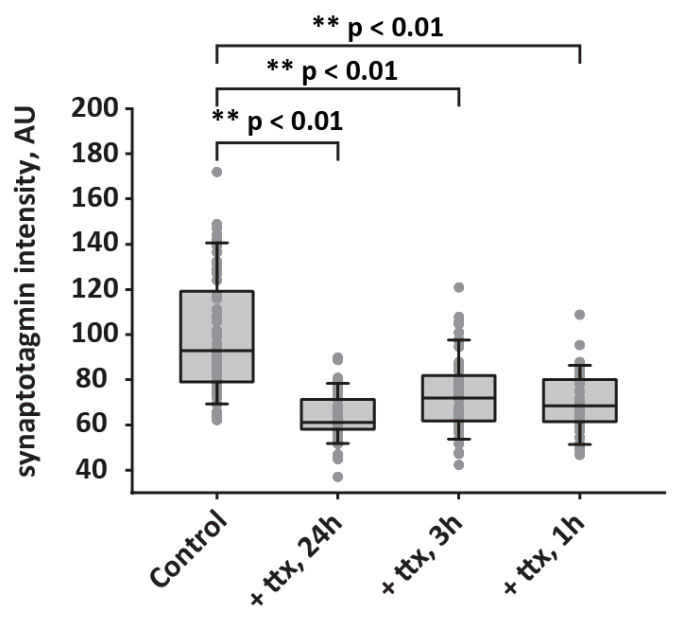

+ bic

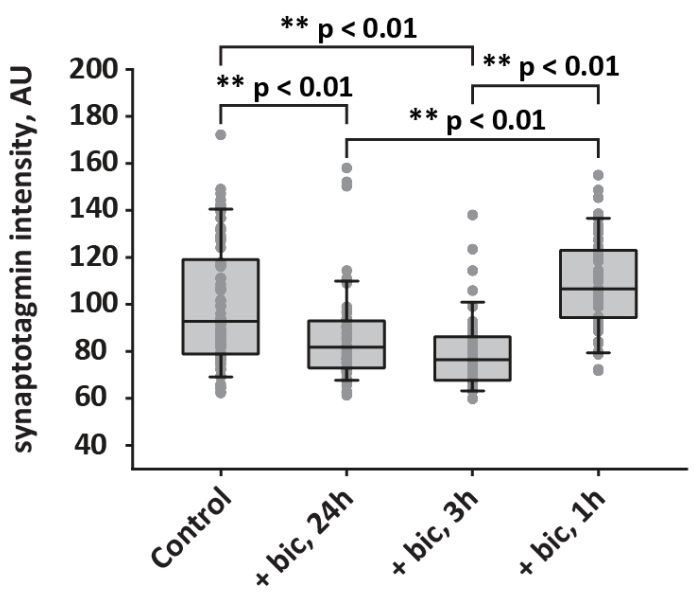

+ cycloheximide

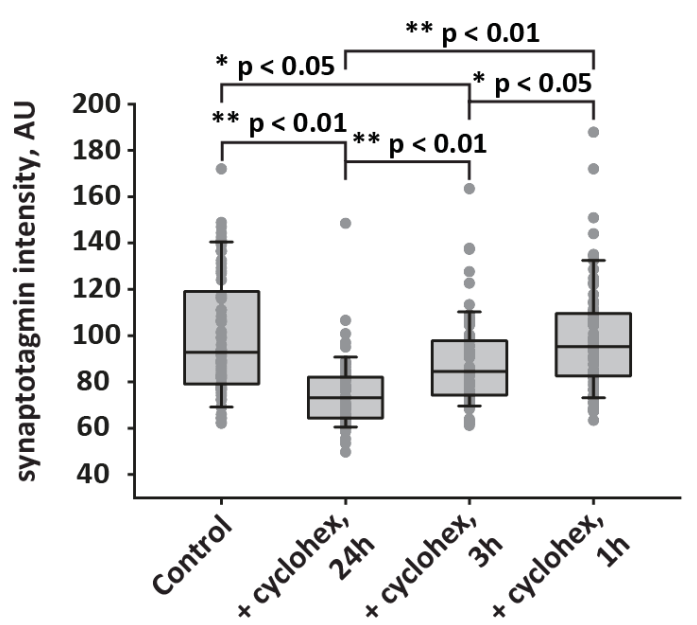

Figure 84: Inhibiting protein translation reduces synaptic activity. TTX TTX was used to chronically reduce neuronal activity via blockage of voltage gated $\mathrm{Na}^{+}$channels. I tested how TTX treatment affected neuronal activity over time. Already after 1h, neuronal activity was significantly reduced and remained low. This was expected as TTX blocks action potentials, allowing only spontaneous release. bic After treatment with bicuculline, which blocks inhibitory neurotransmission, I detected an initial increase in synaptic activity, followed by a decrease. This decrease is presumably an adaptive mechanism, such as has been describes as homeostatic scaling. cycloheximide I blocked protein translation using cycloheximide and measured synaptic activity after $1 \mathrm{~h}, 3 \mathrm{~h}$, and $24 \mathrm{~h}$ of treatment. Synaptic activity was reduced significantly after $3 \mathrm{~h}$ of treatment and was further reduced after $24 \mathrm{~h}$. Thus, the availability of new proteins has an effect on neuronal activity. Data is plotted as box plots showing the median, the 25th and 75th percentile (box boundaries), and the 10th and 90th percentile (bars). I carried out an ANOVA with a Bonferroni correction. 


\section{Discussion}

I here present the first comprehensive volumetric and structural assessment of cultured hippocampal neurons and their compartments. I studied the length, branching numbers, branching angles, and volumes of dendrites and axons. With a combination of confocal microscopy, super-resolution microscopy and electron microscopy, I determined the arrangement of various subcellular compartments and organelles and estimated their volumes.

In the future, we will combine these measurements with quantitative mass spectrometry, super-resolution microscopy, and comparative imaging to build a comprehensive molecular model of an entire neuron, the neuron nanomap. It will comprise the organelle arrangement of neurons, and a thorough molecular description. We will determine the molecules present, as well as their amounts, and for a subset of these molecules also their subcellular distribution and location.

This will ultimately enable us and other researchers to look at bigger functional pathways in a quantitative manner, such as the protein import into synapses, the regulation of metabolism and synaptic activity, calcium dynamics, protein dynamics, and cell signalling.

This neuronal nanomap will provide a reference that can be used to quantitatively assess specific neuron types in vitro as well as in vivo, to model specific functional pathways, and to check disease models, such as Alzheimer's disease and Parkinson's disease.

Banker cultures serve as a good model system for the quantitative molecular assessment of neurons, as they are mostly consisting of a monolayer of pyramidal neurons

The brain contains many different types of neurons with diverse functions. They may be excitatory or inhibitory, and their morphologies can vary strongly, with Purkinje cells in the cerebellum having extensive dendritic trees to pyramidal neurons in the cortex having a small dendritic tree with long axons (Cajal, 1894). However, all neurons share common features, such as their polarity, their ability to generate electrical potentials, and their connections via synapses. I here set out to create a quantitative molecular model or nanomap of a neuronal cell, which will reveal the average functional and molecular organization of cultured hippocampal neurons. In order to do so, I need a model system 
that can be used for biochemical assessment and imaging. The hippocampal sandwich culture I decided to use for this study is ideal for this purpose, as it has a low amount of other cell types (preventing contamination in biochemical analyses) and as it forms a monolayer, which can be easily imaged.

Our Banker culture had a low density, of around 58 neurons per $\mathrm{mm}^{2}$, which is around 14760 cells per coverslip (18 $\mathrm{mm}$ diameter). The neurons form a monolayer with clearly distinguishable cell bodies. This is ideal for imaging, as the cells can be separated from one another. Furthermore, there are no problems with out-of-focus light or with the light penetrating the cells. This might for example be a problem when imaging tissue, which has a different refractive index. Recently, clearing methods have been developed that can overcome this, though (Chung and Deisseroth, 2013; Gradinaru et al., 2018; Tomer et al., 2014).

Due to the separation of glia and neurons in the Banker culture, there are almost no astrocytes on the coverslips. Only 3.33\% of all cells in the culture were astrocytes. This is even lower than the $10 \%$ previously described for this type of culture (Brewer and Cotman, 1989). Also, other potential non-neuronal cell types, such as microglia, macrophages, and oligodendrocytes, were only present in very low amounts (below $1 \%$ of all cells) (Table 9). Thus, a biochemical analysis, for instance with quantitative mass spectrometry, of neurons is possible with this culture system. This is a strong advantage over using a co-culture system, which contains many astrocytes (see Figure 4) (Huettner and Baughman, 1986), and also over using brain tissue. It is not possible to isolate and purify entire neurons from brain tissue, which makes a quantitative mass spectrometry specific for brain tissue-derived neurons impossible.

There is the possibility to do cell sorting on brain tissue cells, or even subcellular structures, followed by a proteomic analysis (Poulopoulos et al., 2019; Wilson and Nairn, 2018). However, such procedures remove the neurites, and have been shown to have an influence on the molecular composition (Binek et al., 2019). Axons and dendrites in particular, however, are the important and specialized structures of neurons and of great interest for our study. Thus, cell sorting combined with proteomics is not an option. There are also new imaging methods, such as mass spectrometry approaches, being developed, including time-of-flight secondary ion mass spectrometry (TOF-SIMS) and matrix-assisted 
laser desorption ionisation mass spectrometry imaging (MALDI-MSI), that allow a molecular analysis within tissue (Mohammadi et al., 2016; Phan et al., 2017). However, these techniques are limited in spatial resolution, in the amounts and size of molecules detectable. Thus, if we want to analyse the entire proteome of the neurons, TOF-SIMS and MALDI-MSI are still not feasible techniques. If developed further, they would be ideal for this type of study.

Apart from being ideal for biochemical analysis and imaging, using the Banker culture as a model system has a direct relevance to research, as it has been used by numerous groups to study basic neuronal functions (Kaech and Banker, 2006).

Of course, using a primary culture can be physiologically problematic, as it does not quite reflect the situation present in brain tissue. For example, cultured neurons form monolayers and do not have a three-dimensional arrangement as in the tissue. Thus, they might show a similar morphology, but not quite the same. They do not have direct contact to astrocytes, oligodendrocytes and microglia, which will affect their physiology (Perea et al., 2009). Astrocytes usually take part in removing excess neurotransmitter from the synapse. They also release trophic factors that support neurons (Hertz and Zielke, 2004; Newman, 2003). In the sandwich culture, this direct contact is not given, but astrocytes are still present. Naturally, the cell type specification is not the same in the culture system, i.e. the neurons do not fully specialize like the ones in the brain. However, they still have specific neurotransmitters and are thus either excitatory or inhibitory. Also, their morphology, at least in the case of pyramidal neurons, is partially maintained (Banker and Cowan, 1977; Benson et al., 1994).

Nevertheless, as stated above, the quantitative biochemical approach that we are planning to combine with the morphological and volumetric analysis of these neurons and their organelles, was only possible using this particular culture model. Once this model is finalized, we will also be able to use it as a reference against more specific neuron types in situ. I will explain this in the outlook.

I found that the number of pre- and postsynapses in the Banker culture system correlated very strongly with one another. While the average number of presynapses per cultured neuron was $294.25 \pm 20.02$, the number of postsynapses was $299.11 \pm 17.5$. This is in accordance with previous findings that suggested the presence of around 400 synapses 
per neuron in low density cultures (Cullen et al., 2010). My culture had a very low density with 58 cells per $\mathrm{mm}^{3}$, which might explain, why I obtained less synapses per neuron. Apart from the density of the cultures, the number of synapses per neuron might be influenced by the maturity of the cells. After plating, cultured hippocampal neurons undergo several developmental stages before they are 'mature' and before they have fully functional synaptic connections (Kaech and Banker, 2006). Only after 1.5 days in culture, the axon starts to develop. After 4 days, the first dendrites follow (Dotti et al., 1988) and synapses are starting to form (Fletcher and Banker, 1989). It takes however at least one week before dendrites develop spines. Only after 3 weeks in culture the spine morphology resembles the one found in vivo with dendrites containing mushroom type spines (Papa et al., 2018). Also, the number of synapses changes during this maturation process. Thus, the number of synapses that I measured reflects the developmental stage and the cell density of the neuronal culture.

Ideally, one would use cultures at DIV 21 to ensure properly developed neurons with a synapse structure resembling synapses in vivo. For almost all of the experiments I did adhere to this, except for the experiments that I carried out to determine the neuronal morphology and synapse numbers per neuron. I sparsely transfected cells with a membrane-bound EGFP construct to ensure spatially separated labelled neurons (Matsuda and Cepko, 2007). This was only possible with neurons up to 15 days in vitro. After that stage, the cultures either died during the transfections or the constructs were not expressed. I tested several low efficiency transfection methods to improve this, including Calcium-Phosphate transfections, lipofections with lipofectamine or effectene, and magnetofections (data not shown) (Buerli et al., 2007; Felgner et al., 1987; Jiang and Chen, 2006; Ohki et al., 2001). The latter technique was the most reliable of these three methods, but did not help in overcoming the problem. Thus, the measurements on the morphology and the synapse were done with neurons of DIV 15. This might create a slight incoherence with the remaining data taken at DIV 21 . The axon and dendrites are likely to be longer and more branched, the number of synapses is probably higher at DIV 21.

As mentioned above, the number of presynapses corresponds to the number of postsynapses. This indicates that at this stage each presynapse is coupled to a postsynapse. This is quite remarkable since the axonal and dendritic areas showed big 
differences in the length and volumes occupied. The dendrites were on average more than 4 times smaller than the axons per neuron. This necessitates a higher density of postsynapses along dendrites than presynapses in axons.

With the knowledge on the neurites and synapses, we might be able to model synaptic transmission and synaptic integration (Spruston, 2008). We can simulate where signals on the dendritic tree are received, modulate the EPSP and the spread/integration of this signal within the dendrites. The integration of postsynaptic potentials is very much dependent on the positions/distances of the postsynapses, as well as on the volumes of the dendrites, which I both provide information on (Gulledge et al., 2005).

The size and distribution of neuronal organelles and compartments varies depending on the subcellular location

Using immunostainings and confocal microscopy, I determined the distribution of 32 different organelle, compartment, and cytoskeletal markers within neuronal cell bodies, proximal axons, and proximal dendrites (Figures 12 to 71). To my knowledge, this is the most comprehensive dataset on neuronal organelles to date and it shall serve as a description of the functional composition of neurons. Organelles and compartments usually serve a specific function by segregating chemical reactions and biological processes from one another. They usually have a distinct molecular composition, such as the organelles of the secretory pathway (Bonifacino and Glick, 2004; Zerial and McBride, 2001). For example, the ER is known to be involved in the translation and posttranslational modifications of proteins. For this it has a specialized set of molecules, such as the protein disulphide isomerase, which is involved in the correct formation of disulphide bonds within proteins (Wilkinson and Gilbert, 2004). The ER also functions as a calcium store, which might have several functional implications, as calcium is a highly potent signalling molecule (Verkhratsky, 2002). With the data on the volume, shapes, and arrangement to one another for the most common organelles, we should be able to increase our understanding of certain functional aspects related to them. In the case of the ER, we can use our information to estimate the location of calcium stores in neurons. 
Even though organelles segregate molecular functions, they are often well connected (Allison et al., 2017; Valm et al., 2017; Wu et al., 2017). With my data, I cannot directly look at the interactions between the organelles, but I can assess how the parameters for each organelle of a certain pathway are behaving in different cellular substructures. For example, I can look at the presence of ribosomes and ER proteins in axons and ask: Do the dimensions of the ER change in axons as compared to the cell body? Does this change correlate to changes in the ribosome number or density? This might be an important information for understanding synaptic biogenesis and homeostasis, as a local protein production machinery might have a role in maintaining presynaptic function (Hafner et al., 2018).

Another interesting feature to study is the distribution of different organelle markers within one organelle in different locations. In order to gain as much information as possible on the ER, I used more than one marker, namely CTP1c, calnexin, calreticulin, PDI, and ribophorin1. These proteins have different functions, ranging from enzymatic activities for PDI to chaperone functions in the case of calreticulin and calnexin (Danilczyk et al., 2000; Wilkinson and Gilbert, 2004). Is the distribution of these molecules similar or different in the axon, the dendrite or the cell body and what implication might that have on ER function?

The organelle distribution data presented should be able to help elucidate these types of questions. For that the dataset will require some further exploration and data analysis. What can so far be already said is that many of the markers I analysed showed significant differences in their size, dimensions, and distribution when comparing the signals between axon, dendrite, and cell body. This is not fully unexpected, as the environment is quite different, i.e. axons have a limited space due to their small diameter, whereas this restriction is not given in the cell body. It would be interesting to see, if organelles are generally smaller in axon and dendrites when compared to the cell body.

\section{Organelles and compartments occupy most of the cell body volume}

I determined the average volumes of 32 organelle markers, as well as their total proportions in the neuronal cell body (see Figure 72). This is a very extensive volumetric 
description, which has not yet been performed for organelles in such a large scale. Remarkably, most of the cell body volume was occupied by organelles, leaving only about $12 \%$ for the cytoplasm. This might have several implications for cellular functions. Since the organelles occupy most of the space, movement becomes more difficult. Transport vesicles, endosomes, and mitochondria are highly dynamic and mobile organelles. If there is only about $12 \%$ of the cell body space available, this movement needs to be highly coordinated in order to work. Otherwise organelles might get stuck on other organelles during transport. It would be interesting to study this coordination.

The volumetric determination will open up many possibilities for further studies. It allows, for example, the determination of internal solute concentrations. In the case of the ER one could look at the calcium concentrations and amounts available (Koch, 1990). In the future we are planning to combine this data with quantitative mass spectrometry. Knowing the organelle volumes will allow a much better estimation of protein concentrations within the cytoplasm and within and on organelles (Takamori et al., 2006; Wilhelm et al., 2014). My data on the organelle contents and volumes, as well as the planned studies on protein concentrations can also greatly benefit the modelling of protein dynamics and cell signalling cascades. Gallimore et al. modelled long-term potentiation and long-term depression in the Cerebellum (Gallimore et al., 2018). To get to the model, they had to first carry out an extensive literature search in order to find estimated protein concentrations, which is very time consuming and error prone as it involved drawing data from many different preparations. Also, the model did not include information on the cellular environment. However, this might change the signalling cascades and protein dynamics drastically. Thus, ultimately my organelle dataset will be able to provide the required information directly and from the same model system, which can enhance this type of modelling studies.

One potential problem with the volumetric measurements carried out with confocal microscopy is the resolution limit of such a setup. A lot of the smaller organelles, such as SVs and peroxisomes are too small for accurate size estimations with confocal microscopy. I tried to overcome this problem by using EM and super-resolution microscopy. With FIB-SEM I was able to semi-automatically reconstruct the mitochondrial network in ten neuronal cell bodies. The analysis was comparable with manual 
reconstructions, suggesting that objects with a strong contrast difference can be automatically segmented. This is very useful in case of such a large dataset, where manual reconstructions are simply not feasible. Due to the advancements in connectomics and FIB-SEM imaging (Xu et al., 2017; Zheng et al., 2018), one can hope also for advancements in the automatization of EM image analysis (Jones and Spiers, 2018; Jorstad et al., 2015; Plaza et al., 2014). In this case, FIB-SEM reconstructions to map all the cellular organelles would allow studying all the organelles at the same time, looking at contact sites, volumes, and changes in different subcellular compartments.

Right now, this was not possible, so I took advantage of 3D-dSTORM, a super-resolution microscopy technique (Huang et al., 2008a). I was able to measure the volumes of several smaller organelles. The volumes obtained during these measurements were considerably smaller than the ones from confocal imaging. I calculated the minimum theoretical volume the confocal setup can resolve and realized that the measured volumes were relatively close to this limit, suggesting that the actual organelles are too small to be resolved. The 3D-dSTORM measurements on the other hand were much closer to the expected volumes, as shown for peroxisomes. Thus, 3D-dSTORM is a good method to overcome the resolution limit of confocal microscopy and to provide accurate volume estimates of organelles. For larger organelles, such as the Golgi network, the confocal measurements should be sufficient. Also, for the distribution and object properties, confocal microscopy was the method of choice, as it allowed the sampling of more cells and the imaging of larger areas.

\section{Presynaptic protein turnover is correlated to synaptic activity}

The turnover of proteins at the synapse and its regulation has been of great interest in the field. Already the fact that neurons have long axons and dendrites far away from the cell body, which is usually the main place of protein expression and translation, has sparked interest on how new proteins are imported into synapses and how this is regulated. Neurons rely heavily on their property to form and scale synapses, a feature which makes them plastic and allows the remodelling of circuits (Herring and Nicoll, 2016). 
So, it has been shown that synapses can be strengthened and weakened depending on the input they receive. This mechanism has been shown to be involved in learning. For the synapse to stay potentiated for an extended period of time, an effect called LTP, protein expression and translation is required.

It was also shown that neurons try to maintain or adjust their activity levels when their activity is up- or downregulated (pharmacologically). This is called homeostatic scaling (O’Brien et al., 1998; Turrigiano, 2008; Turrigiano et al., 1998), and it has been linked to changes in protein expression and translation (Ibata et al., 2008; Schanzenbächer et al., 2016). Even though we know many of the molecular details involved in LTP and the proteomic changes associated to synaptic scaling (Herring and Nicoll, 2016; Schanzenbächer et al., 2016, 2018), it is still unclear how the activity of a single synapse may have an impact on its protein turnover. Is the protein turnover globally regulated, does it respond to changes in the activity of a synapse? Are there differences between the pre- and postsynaptic regulation of protein turnover?

Truckenbrodt et al. showed that old proteins are dangerous for cellular functions and that a supply of new proteins is necessary for correct SV release at the presynapse. The ageing of the SVs was linked to the amount of recycling, ergo activity. This means that a synapse that was more active requires more new proteins. Is this actually reflected by the protein turnover at the synapse? I performed correlative light and mass spectrometry experiments to tackle this question and found that on the synapse level the presynaptic protein turnover is positively correlated to synaptic activity (Figure 82). This is not the case for the corresponding postsynaptic protein turnover. It is intriguing that the presynapse, which is often far away from the cell body (in our culture system: up to $1 \mathrm{~mm}$ apart) has this form of regulation. I can imagine two possible ways on how this coupling of synaptic activity and presynaptic protein turnover is achieved.

If there is a local protein expression and translation machinery close to presynaptic terminals, the synapse could signal to this machinery that it requires new proteins. There is some evidence that the protein expression and translation machinery is present in axons, so this coupling may be possible (Hafner et al., 2018; Krijnse-Locker et al., 1995; Ramirez and Couve, 2011). My organelle dataset confirms the presence of ribosomes, the ER markers calnexin, calreticulin, CPT1c, and ribophorin1 in proximal axons. The other 
possibility is that there are mechanisms in place that increase or decrease the targeting of precursor SVs and other protein cargoes into the synapse, depending on its activity.

The synaptic turnover was not correlated to the size of the presynaptic vesicle population or the size of the postsynaptic Homer1 structure. Thus, the synaptic size does not seem to have an influence on protein turnover. In general, I was able to see a coupling between the presynaptic and the postsynaptic protein turnover. When the presynaptic turnover was higher, this was also the case for the postsynaptic one. This would be in line with the Hebbian synapse theory that postulates that the strength of the pre and postsynapse influence each other (Miller, 1996). The mean fold enrichment of $15 \mathrm{~N}$-Leucine was 5 to 6 times above the atmospheric ${ }^{15} \mathrm{~N}$ amount. ${ }^{15} \mathrm{~N}$-leucine is a highly abundant amino acid making about $9-10 \%$ of all amino acids in proteins (Smith, 1966). Thus, the fold enrichment corresponds to about a change of $50 \%$ of all proteins. This net change will be due to the degradation of old proteins and the generation of new proteins containing ${ }^{15} \mathrm{~N}$ leucine.

When I chronically increased the activation of the culture with bicuculline or decrease the activity with TTX, I observed a homeostatic scaling effect. Overall, the protein turnover decreased with an increase activity and vice versa (Figure 81). Thus, it is not only the expression and translation profiles that change during synaptic scaling, but also the amount of pre-and postsynaptic protein turnover. Interestingly, the chronic treatment abolished the activity dependent turnover regulation (Figure 83). This is somewhat expected, as the whole neuron is probably shifted into a different physiological state, as was shown by strongly altered protein translation profiles (Schanzenbächer et al., 2016, 2018). Probably, the normal regulation machinery is not functional in this state.

A question that remains open is the directionality of this effect. Is a synapse that receives more new proteins pushed to be more active, or does an active synapse request more newly made proteins? Both scenarios are plausible, and my data does not allow to answer this question. I blocked protein translation with cycloheximide and checked synaptic activity over time. After cycloheximide addition, the synaptic activity gradually decreases. This change was significant and shows that new proteins are required for presynaptic activity, as was previously shown for SVs (Truckenbrodt et al., 2018). However, as stated before, a chronic change of synaptic activity elicited by 
pharmacological means also has an effect on the amount of protein turnover. Thus, both scenarios, the protein turnover influencing the synaptic activity and vice versa are possible. In fact, a bi-directional mechanism might be plausible and would make sense. It would allow the synapses to on the one hand demand more new proteins in case of a higher activity. On the other hand, it would enable the neuron to globally regulate synaptic activity, as in the case of homeostatic scaling.

Of course, it would also be desirable to study the mechanism behind the described regulation in more detail. Which molecules are involved in the regulation of protein turnover by an increased synaptic activity? Is the increased presynaptic turnover due to a local or a global protein production? How is the synaptic activity affected by increased availability of new proteins? We would like to follow-up on these questions and hopefully the quantitative neuronal nanomap that we are planning to finish will help us to elucidate some of them.

The COIN method used to study the local turnover and synaptic activity is a good method for this line of work, as it combines the molecular specificity of fluorescence microscopy with the ability to quantitatively study long term changes in molecule composition. Over the similar - only based on fluorescence microscopy - method FUNCAT, it has the advantage that it uses stable isotope tracers, which have been shown to not have an influence on the physiology of the cells and not even on organisms (Steinhauser and Lechene, 2013). The FUNCAT non-canonical amino acids HPG and AHA are not ideal for the cells to be used instead of the natural amino acids, require a medium substitution, and thus generally affect the neurons' metabolism and signalling (Dieterich et al., 2010).

One potential problem associated with the correlative method is, however, that the regions of interest need to be carefully marked, so that they can be found both in the fluorescence microscope and later in the nanoSIMS. This is time-consuming. Also, the overlay of the fluorescence and nanoscopic images is not straightforward. The high vacuum of the SIMS may distort the sample in some ways and the sample milling by the nanoSIMS primary ion beam might not be fully homogenous (Terlier et al., 2018). This requires careful warping of the images to achieve the best fit. 
There are algorithm-based methods for image fusion (Vollnhals et al., 2017), but I relied here on a manual fusion. While this is a possible approach, it is also laborious and might result in the loss of some precision.

Another problem may spring from the fact that in fluorescence microscopy, I measured the fluorescence within the whole sample slice (200 $\mathrm{nm}$ thickness). The nanoSIMS measurements usually take $10-20 \mathrm{~nm}$ sections, i.e. not the whole sample slice. This might cause a discrepancy. These problems can be overcome now, since we developed specific molecular probes containing stable isotopes. These probes can be incorporated into the sample via CLICK chemistry or nanobodies, and may contain boron for measurements in the oxygen mode or ${ }^{19} \mathrm{~F}$ for measurements in the caesium mode (Agüi-Gonzalez et al., 2019; Kabatas et al., 2015; Vreja et al., 2015). With these probes, all measurements can be fully performed with the nanoSIMS alone, which will eliminate the above-mentioned difficulties.

\section{Limitation of the model}

The comprehensive description of neuronal morphology and subcellular structure that I am presenting has some limitations, including the use of a culture system, the averaging of parameters across many measurements, the study or each organelle in isolation, and the use of antibodies as probes. I will discuss each of these points on the following pages.

First of all, the measurements are based on a primary hippocampal culture system (Banker and Cowan, 1977; Brewer and Cotman, 1989; Kaech and Banker, 2006). While this provides the optimal condition for the measurements carried-out and for the quantitative model that is planned, it is still a culture system that does not fully reflect the situation in vivo. For example, the cells grow in monolayers, which means that their morphology is different to the cells in tissue. The cells are not embedded in a real circuit. They also do not have the same tripartite synapse arrangement as in vivo. I must make this sacrifice though, in order to achieve a thorough and clean analysis. Furthermore, using a comparative imaging approach, we will be able to compare our model system with a specific cell type. This will then allow us to estimate the amounts and positions of 
organelles and ultimately molecules for any neuron type, overcoming the culture system limitation (Richter et al., 2018).

Second, the measured parameters for neurites and organelles are based on averaging parameters across many cells from several culture dates. This will cause a loss of information, as the averaging might remove certain finer details. For example, very long neurite branches, which are not very common, will not be weighted in the same way. Also, the averaging will not account for the presence of different neuron types. However, in order to obtain meaningful results, I am bound to average over many cells. This is also necessary for the protein analysis, which has already been carried out by a colleague of mine, and which is a bulk measurement over many cultures. To overcome some of the potential problems of averaging, I am presenting most of my results as histograms or box plots, which do not only provide the average parameters, but also the distribution of these parameters. With this, I hope to ensure that the whole range of observations is accessible.

Third, I look at the organelles each at a time. Organelles, though forming a functional compartment and as such as separation, are interconnected. To consider, for example, the secretory pathway: a protein is being made on ribosomes, imported into the ER, modified and further transported through the Golgi apparatus, and then shipped via secretory granules to the plasma membrane (Bonifacino and Glick, 2004). In each of these steps, the organelles are in contact with each other and these contact sites play an important role in proper cell function (Allison et al., 2017; Dong et al., 2016; Wu et al., 2017). Thus, it would be ideal to study the organelle organisation in a way that allows the visualisation of all organelles at the same time. One could argue that this is possible with electron microscopy, but the sample size and reconstruction times are simply too extensive for a robust study of many cells. Also, in our case the contrast was too low to study organelles other than the nucleus, nucleoli, mitochondria, and vacuoles (see Figure 74A). The contrast issue can probably be overcome by improving the sample preparation and the FIB-SEM system. FIB-SEM has been shown to be able to resolve finer structures such as ER tubules and the Golgi apparatus (Xu et al., 2017). However, the segmentation of the organelles from the data remains a challenge. There have been attempts to automatize this, or distribute the task among many people, but both attempts are not yet 
so easily applicable for different samples (Jones and Spiers, 2018; Jorstad et al., 2015; Plaza et al., 2014). Thus, the analysis remains the limiting factor of this approach. Alternatively, there have been several recent attempts to multiplex super-resolution microscopy to study several markers in the same sample (Jungmann et al., 2014; Kiuchi et al., 2015; Schueder et al., 2017; Valm et al., 2017). While it is theoretically possible to multiplex a high number of targets, for examples with DNA Exchange (Schueder et al., 2017) in practice this is still very difficult, time-consuming, and ultimately lowthroughput.

Lastly, this project relies heavily on antibodies. All the organelle markers were immunostained against, using a classical primary and secondary antibody approach (except the dSTORM samples, where I used Fab-fragments instead of secondary antibodies). This can create an array of difficulties (Maidorn et al., 2016). For examples, commercially available antibodies often do not work properly or are not specific (Buchwalow et al., 2011). Thus, the antibodies should be tested and validated (Uhlen et al., 2016). Since organelles generally have a certain morphology, like the Golgi network, it is easier to determine whether a staining looks good or not. This becomes much more difficult when looking at targets that have not been studied or that have a not so welldefined morphology. In this case, a proper validation should be carried-out. One may overexpress a protein of interest with a fluorescent protein. The co-localization of this signal with the antibody can then be assessed.

Another issue with antibodies is their size. A typical primary plus secondary antibody arrangement has a size of $15-20 \mathrm{~nm}$. When studying smaller structures, such as cytoskeletal elements or SVs, with super-resolution microscopy, this can become a problem. The signal will be displaced from the actual structure, the structure will appear bigger, and because of its size only a few epitopes will be accessible for antibodies, which means not the whole structure will be covered. As an example, cytoskeletal elements will, when looked at in super-resolution microscopy, appear as dotted lines rather than continuous lines (Mikhaylova et al., 2015). This was also a problem for some of my dSTORM measurements. Often, the membrane of the organelles studied was not continuously labeled, making a volumetric analysis more difficult. Since antibodies have two binding sites (bivalent), they have been shown to cause clustering of molecules. This 
is even enhanced when combined with secondary antibodies and might cause the disarrangement of molecules, such as has been shown for syntaxin1a (Maidorn et al., 2019). These difficulties may be overcome by using smaller, monovalent probes, such as affibodies or nanobodies (Hassanzadeh-Ghassabeh et al., 2013; Herce et al., 2017; Löfblom et al., 2010; Maidorn et al., 2016). Since they are smaller, they have a better access to the epitopes, and the signal is less displaced from the actual tagged structure. As they only have one binding site, a clustering or rearrangement of molecules is less problematic. It has, however, proven difficult to engineer or obtain nanobodies against many different targets. Where possible, one should try to use monovalent probes.

The functional characterization of neurons is a first step towards a quantitative neuronal nanomap

The presented comprehensive description of morphology and functional organisation of cultured hippocampal neurons will be the basis for further quantitative studies and neuronal modelling.

We aim to combine the measurements presented here with quantitative mass spectrometry and comparative imaging to create a molecular nanomap (Richter et al., 2018; Schwanhäusser et al., 2011), in a similar manner to the presynaptic nanomap of Wilhelm et al. (Wilhelm et al., 2014). We would like to determine the proteome of the neurons in the Banker culture, and from this calculate the protein copy numbers per neuron. We will then determine the localization and distribution of a subset of these proteins. Finally, we plan to integrate this information into a molecular nanomap of a hippocampal neuron that will be useable as an in silico model.

The first steps have already been taken to realize this neuron nanomap. Colleagues of mine have determined the proteome of the cells in our culture system (Martin Helm, PhD thesis). They have identified and quantified 6194 proteins. Since we know the density of our culture system, they were able to calculate the protein copy numbers per neuron. This is by far the most extensive quantification of proteins in neurons so far. Wang et al. studied the mouse brain proteome, including additional cell types, and identified around 7800 proteins (Wang et al., 2006). While there are many more studies on the neuronal 
proteome, its changes during treatments and in disease models, most of the results are of a qualitative nature, i.e. they measure the relative amounts (Morciano et al., 2009; Poulopoulos et al., 2019; Schanzenbächer et al., 2016; Thul et al., 2017; Yu et al., 2004). For our model, knowing the numbers of proteins per neuron as well as the neuronal volumes (of neurites, cell body, and organelles, from this study), we will be able to determine the actual protein concentrations.

To expand this information, we are also planning to determine the distribution of a subset of these proteins within the neuron. Once we know the average copy numbers of proteins per neuron, we can image any protein across an entire neuron and determine the local concentration of this protein by comparing the fluorescence intensity in the region of interest to the total fluorescence intensity of the neuron. This has been done for 150 different proteins in combination with a Homer1 co-staining, allowing the calculation of protein amounts in the postsynapse (Martin Helm, PhD thesis). This approach can be used to determine the protein copy number for proteins of interest in a specific subcellular compartment such as the axon initial segment or mitochondria. We are planning to do this for around 200 proteins. The regions of interest have to be defined first, though. I would suggest to pick candidate proteins for sub-regions depending on their known functionality. For example, it would be interesting to look at the transport machinery involved in synaptic protein import into synapses. This has not been studied much, and it would be interesting to elucidate the stoichiometry of SV proteins within different transport vesicles and SV precursors. This could for example elucidate, if the SV proteins are organized in a similar way to the SVs in the synapse while they are being trafficked to the synapse (Rizzoli, 2014).

The neuronal nanomap can also incorporate the already existing molecular nanomaps of the synaptic vesicle and the presynapse (Wilhelm et al., 2014). Recently, our group has finished the measurements to obtain a high resolution nanomap of the dendritic spine. These nanomaps are from the same model system as the information presented in this thesis, and can serve to complement it by fitting in the nanoscale arrangement of proteins.

What would be the potential applications of such a neuronal nanomap? We and other research groups will finally be able to use our data to study several central physiological 
parameters of neurons on a quantitative level. For example, the calcium dynamics of neurons can be elucidated, as we will know the distribution and volumes of the calcium storage compartments (for example the ER (Koch, 1990)) as well as the distribution and numbers of calcium channels along the membranes (internal and external) and of calcium buffer molecules inside the compartments. Second, the electrophysiological parameters of the neurons can be modelled in silico, since we will know the location and the numbers of the ion channels involved. Furthermore, it will become possible to look at the protein composition of compartments and organelles that cannot be isolated and have thus not been studied in a quantitative manner. These compartments can then be compared with each other. This might be especially interesting for organelles that have been difficult to identify and study. For example, the different endosome populations, such as early endosomes, late endosomes, and recycling endosomes have proven very difficult to investigate as defined entities, as they seem to be very heterogeneous (Jähne et al., 2015; Miaczynska and Zerial, 2002; Zerial and McBride, 2001). Similarly, it is still very difficult to study the differences between SVs in different functional pools, such as the recycling pool, the readily releasable pool, or the reserve pool (Denker et al., 2011a; Richards et al., 2003; Truckenbrodt et al., 2018). Do the SVs in these pools have molecular differences or is it something else that determines their state? The SV biogenesis is another pathway which has been difficult to study. It is not quite clear yet, how SVs are generated and how SV proteins are transported and targeted to synapses (Rizzoli, 2014). The neuron nanomap will allow us to look at the co-localization of SV proteins in various organelles of the secretory pathway, such as the Golgi-apparatus and secretory vesicles. We will also be able to look at the protein production and degradation machineries and how they are organised (Luzio et al., 2007). We can look at the presence and amounts of ribosomes, ER tubules, and Golgi tubes in different neuronal compartments, such as in dendrites and axons. Or, conversely, we can look at the organisation of the proteasome and the lysosomes in order to understand, where protein degradation is organised.

Our nanomap will also allow us to look into specific functional pathways and determine the potential bottlenecks and limiting factors. This would not be possible without knowing the actual protein numbers (Takamori et al., 2006; Wilhelm et al., 2014). Our data will eventually allow the generation of an in silico neuron, which can be used to 
study several pathways in an interconnected manner, to look at protein dynamics and protein interactions.

Furthermore, we will be able to use this nanomap as a reference database that can be used to look into the proteome and organisation of more specific neuronal cell types or to look at the quantitative proteomic changes that are related to disease models. How can we achieve this? By using a comparative imaging approach, such as the one described by Richter et al. (Richter et al., 2018). They used a synaptosome preparation, which has been thoroughly characterized and quantified as a tool to estimate the protein copy numbers in an unknown sample by comparative imaging. Our neuronal nanomap will expand on this principle by providing the copy numbers of almost 7000 proteins. Any of these 7000 proteins will be quantifiable in a different cell type or under different conditions.

This will allow us or other research groups to study different neuronal cell types in a quantitative manner, which has been difficult or impossible up to now. We can, for example, start to study the differences in molecular composition of pyramidal neurons, different interneuron types, and Purkinje cells. We can also look at disease models, such as Alzheimer disease or Parkinson disease models (Lewis et al., 2000; Oakley et al., 2006) and study the structural changes and differences in the protein amounts. Rather than just looking at the relative changes, we will be able to determine the actual amounts and probably even their distribution. This might improve the detection of molecular targets that are implicated in the disease and with that potential targets for therapy. 


\section{Bibliography}

Agüi-Gonzalez, P., Opazo, F., Saal, K.-A., Jähne, S., Kabatas, S., Phan, N.T.N., and Rizzoli, S.O. (2019). Boron-Containing Probes for Non-optical High-Resolution Imaging of Biological Samples. Angew. Chemie Int. Ed. 3438-3443.

Ahnert-Hilger, G., Höltje, M., Pahner, I., Winter, S., and Brunk, I. (2004). Regulation of vesicular neurotreansmitter transporters. In Reviews of Physiology, Biochemistry and Pharmacology SE - 4, (Springer Berlin Heidelberg), pp. 140-160.

Alberts, B. (2008). Molecular Biology of the Cell: Fifth edition (Garland Science).

Allison, R., Edgar, J.R., Pearson, G., Rizo, T., Newton, T., Günther, S., Berner, F., Hague, J., Connell, J.W., Winkler, J., et al. (2017). Defects in ER-endosome contacts impact lysosome function in hereditary spastic paraplegia. J. Cell Biol. 216, 1337-1355.

Banker, G.A., and Cowan, W.M. (1977). Rat hippocampal neurons in dispersed cell culture. Brain Res. 126, 397-42.

Bastacky, J., Hayes, T.L., and Gelinas, R.P. (1985). Quantitation of shrinkage during preparation for scanning electron microscopy: Human lung. Scanning 7, 134-140.

Baude, A., Nusser, Z., Roberts, J.D.B., Mulvihill, E., Jeffrey Mcllhinney, R.A., and Somogyi, P. (1993). The metabotropic glutamate receptor (mGluRla) is concentrated at perisynaptic membrane of neuronal subpopulations as detected by immunogold reaction. Neuron 11, 771-787.

Baudhuin, P., Beaufay, H., and De Duve, C. (1965). Combined biochemical and morphological study of particulate fractions from rat liver. Analysis of preparations enriched in lysosomes or in particles containing urate oxidase, D-amino acid oxidase, and catalase. J. Cell Biol. 26, 219-243.

Beaudoin, G.M.J., Lee, S.-H., Singh, D., Yuan, Y., Ng, Y.-G., Reichardt, L.F., and Arikkath, J. (2012). Culturing pyramidal neurons from the early postnatal mouse hippocampus and cortex. Nat. Protoc. 7, 1741-1754.

Bennett, M.V.., and Zukin, R.S. (2004). Electrical Coupling and Neuronal Synchronization in the Mammalian Brain. Neuron 41, 495-511.

Benson, D.L., Watkins, F.H., Steward, O., and Banker, G. (1994). Characterization of 
GABAergic neurons in hippocampal cell cultures. J. Neurocytol. 23, 279-295.

Betzig, E., Patterson, G.H., Sougrat, R., Lindwasser, O.W., Olenych, S., Bonifacino, J.S., Davidson, M.W., Lippincott-Schwartz, J., and Hess, H.F. (2006). Imaging intracellular fluorescent proteins at nanometer resolution. Science (80-. ). 313, 1642-1645.

Binek, A., Rojo, D., Godzien, J., Rupérez, F.J., Nunez, V., Jorge, I., Ricote, M., Vázquez, J., and Barbas, C. (2019). Flow Cytometry Has a Significant Impact on the Cellular Metabolome. J. Proteome Res. 18, 169-181.

Bonanomi, D., Benfenati, F., and Valtorta, F. (2006). Protein sorting in the synaptic vesicle life cycle. Prog. Neurobiol. 80, 177-217.

Bonifacino, J.S., and Glick, B.S. (2004). The mechanisms of vesicle budding and fusion. Cell $116,153-166$.

Brakeman, P.R., Lanahan, A.A., O'Brien, R., Roche, K., Barnes, C.A., Huganir, R.L., and Worley, P.F. (1997). Homer: a protein that selectively binds metabotropic glutamate receptors. Nature 386, 284-288.

Brewer, G.J., and Cotman, C.W. (1989). Survival and growth of hippocampal neurons in defined medium at low density: advantages of a sandwich culture technique or low oxygen. Brain Res. 494, 65-74.

Brose, N., Petrenko, A.G., Südhof, T.C., and Jahn, R. (1992). Synaptotagmin: a calcium sensor on the synaptic vesicle surface. Science 256, 1021-1025.

Buchwalow, I., Samoilova, V., Boecker, W., and Tiemann, M. (2011). Non-specific binding of antibodies in immunohistochemistry: fallacies and facts. Sci. Rep. 1, 1-6.

Buerli, T., Pellegrino, C., Baer, K., Lardi-Studler, B., Chudotvorova, I., Fritschy, J., Medina, I., and Fuhrer, C. (2007). Efficient transfection of DNA or shRNA vectors into neurons using magnetofection. Nat. Protoc. 2, 3090-3101.

Burger, P.M., Mehl, E., Cameron, P.L., Maycox, P.R., Baumert, M., Lottspeich, F., De Camilli, P., and Jahn, R. (1989). Synaptic vesicles immunoisolated from rat cerebral cortex contain high levels of glutamate. Neuron 3, 715-720.

Cajal, S.R.Y. (1894). The Croonian Lecture: La Fine Structure des Centres Nerveux. Proc. R. Soc. London 55, 444-468. 
Cajigas, I.J., Tushev, G., Will, T.J., tom Dieck, S., Fuerst, N., and Schuman, E.M. (2012). The Local Transcriptome in the Synaptic Neuropil Revealed by Deep Sequencing and HighResolution Imaging. Neuron 74, 453-466.

Ceccarelli, B., Hurlbut, W.P., and Mauro, A. (1973). Turnover of transmitter and synaptic vesicles at the frog neuromuscular junction. J. Cell Biol. 57, 499-524.

Chen, Z.-W., Ahren, B., Ostenson, C.-G., Cintra, A., Bergman, T., Moller, C., Fuxe, K., Mutt, V., Jornvall, H., and Efendic, S. (1997). Identification, isolation, and characterization of daintain (allograft inflammatory factor 1 ), a macrophage polypeptide with effects on insulin secretion and abundantly present in the pancreas of prediabetic BB rats. Proc. Natl. Acad. Sci. 94, 13879-13884.

Cheng, C., Trzcinski, O., and Doering, L.C. (2014). Fluorescent labeling of dendritic spines in cell cultures with the carbocyanine dye "Dil". Front. Neuroanat. 8, 1-8.

Cheng, D., Hoogenraad, C.C., Rush, J., Ramm, E., Schlager, M.A., Duong, D.M., Xu, P., Wijayawardana, S.R., Hanfelt, J., Nakagawa, T., et al. (2006). Relative and Absolute Quantification of Postsynaptic Density Proteome Isolated from Rat Forebrain and Cerebellum. Mol. Cell. Proteomics 5, 1158-1170.

Cheung, G., Jupp, O.J., and Cousin, M. a (2010). Activity-dependent bulk endocytosis and clathrin-dependent endocytosis replenish specific synaptic vesicle pools in central nerve terminals. J. Neurosci. 30, 8151-8161.

Cho, K.-O., Hunt, C. a., and Kennedy, M.B. (1992). The rat brain postsynaptic density fraction contains a homolog of the drosophila discs-large tumor suppressor protein. Neuron 9, 929-942.

Chung, K., and Deisseroth, K. (2013). CLARITY for mapping the nervous system. Nat. Methods 10, 508-513.

Claude, A. (1946a). FRACTIONATION OF MAMMALIAN LIVER CELLS BY DIFFERENTIAL CENTRIFUGATION : II. EXPERIMENTAL PROCEDURES AND RESULTS. J. Exp. Med. 84, 6189.

Claude, A. (1946b). FRACTIONATION OF MAMMALIAN LIVER CELLS BY DIFFERENTIAL CENTRIFUGATION : I. PROBLEMS, METHODS, AND PREPARATION OF EXTRACT. J. EXP. 
Med. 84, 51-59.

Clayton, E.L., Evans, G.J.O., and Cousin, M.A. (2007). Activity-dependent control of bulk endocytosis by protein dephosphorylation in central nerve terminals. J. Physiol. 585, 687691.

Clayton, E.L., Sue, N., Smillie, K.J., O'Leary, T., Bache, N., Cheung, G., Cole, A.R., Wyllie, D.J., Sutherland, C., Robinson, P.J., et al. (2010). Dynamin I phosphorylation by GSK3 controls activity-dependent bulk endocytosis of synaptic vesicles. Nat. Neurosci. 13, 845851.

Cullen, D.K., Gilroy, M.E., Irons, H.R., and Laplaca, M.C. (2010). Synapse-to-neuron ratio is inversely related to neuronal density in mature neuronal cultures. Brain Res. 1359, 44-55.

Danilczyk, U.G., Cohen-Doyle, M.F., and Williams, D.B. (2000). Functional relationship between calreticulin, calnexin, and the endoplasmic reticulum luminal domain of calnexin. J. Biol. Chem. 275, 13089-13097.

Daumke, O., Roux, A., and Haucke, V. (2014). BAR domain scaffolds in dynamin-mediated membrane fission. Cell 156, 882-892.

Deerinck, T.J., Bushong, E., Thor, A., and Ellisman, M. (2010). NCMIR methods for 3D EM: A new protocol for preparation of biological specimens for serial block face scanning electron microscopy. Nat Cent. Microsc Imag Res 6-8.

Denk, W., and Horstmann, H. (2004). Serial block-face scanning electron microscopy to reconstruct three-dimensional tissue nanostructure. PLoS Biol. 2.

Denker, A., Bethani, I., Kröhnert, K., Körber, C., Horstmann, H., Wilhelm, B.G., Barysch, S. V, Kuner, T., Neher, E., and Rizzoli, S.O. (2011a). A small pool of vesicles maintains synaptic activity in vivo. Proc. Natl. Acad. Sci. U. S. A. 108, 17177-17182.

Denker, A., Kröhnert, K., Bückers, J., Neher, E., and Rizzoli, S.O. (2011b). The reserve pool of synaptic vesicles acts as a buffer for proteins involved in synaptic vesicle recycling. Proc. Natl. Acad. Sci. U. S. A. 108, 17183-17188.

Dieterich, D.C., Hodas, J.J.L., Gouzer, G., Shadrin, I.Y., Ngo, J.T., Triller, A., Tirrell, D. a, and Schuman, E.M. (2010). In situ visualization and dynamics of newly synthesized proteins in rat hippocampal neurons. Nat. Neurosci. 13, 897-905. 
Dong, R., Saheki, Y., Swarup, S., Lucast, L., Harper, J.W., Camilli, P. De, Dong, R., Saheki, Y., Swarup, S., Lucast, L., et al. (2016). Endosome-ER Contacts Control Actin Nucleation and Retromer Function through VAP-Dependent Regulation of PI4P Article Endosome-ER Contacts Control Actin Nucleation and Retromer Function through VAP-Dependent Regulation of PI4P. Cell 166, 408-423.

Donohue, D.E., and Ascoli, G.A. (2011). Automated reconstruction of neuronal morphology: An overview. Brain Res. Rev. 67, 94-102.

Dotti, C.G., Sullivan, C.A., and Banker, G.A. (1988). The establishment of polarity by hippocampal neurons in culture. J. Neurosci. 8, 1454-1468.

Edelsbrunner, H., and Mücke, E.P. (1994). Three-dimensional alpha shapes. ACM Trans. Graph. 13, 43-72.

Edelsbrunner, H., Kirkpatrick, D., and Seidel, R. (1983). On the shape of a set of points in the plane. IEEE Trans. Inf. Theory 29, 551-559.

Edelstein, A., Amodaj, N., Hoover, K., Vale, R., and Stuurman, N. (2010). Computer Control of Microscopes Using $\mu$ Manager. Curr. Protoc. Mol. Biol. 1-17.

Edelstein, A.D., Tsuchida, M.A., Amodaj, N., Pinkard, H., Vale, R.D., and Stuurman, N. (2014). Advanced methods of microscope control using $\mu$ Manager software. J. Biol. Methods 1, 10.

Ehlers, M.D. (2003). Activity level controls postsynaptic composition and signaling via the ubiquitin-proteasome system. Nat. Neurosci. 6, 231-242.

Erwig, M.S., Patzig, J., Steyer, A.M., Dibaj, P., Heilmann, M., Heilmann, I., Jung, R.B., Kusch, K., Möbius, W., Jahn, O., et al. (2019). Anillin facilitates septin assembly to prevent pathological outfoldings of central nervous system myelin. Elife 8, 1-18.

Farquhar, M.G., and Palade, G.E. (1998). The Golgi apparatus: 100 years of progress and controversy. Trends Cell Biol. 8, 2-10.

Felgner, P.L., Gadek, T.R., Holm, M., Roman, R., Chan, H.W., Wenz, M., Northrop, J.P., Ringold, G.M., and Danielsen, M. (1987). Lipofection: a highly efficient, lipid-mediated DNA-transfection procedure. Proc. Natl. Acad. Sci. U. S. A. 84, 7413-7417.

Fletcher, D.A., and Theriot, J.A. (2004). An introduction to cell motility for the physical 
scientist. Phys. Biol. 1.

Fletcher, T.L., and Banker, G.A. (1989). The establishment of polarity by hippocampal neurons: The relationship between the stage of a cell's development in situ and its subsequent development in culture. Dev. Biol. 136, 446-454.

Friedman, H.V., Bresler, T., Garner, C.C., and Ziv, N.E. (2000). Assembly of new individual excitatory synapses: time course and temporal order of synaptic molecule recruitment. Neuron 27, 57-69.

Gallimore, A.R., Kim, T., Tanaka-Yamamoto, K., and De Schutter, E. (2018). Switching On Depression and Potentiation in the Cerebellum. Cell Rep. 22, 722-733.

Godement, P., Vanselow, J., Thanos, S., and Bonhoeffer, F. (1987). A study in developing visual systems with a new method of staining neurones and their processes in fixed tissue. Development 101, 697-713.

Gradinaru, V., Treweek, J., Overton, K., and Deisseroth, K. (2018). Hydrogel-Tissue Chemistry: Principles and Applications. Annu. Rev. Biophys. 47, 355-376.

Gray, E.G. (1959). Axo-somatic and axo-dendritic synapses of the cerebral cortex: an electron microscope study. J. Anat. 93, 420-433.

Grubb, M.S., and Burrone, J. (2010). Activity-dependent relocation of the axon initial segment fine-tunes neuronal excitability. Nature 465, 1070-1074.

Gulledge, A.T., Kampa, B.M., and Stuart, G.J. (2005). Synaptic integration in dendritic trees. J. Neurobiol. 64, 75-90.

Gundelfinger, E.D., Reissner, C., and Garner, C.C. (2016). Role of Bassoon and Piccolo in Assembly and Molecular Organization of the Active Zone. Front. Synaptic Neurosci. 7. Haesemeyer, M., Robson, D.N., Li, J.M., Schier, A.F., and Engert, F. (2018). A Brain-wide Circuit Model of Heat-Evoked Swimming Behavior in Larval Zebrafish. Neuron 98, 817831.e6.

Hafner, A.-S., Donlin-Asp, P., Leitch, B., Herzog, E., and Schuman, E.M. (2018). Local protein synthesis in axon terminals and dendritic spines differentiates plasticity contexts. BioRxiv 363184. 
Hanus, C., and Schuman, E.M. (2013). Proteostasis in complex dendrites. Nat. Rev. Neurosci. 14, 638-648.

Hassanzadeh-Ghassabeh, G., Devoogdt, N., De Pauw, P., Vincke, C., and Muyldermans, S. (2013). Nanobodies and their potential applications. Nanomedicine 8, 1013-1026.

Hassouna, I., Ott, C., Wüstefeld, L., Offen, N., Neher, R.A., Mitkovski, M., Winkler, D., Sperling, S., Fries, L., Goebbels, S., et al. (2016). Revisiting adult neurogenesis and the role of erythropoietin for neuronal and oligodendroglial differentiation in the hippocampus. Mol. Psychiatry 21, 1752-1767.

Hawrylycz, M.J., Lein, E.S., Guillozet-Bongaarts, A.L., Shen, E.H., Ng, L., Miller, J.A., van de Lagemaat, L.N., Smith, K.A., Ebbert, A., Riley, Z.L., et al. (2012). An anatomically comprehensive atlas of the adult human brain transcriptome. Nature 489, 391-399.

Hedstrom, K.L., Xu, X., Ogawa, Y., Frischknecht, R., Seidenbecher, C.I., Shrager, P., and Rasband, M.N. (2007). Neurofascin assembles a specialized extracellular matrix at the axon initial segment. J. Cell Biol. 178, 875-886.

Heilemann, M., van de Linde, S., Schüttpelz, M., Kasper, R., Seefeldt, B., Mukherjee, A., Tinnefeld, P., and Sauer, M. (2008). Subdiffraction-resolution fluorescence imaging with conventional fluorescent probes. Angew. Chem. Int. Ed. Engl. 47, 6172-6176.

Hell, S.W., and Wichmann, J. (1994). Breaking the diffraction resolution limit by stimulated emission: stimulated-emission-depletion fluorescence microscopy. Opt. Lett. $19,780-782$.

Herce, H.D., Schumacher, D., Schneider, A.F.L., Ludwig, A.K., Mann, F.A., Fillies, M., Kasper, M.A., Reinke, S., Krause, E., Leonhardt, H., et al. (2017). Cell-permeable nanobodies for targeted immunolabelling and antigen manipulation in living cells. Nat. Chem. 9, 762-771.

Herring, B.E., and Nicoll, R.A. (2016). Long-Term Potentiation: From CaMKII to AMPA Receptor Trafficking. Annu. Rev. Physiol. 78, 351-365.

Hertz, L., and Zielke, H.R. (2004). Astrocytic control of glutamatergic activity: astrocytes as stars of the show. Trends Neurosci. 27, 735-743.

Heuser, J.E., and Reese, T.S. (1973). Evidence for recycling of synaptic vesicle membrane 
during transmitter release at the frog neuromuscular junction. J. Cell Biol. 57, 315-344. Heuser, J.E., Reese, T.S., Dennis, M.J., Jan, Y., Jan, L., and Evans, L. (1979). Synaptic vesicle exocytosis captured by quick freezing and correlated with quantal transmitter release. J. Cell Biol. 81, 275-300.

Hildebrand, D.G.C., Cicconet, M., Torres, R.M., Choi, W., Quan, T.M., Moon, J., Wetzel, A.W., Scott Champion, A., Graham, B.J., Randlett, O., et al. (2017). Whole-brain serialsection electron microscopy in larval zebrafish. Nature 545, 345-349.

Hirokawa, N., Niwa, S., and Tanaka, Y. (2010). Molecular Motors in Neurons: Transport Mechanisms and Roles in Brain Function, Development, and Disease. Neuron 68, 610638.

Hoch, D.B., and Dingledine, R. (1986). GABAergic neurons in rat hippocampal culture. Dev. Brain Res. 25, 53-64.

Holtzman, E., Teichberg, S., Abrahams, S.J., Citkowitz, E., Crain, S.M., Kawai, N., and Peterson, E.R. (1973). Notes on synaptic vesicles and related structures, endoplasmic reticulum, lysosomes and peroxisomes in nervous tissue and the adrenal medulla. J. Histochem. Cytochem. 21, 349-385.

Honig, M.G., and Hume, R.I. (1986). Fluorescent Carbocyanine Dyes Allow Living Neurons of Identified Origin to Be Studied in Long-Term Cultures. J. Cell Biol. 103, 171-187. Hormuzdi, S.G., Filippov, M.A., Mitropoulou, G., Monyer, H., and Bruzzone, R. (2004). Electrical synapses: a dynamic signaling system that shapes the activity of neuronal networks. Biochim. Biophys. Acta - Biomembr. 1662, 113-137.

Huang, B., Wang, W., Bates, M., and Zhuang, X. (2008a). Three-Dimensional SuperResolution Imaging by Stochastic Optical Reconstruction Microscopy. Science (80-. ). 319, 810-813.

Huang, B., Jones, S.A., Brandenburg, B., and Zhuang, X. (2008b). Whole-cell 3D STORM reveals interactions between cellular structures with nanometer-scale resolution. Nat. Methods 5, 1047-1052.

Huettner, J., and Baughman, R. (1986). Primary culture of identified neurons from the visual cortex of postnatal rats. J. Neurosci. 6, 3044-3060. 
Hunt, C.A., Schenker, L.J., and Kennedy, M.B. (1996). PSD-95 is associated with the postsynaptic density and not with the presynaptic membrane at forebrain synapses. J. Neurosci. 16, 1380-1388.

Ibata, K., Sun, Q., and Turrigiano, G.G. (2008). Rapid Synaptic Scaling Induced by Changes in Postsynaptic Firing. Neuron 57, 819-826.

Imai, Y., Ibata, I., Ito, D., Ohsawa, K., and Kohsaka, S. (1996). A novel gene iba1 in the major histocompatibility complex class III region encoding an EF hand protein expressed in a monocytic lineage. Biochem. Biophys. Res. Commun. 224, 855-862.

Inagaki, N., Chihara, K., Arimura, N., Ménager, C., Kawano, Y., Matsuo, N., Nishimura, T., Amano, M., and Kaibuchi, K. (2001). CRMP-2 induces axons in cultured hippocampal neurons. Nat. Neurosci. 4, 781-782.

Jahn, R., and Fasshauer, D. (2012). Molecular machines governing exocytosis of synaptic vesicles. Nature 490, 201-207.

Jahn, R., and Scheller, R.H. (2006). SNAREs--engines for membrane fusion. Nat. Rev. Mol. Cell Biol. 7, 631-643.

Jahn, R., Lang, T., and Su, T.C. (2003). Membrane Fusion. Cell 112, 519-533.

Jähne, S., Rizzoli, S.O., and Helm, M.S. (2015). The structure and function of presynaptic endosomes. Exp. Cell Res. 335, 172-179.

Jiang, M., and Chen, G. (2006). High Ca2+-phosphate transfection efficiency in low-density neuronal cultures. Nat. Protoc. 1, 695-700.

Jiang, H., Favaro, E., Goulbourne, C.N., Rakowska, P.D., Hughes, G.M., Ryadnov, M.G., Fong, L.G., Young, S.G., Ferguson, D.J.P., Harris, A.L., et al. (2014). Stable isotope imaging of biological samples with high resolution secondary ion mass spectrometry and complementary techniques. Methods 68, 317-324.

Jockusch, W.J., Praefcke, G.J.K., McMahon, H.T., and Lagnado, L. (2005). Clathrindependent and clathrin-independent retrieval of synaptic vesicles in retinal bipolar cells. Neuron 46, 869-878.

Jones, M.L., and Spiers, H. (2018). The crowd storms the ivory tower. Nat. Methods 15, 579-580. 
Jorstad, A., Nigro, B., Cali, C., Wawrzyniak, M., Fua, P., and Knott, G. (2015). NeuroMorph: A Toolset for the Morphometric Analysis and Visualization of 3D Models Derived from Electron Microscopy Image Stacks. Neuroinformatics 13, 83-92.

Jungmann, R., Avendaño, M.S., Woehrstein, J.B., Dai, M., Shih, W.M., and Yin, P. (2014). Multiplexed 3D cellular super-resolution imaging with DNA-PAINT and Exchange-PAINT. Nat. Methods 11, 313-318.

Kabatas, S., Vreja, I.C., Saka, S.K., Höschen, C., Kröhnert, K., Opazo, F., Rizzoli, S.O., and Diederichsen, U. (2015). A contamination-insensitive probe for imaging specific biomolecules by secondary ion mass spectrometry. Chem. Commun. 51, 13221-13224. Kaech, S., and Banker, G. (2006). Culturing hippocampal neurons. Nat. Protoc. 1, 24062415.

Kamijo, K., Kamijo, T., Ueno, I., Osumi, T., and Hashimoto, T. (1992). Nucleotide sequence of the human $70 \mathrm{kDa}$ peroxisomal membrane protein: a member of ATP-binding cassette transporters. Biochim. Biophys. Acta 1129, 323-327.

Kandel, E. (2013a). Principles of Neural Science, Fifth Edition (McGraw-Hill Education). Kandel, E. (2013b). Membrane Potential and the Passive Electrical Properties of the Neuron. In Principles of Neural Science, pp. 126-147.

Kang, H., and Schuman, E.M. (1996). A requirement for local protein synthesis in neurotrophin-induced hippocampal synaptic plasticity. Science (80-. ). 273, 1402-1406.

Kang, H.J., Kawasawa, Y.I., Cheng, F., Zhu, Y., Xu, X., Li, M., Sousa, A.M.M., Pletikos, M., Meyer, K.A., Sedmak, G., et al. (2011). Spatio-temporal transcriptome of the human brain. Nature 478, 483-489.

Kiuchi, T., Higuchi, M., Takamura, A., Maruoka, M., and Watanabe, N. (2015). Multitarget super-resolution microscopy with high-density labeling by exchangeable probes. Nat. Methods 12, 743-746.

Klar, T.A., Jakobs, S., Dyba, M., Egner, A., and Hell, S.W. (2000). Fluorescence microscopy with diffraction resolution barrier broken by stimulated emission. Proc. Natl. Acad. Sci. U. S. A. $97,8206-8210$.

Knott, G., Marchman, H., Wall, D., and Lich, B. (2008). Serial Section Scanning Electron 
Microscopy of Adult Brain Tissue Using Focused Ion Beam Milling. J. Neurosci. 28, 29592964.

Knott, G., Rosset, S., and Cantoni, M. (2011). Focussed Ion Beam Milling and Scanning Electron Microscopy of Brain Tissue. J. Vis. Exp. 3-6.

Koch, G.L.E. (1990). The endoplasmic reticulum and calcium storage. BioEssays 12, 527531.

Kole, M.H.P., Ilschner, S.U., Kampa, B.M., Williams, S.R., Ruben, P.C., and Stuart, G.J. (2008). Action potential generation requires a high sodium channel density in the axon initial segment. Nat. Neurosci. 11, 178-186.

Kosinski, J., Mosalaganti, S., von Appen, A., Teimer, R., DiGuilio, A.L., Wan, W., Bui, K.H., Hagen, W.J.H., Briggs, J.A.G., Glavy, J.S., et al. (2016). Molecular architecture of the inner ring scaffold of the human nuclear pore complex. Science (80-. ). 352, 363-365.

Köthe, U., Herrmannsdörfer, F., Kats, I., and Hamprecht, F.A. (2014). SimpleSTORM: A fast, self-calibrating reconstruction algorithm for localization microscopy. Histochem. Cell Biol. 141, 613-627.

Kraszewski, K., Mundigl, O., Daniell, L., Verderio, C., Matteoli, M., and De Camilli, P. (1995). Synaptic vesicle dynamics in living cultured hippocampal neurons visualized with CY3-conjugated antibodies directed against the lumenal domain of synaptotagmin. J. Neurosci. 15, 4328-4342.

Kreibich, G., Ulrich, B.L., and Sabatini, D.D. (1978). Proteins of rough microsomal membranes related to ribosome binding. I. Identification of ribophorins I and II, membrane proteins characteristics of rough microsomes. J. Cell Biol. 77, 464-487. Krijnse-Locker, J., Parton, R.G., Fuller, S.D., Griffiths, G., and Dotti, C.G. (1995). The organization of the endoplasmic reticulum and the intermediate compartment in cultured rat hippocampal neurons. Mol. Biol. Cell 6, 1315-1332.

Ladinsky, M.S., Mastronarde, D.N., McIntosh, J.R., Howell, K.E., and Staehelin, L.A. (1999). Golgi structure in three dimensions: functional insights from the normal rat kidney cell. J. Cell Biol. 144, 1135-1149.

Lakadamyali, M., Babcock, H., Bates, M., Zhuang, X., and Lichtman, J. (2012). 3D 
multicolor super-resolution imaging offers improved accuracy in neuron tracing. PLoS One 7, e30826.

Lampe, A., Haucke, V., Sigrist, S.J., Heilemann, M., and Schmoranzer, J. (2012). Multicolour direct STORM with red emitting carbocyanines. Biol. Cell 104, 229-237.

Lehmann, M., Lichtner, G., Klenz, H., and Schmoranzer, J. (2015). Novel organic dyes for multicolor localization-based super-resolution microscopy. J. Biophotonics 10, n/a-n/a.

Lein, E.S., Hawrylycz, M.J., Ao, N., Ayres, M., Bensinger, A., Bernard, A., Boe, A.F., Boguski, M.S., Brockway, K.S., Byrnes, E.J., et al. (2007). Genome-wide atlas of gene expression in the adult mouse brain. Nature 445, 168-176.

Lester, R.A., Quarum, M.L., Parker, J.D., Weber, E., and Jahr, C.E. (1989). Interaction of 6cyano-7-nitroquinoxaline-2,3-dione with the N-methyl-D-aspartate receptor-associated glycine binding site. Mol. Pharmacol. 35, 565-570.

Leterrier, C., Potier, J., Caillol, G., Boroni, F.R., and Dargent, B. (2015). Nanoscale architecture of the axon initial segment reveals an organized and robust scaffold. BiorXiv $1-17$.

Lewis, J., McGowan, E., Rockwood, J., Melrose, H., Nacharaju, P., Van Slegtenhorst, M., Gwinn-Hardy, K., Paul Murphy, M., Baker, M., Yu, X., et al. (2000). Neurofibrillary tangles, amyotrophy and progressive motor disturbance in mice expressing mutant (P301L) tau protein. Nat. Genet. 25, 402-405.

Li, L., Tasic, B., Micheva, K.D., Ivanov, V.M., Spletter, M.L., Smith, S.J., and Luo, L. (2010). Visualizing the distribution of synapses from individual neurons in the mouse brain. PLoS One 5.

van de Linde, S., Sauer, M., and Heilemann, M. (2008). Subdiffraction-resolution fluorescence imaging of proteins in the mitochondrial inner membrane with photoswitchable fluorophores. J. Struct. Biol. 164, 250-254.

Littleton, J.T., Chapman, E.R., Kreber, R., Garment, M.B., Carlson, S.D., and Ganetzky, B. (1998). Temperature-sensitive paralytic mutations demonstrate that synaptic exocytosis requires SNARE complex assembly and disassembly. Neuron 21, 401-413.

Liu, Y., Fisher, D.A., and Storm, D.R. (1993). Analysis of the Palmitoylation and Membrane 
Targeting Domain of Neuromodulin (GAP-43) by Site-Specific Mutagenesis. Biochemistry 32, 10714-10719.

Livet, J., Weissman, T.A., Kang, H., Draft, R.W., Lu, J., Bennis, R.A., Sanes, J.R., and Lichtman, J.W. (2007). Transgenic strategies for combinatorial expression of fluorescent proteins in the nervous system. Nature $450,56-62$.

Loewi, O. (1926). About the vagus - substance. Naturwissenschaften 14, 994 - 995.

Löfblom, J., Feldwisch, J., Tolmachev, V., Carlsson, J., Ståhl, S., and Frejd, F.Y. (2010). Affibody molecules: engineered proteins for therapeutic, diagnostic and biotechnological applications. FEBS Lett. 584, 2670-2680.

Loschberger, A., Franke, C., Krohne, G., van de Linde, S., and Sauer, M. (2014). Correlative super-resolution fluorescence and electron microscopy of the nuclear pore complex with molecular resolution. J. Cell Sci. 127, 4351-4355.

Löschberger, A., van de Linde, S., Dabauvalle, M.-C., Rieger, B., Heilemann, M., Krohne, G., and Sauer, M. (2012). Super-resolution imaging visualizes the eightfold symmetry of gp210 proteins around the nuclear pore complex and resolves the central channel with nanometer resolution. J. Cell Sci. 125, 570-575.

Lukas, J.-R., Aigner, M., Denk, M., Heinzl, H., Burian, M., and Mayr, R. (1998).

Carbocyanine Postmortem Neuronal Tracing: Influence of Different Parameters on Tracing Distance and Combination with Immunocytochemistry. J. Histochem. Cytochem. 46, 901-910.

Luzio, J.P., Pryor, P.R., and Bright, N.A. (2007). Lysosomes: fusion and function. Nat. Rev. Mol. Cell Biol. 8, 622-632.

Maidorn, M., Rizzoli, S.O., and Opazo, F. (2016). Tools and limitations to study the molecular composition of synapses by fluorescence microscopy. Biochem. J. 473, 33853399.

Maidorn, M., Olichon, A., Rizzoli, S.O., and Opazo, F. (2019). Nanobodies reveal an extrasynaptic population of SNAP-25 and Syntaxin 1A in hippocampal neurons. MAbs 11, 305321.

Markham, J.A., and Fifková, E. (1986). Actin filament organization within dendrites and 
dendritic spines during development. Brain Res. 392, 263-269.

Matsubayashi, Y., Iwai, L., and Kawasaki, H. (2008). Fluorescent double-labeling with carbocyanine neuronal tracing and immunohistochemistry using a cholesterol-specific detergent digitonin. J. Neurosci. Methods 174, 71-81.

Matsuda, T., and Cepko, C.L. (2007). Controlled expression of transgenes introduced by in vivo electroporation. Proc. Natl. Acad. Sci. 104, 1027-1032.

Matthew, W.D., Tsavaler, L., and Reichardt, L.F. (1981). Identification of a synaptic vesiclespecific membrane protein with a wide distribution in neuronal and neurosecretory tissue. J. Cell Biol. 91, 257-269.

Mayer, M.L. (2005). Glutamate receptor ion channels. Curr. Opin. Neurobiol. 15, 282-288. Meijering, E., Jacob, M., Sarria, J.-C.F., Steiner, P., Hirling, H., and Unser, M. (2004). Design and validation of a tool for neurite tracing and analysis in fluorescence microscopy images. Cytometry 58A, 167-176.

Miaczynska, M., and Zerial, M. (2002). Mosaic organization of the endocytic pathway. Exp. Cell Res. 272, 8-14.

Mikhaylova, M., Cloin, B.M.C., Finan, K., van den Berg, R., Teeuw, J., Kijanka, M.M., Sokolowski, M., Katrukha, E. a., Maidorn, M., Opazo, F., et al. (2015). Resolving bundled microtubules using anti-tubulin nanobodies. Nat. Commun. 6, 7933.

Miller, K.D. (1996). Synaptic economics: Competition and cooperation in synaptic plasticity. Neuron 17, 371-374.

Mishchenko, Y. (2010). On optical detection of densely labeled synapses in neuropil and mapping connectivity with combinatorially multiplexed fluorescent synaptic markers. PLoS One 5.

Mohammadi, A.S., Phan, N.T.N., Fletcher, J.S., and Ewing, A.G. (2016). Intact lipid imaging of mouse brain samples: MALDI, nanoparticle-laser desorption ionization, and $40 \mathrm{keV}$ argon cluster secondary ion mass spectrometry. Anal. Bioanal. Chem. 408, 6857-6868. Morciano, M., Beckhaus, T., Karas, M., Zimmermann, H., and Volknandt, W. (2009). The proteome of the presynaptic active zone: from docked synaptic vesicles to adhesion molecules and maxi-channels. J. Neurochem. 108, 662-675. 
Munro, S. (1998). Localization of proteins to the Golgi apparatus. Trends Cell Biol. 8, 1115.

Newman, E.A. (2003). New roles for astrocytes: regulation of synaptic transmission. Trends Neurosci. 26, 536-542.

Nicovich, P.R., Owen, D.M., and Gaus, K. (2017). Turning single-molecule localization microscopy into a quantitative bioanalytical tool. Nat. Protoc. 12, 453-461.

Niswender, C.M., and Conn, P.J. (2010). Metabotropic Glutamate Receptors: Physiology, Pharmacology, and Disease. Annu. Rev. Pharmacol. Toxicol. 50, 295-322.

Novick, P., and Zerial, M. (1997). The diversity of Rab proteins in vesicle transport. Curr. Opin. Cell Biol. 9, 496-504.

O’Brien, R.J., Kamboj, S., Ehlers, M.D., Rosen, K.R., Fischbach, G.D., and Huganir, R.L. (1998). Activity-Dependent Modulation of Synaptic AMPA Receptor Accumulation. Neuron 21, 1067-1078.

Oakley, H., Cole, S.L., Logan, S., Maus, E., Shao, P., Craft, J., Guillozet-Bongaarts, A., Ohno, M., Disterhoft, J., Van Eldik, L., et al. (2006). Intraneuronal $\beta$-Amyloid Aggregates, Neurodegeneration, and Neuron Loss in Transgenic Mice with Five Familial Alzheimer's Disease Mutations: Potential Factors in Amyloid Plaque Formation. J. Neurosci. 26, 10129-10140.

Oguri, T., Takahata, I., Katsuta, K., Nomura, E., Hidaka, M., and Inagaki, N. (2002). Proteome analysis of rat hippocampal neurons by multiple large gel two-dimensional electrophoresis. Proteomics 2, 666-672.

Oh, S.W., Harris, J.A., Ng, L., Winslow, B., Cain, N., Mihalas, S., Wang, Q., Lau, C., Kuan, L., Henry, A.M., et al. (2014). A mesoscale connectome of the mouse brain. Nature 508, 207214.

Ohki, E.C., Tilkins, M.L., Ciccarone, V.C., and Price, P.J. (2001). Improving the transfection efficiency of post-mitotic neurons. J. Neurosci. Methods 112, 95-99.

Ovesný, M., Křížek, P., Borkovec, J., Švindrych, Z., and Hagen, G.M. (2014). ThunderSTORM: A comprehensive ImageJ plug-in for PALM and STORM data analysis and super-resolution imaging. Bioinformatics 30, 2389-2390. 
Palade, G.E. (1975). Intracellular Aspects of the Process of Protein Synthesis. Science (80-. ). 189, 347-358.

Palay, S.L. (1956). Synapses in the central nervous system. J. Biophys. Biochem. Cytol. 2, 193-202.

Palay, S.L., and Palade, G.E. (1955). The Fine Structure of Neurons. J. Biophys. Biochem. Cytol. 1, 69-88.

Papa, M., Bundman, M., Greenberger, V., and Segal, M. (2018). Morphological analysis of dendritic spine development in primary cultures of hippocampal neurons. J. Neurosci. 15, $1-11$.

Papandréou, M.J., and Leterrier, C. (2018). The functional architecture of axonal actin. Mol. Cell. Neurosci. 1-10.

Pathak, G.K., Love, J.M., Chetta, J., and Shah, S.B. (2013). A comparative quantitative assessment of axonal and dendritic mRNA transport in maturing hippocampal neurons. PLoS One 8, e65917.

Perea, G., Navarrete, M., and Araque, A. (2009). Tripartite synapses: astrocytes process and control synaptic information. Trends Neurosci. 32, 421-431.

Peteranderl, R., and Lechene, C. (2004). Measure of carbon and nitrogen stable isotope ratios in cultured cells. J. Am. Soc. Mass Spectrom. 15, 478-485.

Phan, N.T.N., Munem, M., Ewing, A.G., and Fletcher, J.S. (2017). MS/MS analysis and imaging of lipids across Drosophila brain using secondary ion mass spectrometry. Anal. Bioanal. Chem. 409, 3923-3932.

Pierce, J.P., Mayer, T., and McCarthy, J.B. (2001). Evidence for a satellite secretory pathway in neuronal dendritic spines. Curr. Biol. 11, 351-355.

Plaza, S.M., Scheffer, L.K., and Chklovskii, D.B. (2014). Toward large-scale connectome reconstructions. Curr. Opin. Neurobiol. 25, 201-210.

Poulopoulos, A., Murphy, A.J., Ozkan, A., Davis, P., Hatch, J., Kirchner, R., and Macklis, J.D. (2019). Subcellular transcriptomes and proteomes of developing axon projections in the cerebral cortex. Nature 565, 356-360. 
Pu, M., and Berson, D.M. (1992). A method for reliable and permanent intracellular staining of retinal ganglion cells. J. Neurosci. Methods 41, 45-51.

Ramirez, O.A., and Couve, A. (2011). The endoplasmic reticulum and protein trafficking in dendrites and axons. Trends Cell Biol. 21, 219-227.

Revelo, N.H., Kamin, D., Truckenbrodt, S., Wong, A.B., Reuter-Jessen, K., Reisinger, E., Moser, T., and Rizzoli, S.O. (2014). A new probe for super-resolution imaging of membranes elucidates trafficking pathways. J. Cell Biol. 205, 591-606.

Richards, D.A., Guatimosim, C., Rizzoli, S.O., and Betz, W.J. (2003). Synaptic Vesicle Pools at the Frog Neuromuscular Junction. Neuron 39, 529-541.

Richter, K.N., Rizzoli, S.O., Jähne, S., Vogts, A., and Lovric, J. (2017a). Review of combined isotopic and optical nanoscopy. Neurophotonics 4, 020901.

Richter, K.N., Revelo, N.H., Seitz, K.J., Helm, M.S., Sarkar, D., Saleeb, R.S., D’ Este, E., Eberle, J., Wagner, E., Vogl, C., et al. (2017b). Glyoxal as an alternative fixative to formaldehyde in immunostaining and super - resolution microscopy. EMBO J. e201695709.

Richter, K.N., Wildhagen, H., Helm, M.S., Ußling, J.-E., Schikorski, T., and Rizzoli, S.O. (2018). Comparative synaptosome imaging: a semi-quantitative method to obtain copy numbers for synaptic and neuronal proteins. Sci. Rep. 8, 14838.

Ritchie, K., Shan, X.-Y., Kondo, J., Iwasawa, K., Fujiwara, T., and Kusumi, A. (2005). Detection of non-Brownian diffusion in the cell membrane in single molecule tracking. Biophys. J. 88, 2266-2277.

Rizzoli, S.O. (2014). Synaptic vesicle recycling: steps and principles. EMBO J. 33, 788-822. Rizzoli, S.O., and Jahn, R. (2007). Kiss-and-run, collapse and "readily retrievable" vesicles. Traffic 8, 1137-1144.

Rolls, M.M., Hall, D.H., Victor, M., Stelzer, E.H.K., and Rapoport, T.A. (2002). Targeting of Rough Endoplasmic Reticulum Membrane Proteins and Ribosomes in Invertebrate Neurons. Mol. Biol. Cell 13, 1778-1791.

Rust, M.J., Bates, M., and Zhuang, X. (2006). Stochastic optical reconstruction microscopy 
(STORM) provides sub-diffraction-limit image resolution. Nat. Methods 3, 793-795.

Sage, D., Kirshner, H., Pengo, T., Stuurman, N., Min, J., Manley, S., and Unser, M. (2015).

Quantitative evaluation of software packages for single-molecule localization microscopy. Nat. Methods 12, 717-724.

Saheki, Y., and De Camilli, P. (2012). Synaptic vesicle endocytosis. Cold Spring Harb.

Perspect. Biol. 4, a005645.

Saka, S.K., Vogts, A., Kröhnert, K., Hillion, F., Rizzoli, S.O., and Wessels, J.T. (2014).

Correlated optical and isotopic nanoscopy. Nat. Commun. 5, 3664.

Santos, M.S., Li, H., and VogImaier, S.M. (2009). Synaptic vesicle protein trafficking at the glutamate synapse. Neuroscience 158, 189-203.

Schanzenbächer, C.T., Sambandan, S., Langer, J.D., and Schuman, E.M. (2016). Nascent Proteome Remodeling following Homeostatic Scaling at Hippocampal Synapses. Neuron $92,358-371$.

Schanzenbächer, C.T., Langer, J.D., and Schuman, E.M. (2018). Time- and polaritydependent proteomic changes associated with homeostatic scaling at central synapses. Elife 7, 1-20.

Schneider, C.A., Rasband, W.S., and Eliceiri, K.W. (2012). NIH Image to ImageJ: 25 years of image analysis. Nat. Methods 9, 671-675.

Schueder, F., Strauss, M.T., Hoerl, D., Schnitzbauer, J., Schlichthaerle, T., Strauss, S., Yin, P., Harz, H., Leonhardt, H., and Jungmann, R. (2017). Universal Super-Resolution Multiplexing by DNA Exchange. Angew. Chem. Int. Ed. Engl. 56, 4052-4055.

Schwanhäusser, B., Busse, D., Li, N., Dittmar, G., Schuchhardt, J., Wolf, J., Chen, W., and Selbach, M. (2011). Global quantification of mammalian gene expression control. Nature 473, 337-342.

Shemesh, T., Klemm, R.W., Romano, F.B., Wang, S., Vaughan, J., Zhuang, X., Tukachinsky, H., Kozlov, M.M., and Rapoport, T. a. (2014). A model for the generation and interconversion of ER morphologies. Proc. Natl. Acad. Sci. 111, E5243-E5251.

Sheng, M., and Hoogenraad, C.C. (2007). The postsynaptic architecture of excitatory synapses: a more quantitative view. Annu. Rev. Biochem. 76, 823-847. 
Shim, S., Xia, C., Zhong, G., Babcock, H.P., Vaughan, J.C., Huang, B., Wang, X., Xu, C., Bi, G.Q., and Zhuang, X. (2012). Super-resolution fluorescence imaging of organelles in live cells with photoswitchable membrane probes. Proc. Natl. Acad. Sci. U. S. A. 109, 13978-13983. Sierra, A.Y., Gratacós, E., Carrasco, P., Clotet, J., Ureña, J., Serra, D., Asins, G., Hegardt, F.G., and Casals, N. (2008). CPT1c is localized in endoplasmic reticulum of neurons and has carnitine palmitoyltransferase activity. J. Biol. Chem. 283, 6878-6885.

Sinha, R., Ahmed, S., Jahn, R., and Klingauf, J. (2011). Two synaptobrevin molecules are sufficient for vesicle fusion in central nervous system synapses. Proc. Natl. Acad. Sci. U. S. A. $108,14318-14323$.

Smith, M.H. (1966). The amino acid composition of proteins. J. Theor. Biol. 13, 261-282.

Smith, S.J. (2007). Circuit reconstruction tools today. Curr. Opin. Neurobiol. 17, 601-608.

Söllner, T., Bennett, M.K., Whiteheart, S.W., Scheller, R.H., and Rothman, J.E. (1993). A protein assembly-disassembly pathway in vitro that may correspond to sequential steps of synaptic vesicle docking, activation, and fusion. Cell 75, 409-418.

Spacek, J., and Harris, K.M. (2018). Three-Dimensional Organization of Smooth Endoplasmic Reticulum in Hippocampal CA1 Dendrites and Dendritic Spines of the Immature and Mature Rat. J. Neurosci. 17, 190-203.

Spruston, N. (2008). Pyramidal neurons: dendritic structure and synaptic integration. Nat. Rev. Neurosci. 9, 206-221.

Steinhauser, M.L., and Lechene, C.P. (2013). Quantitative imaging of subcellular metabolism with stable isotopes and multi-isotope imaging mass spectrometry. Semin. Cell Dev. Biol. 24, 661-667.

Südhof, T.C. (2004). The synaptic vesicle cycle. Annu. Rev. Neurosci. 27, 509-547.

Südhof, T.C., and Rizo, J. (1996). Synaptotagmins: C2-domain proteins that regulate membrane traffic. Neuron 17, 379-388.

Swedlow, J.R., and Lamond, A.I. (2001). Nuclear dynamics: where genes are and how they got there. Genome Biol. 2.

Takamori, S. (2006). VGLUTs: "exciting" times for glutamatergic research? Neurosci. Res. 
$55,343-351$.

Takamori, S., Holt, M., Stenius, K., Lemke, E. a, Grønborg, M., Riedel, D., Urlaub, H., Schenck, S., Brügger, B., Ringler, P., et al. (2006). Molecular anatomy of a trafficking organelle. Cell 127, 831-846.

Takemura, S., Bharioke, A., Lu, Z., Nern, A., Vitaladevuni, S., Rivlin, P.K., Katz, W.T., Olbris, D.J., Plaza, S.M., Winston, P., et al. (2013). A visual motion detection circuit suggested by Drosophila connectomics. Nature 500, 175-181.

Tang, A., Chen, H., Li, T.P., Metzbower, S.R., MacGillavry, H.D., and Blanpied, T.A. (2016). A trans-synaptic nanocolumn aligns neurotransmitter release to receptors. Nature 536, 210-214.

Terlier, T., Lee, J., Lee, K., and Lee, Y. (2018). Improvement of the Correlative AFM and ToF-SIMS Approach Using an Empirical Sputter Model for 3D Chemical Characterization. Anal. Chem. 90, 1701-1709.

Thul, P.J., Åkesson, L., Wiking, M., Mahdessian, D., Geladaki, A., Ait Blal, H., Alm, T., Asplund, A., Björk, L., Breckels, L.M., et al. (2017). A subcellular map of the human proteome. Science 356, eaal3321.

tom Dieck, S., Kochen, L., Hanus, C., Heumüller, M., Bartnik, I., Nassim-Assir, B., Merk, K., Mosler, T., Garg, S., Bunse, S., et al. (2015). Direct visualization of newly synthesized target proteins in situ. Nat. Methods 12, 411-414.

Tomer, R., Ye, L., Hsueh, B., and Deisseroth, K. (2014). Advanced CLARITY for rapid and high-resolution imaging of intact tissues. Nat. Protoc. 9, 1682-1697.

Towbin, H., Staehelin, T., and Gordon, J. (1992). Electrophoretic transfer of proteins from polyacrylamide gels to nitrocellulose sheets: procedure and some applications. 1979. Biotechnology 24, 145-149.

Truckenbrodt, S., Viplav, A., Jähne, S., Vogts, A., Denker, A., Wildhagen, H., Fornasiero, E.F., and Rizzoli, S.O. (2018). Newly produced synaptic vesicle proteins are preferentially used in synaptic transmission. EMBO J. 37, e98044.

Turrigiano, G.G. (2008). The Self-Tuning Neuron: Synaptic Scaling of Excitatory Synapses. Cell 135, 422-435. 
Turrigiano, G.G., Leslie, K.R., Desai, N.S., Rutherford, L.C., and Nelson, S.B. (1998). Activitydependent scaling of quantal amplitude in neocortical neurons. Nature 391, 892-896.

Uhlen, M., Bandrowski, A., Carr, S., Edwards, A., Ellenberg, J., Lundberg, E., Rimm, D.L., Rodriguez, H., Hiltke, T., Snyder, M., et al. (2016). A proposal for validation of antibodies. Nat. Methods 13, 823-827.

Vale, R.D. (2003). The Molecular Motor Toolbox for Intracellular Transport. Cell 112, 467480.

Valm, A.M., Cohen, S., Legant, W.R., Melunis, J., Hershberg, U., Wait, E., Cohen, A.R., Davidson, M.W., Betzig, E., and Lippincott-Schwartz, J. (2017). Applying systems-level spectral imaging and analysis to reveal the organelle interactome. Nature 546, 162-167. Verkhratsky, A. (2002). The endoplasmic reticulum and neuronal calcium signalling. Cell Calcium 32, 393-404.

Vollnhals, F., Audinot, J.N., Wirtz, T., Mercier-Bonin, M., Fourquaux, I., Schroeppel, B., Kraushaar, U., Lev-Ram, V., Ellisman, M.H., and Eswara, S. (2017). Correlative Microscopy Combining Secondary Ion Mass Spectrometry and Electron Microscopy: Comparison of Intensity-Hue-Saturation and Laplacian Pyramid Methods for Image Fusion. Anal. Chem. 89, 10702-10710.

Vreja, I.C., Kabatas, S., Saka, S.K., Kröhnert, K., Höschen, C., Opazo, F., Diederichsen, U., and Rizzoli, S.O. (2015). Secondary-Ion Mass Spectrometry of Genetically Encoded Targets. Angew. Chem. Int. Ed. Engl. 1-6.

Wang, H., Qian, W.-J., Chin, M.H., Petyuk, V.A., Barry, R.C., Liu, T., Gritsenko, M.A., Mottaz, H.M., Moore, R.J., Camp, D.G., et al. (2006). Characterization of the Mouse Brain Proteome Using Global Proteomic Analysis Complemented with Cysteinyl-Peptide Enrichment. J. Proteome Res. 5, 361-369.

Wang, X., Allen, W.E., Wright, M.A., Sylwestrak, E.L., Samusik, N., Vesuna, S., Evans, K., Liu, C., Ramakrishnan, C., Liu, J., et al. (2018). Three-dimensional intact-tissue sequencing of single-cell transcriptional states. Science (80-. ). 361, eaat5691.

Washbourne, P., and McAllister, A.K. (2002). Techniques for gene transfer into neurons. Curr. Opin. Neurobiol. 12, 566-573. 
Watanabe, S., Rost, B.R., Camacho-Pérez, M., Davis, M.W., Söhl-Kielczynski, B., Rosenmund, C., and Jorgensen, E.M. (2013a). Ultrafast endocytosis at mouse hippocampal synapses. Nature 504, 242-247.

Watanabe, S., Liu, Q., Davis, M.W., Hollopeter, G., Thomas, N., Jorgensen, N.B., and Jorgensen, E.M. (2013b). Ultrafast endocytosis at Caenorhabditis elegans neuromuscular junctions. Elife 2, e00723.

Weil, M.-T., Ruhwedel, T., Möbius, W., and Simons, M. (2017). Intracerebral Injections and Ultrastructural Analysis of High-Pressure Frozen Brain Tissue. Curr. Protoc. Neurosci. 78, 2.27.1-2.27.18.

Weil, M.-T., Heibeck, S., Töpperwien, M., tom Dieck, S., Ruhwedel, T., Salditt, T., Rodicio, M.C., Morgan, J.R., Nave, K.-A., Möbius, W., et al. (2018). Axonal Ensheathment in the Nervous System of Lamprey: Implications for the Evolution of Myelinating Glia. J. Neurosci. 38, 6586-6596.

Wilhelm, B.G., Groemer, T.W., and Rizzoli, S.O. (2010). The same synaptic vesicles drive active and spontaneous release. Nat. Neurosci. 13, 1454-1456.

Wilhelm, B.G., Mandad, S., Truckenbrodt, S., Kröhnert, K., Schäfer, C., Rammner, B., Koo, S.J., Claßen, G. a, Krauss, M., Haucke, V., et al. (2014). Composition of isolated synaptic boutons reveals the amounts of vesicle trafficking proteins. Science 344, 1023-1028. Wilkinson, B., and Gilbert, H.F. (2004). Protein disulfide isomerase. Biochim. Biophys. Acta $1699,35-44$.

Williams, D.B. (2006). Beyond lectins: the calnexin/calreticulin chaperone system of the endoplasmic reticulum. J. Cell Sci. 119, 615-623.

Willig, K.I., Rizzoli, S.O., Westphal, V., Jahn, R., and Hell, S.W. (2006). STED microscopy reveals that synaptotagmin remains clustered after synaptic vesicle exocytosis. Nature 440, 935-939.

Wilson, R.S., and Nairn, A.C. (2018). Cell-Type-Specific Proteomics: A Neuroscience Perspective. Proteomes 6, 51.

Wirtz, T., Philipp, P., Audinot, J.N., Dowsett, D., and Eswara, S. (2015). High-resolution high-sensitivity elemental imaging by secondary ion mass spectrometry: From traditional 
2D and 3D imaging to correlative microscopy. Nanotechnology 26.

Wolter, S., Löschberger, A., Holm, T., Aufmkolk, S., Dabauvalle, M.-C., van de Linde, S., and Sauer, M. (2012). rapidSTORM : accurate, fast open-source software for localization microscopy. Nat. Methods 9, 1040-1041.

Wu, Y., Whiteus, C., Xu, C.S., Hayworth, K.J., Weinberg, R.J., Hess, H.F., and De Camilli, P. (2017). Contacts between the endoplasmic reticulum and other membranes in neurons. Proc. Natl. Acad. Sci. 114, E4859-E4867.

Xu, C.S., Hayworth, K.J., Lu, Z., Grob, P., Hassan, A.M., García-Cerdán, J.G., Niyogi, K.K., Nogales, E., Weinberg, R.J., and Hess, H.F. (2017). Enhanced FIB-SEM systems for largevolume 3D imaging. Elife 6, 1-36.

Xu, K., Babcock, H.P., and Zhuang, X. (2012). Dual-objective STORM reveals threedimensional filament organization in the actin cytoskeleton. Nat. Methods 9, 185-188. Xu, K., Zhong, G., and Zhuang, X. (2013). Actin, spectrin, and associated proteins form a periodic cytoskeletal structure in axons. Science 339, 452-456.

Yu, L.-R., Conrads, T.P., Uo, T., Kinoshita, Y., Morrison, R.S., Lucas, D. a, Chan, K.C., Blonder, J., Issaq, H.J., and Veenstra, T.D. (2004). Global analysis of the cortical neuron proteome. Mol. Cell. Proteomics 3, 896-907.

Zerial, M., and McBride, H. (2001). Rab proteins as membrane organizers. Nat. Rev. Mol. Cell Biol. 2, 107-117.

Zheng, Z., Lauritzen, J.S., Perlman, E., Robinson, C.G., Nichols, M., Milkie, D., Torrens, O., Price, J., Fisher, C.B., Sharifi, N., et al. (2018). A Complete Electron Microscopy Volume of the Brain of Adult Drosophila melanogaster. Cell 174, 730-743.e22.

Zhou, Z., Sorensen, S.A., and Peng, H. (2015). Neuron crawler: An automatic tracing algorithm for very large neuron images. In 2015 IEEE 12th International Symposium on Biomedical Imaging (ISBI), (IEEE), pp. 870-874.

Zhou, Z., Liu, X., Long, B., and Peng, H. (2016). TReMAP: Automatic 3D Neuron Reconstruction Based on Tracing, Reverse Mapping and Assembling of 2D Projections. Neuroinformatics 14, 41-50. 


\section{Abbreviations}

AIS

ATP

BIC

CAM

CCD

CCV

CNS

COP

DAPI

DiO

DIV

DNA

dSTORM

EM

EM

ER

$\mathrm{EtOH}$

$\mathrm{EtOH}$

FIB-SEM axon initial segment

adenosine-5'-triphosphate

bicuculline

cell adhesion molecule

charge coupled device

clathrin-coated vesicle

central nervous system

coatamer protein complex

4',6-Diamidino-2-Phenylindole

3,3'-dioctadecyloxacarbocyanine perchlorate

Days in vitro

deoxyribonucleic acid

direct stochastic optical reconstruction microscopy

electron microscopy

Electron microscopy

endoplasmic reticulum

ethanol

ethanol

focused ion beam scanning electron microscopy 
FWHM

GA

GABA

GPCR

GS27

GTP

Leu

LUT

MAP-2

nanoSIMS

NSF

$\mathrm{OsO}_{4}$

PDI

PFA

PNS

PSD

PSF

Q

$\mathrm{R}$

Rab full width at half maximum

glutaraldehyde

-aminobutyric acid

g-protein coupled receptor

golgi SNARE of $27 \mathrm{kDa}$

guanosine-5'-triphosphate

leucine

look up table

microtubule-associated protein 2

Nanoscale secondary ion mass spectrometry

$\mathrm{N}$-ethylmaleimide-sensitive factor

Osmium tetroxide

protein disulphide isomerase

paraformaldehyde

peripheral nervous system

postsynaptic density

point spread function

glutamine

arginine

ras related in brain 
RER

RNA

ROI

RT

SEM

SEM

SER

SIMS

SIMS

SNAP

SNARE

STED

STORM

SV

TEM

TGN

TTX

USE

VAMP

VTI rough endoplasmic reticulum

ribonucleic acid

region of interest

room temperature

standard error of the mean

Scanning electron microscopy

smooth endoplasmic reticulum

secondary ion mass spectrometry

Secondary ion mass spectrometry

soluble NSF attachment protein

soluble NSF attachment protein receptor

stimulated emission depletion

stochastic optical reconstruction microscopy

synaptic vesicle

Transmission electron microscopy

trans Golgi network

tetrodotoxin

unconventional SNARE in the ER protein

vesicle associated membrane protein

vps ten interacting 


\section{List of Figures}

Figure $1 \quad$ Morphology and functional organization of neurons and synapses.

Figure 2 Correlated optic and isotopic nanoscopy

Figure $3 \quad$ Neuronal Sandwich Culture

Figure $4 \quad$ Astroglia contribution to dispersed cultures of rat hippocampal neurons

Figure $5 \quad$ Microglia and oligodendrocyte content in the Banker culture system

Figure $6 \quad$ GABAergic cells in Banker cultures

Figure $7 \quad$ Morphology of cultured hippocampal neurons - transfections with membrane bound EGFP and neurite tracing

Figure $8 \quad$ Analysis of neurite lengths, thicknesses, and branching angles

Figure $9 \quad$ Number of synapses per neuron

Figure 10 beta 3 tubulin, characterization in cell bodies, axons, and dendrites

Figure $11 \quad$ Distribution of beta-3-tubulin

Figure 12 brevican, characterization in cell bodies, axons, and dendrites

Figure 13 Distribution of brevican

Figure 14 calnexin, characterization in cell bodies, axons, and dendrites

Figure $15 \quad$ Distribution of calnexin

Figure 16 calreticulin, characterization in cell bodies, axons, and dendrites

Figure 17 Distribution of calreticulin.

Figure 18 catalase, characterization in cell bodies, axons, and dendrites

Figure 19 Distribution of catalase 
Figure 20 Clathrin, characterization in cell bodies, axons, and dendrites

Figure $21 \quad$ Distribution of clathrin.

Figure 22 CPT1c, characterization in cell bodies, axons, and dendrites

Figure $23 \quad$ Distribution of CPT1C

Figure 24 EEA1, characterization in cell bodies, axons, and dendrites

Figure $25 \quad$ Distribution of EEA1

Figure 26 ERp72, characterization in cell bodies, axons, and dendrites.

Figure $27 \quad$ Distribution of ERp72.

Figure 28 fibrillarin, characterization in cell bodies, axons, and dendrites

Figure $29 \quad$ Distribution of fibrillarin

Figure 30 GM130, characterization in cell bodies, axons, and dendrites

Figure $31 \quad$ Distribution of GM130

Figure 32 homer1, characterization in cell bodies, axons, and dendrites

Figure $33 \quad$ Distribution of homer1

Figure 34 internexin, characterization in cell bodies, axons, and dendrites

Figure $35 \quad$ Distribution of internexin

Figure 36 LAMP1, characterization in cell bodies, axons, and dendrites

Figure $37 \quad$ Distribution of LAMP1

Figure 38 MAP2, characterization in cell bodies, axons, and dendrites

Figure $39 \quad$ Distribution of MAP2 
Figure $40 \quad \mathrm{PDI}$, characterization in cell bodies, axons, and dendrites

Figure $41 \quad$ Distribution of PDI

Figure 42 PMP70, characterization in cell bodies, axons, and dendrites

Figure $43 \quad$ Distribution of PMP70

Figure 44 Rab5, characterization in cell bodies, axons, and dendrites

Figure $45 \quad$ Distribution of Rab5

Figure 46 Rab7, characterization in cell bodies, axons, and dendrites

Figure $47 \quad$ Distribution of Rab7

Figure 48 Rab11a, characterization in cell bodies, axons, and dendrites

Figure $49 \quad$ Distribution of Rab11a

Figure 50 ribophorin1, characterization in cell bodies, axons, and dendrites

Figure $51 \quad$ Distribution of ribophorin1

Figure 52 ribosomal protein S3, characterization in cell bodies, axons, and dendrites

Figure $53 \quad$ Distribution of ribosomal protein S3

Figure 54 ribosomal protein S6, characterization in cell bodies, axons, and dendrites

Figure $55 \quad$ Distribution of ribosomal protein S6

Figure 56 synaptophysin, characterization in cell bodies, axons, and dendrites

Figure $57 \quad$ Distribution of synaptophysin

Figure 58 transferrin receptor, characterization in cell bodies, axons, and dendrites

Figure 59 Distribution of transferrin receptor 
Figure 60

Figure 61

Figure 62

Figure 63

Figure 64

Figure 65

Figure 66

Figure 67

Figure 68

Figure 69

Figure 70

Figure 71

Figure 72

Figure 73

Figure 74

Figure 75

Figure 76

Figure 77

Figure 78
TGN38, characterization in cell bodies, axons, and dendrites

Distribution of TGN38

TOMM20 b - alternative marker, characterization in cell bodies, axons, and dendrites

Distribution of TOMM20 b

TOMM20, characterization in cell bodies, axons, and dendrites

Distribution of TOMM20

VAMP2, characterization in cell bodies, axons, and dendrites

Distribution of VAMP2

vGLUT, characterization in cell bodies, axons, and dendrites

Distribution of vGLUT

vimentin, characterization in cell bodies, axons, and dendrites

Distribution of vimentin

Volumes of the neuronal cell bodies and its organelles and compartments

Organelle/compartment volumes in neuronal cell bodies

FIB-SEM recording of entire neuronal cell bodies

Half-automatized segmentations of neuronal cell bodies imaged by FIB-SEM

Neuronal cell body, nucleus, and mitochondria volumes determined by FIB-

SEM measurements

3D-dSTORM imaging and volume analysis of neuronal organelles

Improved volume estimations of neuronal organelles by using 3D-dSTORM 
Figure 79 dSTORM measurements improve the volumetric analysis of organelles

Figure 80 Pre- and postsynaptic protein turnover are positively correlated to each other

Figure $81 \quad$ Modulating synaptic activity affects pre- and postsynaptic protein turnover

Figure 82 Pre-, but not postsynaptic protein turnover is correlated to synaptic activity

Figure $83 \quad$ Modulating synaptic activity deregulates activity-turnover coupling

Figure $84 \quad$ Inhibiting protein translation reduces synaptic activity 


\section{List of Tables}

Table 1 Media and solutions used for the preparation of primary hippocampal neurons

Table 2 Primary antibodies used to label organelles, compartments, and cytoskeletal elements

Table 3 Primary antibodies used as markers against different cell types to test the composition of the Banker culture

Table $4 \quad$ List of secondary antibodies

Table 5 Filter-sets, inverted fluorescence microscope, Nikon Eclipse Ti-E

Table $6 \quad$ Lasers, confocal microscope, Leica TCS SP5

Table 7 Setup used for the different fluorophores, confocal microscope, Leica TCS SP5

Table 8 dSTORM imaging buffer

Table 9 Characterization of Banker cultures 


\section{List of Publications}

Agüi-Gonzalez, P., Jähne, S., and Phan, N.T.N. (2019). SIMS imaging in neurobiology and cell biology. J. Anal. At. Spectrom. 34.

Kabatas, S., Agüi-Gonzalez, P., Hinrichs, R., Jähne, S., Opazo, F., Diederichsen, U., Rizzoli, S.O., and Phan, N.T.N. (2019). Fluorinated nanobodies for targeted molecular imaging of biological samples using nanoscale secondary ion mass spectrometry. J. Anal. At. Spectrom. 34.

Kabatas, S., Agüi-Gonzalez, P., Saal, K.-A., Jähne, S., Opazo, F., Rizzoli, S.O., and Phan, N.T.N. (2019). Boron-Containing Probes for Non-optical High-Resolution Imaging of Biological Samples. Angew. Chemie - Int. Ed. 58.

Truckenbrodt, S., Viplan, A., Jähne, S., Vogts, A., Denker, A., Wildhagen, H., Fornasiero, E.F., and Rizzoli, S.O. (2018). Newly produced synaptic vesicle proteins are preferentially used in synaptic transmission. EMBO J. 1-24.

Richter, K.N., Rizzoli, S.O., Jähne, S., Vogts, A., and Lovric, J. (2017). Review of combined isotopic and optical nanoscopy. Neurophotonics 4, 020901.

Jähne, S., Rizzoli, S.O., and Helm, M.S. (2015). The structure and function of presynaptic endosomes. Exp. Cell Res. 335, 172-179. 